\title{
Of Six Minds on the Matter: A Psychology-based Typology of Hawkish and Dovish Decision Makers
}

\author{
By \\ (C) 2017 \\ Adam David Brown \\ Ph.D., University of Kansas, 2017 \\ M.A., University of Kansas, 2008 \\ B.Sc., Missouri Western State University, 2006 \\ Submitted to the graduate degree program in Political Science and the Graduate Faculty of the \\ University of Kansas in partial fulfillment of the requirements for the degree of Doctor of \\ Philosophy.
}

Co-Chair: Mark Joslyn

Co-Chair: Juliet Kaarbo

Donald Haider-Markel

John Kennedy

Ludwin Molina

Date Defended: 28 June 2017 
The dissertation committee for Adam David Brown certifies that this is the approved version of the following dissertation:

\section{Of Six Minds on the Matter: A Psychology-based Typology of Hawkish and Dovish Decision Makers}

Co-Chair: Mark Joslyn

Co-Chair: Juliet Kaarbo

Date Approved: 28 June 2017 


\begin{abstract}
Foreign policy elites are often labeled "hawks" or "doves," and states' foreign policies can vary widely depending on whether hawks or doves prevail. Yet seldom asked is this question: why are some elites hawks and others doves? I seek to answer this question. A few previous studies also address this question. However, they typically suffer one or both of the following shortcomings. First, they often overlook variations among elites within the hawk and dove categories. Second, they typically fail to systematically assess the characteristics distinguishing hawks from doves. I provide an improvement by systematically assessing the characteristics distinguishing hawks from doves and exploring differences among elites within the two categories. Specifically, I propose a psychology-based six-fold typology comprising three hawkish and three dovish decision maker types. I distinguish among the types via differing operational codes, personality traits, hypothesized susceptibilities to cognitive errors/biases, and hypothesized foreign policy positions. To test my typology's validity, I examine content analysis of selected George W. Bush administration officials' verbal behavior. This facilitates determining if elites are classifiable via my typology. To test my typology's hypotheses, I use congruence analysis of selected elites' decision making leading up to the 2003 United States-led invasion of Iraq. This qualitative analysis allows me to determine the errors and biases to which examined elites are susceptible and the elites' policy positions.
\end{abstract}




\section{Acknowledgements}

I would like to offer to my committee heartfelt thanks for their assistance with what has been a long process. Juliet Kaarbo, co-chair of my committee, has been generous beyond all reasonable expectation. She has patiently encouraged, guided, and helped me even as her career took her across the Atlantic. I owe her a tremendous debt of gratitude. Mark Joslyn, also co-chair of my committee, has given me crucial moral support. Further, he and Donald Haider-Markel have played key roles in shepherding this project. I cannot overstate the importance of their support and the support of my entire committee. Above all, I thank my wife and family. They have

tirelessly stood by me over the years, and the completion of my dissertation would not have been possible without them. 


\section{Table of Contents}

Introduction $\quad$ 1-14

$\begin{array}{lr}\text { Chapter 1: } \text { Theoretical Framework } & \mathbf{1 5 - 9 8}\end{array}$

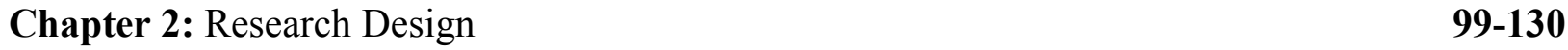

Chapter 3: Quantitative Analysis of Personality Trait and Beliefs $\quad$ 131-170

Chapter 4: Qualitative Analysis of Decision Making $\quad$ 171-227

Chapter 5: Conclusion $\quad$ 228-233

$\begin{array}{lr}\text { References } & \mathbf{2 3 4 - 2 4 6}\end{array}$

$\begin{array}{lr}\text { Appendix A } & 247\end{array}$

$\begin{array}{lr}\text { Appendix B } & \text { 248-249 }\end{array}$ 


\section{Introduction}

After the terrorist attacks of 11 September 2001, as Iraq became increasingly prominent in the United States' foreign policy agenda, President George W. Bush faced competing pressures from the so-called "hawks" and "doves" in his administration. The hawks - Vice President Richard "Dick" Cheney, Secretary of Defense Donald Rumsfeld, and especially Deputy Secretary of Defense Paul Wolfowitz - proposed, and sometimes vigorously advocated, attacking Iraq to oust Saddam Hussein's regime (Binnendjik and Lin 2014; Gordon and Trainor 2006; Ricks 2006; Robison 2006; Woodward 2002; 2004). The doves, principally Secretary of State Colin Powell, counselled against war and for a peaceful course of action under United Nations auspices (Gordon and Trainor 2006; Harnden 2003; Ricks 2006; Robison 2006; Woodward 2002; 2004). Though hawkish pressures eventually prevailed and the US invaded Iraq in March 2003, in accounts of the administration's eventual decision for war with Iraq both the hawks and doves are key players (see e.g., Gordon and Trainor 2006; Ricks 2006; Woodward $2002 ; 2004)$.

The case of the US decision to invade Iraq is not unique in being marked by hawk-dove struggles to win in foreign policy debates. "Hawks" and "doves" are often central figures in matters of war and peace, arguably the most critical aspects of international relations. Unfortunately, though, we know precious little about either hawks or doves. The labels hawk and dove are commonly, even popularly (e.g., Alsop and Bartlett 1962; Gelb 1992; Left 2002), applied to foreign policy decision makers, and the decision makers bearing these labels can play, and indeed have played, key roles in shaping their states' foreign policies. Hawks and doves are often highlighted by scholars' accounts of all conflict stages - rivalry to crisis, crisis to war, war to peacemaking (e.g., Iklé 2005; Heffington 2016; Schultz 2005; Snyder and Diesing 1977; 
Stanley 2009a, 2009b; Vasquez 1993). Yet, in spite of the frequent application of the labels and the importance of foreign policy elites bearing them, we have a very limited understanding of hawks and doves. Little work has gone into peeling back the labels to explore this question: why are some foreign policy decision makers hawks while others are doves? In fact the question is all too infrequently even asked. Without asking this question, much less answering it, we are poorly positioned either to anticipate which decision makers will be hawkish or dovish, or to understand why hawkish and dovish elites act the way they do. This lack of attention is thus problematic and in need of redressing. The dichotomous categorization inhering in the terms themselves is perhaps equally problematic. The assignment of one-size-fits-all hawk and dove labels risks papering over substantial differences among elites within each of the broad categories. A systematic way of identifying hawkish and dovish elites and distinguishing among elites of each type is sorely needed.

This work lays out just such systematic means for identifying hawkish and dovish decision makers as well as ways to differentiate among elites residing within the hawkish and dovish camps. Specifically, I offer a six-fold typology consisting of three hawkish and three dovish foreign policy decision maker types. This typology is firmly rooted in psychology, with distinctions among the types based on varying beliefs, personality traits, preferences (stemming from beliefs), and perceptions of opponents' preferences. Decision maker types are also distinguished by hypothesized varying proneness to specific cognitive errors and biases. Susceptibilities to errors and biases are, I propose, affected by the other variables that differentiate the types, but the susceptibilities also further distinguish the types and facilitate anticipating their behavior. I ultimately derive from my typology hypotheses predicting each decision maker type's likely foreign policy positions. The validity of the typology and all 
hypotheses stemming from it are subjected to close scrutiny via mixed-methods empirical testing.

These various aspects of my study offer much in the way of correcting the current shortcomings in our understanding of hawks and doves. My typology serves to answer the questions of why some elites are dovish, why some decision makers are hawkish, and why hawkish and dovish decision makers behave as they do. Moreover, by breaking the hawk-dove dichotomy open and providing a six-fold classification of hawkish and dovish decision makers, this work helps to overcome the restrictive and over-simplified view that currently dominates thinking about dovish and hawkish foreign policy makers.

The remainder of this chapter begins with a short discussion intended to illustrate hawkish and dovish decision makers' crucial roles in matters of war and peace. I next provide a critical assessment of past efforts to define and identify hawkish and dovish decision makers. I follow this critical assessment by very briefly introducing and explaining the benefits of my own approach to defining and theorizing about hawkish and dovish foreign policy elites. I then discuss the broader contributions offered by my approach. The chapter concludes with a succinct roadmap of the remainder of this work.

\section{War and Peace: The Importance of Hawks and Doves}

Dovish and hawkish decision makers have often occupied a prominent place in accounts

of international rivalries, crises, militarized disputes, war, and conflict termination (e.g., Colaresi 2004; Heffington 2016; Iklé 2005; Schultz 2005; Snyder and Diesing 1977; Stanley 2009a, 2009b; Vasquez 1993). A few examples illustrate the importance placed upon hawks and doves' roles in both war and peace. John Vasquez (1993: 223), in his explanation of war between rivals, emphasizes increasing influence of hawkish elites at the expense of dovish decision makers as 
"an important step toward war."1 Glenn H. Snyder and Paul Diesing (1977: 297) argue that analysis of hawkish and dovish elites "is absolutely necessary to an understanding not only of information processing in a crisis, but also decision making." ${ }^{2}$ In fact, Snyder and Diesing view hawkish and dovish elites as so crucial to explaining crises that they undertake the first systematic effort to describe the psychological characteristics of hawks and doves (see below).

While Vasquez (1993) and Snyder and Diesing (1977) highlight the role of hawks and doves in the genesis of international conflicts, others focus on the place of doves and hawks in the termination of conflicts. Kenneth Schultz (2005), for example, places hawkish and dovish leaders at the center of his effort to model how rivalries end. Regarding ending wars, Elizabeth Stanley (2009a; 2009b) emphasizes how the balance of hawkish and dovish elites in belligerent states affects the processes of war termination. Fred Iklé (2005), also seeking to explain how wars are terminated, more forcefully asserts the central part hawks and doves play, arguing that decisions to end war are the product of (sometimes violent) domestic struggles between the hawks and doves in belligerent states.

As I hope the above examples have demonstrated, the decision makers who bear the hawk and dove labels are recognized for the central parts they play in international conflict and peacemaking. Recognition of doves and hawks' centrality to war and peace has spurred sporadic efforts to define and identify decision makers of these types. I discuss these efforts below.

\section{The Labels: Past Efforts to Define and Identify Hawks and Doves}

\footnotetext{
${ }^{1}$ Vasquez (1993: 201) consciously eschews the terms hawk and dove, instead using the label "hard-liner" as a standin for hawk and the term "accommodationist" as a substitute for dove. Nonetheless, the terms for the respective decision maker types remain sufficiently interchangeable.

2 Snyder and Diesing (1977: 297) also avoid the labels hawk and dove, relying instead on the terms "hard-line" and "soft-line," respectively. They do, however, recognize the hawk and dove labels as alternative terms for the ones they choose to employ.
} 
Hawks and doves are most commonly defined and identified via their observed policy positions. The label hawk is generally associated with foreign policy elites who espouse adversarial positions and emphasize sending clear, credible signals of firm resolve and military strength to deter opponents from engaging in undesired behavior (Heffington 2016; Nordlinger 1995; Nye, Allison, and Carnesale 1985; Snyder and Diesing 1977: 297-310). In the case of wartime decision making, hawks are usually defined as decision makers who oppose negotiation and advocate continued fighting in order to achieve "ambitious war aims" (Iklé 2005: 84). In contrast, the label dove is typically assigned to decision-making elites who advocate accommodation and conciliation towards opponents (Nordlinger 1995; Nye, Allison, and Carnesale 1985; Snyder and Diesing 1977: 297-310; see also Heffington 2016). And in decision making during war, doves are conventionally defined as individuals who want to end war via negotiated settlement, even if that settlement may require making compromises and granting concessions (Iklé 2005: 84-85). While defining and identifying hawks and doves via their observed policy positions may be descriptively accurate, such a basis for labeling neither provides insight into why hawks and doves take these positions nor facilitates identifying hawks and doves prior to their taking of policy positions. Consequently, we are poorly placed to predict which decision makers are likely to take hawkish or dovish policy stances until they have first espoused a policy position, and we have little more than past or present policy stands on which to base predictions of apparently hawkish and dovish elites' future behavior. Moreover, studies employing this basis for defining and identifying hawks and doves commonly fail to adequately address potential variations across hawks and across doves (see Hagan 1994: 198, 199). In short, this foundation for labeling is superficial, oversimplified in its dichotomous categorization, and thus fraught with limitations. 
Notably, not all efforts to label hawks and doves have stopped at a superficial or overly simplistic dichotomous method of defining and identifying hawks and doves. Several studies go beyond the hawk-dove dichotomy and recognize that hawks and doves are ideal-types on opposite ends of a continuum of decision makers. This recognition allows for variation among hawks and doves as well as the existence of "middle-line" (Snyder and Diesing 1977: 297) or "moderate" (Schultz 2005: 7) elites who are neither hawks nor doves (see also Hagan 1993; 1994; Nordlinger 1995; Nye, Allison, and Carnesale 1985; Stanley 2009a). However, with very few exceptions (Hagan 1993: 213-218; 1994: 198-201; Snyder and Diesing 1977: 297-310; see also Vasquez 1993: 200-207), these studies fail to explicitly explore why some decision makers are hawkish while others are dovish and thus remain superficial in their means of defining and identifying decision maker types. The exceptional studies of Hagan (1993: 213-218; 1994: 198201) and Snyder and Diesing (1977: 297-310) have sought to distinguish hawkish and dovish foreign policy elites based on sets of deeper personal characteristics that lead decision makers to play hawkish and dovish parts. ${ }^{3}$

Snyder and Diesing's (1977: 297-310) research represents the earliest and most systematic and thorough attempt to differentiate between hawks and doves (in their terminology, hard-liners and soft-liners, respectively) based on personal characteristics. They provide a theoretical framework for distinguishing hawks and doves via each decision maker type's personal characteristics, namely attitudes rooted in the types' personalities. Specifically, Snyder and Diesing (1977: 298) present a two-fold hawk-dove typology based on "general world-views

\footnotetext{
${ }^{3}$ Though I have cited Vasquez (1993: 200-207) as a researcher who explores why some decision makers are hawks while others are doves, his exploration is quite limited and focused mostly on hawks. Even regarding hawks, which receive the bulk of his attention, he deems his inquiry "an initial attempt to capture some of those traits [that make a decision maker a hawk] without knowing exactly what they are" (Vasquez 1993: 204). Vasquez then briefly draws upon political psychology literature to suggest a handful of characteristics that may predispose a decision maker to hawkish views. Given the cursory nature of Vasquez's exploration, I do not give it the more in-depth treatment afforded to the analyses conducted by Hagan (1993: 213-218; 1994: 198-201) and Snyder and Diesing (1977: 297310)
} 
or 'theories,' images of the opponent, self-images, and strategy preferences." These personalitybased differences offer the promise of explaining and predicting who will be a dove or hawk and thus identifying hawks and doves prior to their actual espousal of policy positions.

Unfortunately, however, Snyder and Diesing's (1977: 297-310) framework suffers from serious shortcomings. First, their theoretical framework explicitly eschews any attempt to account for potential variations across decision makers within the hawk and dove categories. Second, Snyder and Diesing do not offer a methodology for employing their framework or replicating their analysis. These shortcomings greatly diminish the utility of their framework.

Hagan's (1993: 213-218; 1994: 198-201) studies provide a framework of "leader orientations" that does more than the Snyder-Diesing framework to explore decision maker types as a continuum ranging from most dovish to most hawkish (in Hagan's terminology, moderate to most hard-line, respectively). Hagan's framework identifies four ideal types of leader orientation listed in order of increasing hard-line orientations: moderate or acquiescent, pragmatic, militant, and radical. Separating the ideal types are differing perceptions of the international environment and opponents as well as different preferences over foreign policy alternatives.

While Hagan's (1993: 213-218; 1994: 198-201) typological framework has an advantage over the Snyder-Diesing framework in that Hagan explicitly seeks via his typology to move beyond the hawk-dove dichotomy, it is less systematic and thorough than the Snyder-Diesing framework. Also, as is the case with the theoretical framework introduced by Snyder and Diesing (1977: 297-310), Hagan does not provide a method for employing his typology. In sum, Hagan's framework, though possessed of certain advantages over other treatments of hawks and doves, is severely limited by key shortcomings. 
Given the problems with previous scholarly treatments of hawkish and dovish decision makers, it is clear that we need an improved typological framework that overcomes the shortcomings of previous efforts to define and identify hawkish and dovish elites. An improved framework should accomplish three tasks. First, it should provide systematic means for identifying hawkish and dovish decision makers prior to their espousal of policy stands. This will lay a firmer foundation than is currently available on which to base predictions of decision makers' behavior. Second, an improved framework needs to explicitly capture potential variations among decision makers within the hawkish and dovish categories. Doing so will provide a more nuanced understanding of hawkish and dovish decision makers and improve the prospects of predicting the policy positions of elites. Third, any framework claiming to offer progress over past work should also provide clear, systematic methods for its application. Fulfilling all three tasks will result in a package of theory and methods that researchers can employ to identify varieties of hawks and doves from among the world's foreign policy decision makers. The framework I present and test in this study is designed to ultimately accomplish these three tasks.

\section{Hawks and Doves: New Language for Old Labels}

The flaws in past efforts to define and identify hawkish and dovish foreign policy elites largely give rise to the general questions that inspire this study: Why are some decision makers hawks while others are doves? Do decision makers within the hawkish and dovish categories vary and, if so, how? Are hawkishness and dovishness the products of differences in psychological characteristics rather than the products of situational variables? Can hawkish and dovish elites be identified and their future behavior predicted by means more sophisticated and systematic than simply examining the elites' situations, past behavior, or present actions? These 
questions motivate me to examine decision makers through the lens of psychology. If we can identify the psychological characteristics that typify hawkish and dovish policy makers, then we can move beyond predicting their future policy behavior using past or present behavior as guides. We will then also be able to reduce reliance on situational factors to understand and predict who will exhibit hawkishness or dovishness. Hawks and doves will be recognized by their psychology, and we will recognize them before they face, and act in, foreign policy situations.

The pioneering efforts of Hagan (1993: 213-218; 1994: 198-201) and especially Snyder and Diesing (1977: 297-310) to link hawkish and dovish tendencies to psychological variables inspired a narrower and (to my mind) more fruitful set of research questions. ${ }^{4}$ Importantly, Hagan and Snyder and Diesing present a promising answer to the question of whether hawkish and dovish decision makers can be identified and their behavior predicted via systematic means. Their answer is yes, and the means their efforts suggest are psychological analysis. Their suggestion of psychological analysis also reframes the other questions that guide this research. The reframed questions are as follows: Do significant psychological differences exist between hawks and doves? Do psychological variations provide for further differentiation of decision makers within the hawk and dove categories? Do psychological characteristics offer a basis for predicting the behavior, especially policy stances, of hawkish and dovish decision makers?

I believe the answer to all of the above questions is "yes." What is needed is a systematic, psychology-based theoretical framework for identifying and predicting the behavior of hawkish and dovish decision makers. Snyder and Diesing's (1977: 297-310) framework for distinguishing hawks and doves - as it is the strongest effort to identify hawks and doves using

\footnotetext{
${ }^{4}$ Vasquez (1993: 200-207) is deserving of mention here, too, as he made some effort to root hawkish tendencies in psychological variables (see the preceding footnote).
} 
psychological variables - provides an excellent jumping-off point. The concepts of "general world-views or 'theories,' images of the opponent, self-images, and strategy preferences" Snyder and Diesing (1977: 298) use to differentiate hawks and doves must, though, be translated into language that allows the shortcomings of their approach to be overcome. Namely, their framework must be converted into concepts and theory that facilitate both the use of systematic research methods as well as the exploration of variations across decision makers inside the hawkish and dovish categories.

Fortunately, the conceptual and theoretical language needed for this translation is readily available. The established Operational Code Analysis (OCA) and Leadership Trait Analysis (LTA) research programs (e.g., George 1969; Hermann 2003; Walker 1990; Walker and Schafer 2006), through their conceptualization of, and theorizing about, beliefs and personality traits, respectively, provide the conceptual and theoretical vocabulary by which to construct a new framework for identifying and predicting the behavior of a range of hawkish and dovish decision makers. In the next chapter I recast the Snyder-Diesing framework (Snyder and Diesing 1977: 297-310) in the lexicon of operational code beliefs and personality traits in order to form the basis of a new psychology-based theoretical approach to hawkish and dovish decision makers.

The theoretical framework I build upon this translation of Snyder and Diesing's (1977: 297-310) approach is not merely a rebranding of their work. As the succeeding chapter demonstrates, putting the Snyder-Diesing framework into the language of OCA and LTA allows for the formulation of a psychology-based six-fold typology comprised of three hawkish and three dovish decision maker types. The distinctions among the six decision maker types are founded on variations in operational code beliefs and personality traits, which in turn produce in each type distinct preferences and perceptions of adversaries' preferences. From the starting 
point of the basic typology I add greater nuance to the differences across the six decision maker types by hypothesizing about each type's distinctive susceptibilities to cognitive errors and biases and, ultimately, each type's general policy positions. Consequently, my framework overcomes the problem inherent in Snyder and Diesing's dichotomous approach to hawkish and dovish elites.

Building on Snyder and Diesing's (1977: 297-310) framework as I do also adds the important benefit of bringing well-established, systematic research methods to bear on the subject of hawks and doves. The OCA and LTA research programs have developed sophisticated, reliable, and repeatable methods for the study of the beliefs and personality traits at the heart of my theoretical framework (see, for example, Hermann 2003; Schafer and Walker 2006). My own use of these methods allows me to analyze hawkish and dovish decision makers in a more systematic way than has heretofore been accomplished. Moreover, the methods of LTA and OCA provide the opportunity to identify hawkish and dovish elites prior to their actual commitment to particular policy stands.

In sum, my theoretical framework and its associated methods provide essential correctives to the weaknesses of previous approaches to the subject of hawks and doves. It offers systematic means to identify a range of hawkish and dovish decision makers before they commit to a particular position. In other words this study's framework offers the nuance and predictive ability earlier research has lacked.

\section{Broader Contributions}

Although this work is focused on the narrow goal of improving the analysis and understanding of hawkish and dovish decision makers, the present study also makes contributions with broader impact. Most obviously, my framework has the potential to benefit 
the international security subfield. As I point out above, hawkish and dovish decision makers are often central actors in accounts of international conflict and peacemaking. A better understanding of the decision makers subject to these labels promises to also better our understanding of the phenomena at the core of international security.

This study's theoretical framework also adds to research areas in political psychology and foreign policy analysis. While I rely heavily on extant concepts, theory, and methods from these research areas, I hope to give back some measure of contribution to political psychology and foreign policy analysis (FPA). Specifically, as will become clear as I lay out my theoretical framework in the following chapter, this study connects operational code beliefs and personality traits with cognitive errors and biases.

The importance of operational code beliefs, personality traits, and cognitive errors and biases in foreign policy decision making is well-established in political psychology and foreign policy analysis (see, for example, Dyson and Parent 2017; Hermann 1980; Kahneman and Renshon 2009; Levy 2000; Levy and Thompson 2010: 140-150; Shannon 2007; Walker 1977; Walker and Schafer 2006; Walker, Schafer, and Young 1999). That said, while the explanatory and predictive power of operational code beliefs and personality traits is recognized, the analytical usefulness of theory pertaining to cognitive errors and biases is greeted with more skepticism. For example, perception is an important component of cognitive errors and biases, and as Robert Jervis (1976: 7) points out, "there is no easy way to determine the accuracy of perceptions.” Even Daniel Kahneman and Jonathan Renshon (2009: 92-93), who argue that cognitive errors and biases promote hawkish foreign policy, express serious doubts about the explanatory and predictive power to be derived from theories pertaining to these aspects of cognition. Kahneman and Renshon (2009: 92) refer to using theories of cognitive errors and 
biases to explain and predict foreign policy behavior variously as "unreasonable" and "impossible." A major source of their dim view of these cognition theories appears to be that identifying the influence of errors and biases relies on tentative post hoc analysis.

My theoretical framework offers an alternative to identifying the role of cognitive errors and biases via post hoc analysis. In particular, my theoretical framework uses a decision maker's operational code beliefs and personality traits to predict susceptibility to specific errors and biases. If an elite's errors and biases can be explained and anticipated based on measurable beliefs and personality traits, then evidence for the presence of such errors and biases in the elite's decision making can be viewed with greater confidence.

Thus far I have considered this study's contributions to the research areas of international security, political psychology, and foreign policy individually. Notably, though, the final contribution of my framework is to foster further cross-fertilization between, on the one hand, international security and, on the other hand, political psychology and foreign policy analysis. The centrality of hawkish and dovish decision makers to international security combined with the potential for political psychology and foreign policy analysis to generate a deeper understanding of such elites indeed suggests fruitful opportunity for cross-fertilization.

\section{The Course of the Study}

The remainder of the study begins with the delineation of my theoretical framework. The framework entails a complex interweaving of independent and intervening variables, the goals of which are to create a psychology-based six-fold typology of hawkish and dovish decision makers, and ultimately to explain and predict outcomes on the dependent variable: decision makers' foreign policy positions. The seventeen hypotheses presented in this first chapter and 
tested later in the study ensure that my framework's validity is sufficiently subject to empirical scrutiny.

While the first chapter introduces variables conceptually, the second presents them in their operationalized forms. The second chapter also presents my research methods. This study employs a mixed-methods approach. The operational code beliefs and personality traits of real world decision makers examined in this study will be measured quantitatively via methods rooted in automated content analysis. Qualitative congruence analysis will be employed for all other empirical analysis. This chapter additionally introduces the case that will be the focus of my empirical analysis. The case studied here is the George W. Bush administration's decision to pursue the invasion of Iraq in 2003. I explain the selection of this case, identify the decision makers I will undertake to analyze, and describe my data collection processes.

The third and fourth chapters present my empirical analysis. Chapter three contains the quantitative component of my analysis. Relying on automated content analysis techniques, I seek to classify members of the Bush administration according to my typology of hawkish and dovish decision makers. I will then, to the extent possible, make predictions about the administration members' values on intervening and dependent variables. Chapter four comprises the qualitative thrust of my empirical analysis and contains a detailed congruence analysis (George and Bennett 2004) of administration decision making leading up to the United States' invasion of Iraq.

The concluding chapter serves three main purposes. First, it briefly recounts the present study's significance and contributions. Second, the chapter summarizes the empirical findings' implications for my theoretical framework. Third, it suggests directions for future work based on my framework and analysis. 


\section{Chapter 1: Theoretical Framework}

In this chapter I lay out my theoretical framework. I begin by introducing the variables at the heart of my framework. I then weave these variables into a six-fold typology of hawkish and dovish decision makers. To further distinguish among decision maker types I present hypotheses regarding the cognitive errors and biases to which each type is susceptible. Finally, I propose six hypotheses regarding the foreign policy positions I expect each decision maker type to espouse.

\section{Variables}

The foreign policy positions of individual decision making elites comprise this study's dependent variable. I will seek to account for outcomes on the dependent variable via hypothesized relationships between various independent variables, intervening variables, and decision makers' policy positions. In the remainder of this section I describe, conceptually, the variables at the heart of this study. I define the variables operationally in the next chapter (to follow).

The Dependent Variable: Foreign Policy Positions

In the end, decision making elites' foreign policy positions are the dependent variables whose outcomes I seek to explain. These outcomes vary primarily along a continuum of cooperative to conflictual policy positions. On the cooperative extreme, a decision maker may advocate a policy of mutual accommodation with an adversary followed by appeasement or submission if necessary. At the opposite end of the continuum an elite may advocate bullying policies such as initiating aggressive military action or making expansionist demands of an opponent with no intention of moderating those demands. I describe foreign policy positions residing between these two extremes in the hypotheses section below. Intervening Variables: Errors, Biases, and Preferences over Outcomes 
In this study, I theorize a number of variables acting as intervening variables (i.e., variables that are affected by other independent variables and in turn affect the dependent variable). The first variable is a decision maker's preferences over foreign policy outcomes. The second variable is a decision maker's beliefs about their opponent's preferred foreign policy outcomes. The remaining intervening variables are cognitive errors and biases a decision maker may experience.

\section{Preferences over Outcomes}

This variable refers to a decision maker's preferences regarding outcomes of interactions with foreign actors (e.g., other states, terrorist groups, corporations, etc.) and comes directly from the "Theory of Inferences about Preferences (TIP)" developed for the operational code analysis (OCA) research program (Marfleet and Walker 2006: 56-58; Walker 2004). This variable can take the form of one of six possible orderings of preferences over the following outcomes: submission, settlement, deadlock, and domination. Walker (2004) derived these preference rankings from Holsti's (1977) operational code typology. The first ordering, associated with appeasing opponents, ranks settlement first followed in descending order by deadlock, submission, and domination. The second ordering, linked to rewarding others' cooperation and deterring others from conflictual behavior, ranks settlement over deadlock, deadlock over domination, and domination over submission. Third, the ordering associated with cooperative but exploitative behavior ranks settlement as its first preference followed in order of descending preference by domination, deadlock, and submission. In contrast to the first three orderings, the next three all rank domination first. The fourth preference ranking is tied to bluffing behavior and has as its first preference domination followed in order of decreasing preference by settlement, submission, and deadlock. The fifth ordering, associated with punishing or 
compelling others, ranks domination over settlement, settlement over deadlock, and deadlock over submission. The sixth and final ordering, which is linked to expansionistic and bullying behaviors, ranks domination first, followed in descending order by deadlock, settlement, and submission. As I explain in the hypotheses section, these preference orderings affect a decision maker's foreign policy positions but are themselves affected by other independent variables.

\section{Beliefs about Opponents' Preferences over Outcomes}

This variable refers to a decision maker's beliefs about their opponent's preferences over the possible outcomes of interactions between the opponent and the decision maker (or the decision maker's group). This variable, which also derives directly from TIP, can take the form of one of the same six preference rankings discussed directly above. The key difference is that rather than being the preference ranking of the decision maker, this variable is the ranking of preferences the decision maker believes their opponent possesses. As I explain in the hypotheses section, this variable affects a decision maker's foreign policy positions but, too, is itself affected by other independent variables.

\section{Errors and Biases}

Numerous cognitive errors and biases function as intervening variables in my theoretical model. One set of errors and biases, compiled by Kahneman and Renshon (2009; see also Renshon and Kahneman 2017), is associated with hawkishness. Included in this study are the following biases and errors from their set: positive illusions, the fundamental attribution error, reactive devaluation, pseudo-certainty, as well as concession aversion and "risk seeking in losses." 1

\footnotetext{
${ }^{1}$ I do not include the "illusion of transparency" bias described by Kahneman and Renshon (2009: 84-85; see aldso Renshon and Kahneman 2017) as a "hawkish bias." Kahneman and Renshon (2009: 85; Renshon and Kahneman 2017: 53) explain how this bias can lead to "hawkish outcomes" - i.e. conflictual outcomes - in interactions between opponents. However, the hawkishness produced is a property only of the interaction, not a property
} 
Positive illusions come in three forms. One positive illusion to which an individual may succumb is an "unrealistically positive view of one's abilities and character" (Kahneman and Renshon 2009: 81; see also Renshon and Kahneman 2017: 59-61). Another is the "illusion of control," an inflated sense of one's ability to determine outcomes (Kahneman and Renshon 2009: 81; Renshon and Kahneman 2017: 59-61). The third, "unrealistic optimism," is partly rooted in an exaggerated perception that one is more likely than others to experience favorable outcomes and less prone than others to negative outcomes (Kahneman and Renshon 2009: 81; Renshon and Kahneman 2017: 59-61). This exaggerated perception can in turn stem from an individual's discounting of an opponent's abilities. Unrealistic optimism may also derive from the "wishful thinking" bias (Levy 2003: 268; see also Kahneman and Renshon 2009: 81; Renshon and Kahneman 2017: 59-61) which leads individuals to overestimate the likelihood of desirable outcomes while underestimating the probability of undesirable outcomes. Each of these positive illusions has the potential to produce in a decision maker overconfidence, overconfidence that predisposes that decision maker to hawkish, conflictual behavior (Altman 2015; Johnson 2004; Johnson, McDermott, Barrett, and Cowden 2006; Johnson and Tierney 2011; Kahneman and Renshon 2009: 82; Kahneman and Tversky 1995; Renshon and Kahneman ; 2017: 59-61; Van Evera 1999). ${ }^{2}$

The fundamental attribution error refers to individuals' "general tendency to overestimate the importance of personal or dispositional factors relative to environmental influences" when accounting for others' actions (Ross 1977: 184). This tendency is particularly pronounced in an individual's explanation of another actor's undesirable actions (Levy 2003:

inhering in either party to the interaction. Because I am interested in the hawkishness (or dovishness) of individual decision makers, this bias is not pertinent to the present study.

${ }^{2}$ Note, however, that I will also claim (see the hypotheses section below) dovish decision makers are susceptible to one type of unrealistic optimism. 
266; Nisbett and Ross 1980). Moreover, an individual is especially likely to attribute the undesirable actions of an adversary to the adversary's disposition rather than environmental, situational factors (e.g., constraints) that might also explain the adversary's undesirable behavior (Heradstveit 1981: 23-26; Kahneman and Renshon 2009: 83-84; Levy 2003: 266; Renshon and Kahneman 2017: 53. 61-63). However, when an individual's adversary acts in a desirable way, the fundamental attribution error leads that individual to attribute the adversary's desirable behavior to situational factors such as coercion (Heradstveit 1981: 48-76; Kahneman and Renshon 2009: 83-84; Renshon and Kahneman 2017: 53). In short, due to the fundamental attribution error, an adversary's undesirable actions buttress an individual's preexisting beliefs that the adversary has a hostile disposition, while desirable actions are dismissed as the products of coercion or constraints (Kahneman and Renshon 2009: 84; Renshon and Kahneman 2017: 53, 61-63). ${ }^{3}$ The fundamental attribution error thus encourages hawkishness by supporting a decision making elite's prior perceptions of an adversary as inherently hostile and untrustworthy when the adversary's actions are undesirable, while leading the elite to think that an adversary's desirable behavior is a response to tough action from the decision maker or their group (Kahneman and Renshon 2009: 84; Renshon and Kahneman 2017: 53, 61-63; Snyder 1991: 29). In the context of negotiations between opponents, reactive devaluation is a bias that leads an individual to undervalue their adversary's proposals simply because the offers are made by the adversary (Kahneman and Renshon 2009: 92; Maoz, Ward, Katz, and Ross 2002; Renshon and Kahneman 2017; Ross 1995; Stillinger and Ross 1991). For instance, in a 1986 survey experiment (Stillinger, Epelbaum, Keltner, and Ross 1991), of respondents who were presented

\footnotetext{
${ }^{3}$ For the sake of illustration, consider the following example: "when America behaved as [Leonid] Brezhnev desired, he said it was because the power of the socialist camp gave America no alternative; but when America misbehaved, it was a reflection of the innate aggressiveness of capitalism" (Snyder 1991: 29).
} 
with a proposal for nuclear disarmament credited to Ronald Reagan, nine out of ten rated the proposal as favorable or fair to the United States. However, of those were presented with an identical proposal credited to Mikhail Gorbachev, less than half gave such positive ratings. Reactive devaluation fosters hawkish behavior by encouraging a decision maker to reject concessions and proposals for compromise offered by an adversary as trivial or made in bad faith (Ross 1995; see also Kahneman and Renshon 2009: 92; Renshon and Kahneman 2017).

Pseudo-certainty is a bias that tends to afflict individuals facing a problem with multiple stages. As Kahneman and Renshon (2009: 91; Renshon and Kahneman 2017: 53; see also Tversky and Kahneman 1986: S265-S270) explain, “[w]hen contemplating multiple-stage problems in which the first-stage is probabilistic and the second-stage contains a certain outcome, individuals tend to ignore the first-stage altogether." According to the authors, the effect of the pseudo certainty bias on international negotiations is to make decision making elites more hesitant to grant concessions of strategic importance. Kahneman and Renshon illustrate their point with the case of 1970s Egyptian-Israeli peace talks. Egypt wanted the return of the Sinai Peninsula from Israel, but hawks on the Israeli side opposed the return because Israeli control of the Sinai would certainly be strategically valuable in the event of another war between Egypt and Israel. As Kahneman and Renshon (2009: 91; see also Renshon and Kahneman 2017) argue, the dilemma Israeli decision makers faced had two stages. The first was whether Egypt and Israel would again go to war, and the second was the result of a hypothetical future Egyptian-Israeli war. The authors claim that Israel's hawks, who seem to have been affected by the pseudo-certainty bias, were fixated on the certainty of the Sinai's strategic value in a future Egyptian-Israeli war while ignoring that the outbreak of a future war was not certain to occur. 
Moreover, Kahneman and Renshon point out that Israel's hawks seem to have overlooked the extent to which returning the Sinai Peninsula could reduce the likelihood of another war.

Concession aversion is a manifestation of loss aversion (Kahneman and Renshon 2009: 87; Kahneman and Tversky 1995: 56; Levy 2000: 209-210; Renshon and Kahneman 2017). Loss aversion is a core component of Khaneman and Tversky's (1979) prospect theory. In prospect theory, loss aversion refers to individuals' tendency to place more importance on assets lost than assets gained. As Levy (2000: 194) pithily summarizes loss aversion, "the pain of losses exceeds the pleasure from gains." In international negotiations loss aversion takes the form of concession aversion (Kahneman and Renshon 2009: 87; Levy 2000: 209-210; Renshon and Kahneman 2017); decision making elites will perceive concessions they make as losses and the concessions made by the other side as gains, thus even if an exchange of concessions is fair from an objective standpoint, the decision makers are likely to exaggerate the value of what is lost compared to what is gained. The upshot of concession aversion is that decision makers are prone to risking deadlock rather than reaching an agreement based on mutual accommodation (Levy 2000: 209-210).

Risk seeking in losses, which also flows from prospect theory, denotes individuals' tendency to be risk averse when pursuing gains, but risk seeking when suffering or trying to avoid losses (Kahneman and Tversky 1979; Tversky and Kahneman 1986). Additionally, individuals assign an exaggerated importance to certain losses (such as assets already lost) relative to the importance assigned to a probable loss (Tversky and Kahneman 1981: 455; see also Tversky and Kahneman 1986). Consequently, in situations where an individual is forced to choose a certain considerable loss (e.g., a major concession) or a possible debacle, but where there is also some possibility of recovering some or all of the certain loss, the individual is liable 
to engage in risky behavior an objective third party would deem irrational (Kahneman and Renshon 2009: 89; Renshon and Kahneman 2017).

In the domain of international conflict, risk seeking in losses principally manifests in four ways. First, decision making elites are likely to advocate riskier (and perhaps more conflictual) foreign policies to preserve their state's reputation or position in international politics than they would advocate to improve that reputation or position (Berejikian and Early 2013; Jervis 1992: 192-193; Levy 2000: 200-210, 2003: 270-271; see also Renshon 2015). Second, if a violent conflict has begun, decision makers are likely to view sunk costs like casualties "as a certain loss in the absence of further action" (Levy 2000: 204; see also Renshon 2015) and therefore persevere to make sure the casualties have not been in vain. Third, decision making elites on the side losing a conflict are prone to persist in the fight even if the likelihood of resurrection is small because the decision makers likely weight the relatively certain costs of surrendering now more than the probable costs of being defeated later (Kahneman and Renshon 2009: 89-90; Renshon and Kahneman 2017). Fourth, decision makers whose side in a conflict has been defeated and lost something (e.g., territory) are unlikely to readily adapt to this loss (Jervis 1992: 196; Levy 2000: 206-213), suggesting that at some point they will be liable to engage in risky foreign policy to regain what was lost. All of these manifestations of risk seeking in losses clearly lend themselves to hawkish policy choices.

As noted, each of the foregoing biases and errors is associated with hawkish behavior. The following set of errors, delineated by Snyder and Diesing (1977: 302-304), is linked to dovishness. As will be evident, our understanding of the errors in this set is far less developed than is the case for the errors and biases linked to hawkishness. 
In their pathbreaking theoretical framework for distinguishing hawks and doves, Snyder and Diesing (1977: 302-304) posit five errors associated with dovishness. ${ }^{4}$ The first error that foreign policy elites may make is to underestimate the level of conflict between their side and their opponent. Elites may also generally overestimate the opponent's propensity for compromise. Similarly, decision makers can overestimate the opponent's internal disagreement by perceiving more conflict between hawkish and dovish elements in the opponent's decision making apparatus than actually exists. At the same time a decision making elite may overestimate agreement with the opponent's dovish elements, seeing more harmony between themself and dovish elites in the opponent's decision making apparatus than is really present. Finally, a decision making elite may overestimate the value of their side's concessions to the opponent. All of these errors foster dovishness by leading a decision maker to overestimate the probability that a dispute can be settled by mutual accommodation. Importantly, the third of these errors also represents a positive illusion in its own way. Namely, dovish decision makers see what they desire to see: fellow dovish elites with whom they can reach agreement. This suggests that dovish types fall prey to wishful thinking-induced unrealistic optimism (see Lebow 1981: 169-170; Levy 2003: 268-269).

In the hypotheses section, I explain more explicitly how the errors and biases associated with hawkishness and dovishness affect the dependent variable. Also in the hypotheses section, I lay out a framework for anticipating the errors and biases to which an individual decision making elite is most susceptible. The next sets of variables I discuss are central to constructing that framework. Independent Variables: Operational Code Beliefs and Leadership Traits

\footnotetext{
${ }^{4}$ Snyder and Diesing use the terms hard-liner and soft-liner rather than hawk and dove, but the terms hard-liner and hawk seem interchangeable, as do the terms soft-liner and dove.
} 
Two clusters of independent variables are central to this study's theoretical framework. One cluster of variables consists of beliefs from the operational code belief system. The other cluster contains personality traits highlighted by leadership trait analysis (LTA). I theorize that these variables affect the dependent variable directly and through the intervening variables. In the hypotheses section I delineate the theorized effects of both sets of variables.

\section{Leadership Traits}

Leadership traits are the personality characteristics that underlie an elite's leadership style (Hermann 2003: 179). Note, however, that in this study I am less interested in a major component of decision makers' leadership styles: how elites participate in and possibly seek to control the process of foreign policy decision making. In other words, I am not focused on understanding how decision makers interact with other elites in their state's decision making apparatus. Instead, I am very much interested in how personality traits associated with leadership style affect the foreign policy positions of individual decision-making elites. ${ }^{5}$ Consequently, my discussion of leadership traits will focus on how these personality characteristics affect foreign policy positions.

Six leadership traits are central variables in my theoretical framework. The first two, "distrust of others" and "in-group bias" comprise a decision maker's "motivation toward [the] world" (Hermann 2003: 199-203). As Hermann (2003: 201) explains, a decision maker's ingroup bias reflects the following: the extent to which their world view places their group (defined politically or otherwise) at "center stage," their emotional connection to the group, whether they sees their group as the best, as well as how much the decision maker focuses on

\footnotetext{
${ }^{5}$ For a more recent example of a study focused on how leadership style affects the foreign policy decision making process see Schafer and Crichlow 2010. An example of a study analyzing the influence of leadership traits on foreign policy positions is provided by Shannon and Keller 2007.
} 
maintaining the status and culture of their group. ${ }^{6} \mathrm{~A}$ decision maker with a strong in-group bias sees little distinction between themself and the group, instead seeing themself and the group as one and the same. The decision maker likely perceives politics as a zero-sum game of us versus them. They are also apt to be blinded to their group's weakness, able only to see good facets of the group. Given these perceptions, a decision maker with a strong in-group bias is likely to espouse policies that favor their group at the expense of others and resist external influences that might undermine their group's independence or identity. Furthermore, such a decision maker is likely to rally their fellow group members by scapegoating foreign actors as enemies who have caused the group's every trouble. In contrast, an elite low in this bias, while not unconcerned with their group and its independence and identity, is less apt to possess an us-versus-them mentality. They are also less likely to engage in the behaviors, such as scapegoating, that typify a decision maker high in this bias. Hermann does not provide clear guidance regarding the expected behavior of decision makers with a moderate in-group bias, but this is of little concern because, as will become evident below, my focus is on decision making elites who are either high or low in this bias.

As a personality trait, Hermann (1980: 21) conceptualizes distrust of others as "a general feeling of doubt, uneasiness, misgiving, and wariness about others; an inclination to suspect the motives and actions of others." Distrust is likely to be focused on adversaries, and some distrust is certainly understandable. However, as Hermann (2003: 203) explains, in the eyes of elites with high levels of distrust, adversaries "can do nothing right" - even benign actions are likely to be seen as stemming from "ulterior motives and designs." ${ }^{77}$ Moreover, highly untrusting decision makers are more likely than relatively trusting elites to view opponents as unremittingly hostile

\footnotetext{
${ }^{6}$ Elsewhere, in-group bias has been labeled nationalism. See Hermann 1980.

${ }^{7}$ On this point see also Holsti 1967.
} 
and, more generally, to perceive the broader environment as threatening (Holsti 1967; Shannon and Keller 2007: 84). Such distrustful elites have a pronounced propensity for advocating forceful foreign policies (Driver 1977; Foster and Keller 2014; Shannon and Keller 2007: 84). In contrast, decision makers with low levels of inherent distrust, though not naïve, adjust the intensity of their suspicion according to the situation and actors involved (Hermann 2003: 203). As a result, more trusting elites should not be as inclined to forceful foreign policies (see Driver 1977; Foster and Keller 2014). The literature provides little in the way of expectations regarding decision makers who fall between low and high levels of distrust. However, as I am primarily interested in these extremes of distrust-trusting, this is no great hindrance.

While the previous two personality traits pertain to a decision maker's motivation towards the world, the next personality trait, conceptual complexity, reflects how a decision making elite processes information from that world. Hermann (2003: 195) defines conceptual complexity as "the degree of differentiation that an individual shows in describing or discussing other people, places, policies, ideas or things." Decision making elites who are conceptually simple see the world in dichotomous terms such as black or white, good or bad. Conceptually complex elites, however, are able to see shades of grey. This makes conceptually complex decision makers more capable than conceptually simple elites of recognizing ambiguity and seeing a number of reasons for an adversary's position. Seeing shades of grey and ambiguity also leads conceptually complex elites to be receptive to various perspectives, new information, and alternative courses of action. In a word, conceptually complex decision makers are flexible. Conceptually simple elites, in contrast, are surer of their existing opinions and positions; less receptive to other perspectives, information, and alternatives; and, not surprisingly, less flexible (Hermann 1984; 2003: 195-196; Shannon and Keller 2007: 85). For the purposes of this study it 
is important to note that conceptual simplicity is associated with greater support for forceful foreign policies (Driver 1977; Foster and Keller 2014; Hermann 1984; Shannon and Keller 2007: $85)$.

The next two personality traits I include in this study, "belief in one's own ability to control events" and "need for power" affect the extent to which a decision making elite challenges or respects the constraints they faces in their environment. Belief in ability to control events is, according to Hermann (2003: 184, 188-190), the extent to which a decision making elite believes themself, their group, or their government "can influence or control what happens." Hermann claims elites high in this belief are confident in their position on a decision and, because they have faith in their ability to make things happen, are less open to deal making or compromise. Conversely, decision makers low in this belief fear failure and are more cautious. Leaders with a moderate belief that they can control events should tend to fall between these extremes.

Need for power, as defined by Hermann (2003: 190), is the extent to which an elite is concerned about "establishing, maintaining, or restoring one's power" and "desire[s] to control, influence, or have an impact on other persons or groups." Elites with a strong need for power want to win and tend to know what it will take to do so. They will manipulate situations to facilitate their control and push limits. In negotiations they are hard bargainers, seeing bargaining in zero-sum terms and seeking to make gains for their side rather than accommodating the other side (Hermann 2003: 190-191; Shannon and Keller 2007: 84). By comparison, decision making elites low in this need are more attuned to the notion of justice (Hermann 2003: 191). As a result, decision makers with a weak need for power should be more 
interested in accommodation and compromise than decision makers with a strong need for power.

The final personality trait I incorporate into my framework is task focus. Task focus refers to the relative importance an elite assigns to solving problems on the one hand and building or maintaining relationships on the other (Hermann 2003: 197; Shannon and Keller 2007: 84). Decision makers highly focused on completing tasks and solving problems care more about accomplishing goals than addressing others' needs or feelings (Shannon and Keller 2007: 84; see also Hermann 2003: 197-199). Elites highly focused on building or maintaining relationships, with a greater sensitivity other's needs and feelings, pursue accommodation with others, including opponents (Shannon and Keller 2007: 84).

\section{Operational Code Beliefs}

As I discuss above, the OCA research program's Theory of Inferences about Preferences (TIP) gives rise to six preference rankings regarding outcomes of interactions with foreign entities (Marfleet and Walker 2006: 56-58; Walker 2004). According to TIP, these preference rankings can be deduced from six distinct combinations of three "master beliefs" (Marfleet and Walker 2006: 56). The trio includes a decision maker's beliefs about the following: the basic nature of politics, especially political opponents; the decision maker's ability to influence events and historical development relative to others' ability to do so; and optimal strategies for political action (Marfleet and Walker 2006: 56). After describing each of these beliefs, I briefly discuss how, in different combinations, they produce distinct preference rankings.

The first two beliefs in the trio are considered philosophical beliefs because they pertain to a decision maker's 'assumptions and premises...regarding the fundamental nature of politics, political conflict, the role of the individual in history, etc" (George: 1969: 199). An elite's belief 
regarding the basic nature of politics and political opponents is the first philosophical belief (abbreviated P-1) in the operational code framework as refined by George (1969: 201-203). In George's conceptualization, P-1 concerns whether a decision maker sees opponents as friendly or hostile and whether the decision maker sees politics as fundamentally conflictual or harmonious (see also Schafer and Walker 2006: 33). P-1 is particularly centered on a decision maker's perceptions of opponents as friendly or hostile because how an elite perceives their opponents is assumed to reflect not only their beliefs about opponents, but also their beliefs about politics generally (Schafer and Walker 2006: 33; see also George 1969: 201).

The extent to which a decision maker believes they are able control events and historical development relative to others' ability to exert such control is the fourth philosophical belief (abbreviated P-4) in the operational code framework as formulated by George (1969: 204; see also Marfleet and Walker 2006: 56; Schafer and Walker 2006: 34). In TIP, P-4 is disaggregated into P-4a and P-4b (Marfleet and Walker 2006: 57). P-4a is how much control a decision maker believes they are able to exert over events (Marfleet and Walker 2006: 57; see also Malici and Buckner 2008: 790-791). P-4b refers to a decision maker's belief about their opponent's ability to control events (Marfleet and Walker 2006: 57; see also Malici and Buckner 2008: 790-791). I include P-4, P-4a, and P-4b in this study. ${ }^{8}$

The trio's third belief is labeled an instrumental belief due to its focus on the relationship of ends to means in politics (George 1969: 199). A decision maker's belief about optimal strategies for political action is the first and most important instrumental belief (abbreviated $I-1$ )

\footnotetext{
${ }^{8}$ On its face, P-4a is nearly identical to the "belief in one's own ability to control events" (Hermann 2003: 188) which is a personality trait in LTA. However, there are important distinctions between P-4a and this personality trait. Recall that, as conceptualized by Hermann (2003: 188-190), belief in ability to control events reflects the extent to which an elite believes they or their government can affect events. In OCA, particularly TIP, however, P$4 \mathrm{a}$ is narrower than the corresponding personality trait and represents a decision maker's belief in their ability to control events in their interactions with foreign actors (see Marfleet and Walker 2006: 56). Additionally, as I discuss below, OCA and LTA operationalize these variables in different ways. In short, despite the ostensible similarities, these variables are distinct and I include both as separate variables in this study.
} 
in George's (1969: 205-211) conceptualization of operational code beliefs. In contemporary OCA research, I-1 refers to whether a decision maker believes the best strategies are conflictual, cooperative, or some mix of the two (Schafer and Walker 2006: 35).

According to TIP (Marfleet and Walker 2006; Walker 2004; see also Malici and Buckner 2008: 790-791), I-1 and P-4a reflect a decision making elite's thinking about what they want and what they perceive as attainable. What the decision maker thinks they want and can achieve produces their preferences over foreign policy outcomes. The assumption here is that I-1 leads the decision maker to favor conflictual, cooperative, or mixed strategies, while P-4a shapes their estimate of whether they are stronger than, equal to, or weaker than the target of their foreign policy: the decision making elite's opponent. ${ }^{9}$

The first three types of decision making elites I discuss all favor cooperative strategies. Decision makers who strongly believe cooperative strategies are optimal and believe they are weaker than their opponents are assumed to rank settlement first in their preference orderings followed in descending order by deadlock, submission, and domination (Marfleet and Walker 2006: 57). According to TIP, this type of decision maker will pursue settlement first followed by deadlock if a settlement is not forthcoming. However, if deadlock is also unattainable, the decision maker will submit to their opponent because the decision maker is unable to dominate their adversary (Malici and Buckner 2008: 791). For these reasons, this type of decision maker is prone to appeasing (Malici and Buckner 2008: 791; Marfleet and Walker 2006: 57).

Elites who firmly believe in the superiority of cooperative strategies and believe they are equal to their opponents rank settlement over deadlock, deadlock over domination, and domination over submission (Marfleet and Walker 2006: 57). TIP theorizes that decision makers who rank their preferences in this order first seek to reach a settlement, but will move to

\footnotetext{
${ }^{9}$ The labels stronger, weaker, and equal come from the application of TIP in Malici and Buckner (2008: 790-791).
} 
deadlocking if settlement is not readily achieved. If deadlock is not successful, this type of decision maker will pursue domination so as not to submit to the opponent (Malici and Buckner 2008: 791). Stated somewhat differently, this type of decision maker tends to reward others' cooperation and deter others from engaging in conflictual behavior directed at the decision maker or their group (Marfleet and Walker 2006: 57).

Decision making elites with a strong belief that cooperative strategies are best who also believe they are stronger than their opponents rank settlement as their first preference followed in order of descending preference by domination, deadlock, and submission (Marfleet and Walker 2006: 57). As Malici and Buckner (2008: 791) explain, a decision maker of this type will try to achieve a settlement with their opponent first; however, if settlement eludes the decision maker, they will employ their perceived "superior power to impose a domination or deadlock outcome in order to avoid submission." These behavioral tendencies can be summed up as cooperative but exploitative (Marfleet and Walker 2006: 57).

The next three types of decision making elites all strongly favor conflictual strategies. Decision makers who firmly believe conflictual strategies are best but believe themselves to be weaker than their adversary have as their first preference domination followed in order of decreasing preference by settlement, submission, and deadlock (Marfleet and Walker 2006: 57). TIP theorizes that this type of elite will at first try to dominate their opponent, but, if domination is not readily attained, will change tack and pursue settlement. If a settlement is also not forthcoming, such a decision maker will submit because they perceive themself as too weak to maintain a deadlock (Malici and Buckner 2008: 791). Not surprisingly this type of decision maker is likely to be a bluffer, analogous to the player who swerves out of the way in a game of chicken (Malici and Buckner 2008: 791; Marfleet and Walker 2006: 57). 
Elites who strongly believe conflictual strategies are optimal and believe they are equal to their opponent rank domination over settlement, settlement over deadlock, and deadlock over submission. According to TIP, elites of this type seek first to dominate their opponents, but will compromise on a settlement outcome if the goal of domination is elusive. If settlement also eludes them, this type of elite will move to deadlock in order to evade submitting (Malici and Buckner 2008: 791). These preferences tend to manifest as an elite seeking to compel or punish their opponent (Marfleet and Walker 2006: 57).

The final type of decision maker firmly believes conflictual strategies are optimal and that they are stronger than their opponent. In their ordering of preferences over outcomes, this decision maker type ranks domination first, followed in descending order by deadlock, settlement, and submission (Marfleet and Walker 2006: 57). This type of decision maker first tries to dominate their opponent. Failing that, they will move to force a deadlock; this decision maker type will not submit or settle (Malici and Buckner 2008: 791). As one might expect, decision makers with these beliefs and preferences engage in bullying foreign policies (Marfleet and Walker 2006: 57).

As I-1 and P-4a produce a decision making elite's preferences over foreign policy outcomes, so P-1 and P-4b produce their beliefs about their opponent's preferences. TIP (Marfleet and Walker 2006; Walker 2004; see also Malici and Buckner 2008: 790-791) theorizes that $\mathrm{P}-1$ and $\mathrm{P}-4 \mathrm{~b}$ indicate a decision maker's beliefs about what their adversary wants and thinks achievable. Underlying TIP is the assumption that P-1 reflects an elite's belief that their adversary is friendly, hostile, or somewhere in between. For its part, $\mathrm{P}-4 \mathrm{~b}$ is assumed to reveal whether the decision making elite believes their opponent sees itself as weaker than, equal to, or stronger than the elite's side. 
A decision maker who believes their opponent is friendly and perceives itself as weaker infers that the opponent prefers settlement to deadlock, deadlock to submission, and submission to domination (Marfleet and Walker 2006: 57). Consequently, the decision maker believes their opponent will first seek settlement, followed by an attempt to deadlock if settlement is not forthcoming. This type of decision making elite further believes that if deadlock is also elusive, their opponent will submit because it perceives domination as impossible (Malici and Buckner 2008: 791). In short, such a decision maker believes their opponent is an appeaser (Marfleet and Walker 2006: 57).

If a decision making elite believes their opponent is friendly and perceives itself to be the decision maker's (or decision maker's side's) equal, the elite sees an opponent who ranks settlement first, followed in order of descending preference by deadlock, domination, and submission (Marfleet and Walker 2006: 57). This belief in turn leads the decision maker to believe that their opponent will pursue settlement first, but will change tack and seek to deadlock if settlement is not readily reached. The decision maker also believes that if their opponent's efforts at deadlocking fail, the opponent will try to dominate so as to avoid submitting (Malici and Buckner 2008: 791). Stated somewhat differently, this type of decision maker expects their opponent to reward the decision maker's own cooperation or deter the decision maker from engaging in conflictual action (Marfleet and Walker 2006: 57).

An elite believing they face a friendly opponent who sees itself as stronger than the elite's side infers that their opponent ranks settlement over domination, domination over deadlock, and deadlock over submission (Marfleet and Walker 2006: 57). Such an elite believes their opponent will seek settlement at first. However, they also believe that their opponent will avoid submission by dominating the elite (or the elite's side) or creating a deadlock (Malici and 
Buckner 2008: 791). In sum, a decision maker of this type believes their opponent is friendly but exploitative.

If a decision maker believes their opponent is hostile but perceives itself as weaker than the decision maker's side, the decision maker sees an adversary whose first preference is domination, followed in descending order of preference by settlement, submission, and deadlock (Marfleet and Walker 2006: 57). This type of elite believes their opponent will try to dominate the elite or the elite's side at first. If domination eludes their opponent, however, the adversary will seek settlement. Moreover, their opponent will also be liable to submit because it does not see itself as strong enough to deadlock (Malici and Buckner 2008: 791). Stated simply, this type of decision maker believes their opponent is a bluffer (Marfleet and Walker 2006: 57).

A decision making elite who believes their adversary is hostile and believes itself to be the equal of the elite or the elite's side sees the opponent as preferring domination to settlement, settlement to deadlock, and deadlock to submission (Marfleet and Walker 2006: 57). Such an elite believes their adversary will first seek to dominate the decision maker or the decision maker's side, but will choose to pursue settlement if domination is not soon achieved. This type of elite further believes that their opponent will avoid submission by deadlocking if settlement is also not forthcoming (Malici and Buckner 2008: 791). In short, this type of decision maker expects their opponent will try to punish or compel the decision maker or their side (Marfleet and Walker 2006: 57).

An elite believing they face_a hostile opponent who sees itself as stronger than the elite's side infers that the opponent ranks domination over deadlock, deadlock over settlement, and settlement over submission (Marfleet and Walker 2006: 57). An elite with this belief expects their opponent to begin by trying to dominate. Should domination fail, the decision maker 
expects their opponent to seek deadlock and reject settling or submitting (Malici and Buckner 2008: 791). Simply put, this type of elite believes their opponent is a bully (Marfleet and Walker 2006: 57).

In the next section, I link together operational code beliefs and personality traits with decision makers' preferences over foreign policy outcomes and decision makers' beliefs about their opponents' preferences. In doing so, I generate a typology for classifying decision making elites. This typology will be the foundation for forming hypotheses about decision makers' susceptibilities to various errors and biases as well as decision makers' foreign policy positions.

\section{Classifying Hawkish and Dovish Decision Making Elites}

In this section I present a scheme for classifying decision making elites. This scheme consists of a six-fold typology that identifies decision makers according to their values on the following independent and intervening variables: operational code beliefs, personality traits, preferences over foreign policy outcomes, and beliefs about opponents' preferences over foreign policy outcomes. My typology focuses on distinguishing among decision makers loosely clustered at opposing ends of the hawkish-dovish continuum.

\section{A Typology of Decision Making Elites}

The starting point for this study's typology is Snyder and Diesing's (1977: 297-310) framework and two-fold typology for distinguishing hard-liners (hawks) from soft-liners (doves). In their typology hawkish and dovish decision making elites are classified according to distinct personalities consisting of different world views, images of self and opponents, and preferences over strategies. My own typology translates these world views, images, and preferences into the language of operational code beliefs and leadership traits. However, my classificatory scheme is not merely a repackaging of the Snyder-Diesing typology. My own typology expands the 
dichotomous hawk-dove distinction by disaggregating the two broad categories of hawk and dove into six distinct decision maker types.

\section{World Views and Images in the Language of OCA and LTA}

In the Snyder-Diesing typology (Snyder and Diesing 1977: 297-310) hawkish world views are those in which the realm of international politics is seen as very conflictual. A hawk sees peace and security as goals achieved through military power and deterrence, as well as through firm resolve in times of crisis. Consequently, a hawkish decision maker feels it necessary to maintain or enhance their side's power. A hawkish decision making elite is also skeptical of accommodation for fear of appearing weak in the eyes of their opponents. This wariness towards accommodation stems in part from the hawks" "image of the opponent" (Snyder and Diesing 1977: 299). A hawkish elite views their opponent as a cool, calculating, and monolithic aggressor whose ultimate aims are unlimited. The opponent's current actions are seen as part of a larger, hostile plan. A hawkish decision making elite presumes that what their opponent does now is intended to test the resolve of the elite's side, demonstrate the opponent's own resolve, enhance the opponent's bargaining position, and accomplish a concrete sub-goal of the opponent's larger plan. A hawkish decision maker also assumes that their opponent is a bluffer, which explains the importance a hawkish elite assigns to deterrence.

Conversely, according to the Snyder-Diesing typology, dovish world views are those in which one sees the potential for harmonious relations and believes that what conflict does exist can be addressed via mutual accommodation. A dovish decision making elite is less concerned than hawks that accommodation will be perceived by opponents as weakness to be exploited. Indeed such an elite is more concerned that military strength and a lack of compromise will be perceived as aggressive by opponents. This openness to accommodation and concern about 
being perceived as aggressive partly reflects the dove's image of their opponent. A dove sees their opponent as an internally divided and emotional (as opposed to cool and calculating) actor whose long term goals are "limited, specific and independent, not linked together in some grand design for world conquest" (Snyder and Diesing 1977: 299). A dovish decision maker also sees their opponent's goals as at least somewhat legitimate. Furthermore, a dove believes their opponent, if not currently peaceful, will become peaceful once its goals are achieved.

These distinct world views have obvious analogs in operational code beliefs P-1 and I-1. In terms of these operational code beliefs, a hawkish world view is one in which politics and opponents are strongly believed to be fundamentally conflictual and conflictual strategies are firmly believed to be the most efficacious. In contrast, a dovish world view consists of firmly held beliefs that politics is basically harmonious, opponents are basically friendly, and that cooperative strategies are optimal.

The connections between world views and images of opponents in the Snyder-Diesing framework and personality traits in the LTA framework are less apparent, but the connections nonetheless exist. First, as is clear in the Snyder-Diesing framework, hawks see the world as a threatening place in which one must always appear strong because opponents are insatiable aggressors who cannot be trusted not to exploit any sign of weakness. This world view and image of the opponent suggest the following personality traits: a high level of distrust and the usagainst-them mentality characteristic of a strong in-group bias (see Hermann 2003: 199-203; Holsti 1967; Shannon and Keller 2007: 84). As Hermann (2003: 200) explains, decision makers who are very untrusting and have a strong in-group bias see hostile, aggressive opponents at the center of international politics and feel that they must stand up to these opponents. This 
description meshes well with the hawkish world view and image of the opponent in the SnyderDiesing framework.

The Snyder-Diesing typology describes doves as seeing a more benign, potentially harmonious world in which opponents are friendly or can be made friendly by accommodation. This implies that in terms of personality traits doves are much more trusting and lack the usagainst-them mindset indicative of a pronounced in-group bias. Indeed, Hermann (2003: 200) describes trusting elites with a weak in-group bias as perceiving a non-threatening world where "cooperation with others is both possible and feasible." This description resonates with the depiction of doves in the Snyder-Diesing typology.

Second, in the Snyder-Diesing framework, hawks clearly have a need to maintain or enhance the power of their side. Hawks also need to avoid appearing weak. Both of these needs suggest that a hawk's personality traits include a high need for power. Consider the following from Hermann's (2003: 190) description of need for power as a personality trait: "need for power indicates a concern for establishing, maintaining, or restoring one's power." In contrast, the Snyder-Diesing typology does not describe doves as having a high need for power. Indeed, if anything, doves are concerned that an increase in their side's power will be interpreted by opponents as threatening and aggressive.

Third, according to the Snyder-Diesing typology doves perceive opponents as internally divided actors whose goals are specific, limited, and not part of a sinister master plan. These perceptions suggest that doves are conceptually complex and thus able to differentiate among individuals or factions within opponents' governments and see more than one reason for opponents' goals (as opposed to seeing each goal as part of a single, coherent, and hostile master plan). Conversely, hawks perceive opponents as monoliths whose every goal is a sub-goal of an 
aggressive master plan. These perceptions imply that hawks are conceptually simple elites unable to see either internal divisions in the opponent or more than a single reason behind opponents' goals. In sum, doves see shades of grey in opponents and opponents' goals where hawks see a black and white world of unitary opponents single-mindedly pursuing a hostile master plan.

Lastly, the Snyder-Diesing typology's distinctions between hawks and doves suggest that hawks have a high task focus while doves have a low task focus. Recall that elites with a high task focus are most concerned with solving problems and relatively unconcerned with others' needs or feelings while those with a low task focus care most about building or maintaining relationships and are more concerned with others' needs and feelings. Hawks' emphasis on providing security for their group through sustained or enhanced power indicates, relative ignorance of opponents' emotions, and skepticism towards accommodating opponents all point to a high task focus. Doves, by contrast, exhibit a low task focus in their concern for mutual accommodation, sensitivity to the role of opponents' emotions, and fear that military strength and intransigence will be threatening to opponents all indicate a low task focus. Indeed, doves are quite focused on building or maintaining relationships with and accommodating opponents. Self-Images in the Language of OCA and LTA

According to the Snyder-Diesing typology, hawks see themselves as cool, calculating individuals. As part of their self-images, hawks also believe their position is legitimate vis-à-vis their opponents. This means hawks in status quo states believe they are defending a legitimate order against aggressive opponents, while hawks in revisionist states see themselves as struggling against a threatening or illegitimate status quo maintained by their opponents. Unlike hawks, doves perceive themselves as given over to emotional reactions. Also, while doves see 
some legitimacy in their position relative to their opponents, they do not see legitimacy as belonging only to their side.

The aspects of self-image concerning whether a decision maker sees themself as calculating or emotional do not translate into the language of OCA or LTA and are not central to the present study. However, the legitimacy component of self-image does translate into LTA parlance. Specifically, a strong in-group bias is evidenced by the hawk's belief that their side's position is legitimate and their opponent's position is illegitimate. As Hermann (2003: 201-202) explains, an elite with a strong in-group bias perceives their own group "as the best" and is only able to see the good in their group. Given this explanation, someone who views their own side as plainly legitimate and their opponent as patently illegitimate clearly exhibits a pronounced ingroup bias. By the same logic, a dove's belief that their side lacks exclusive claim to legitimacy suggests a weak in-group bias.

\section{Preferred Strategies in the Language of OCA and LTA}

In the Snyder-Diesing framework, the strategies hawks prefer to employ in their interactions with opponents are based on military power and firm resolve. Hawks see military power as the key to deterring or coercing opponents and are prone to use or threaten to use military power against adversaries. When negotiating, hawks take a firm stand, resisting conciliation or concessions “on all issues" (Snyder and Diesing 1977: 300, emphasis in original). Hawks' reliance on military strength and intransigence derives from their desire to always appear strong and resolute in the eyes of their opponents. Doves are comparatively unconcerned about maintaining such an appearance. Rather, doves are concerned about maintaining "a reputation for trustworthiness and willingness to accommodate on disputed issues" (Snyder and Diesing 1977: 302). Therefore, doves prefer to use accommodative and conciliatory strategies when 
interacting with opponents. Doves seek to resolve disputes through mutual accommodation.

Doves also faithfully reciprocate opponents' conciliatory behavior in order to burnish their side's reputation for trustworthiness.

The very different preferences of hawks and doves suggest equally distinct operational code beliefs and personality traits. Regarding operational code beliefs, the pertinent belief here is I-1. Hawks' preference for firmness in negotiations as well as deterrence and coercion based on military power further indicates hawks' belief that conflictual strategies are optimal. Doves' partiality towards accommodation and conciliation in turn connotes a belief that cooperative strategies are best.

In terms of LTA, the relevant personality trait in this case is task focus. Hawks' preferences over strategies further demonstrate their emphasis on accomplishing goals and lack of concern with relationships. ${ }^{10}$ Conversely, in their predilection for accommodation and conciliation as well as their concern for their reputations as conciliatory and trustworthy players, doves exhibit a focus on maintaining or creating relationships rather than completing tasks.

\section{The Operational Code Beliefs and Personality Traits of Hawks and Doves}

The foregoing discussion demonstrates that operational code beliefs and personality traits provide means for constructing a typology of hawkish and dovish decision making elites derived from the Snyder-Diesing framework. This typology is structured as follows and summarized in Tables 1 and 2. In terms of operational code belief P-1, hawks strongly believe politics is fundamentally conflictual and opponents are inherently hostile while doves strongly believe politics is essentially harmonious and opponents are basically friendly. Regarding operational code belief I-1, doves see cooperation as the optimal strategy and hawks believe conflictual strategies are best. The differences between the personality traits of hawks and doves are equally

\footnotetext{
${ }^{10}$ After all, intransigence in negotiations seems a rather poor way to foster relationships with opponents.
} 
Table 1: Operational Codes and Leadership Traits Corresponding to Snyder and Diesing's Hawkish (Hard Line) Belief System

Snyder and Diesing's Hawkish Belief System

Worldview and Images:

Very conflictual Peace requires power, strength, and resolve

Adversaries are cool and calculating monoliths

Adversaries have hostile overarching plan: Ultimate aims are unlimited, and specific current aims are part of calculated plans to achieve ultimate hostile goals

Adversaries are bluffers who can be deterred

\section{Self image:}

Cool calculator

Seeking legitimate expansion or to defend a

legitimate current state

\section{Preferred actions:}

Rely on military strength, coercion, deterrence, and firm resolve Avoid accommodation and conciliation

\section{Corresponding Operational Code Beliefs}

\author{
P-1: Conflictual \\ I-1: Conflictual
}

P-1: Conflictual

I-1: Conflictual

\section{Corresponding Leadership $\underline{\text { Traits }}$}

High distrust of others High in-group bias High need for power High task focus

Low conceptual complexity

Low conceptual complexity High distrust of others High in-group bias

High need for power

High in-group bias
I-1: Conflictual
High task focus

stark. Hawks deeply distrust others (particularly opponents), have a strong in-group bias, possess a high need for power, are conceptually simple, and are very task focused. Doves, in contrast, trust others (including opponents), have a weak in-group bias, have a low need for power, are conceptually complex, and are focused on relationships rather than tasks. 
Although this translation of the Snyder-Diesing typology into the conceptual language of OCA and LTA may appear to be a mere rebranding of Snyder and Diesing's (1977) framework, using operational code beliefs and personality traits to distinguish hawks and doves in fact represents an important advance over the Snyder-Diesing framework. One reason is that the OCA and LTA research programs are well-established and thus provide a solid theoretical foundation on which to build. Another is that the OCA and LTA research programs have developed sophisticated and systematic methods for measuring operational code beliefs and personality traits, respectively. ${ }^{1}$ Snyder and Diesing provide no such methods for assessing the world views, images, and preferred strategies central to their classificatory framework.

Consequently, utilizing operational code beliefs and personality traits to classify decision makers as hawks or doves puts this study on firmer ground than would be the case if the Snyder-Diesing framework were employed directly. Still another reason is that the use of operational code beliefs and personality traits allows this study to provide a typology of decision makers that expands beyond the dichotomous hawk-dove distinction of the Snyder-Diesing typology. Such expansion is clearly desirable. Indeed, Snyder and Diesing themselves note that hawks and doves are simply two points on a continuum of decision maker types. This study's expanded typology identifies additional points along the continuum of decision makers. In what follows, I delineate this expanded typology.

Beyond the Dichotomy: Disaggregating Hawks and Doves

As I have stated, hawks and doves can be classified according to differences on two operational code beliefs (P-1 and I-1) and five personality traits (distrust of others, in-group bias, conceptual complexity, need for power, and task focus). However, the categories of hawk and dove themselves can be disaggregated by accounting for variation in decision makers' beliefs

\footnotetext{
${ }^{1}$ Details of these methods are discussed in the methods chapter.
} 
about their ability to control events and historical development. The relevant operational code belief is P-4 (the extent to which one believes they can control events), including P-4a and P-4b, and the pertinent personality trait is, unsurprisingly, the extent to which one believes they can control events. ${ }^{2}$ I have selected elites' beliefs about their ability to control events and historical development as a means of further differentiating among hawkish and dovish decision makers because, in the operational code literature, this belief is considered one of the three "master beliefs" that critically shape the strategies a decision maker employs in their interactions with foreign actors and especially adversaries (Schafer and Walker 2006: 12-17; see also Walker 2004: 93-102)..$^{3}$

In terms of operational code belief P-4 and its constituent elements, P-4a and P-4b, P-4a is the most important for disaggregating the categories of hawk and dove because, according to the Theory of Inferences about Preferences (TIP), P-4a determines a decision maker's perception of whether they are weaker than, equal to, or stronger than their opponent (Malici and Buckner 2008: 790-791). By distinguishing among elites who see themselves as stronger than, equal to, or weaker than their opponents it is possible to expand a dichotomous typology of decision makers to a six-fold typology. It then becomes possible to see three kinds of hawkish decision makers and three kinds of dovish decision makers: those who perceive themselves as stronger

\footnotetext{
${ }^{2}$ Obviously there are manifold other ways to further distinguish among decision makers via operational code beliefs and personality traits. For example, I have only considered decision makers who believe either that politics is a fundamentally hostile arena or a fundamentally harmonious one. What about decision making elites who see the world of politics as neither fundamentally hostile nor fundamentally harmonious but rather something in between those extremes? This and numerous other such questions are not inconsequential, but they are beyond the scope of this study and its typology. In this study, I am concerned with providing a better understanding of hawkish and dovish decision makers. This study thus starts with the ideal types of hawk and dove described by Snyder and Diesing (1977: 297-310), translated here into the conceptual parlance of OCA and LTA, and seeks to provide a more nuanced view of hawkish and dovish elites. The ideal types remain the touchstones of this study, and departures from the ideal types are intentionally circumscribed.

${ }^{3}$ The other master beliefs are P-1 and I-1.
} 
Table 2: Operational Codes and Leadership Traits Corresponding to Snyder and Diesing's Dovish (Soft Line) Belief System

Snyder and Diesing's Dovish Belief System

Worldview and Images:

Potential for harmony Peace via mutual accommodation

Power and obstinacy can be counterproductive

Adversaries are affected by emotion and non-monolithic

Adversaries have no hostile grand design: Seeking limited, at least partially legitimate goals which, when achieved, will make adversaries peaceful

\section{Corresponding Operational} Code Beliefs
P-1: Cooperative

I-1: Cooperative

$-$

$-$

P-1: Cooperative
Corresponding Leadership $\underline{\text { Traits }}$
Low distrust of others

Low in-group bias

Low task focus

Low need for power

Low task focus

High conceptual complexity

Low task focus

High conceptual complexity Low distrust of others

Low in-group bias

Self Image:

Emotional

Defender of legitimate

position, but legitimacy not theirs alone

\section{Preferred actions:}

Compromise, conciliation, and mutual accommodation Maintain reputation for accommodativeness and trustworthiness
I-1: Cooperative
Low task focus

Low in-group bias

than their opponents, those who perceive parity between themselves and their opponents, and those who see themselves as weaker than their opponents.

While P-4a is the most important of the variables capturing a decision maker's belief in their ability to control events and historical development, I also include the corresponding personality trait from LTA. This is partly because the variables are operationalized and assessed differently in OCA and LTA (see the methods chapter [to follow]), and partly because, when 
treated as a personality trait, the long term changeability of this belief in a decision maker should

be more apparent. Furthermore, the ability to measure this belief in two ways provides greater

confidence that the belief is being accurately assessed.

A Six-fold Typology of Decision Makers: Warhawks, Hawks, Chickenhawks, Owls, Ravens, and Doves $^{1}$

The translation of the Snyder-Diesing typology into the conceptual language of OCA and LTA, in conjunction with the foregoing discussion of the role played by decision makers' beliefs about their ability to control events and historical development, provides the components of a new, more nuanced typology of hawkish and dovish decision makers. In what follows, I define three unique hawkish decision maker types - warhawks, hawks, and chickenhawks - and three distinct dovish decision maker types - owls, ravens, and doves. The hawkish and dovish decision makers are all based, respectively, on the Snyder-Diesing framework's archetypal hawks and doves as conceptualized in terms of operational code beliefs and personality traits. Within each category, deviations from the archetypal hawks and doves flow from differences in

\footnotetext{
${ }^{1}$ Some clarification and elaboration regarding labels is necessary. First, hawks and doves in my typology should not be considered as interchangeable with hawks and doves in the Snyder-Diesing typology. I have not only translated Snyder and Diesing's (1977: 297-310) framework into the terminology of OCA and LTA, but also added classificatory criteria not included in the Snyder-Diesing framework. Thus what I mean by hawks and doves is not what Snyder and Diesing mean by hawks and doves. Second, in political discourse, the label "chickenhawk" is typically applied pejoratively to individuals who advocate using military force but who themselves purposely avoided serving in the military (see, for example, Roberts 2004). The label has no derogatory connotations here. As will become clear, in this study, the label chickenhawk refers to the tendency for decision makers of this type to bluff. Third, I have selected the moniker warhawk for the type of hawkish decision maker associated with bullying because I feel this label best captures the aggressive nature of this decision maker type. Fourth, in this study, the term owl means something rather different than what Nye, Allison, and Carnesale (1985) mean when they use the term. Fifth, my choice of the terms owl and raven to describe two of the dovish types of decision making elite may appear puzzling. Without digressing into a treatise in ornithology, a task to which I would be woefully unequal, let me briefly explain these choices. I have chosen the term owl to describe one dovish decision maker type because, while owls are birds of prey and thus clearly possessed of the potential for violence, owls do not seem to have the clear association with aggression that hawks do (think here of the wise, seeming friendly but shrewd and exploitative owl of Tootsie Pop commercials). Thus the term owl seems a fitting label for a dovish decision maker type that, as I explain below, is basically cooperative but has the greatest propensity for conflict of all the dovish decision maker types. Regarding ravens, even the very casual observer would notice that ravens often, but not always, coexist peacefully with each other. One can, however, also commonly see ravens harassing birds of prey. This mix of peaceful and conflictual behavior drew me to this label for the dovish decision maker that, as will be made clear, is very much inclined to peaceful cooperation but retains the potential for conflictual action.
} 
operational code belief $\mathrm{P}-4$, including $\mathrm{P}-4 \mathrm{a}$ and $\mathrm{P}-4 \mathrm{~b}$, and, to some extent, connections between these P-4 variations and other beliefs and personality traits.

The final definition of each decision maker type consists of the type's operational code beliefs, personality traits, beliefs about opponents' preferences, and own preferences over foreign policy outcomes. The result is a six-fold typology of hawkish and dovish decision makers. The typology and definitions of each decision maker type are summarized in Table 3.

Hawkish Decision Maker Type 1: Warhawk. Warhawks emphasize the need to maintain or enhance their side's power and thus, in terms of personality, exhibit a high need for power. Warhawks are also highly distrusting of others and have a strong in-group bias. The combination of these two personality traits fosters an us-against-them mentality and leads warhawks to perceive a threatening environment in which a group of "evil," aggressive adversaries is at the center of international politics (Hermann 2003: 200; Shannon and Keller 2007: 84). Thus it is not surprising that, in terms of operational code belief P-1, warhawks believe politics is fundamentally conflictual and that opponents are essentially hostile. ${ }^{2}$ Additionally, because very untrusting decision makers with a strong in-group bias are inclined to assertive or aggressive behavior (Driver 1977; Foster and Keller 2014; Hermann 2003: 200; Shannon and Keller 2007), it is easy to see why warhawks' operational code belief I-1 reflects a view that conflictual strategies are optimal. Moreover, elites who are highly distrusting and very biased in favor of their in-group focus "on eliminating potential threats and problems" rather

\footnotetext{
${ }^{2}$ This belief also suggests that warhawks have a high need for power. In his discussion of the connection between motivations and operational code beliefs, Walker (Walker 1983, 2003, 2004; see also Schafer and Walker 2006: 12 13) argues that the need for power is a motive associated with the belief that politics is basically conflictual and political opponents are fundamentally hostile. Importantly, because Walker's conceptualization of need for power is the same as that in LTA research, one can be assured that when Walker and LTA researchers such as Hermann refer to the need for power, they are talking about the same thing (see Hermann 1980, 1984; Walker 1983; Winter and Stewart 1977).
} 
Table 3: Summary - Psychology-based Six-fold Typology of Hawkish and Dovish Decision Makers

\begin{tabular}{|c|c|c|c|c|c|}
\hline $\begin{array}{l}\text { Decision Maker } \\
\text { Type }\end{array}$ & $\begin{array}{l}\text { Operational Code } \\
\text { Beliefs }\end{array}$ & Leadership Traits & $\begin{array}{l}\text { Preferences } \\
\text { (Assumed) }\end{array}$ & $\begin{array}{l}\text { Beliefs about } \\
\text { Opponent's } \\
\text { Preferences } \\
\text { (Assumed) }\end{array}$ & $\begin{array}{l}\text { Cognitive Errors and Biases } \\
\text { (Proposed) }\end{array}$ \\
\hline Warhawk & $\begin{array}{l}\text { P-1: Conflictual } \\
\text { I-1: Conflictual } \\
P-4: \text { High } \\
P-4 a: \text { Stronger } \\
P-4 b: \text { Weaker }\end{array}$ & $\begin{array}{l}\text { High distrust of others } \\
\text { High in-group bias } \\
\text { Low conceptual complexity } \\
\text { High need for power } \\
\text { High task focus } \\
\text { High belief in ability to } \\
\text { control events }\end{array}$ & $\begin{array}{l}\text { Dominate }> \\
\text { Deadlock> } \\
\text { Settle }> \\
\text { Submit } \\
\text { (Bully) }\end{array}$ & $\begin{array}{l}\text { Dominate }> \\
\text { Settle }> \\
\text { Submit }> \\
\text { Deadlock } \\
\text { (Bluff) }\end{array}$ & $\begin{array}{l}\text { Positive illusions } \\
\text { Fundamental attribution error } \\
\text { Concession aversion/Risk- } \\
\text { seeking in losses } \\
\text { Pseudo-certainty } \\
\text { Reactive devaluation }\end{array}$ \\
\hline Hawk & $\begin{array}{l}\text { P-1: Conflictual } \\
\text { I-1: Conflictual } \\
P-4: \text { Moderate } \\
P-4 a: \text { Equal } \\
P-4 b: \text { Equal }\end{array}$ & $\begin{array}{l}\text { High distrust of others } \\
\text { High in-group bias } \\
\text { Low conceptual complexity } \\
\text { High need for power } \\
\text { High task focus } \\
\text { Moderate belief in ability to } \\
\text { control events }\end{array}$ & $\begin{array}{l}\text { Dominate }> \\
\text { Settle }> \\
\text { Deadlock }> \\
\text { Submit } \\
\text { (Compel/ } \\
\text { Punish) }\end{array}$ & $\begin{array}{l}\text { Dominate }> \\
\text { Settle> } \\
\text { Deadlock }> \\
\text { Submit } \\
\text { (Compel/ } \\
\text { Punish) }\end{array}$ & $\begin{array}{l}\text { Fundamental attribution error } \\
\text { Concession aversion/Risk- } \\
\text { seeking in losses } \\
\text { Pseudo-certainty } \\
\text { Reactive devaluation }\end{array}$ \\
\hline Chickenhawk & $\begin{array}{l}\text { P-1: Conflictual } \\
\text { I-1: Conflictual } \\
\text { P-4: Low } \\
\text { P-4a: Weaker } \\
\text { P-4b: Stronger }\end{array}$ & $\begin{array}{l}\text { High distrust of others } \\
\text { High in-group bias } \\
\text { Low conceptual complexity } \\
\text { High need for power } \\
\text { High task focus } \\
\text { Low belief in ability to } \\
\text { control events }\end{array}$ & $\begin{array}{l}\text { Dominate }> \\
\text { Settle }> \\
\text { Submit }> \\
\text { Deadlock } \\
\text { (Bluff) }\end{array}$ & $\begin{array}{l}\text { Dominate }> \\
\text { Deadlock> } \\
\text { Settle }> \\
\text { Submit } \\
\text { (Bully) }\end{array}$ & $\begin{array}{l}\text { Fundamental attribution error } \\
\text { Concession aversion/Risk- } \\
\text { seeking in losses } \\
\text { Pseudo-certainty } \\
\text { Reactive devaluation }\end{array}$ \\
\hline Owl & $\begin{array}{l}\text { P-1: Cooperative } \\
\text { I-1: Cooperative } \\
\text { P-4: High } \\
P-4 a: \text { Stronger } \\
P-4 b: \text { Weaker }\end{array}$ & $\begin{array}{l}\text { Low distrust of others } \\
\text { Low in-group bias } \\
\text { High conceptual complexity } \\
\text { Low need for power } \\
\text { Moderate task focus } \\
\text { High belief in ability to } \\
\text { control events }\end{array}$ & $\begin{array}{l}\text { Settle }> \\
\text { Dominate }> \\
\text { Deadlock }> \\
\text { Submit } \\
\text { (Exploit) }\end{array}$ & $\begin{array}{l}\text { Settle }> \\
\text { Deadlock }> \\
\text { Submit }> \\
\text { Dominate } \\
\text { (Appease) }\end{array}$ & $\begin{array}{l}\text { Positive illusions } \\
\text { Moderate concession } \\
\text { aversion/Risk-seeking in losses } \\
\text { Underestimate level of conflict } \\
\text { Overestimate opponent's } \\
\text { propensity for compromise, } \\
\text { value of self's concessions, } \\
\text { opponent's internal } \\
\text { disagreement, agreement with } \\
\text { opponent's moderates }\end{array}$ \\
\hline Raven & $\begin{array}{l}\text { P-1: Cooperative } \\
\text { I-1: Cooperative } \\
P-4: \text { Moderate } \\
P-4 a: \text { Equal } \\
P-4 b: \text { Equal }\end{array}$ & $\begin{array}{l}\text { Low distrust of others } \\
\text { Low in-group bias } \\
\text { High conceptual complexity } \\
\text { Low need for power } \\
\text { Low task focus } \\
\text { Moderate belief in ability to } \\
\text { control events }\end{array}$ & $\begin{array}{l}\text { Settle }> \\
\text { Deadlock }> \\
\text { Dominate }> \\
\text { Submit } \\
\text { (Reward/ } \\
\text { Deter) }\end{array}$ & $\begin{array}{l}\text { Settle }> \\
\text { Deadlock }> \\
\text { Dominate }> \\
\text { Submit } \\
\text { (Reward/ } \\
\text { Deter) }\end{array}$ & $\begin{array}{l}\text { Underestimate level of conflict } \\
\text { Overestimate opponent's } \\
\text { propensity for compromise, } \\
\text { value of self's concessions, } \\
\text { opponent's internal } \\
\text { disagreement, agreement with } \\
\text { opponent's moderates }\end{array}$ \\
\hline Dove & $\begin{array}{l}\text { P-1: Cooperative } \\
\text { I-1: Cooperative } \\
\text { P-4: Low } \\
P-4 a: \text { Weaker } \\
P-4 b: \text { Stronger }\end{array}$ & $\begin{array}{l}\text { Low distrust of others } \\
\text { Low in-group bias } \\
\text { High conceptual complexity } \\
\text { Low need for power } \\
\text { Low task focus } \\
\text { Low belief in ability to } \\
\text { control events }\end{array}$ & $\begin{array}{l}\text { Settle> } \\
\text { Deadlock> } \\
\text { Submit }> \\
\text { Dominate } \\
\text { (Appease) }\end{array}$ & $\begin{array}{l}\text { Settle> } \\
\text { Dominate> } \\
\text { Deadlock>> } \\
\text { Submit } \\
\text { (Exploit) }\end{array}$ & $\begin{array}{l}\text { Underestimate level of conflict } \\
\text { Overestimate opponent's } \\
\text { propensity for compromise, } \\
\text { value of self's concessions, } \\
\text { opponent's internal } \\
\text { disagreement, agreement with } \\
\text { opponent's moderates }\end{array}$ \\
\hline
\end{tabular}

than on building or maintaining relationships with foreign actors (Hermann 2003: 200). Thus

warhawks' high task focus is also readily explicable. 
Warhawks also have a rather sanguine view of their ability to control events and historical development. Their personalities and operational code beliefs (P-4) exhibit a strong belief in this ability. And, in terms of the corresponding operational code belief P-4a, warhawks believe themselves to be stronger than their opponents. This belief is important for two reasons. The first is that this belief reinforces the high task focus of warhawks. Walker $(1983 ; 2003$; 2004) identifies a connection between a strong belief in one's ability to control events and a motivation for achievement (i.e., a "[c]oncern with standards of excellence, unique accomplishments, long term involvement; success in competition" [Winter and Stewart 1977: 46]). While the achievement motive and task focus are not the same thing (Hermann 1984: 63; Winter and Stewart 1977: 44-48), and the achievement motive itself is not associated with the preference for conflictual strategies associated with warhawks (see Walker 1983; Winter and Stewart 1977: 44-48), individuals higher in the achievement motive are more concerned with accomplishing goals than building or sustaining relationships (Winter and Stewart 1977: 44-48).

The second and more important reason this belief is crucial is that warhawks' confidence in their ability to control events and their perception of greater relative strength set warhawks apart from the other five decision maker types. According to the logic of TIP, warhawks' confidence and perception of superior strength combined with their strong inclination toward conflictual strategies lead them to possess the following unique ranking of preferences over outcomes of interactions with opponents: domination is preferred to deadlock, deadlock is preferred to settlement, and settlement is preferred to submitting. This preference ordering reveals warhawks as given to bullying (see Marfleet and Walker 2006: 57). I treat this preference ordering as an assumption about warhawks' characteristics, and do not attempt to submit it to direct empirical testing. As I discuss in the hypotheses section, I test this assumption 
indirectly via "observable implications" (King, Keohane, and Verba 1994: 28-29) of the preference ordering.

TIP's logic also indicates that warhawks perceive opponents differently than the other decision maker types. The flipside of a warhawk's P-4a belief is a P-4b belief that the warhawk's opponent sees itself as weaker than the warhawk's side. Because a warhawk sees their opponent as preferring hostile actions but perceiving itself as relatively weak, warhawks believe their opponents prefer domination most, followed in descending order by settlement, submission, and deadlock. In other words, warhawks believe their opponents are bluffers (see Marfleet and Walker 2006: 60). I assume these beliefs are characteristics of warhawks, and make no effort to directly test this assumption empirically. Instead, I also test this assumption indirectly via its observable implications.

The final characteristic of warhawks is low conceptual complexity. As the SnyderDiesing framework suggests, hawkish decision makers view their opponents as monoliths bent on carrying out a sinister master plan. Internal divisions within opponents are overlooked, and all of the opponents' actions are presumed to be driven by their single-minded effort to carry out their master plan. All of this indicates low conceptual complexity.

Hawkish Decision Maker Type 2: Hawk. Like warhawks, and for the same reasons, hawks have a high need for power; are highly distrusting; have a strong in-group bias; are conceptually simple; are highly task-focused; and, regarding operational code beliefs I-1 and P-1, favor employing conflictual strategies in a world of politics they see as conflictual and occupied by hostile opponents. The one exception here is that hawks lack the pronounced, task-focusreinforcing achievement motive characteristic of warhawks. This does not mean that hawks are not highly task-focused, they are. Hawks simply lack this additional basis for a high task focus. 
Although one might anticipate a weaker task-focus in hawks compared to warhawks, I do not anticipate a significant difference.

The absence of a strong achievement motive in hawks may not be significant, but the reason associated with its absence is crucial for marking hawks as a distinct decision maker type. That reason is hawks' weaker belief that they are able to control events and historical development. ${ }^{1}$ Hawks' personalities and operational code beliefs (P-4) are characterized by a moderate level of this belief. Regarding the parallel operational code belief P-4a, hawks see relative parity of strength between themselves and their opponents. Given hawks' P-4a belief and marked predilection for conflictual strategies, TIP indicates that the ordering of hawks' preferences over outcomes ranks domination first, settlement second, deadlock third, and submission last. This preference ordering, which is exclusive to this decision maker type, suggests hawks seek either to compel opponents to act as the hawks desire or to punish opponents' undesired actions. I assume this ordering is a characteristic of hawks, and do not attempt to submit this assumption to direct empirical testing; rather, I test it indirectly via its observable implications.

Hawks' perceptions of opponents' preferences are also unique. The reverse side of a hawk's P-4a belief is a P-4b belief that their adversary sees itself as equal in strength to the hawk's side. Since a hawk perceives their opponent as favoring hostile actions and believing itself to be the equal of the hawk's, the hawk believes their opponent, like the hawk themself, prefers domination to settlement, settlement to deadlock, and deadlock to submitting. Consequently, hawks believe opponents seek either to compel their side to act as the opponent desires or to punish the hawks' side for actions the opponent views as undesirable (see Marfleet

\footnotetext{
${ }^{1}$ For a discussion of the connection between operational code belief $\mathrm{P}-4 \mathrm{a}$ and the achievement motive refer to the definition of warhawks.
} 
and Walker 2006: 60). I assume these beliefs typify hawks, and make no attempt to directly test this assumption against empirical evidence. Instead, I also test this assumption obliquely by seeking evidence of its observable implications.

Hawkish Decision Maker Type 3: Chickenhawk. As with warhawks and hawks, and again for identical reasons, chickenhawks are characterized by a high need for power; a high level of distrust; a strong in-group bias; low conceptual complexity; a high task focus; and, in terms of operational code beliefs I- 1 and P-1, a penchant for using conflictual strategies in a conflictual political arena in which they face hostile opponents. However, as was the case with hawks, chickenhawks lack the marked achievement motive typical of warhawks. Although they lack this motive, chickenhawks are still very task-focused. I do not expect the task focus of chickenhawks to be appreciably lower than that of warhawks.

Again, the absence of a pronounced need for achievement is not significant, but the reason for its absence is. Chickenhawks' lack of a strong achievement motive is linked to their weak belief that they can control events or historical development. At the level of personality traits and operational code beliefs (P-4), chickenhawks exhibit a rather weak belief in their ability to control events. Furthermore, in terms of the corresponding operational code belief P4a, chickenhawks believe their opponents are stronger than themselves. Given TIP's logic, chickenhawks' propensity for conflictual strategies combined with their belief that they are weaker than their opponents leads them to hold the following distinctive ordering of preferences over outcomes of interactions with opponents: domination is preferred over settlement, settlement is preferred over submission, and submission is preferred over deadlock. This preference ranking indicates that chickenhawks are likely to bluff opponents (see Marfleet and Walker 2006: 57). I treat this preference ranking as an assumption about the nature of 
chickenhawks, and do not submit this assumption to direct empirical testing. I instead assess this assumption's validity indirectly via its observable implications.

The converse of a chickenhawk's P-4a belief is their P-4b belief that their adversary perceives itself as the stronger actor in their interactions. Because a chickenhawk sees their opponent as inclined to hostile strategies and perceiving itself to be stronger than the chickenhawk's side, the chickenhawk believes their opponent most prefers to dominate, followed in order of diminishing preference by deadlocking, settling, and submitting. This belief about opponents is peculiar to chickenhawks and reflects chickenhawks' perception that their opponents seek to bully them (see Marfleet and Walker 2006: 60). I assume these beliefs are characteristic of chickenhawks, and do not attempt to submit this assumption to direct empirical scrutiny; rather I also test this assumption obliquely through its observable implications.

Dovish Decision Maker Type 1: Owl. Unlike the hawkish decision maker types, owls do not express a need to preserve or increase their side's power. ${ }^{2}$ Therefore, in terms of personality traits, owls have a low need for power. Also in contrast to hawkish decision making elites, owls are low in distrust of others and have a weak in-group bias. The mixture of these two traits leads owls to perceive a non-threatening environment in which cooperation is possible and practicable and in which the conflict that does exist is context-specific rather than systemic (Hermann 2003: 200). Given this perception, it is unsurprising that, in terms of operational code belief P-1, owls believe politics is fundamentally harmonious and adversaries are basically friendly. Also, because trusting decision making elites with only a weak in-group bias are "capable of seeing the possibilities for win-win agreements," (Hermann 2003: 201) it is easy to comprehend owls' operational code belief (I-1) that cooperative strategies are best. Furthermore, decision makers

\footnotetext{
${ }^{2}$ Recall from the translation of the Snyder-Diesing framework into the language of LTA that dovish decision makers are concerned that increasing their side's power will be threatening to opponents. This explains owls' low need for power.
} 
low in distrust and in-group bias are focused on relationships (Hermann 2003: 200-201), thus helping to explain why owls have a lower task focus than the three hawkish decision maker types.

Though owls' task focus is not as pronounced as it is in hawkish decision maker types, owls have a moderate task focus that is higher than the other dovish decision maker types. Owls' moderate task focus stems from their rather strong belief that they are able to control events and historical development. This belief manifests in owls' personality traits and in operational code belief P-4. This belief partly reflects a high achievement motive (Walker 1983; 2003; 2004). Again, although the achievement motive is not the same thing as task focus (Hermann 1984: 63; Winter and Stewart 1977: 44-48), people with higher achievement motives are more focused on achieving goals and comparatively less focused on relationships (Winter and Stewart 1977: 4448). This is, of course, not to say that owls are unconcerned with forming and sustaining relationships. Like the other dovish decision maker types, owls emphasize the importance of relationships. However, owls' high achievement motive tempers their focus on relationships and makes accomplishing tasks and achieving goals more salient for owls than for ravens and doves.

The more significant consequences of owls' marked confidence in their ability to control events and historical development are found in their preferences over foreign policy outcomes and their beliefs about their opponents' foreign policy preferences. The logic of TIP indicates that owls' strong belief in their ability to control events, and corresponding belief in their superior strength (P-4a), combined with their predilection for cooperative strategies give rise to a distinct ranking of preferences over outcomes of interactions with opponents. Specifically, owls prefer settlement to domination, domination to deadlock, and deadlock to submitting. This preference ranking suggests owls seek to cooperate with their opponents, but in an exploitative 
manner (see Marfleet and Walker 2006: 57). I assume this preference ordering typifies owls. I make no effort to submit this assumption to direct empirical testing. I instead scrutinize this assumption indirectly via its observable implications.

TIP's logic also specifies that owls perceive opponents differently than the other decision maker types. The littermate to an owl's P-4a belief is their P-4b belief that their opponent sees itself as weaker than the owl's side. Because an owl sees their opponent as given to cooperative actions and seeing itself as relatively weak, an owl believes their opponent prefers settlement first, followed in order of descending preference by deadlock, submission, and domination. Stated simply, owls see their opponents as appeasers (see Marfleet and Walker 2006: 60). I assume these beliefs are characteristics of owls, and do not try to assess this assumption's validity through direct empirical testing. However, I do test this assumption indirectly by seeking evidence pertinent to its observable implications.

The last attribute of owls is high conceptual complexity. As the Snyder-Diesing typology indicates, dovish decision making elites see their opponents as internally divided and are capable of seeing a number of reasons for opponents' actions (as opposed to hawkish decision makers who see opponents' every action as part of a sinister master plan). This pattern of perception is indicative of conceptual complexity.

Dovish Decision Maker Type 2: Raven. Akin to owls, and for identical reasons, ravens have a low need for power; are low in distrust; have only a weak in-group bias; are conceptually complex; and, regarding operational code beliefs I-1 and P-1, are inclined to employ cooperative strategies in an essentially harmonious political world in which opponents are basically friendly. The sole difference so far is that, whereas owls are moderately task-focused due to their strong achievement motive, ravens lack a strong need for achievement and thus have only the weak task 
focus that is the baseline for dovish decision makers. The absence of a strong need for achievement in ravens is linked to ravens' weaker belief in their ability to control events and historical development. ${ }^{3}$

Ravens' belief in their ability to exert control over events and historical development is reflected in their personality traits and operational code belief P-4. Ravens' personalities are marked by a moderate level of this belief and, in terms of the related operational code belief P4a, ravens see themselves and their opponents as roughly equivalent in strength. Given ravens' P-4a belief and inclination toward cooperative strategies, TIP indicates that ravens' ordering of preferences over outcomes ranks settlement over deadlock, deadlock over domination, and domination over submitting. This preference ranking, which is unique to ravens, suggests decision makers of this type act to deter opponents from engaging in conflictual actions and reward opponents who are cooperative (see Marfleet and Walker 2006: 57). I treat this preference ordering as an assumption about ravens' nature. I make no effort to test the validity of this assumption through direct empirical testing; rather, I test it indirectly by way of its observable implications.

Ravens' beliefs about opponents' preferences further distinguish them from the other dovish decision maker types. The counterpart of a raven's P-4a belief is their P-4b belief that their opponent perceives itself as the raven's equal in terms of strength. Because a raven believes their adversary prefers cooperative actions and sees itself as the raven's equal, decision makers of this type perceive that their opponent also prefers settlement over deadlock, deadlock over domination, and domination over submission. As a result, a raven believes their adversary will seek to deter the raven's side from pursuing conflictual policies and reward the raven's side

\footnotetext{
${ }^{3}$ For a discussion of the connection between operational code belief P-4 and the achievement motive refer to the definitions of the warhawk and owl decision maker types.
} 
for cooperating (see Marfleet and Walker 2006: 60). I assume these beliefs typify ravens, and make no effort to directly test this assumption against the empirical record. I instead also assess the validity of this assumption indirectly via its observable implications.

Dovish Decision Maker Type 3: Dove. Like owls and ravens, and again for the same reasons, doves possess a weak need for power; are low in distrust; have but a low in-group bias; are conceptually complex; and, regarding operational code beliefs I-1 and P-1, are inclined to employ cooperative strategies in an essentially harmonious political world in which opponents are basically friendly. Doves, like ravens but unlike owls, also have a low task focus. The reasons for doves' weak task focus are identical to the reasons for raven's low task focus: a low task focus is the baseline trait for dovish decision makers and doves' lack the high need for achievement that might temper their focus on relationships. Doves' lacking achievement motive is connected to their belief that they have little influence over events and historical development. This belief is evinced in doves' personalities and in operational code belief P-4. ${ }^{4}$

Doves' personalities exhibit a weak belief in their ability to control events and, in terms of the corresponding operational code belief P-4a, doves see themselves as weaker than their opponents. According to TIP's logic, doves' P-4a belief and predilection for cooperative strategies lead them to possess the following ranking of preferences over outcomes: settlement is preferred to deadlock, deadlock is preferred to submitting, and submitting is preferred to domination. This distinct preference ranking marks doves as appeasers (see Marfleet and Walker 2006: 57). I assume this preference ordering characterizes doves, and do not conduct a direct empirical test of this assumption. I do, however, test this assumption obliquely by way of its observable implications.

\footnotetext{
${ }^{4}$ For a discussion of the connection between operational code belief P-4 and the achievement motive refer to the definitions of the warhawk and owl decision maker types.
} 
Doves' beliefs about their opponents' preferences over outcomes also set them apart from other dovish decision maker types. The complement of a dove's P-4a belief is their P-4b belief that their opponent sees itself as stronger than the dove. Given that a dove believes their opponent prefers cooperative strategies and sees its strength as superior to the dove's, the dove perceives that their adversary ranks settlement over domination, domination over deadlock, and deadlock over submission. The upshot of this perception is that a dove believes their opponent is a cooperative but exploitive adversary who seeks to get the most favorable outcome from their interactions (see Marfleet and Walker 2006: 57). I assume these beliefs typify doves, and make no attempt to directly scrutinize this assumption through empirical testing. Instead, I also test this assumption indirectly via its observable implications.

Despite the existence of characteristics shared by the three decision maker types within each broader hawkish and dovish category, each of the types I have just described is clearly distinguishable from the others. This represents an incremental but significant advancement in our ability to understand hawkish and dovish decision makers. Snyder and Diesing (1977: 297298) sought to define only hawks and doves as "ideal types," but they recognized the presence of variations among decision makers "within each sector." This typology provides means for exploring these within-sector, within-category variations. However, because the six decision maker types cluster around two sets of common characteristics, this typology cannot claim to capture the full universe of possible decision makers. This should be understood as a limitation of the typology, not a weakness. My typology is intended to provide a systematic and nuanced way of talking about and analyzing two categories of decision makers - categories that are often discussed, but poorly understood. 
In the following section, I extend the theoretical framework undergirding my typology. I discuss how decision maker types can be expected to vary in their susceptibilities to different cognitive errors and biases. I then link each decision maker type and the errors and biases associated with that type to foreign policy positions.

\section{Hypotheses}

The operational code beliefs and personality traits characterizing each decision maker type provide a basis for predicting the cognitive errors and biases to which each type is susceptible as well as, in some cases, the relative extent of susceptibility. In the first part of this section, I delineate these predictions as a series of hypotheses linking each decision maker type to a set of errors and biases. These hypotheses mark an important theoretical advancement in our understanding of the errors and biases that lead elites to depart from models of rational decision making. With few exceptions (e.g., Bar-Joseph and McDermott 2008; Kowert and Hermann 1997; Menon, Sheldon, and Galinsky 2014; Snyder and Diesing 1977: 297-310), commonly studied errors and biases such as the fundamental attribution error (FAE) and risk seeking in the face of losses are portrayed as general afflictions to which susceptibility is the norm (see, e.g., Kahneman and Renshon 2009; Kahneman and Tversky 1979; Renshon and Kahneman 2017; Ross 1977; Ross and Stillinger 1991; Svenson 1981; Tversky and Kahneman 1981). By developing a systematic framework for predicting which decision makers are susceptible to which biases (as opposed to treating all decision makers as similarly susceptible to the same biases and errors), this study seeks to join with the exceptions and provide a more nuanced understanding of the errors and biases that can afflict decision makers.

In the second part of this section, I present another series of hypotheses. These hypotheses consist of predictions about each decision maker type's foreign policy positions. The 
predictions are in turn based on the combined anticipated effects of each type's operational code beliefs, personality traits, preferences, beliefs about opponents' preferences, and cognitive errors and biases. Table 4 presents a list of all hypotheses.

\section{Susceptibility to Errors and Biases}

Just as I theorize that the three decision maker types within each category (i.e., hawkish and dovish categories) have several beliefs and personality traits in common, I expect the three types within each category also share similar, though not identical, susceptibilities to particular errors and biases. I hypothesize one cluster of five errors to which dovish types are particularly prone and another set of four errors and biases to which hawkish decision makers are especially susceptible. Before addressing these sets of errors and biases, I first present a hypothesis regarding one particular set of errors to which warhawks and owls are particularly predisposed. Positive Illusions of Warhawks and Owls. For all their differences, warhawks and owls share one important commonality: decision makers of both types strongly believe they are able to control events and historical development. Equally significant is their shared belief that they are stronger than their opponents. To some extent, warhawks and owls' sense of confidence and strength may be well founded and reasonable. However, it probably leaves them highly predisposed to being unrealistically optimistic, overly sanguine about their abilities, and too confident that their actions determine outcomes. In other words, warhawks and owls should be especially prone to all three of the "positive illusions" described by Kahneman and Renshon (2009: 81-82; Renshon and Kahneman 2017). Because only owls and warhawks are so confident in their strength and abilities, I do not expect any of the other decision maker types to clearly overestimate their abilities or the significance of their actions. Furthermore, while, as I explain below, all three dovish types are prone to one form of unrealistic optimism, I anticipate 
that owls and warhawks will exhibit the most unrealistic optimism. In sum, my first hypothesis is that owls and warhawks alone clearly overestimate their capabilities and the importance of their own actions. Warhawks and owls also most apparently exhibit unrealistic optimism. This hypothesis is significant in part because positive illusions are often treated as a "baseline tendency in human psychology" to which leaders are likely especially prone (Johnson 2004: 5, 24-26; see also Kahneman and Renshon 2009: 81-82; Renshon and Kahneman 2017). I propose that susceptibility to this bias will vary markedly and predictably across decision makers.

Errors Associated with Dovish Decision Makers. Snyder and Diesing (1977: 302-304) argue that dovish decision makers are prone to a cluster of five errors. The first of these errors is underestimating the level of conflict between the decision maker's side and the opponent. The remaining four errors involve overestimates. Specifically, a dovish decision maker is likely to overestimate all of the following: their opponent's internal divisions, their opponent's propensity for compromise, the level of agreement between themself and non-hawkish elements within their opponent regarding the desirability of compromise, and the value of their side's concessions to an opponent. Snyder and Diesing (1977: 302) argue that dovish decision makers are prone to all of these errors, but, with the exception of the first overestimate, provide little in the way of explicit explanation for why this is the case. When their theoretical framework is translated into the language of LTA and OCA, however, reasons for all of these errors become apparent.

In the first place, because all three dovish decision maker types are low in distrust, have a weak in-group bias, believe politics is a fundamentally harmonious arena, and believe opponents are basically friendly, they are likely to underestimate how much conflict exists between 
themselves and their opponents. ${ }^{5}$ Stated simply, it is likely that dovish decision makers are looking at their relationships with opponents through rose-colored glasses. My second hypothesis is thus that owls, ravens, and doves underestimate the level of conflict between their side and their opponent or opponents.

Regarding the first of the overestimates associated with dovish elites, Snyder and Diesing (1977: 303-304) argue that dovish decision makers' preferences over strategies as well as their perceptions regarding the long-term goals of opponents lead them to exaggerate opponents' internal divisions. As Snyder and Diesing (1977: 304) explain, a dovish decision maker tends to look for and to perceive factionalism in the adversary because the success of his preferred strategy of accommodation depends on making contact with, appealing to and strengthening the softs [i.e., dovish decision makers] or moderates in the opposing government, and in not strengthening or provoking the hards [i.e., hawkish decision makers] and extremists.

Put differently, dovish decision makers see what they want and need to see: fellow dovish types with whom they can deal. This suggests that dovish types fall prey to wishful thinking-induced unrealistic optimism (see Lebow 1981: 169-170; Levy 2003: 268-269). Given this inclination to exaggerate opponents' factionalization, my third hypothesis is as follows: owls, ravens, and doves will overestimate hawkish-dovish divisions in their opponents.

Dovish types' belief that the political realm and opponents in it are basically benign also makes it likely that they overestimate their opponents' potential for compromise, the amount of agreement between themselves and non-hawkish decision makers in their opponents, and the value of the concessions offered to opponents. The first of these overestimates is readily

\footnotetext{
${ }^{5}$ Here it is important to recall Hermann's (2003: 200) argument that elites low in both distrust and in-group bias perceive a non-threatening environment in which the conflicts that are present are context-specific rather than systemic.
} 
apparent. Because dovish decision makers see their opponents as basically friendly actors in an essentially harmonious world, dovish elites are at a heightened risk of exaggerating their opponents' potential for conciliation and compromise. The next overestimate is similarly straightforward. If dovish decision makers generally overestimate their opponents' affinity for compromise, it stands to reason that dovish elites are even more prone to exaggerating how strongly non-hawkish elements within their opponents share their own preference for conciliation. The third overestimate is perhaps less straightforward. Dovish types' belief that their opponents are at base friendly, I argue, makes them prone to underestimate how much they must concede in order to satisfy their opponents. In other words, dovish decision makers undervalue their opponents' price for peace. The corollary of this underestimate is that dovish types overestimate their concessions' worth to opponents. As a result dovish elites are wont to unknowingly 'lowball' their opponents.

These overestimates comprise a trio of separate hypotheses. My fourth hypothesis is that owls, ravens, and doves will exaggerate opponents' propensity for compromise. The fifth is that owls, ravens, and doves will overestimate the extent to which non-hawkish elements in their opponents share their own desire for compromise solutions. My sixth hypothesis is as follows: owls, ravens, and doves will overestimate the value of the concessions they offer to opponents.

In total, the set of five cognitive errors and biases to which owls, ravens, and doves are all especially inclined lead these types of decision makers to see more potential for peaceful, accommodative conflict resolution than an objective observer would perceive. Of course hawkish decision makers are not impervious to errors and biases. Indeed warhawks, hawks, and chickenhawks are particularly prone to their own cluster of four cognitive biases and errors. 
Errors and Biases Associated with Hawkish Decision Makers. The errors and biases linked to hawkish decision makers include the fundamental attribution error, concession aversion, risk seeking in losses, pseudo-certainty, and reactive devaluation. Notably, I will also argue that owls are at least somewhat susceptible to concession aversion and risk seeking in losses. I theorize that these errors and biases are tied to the operational code beliefs and personality traits of hawkish decision makers and, in the case of concession aversion and risk seeking in losses, the personality traits of owls. I discuss each error and bias in the order it is listed.

As I have previously explained, the fundamental attribution error refers to individuals' tendency to exaggerate the weight of dispositional factors compared to situational factors when accounting for the actions of others. Recall from my earlier explanation also that this tendency is particularly manifest in an individual's account of another actor's undesirable actions, especially if that actor is an adversary. Yet if another actor, particularly an adversary, behaves desirably, the fundamental attribution error leads the individual to attribute the adversary's actions to situational factors like coercion. While this bias is thought to afflict people in general (Ross 1977: 184), I argue that hawkish decision makers are particularly susceptible. There a number of reasons for this.

In terms of their personalities, all three hawkish decision maker types are highly distrusting of others and possess a strong in-group bias. To these personality traits is added the operational code belief that opponents are basically hostile. This combination of personality traits and beliefs leads all hawkish types to view adversaries as having evil, expansionist dispositions. ${ }^{6}$ Distrust also predisposes hawkish decision makers to see "ulterior motives and

\footnotetext{
${ }^{6}$ Regarding how high distrust and in-group bias help give rise to this perception of opponents see Hermann (2003: 200).
} 
designs" (Hermann 2003: 203) behind even an adversary's favorable actions. As a result of this admixture of personality traits and beliefs, hawkish decision makers are apt to exaggerate the extent to which opponents' actions - whether desired or undesired - are driven by hostile, scheming dispositions. And in cases where hawkish elites do not attribute adversaries' desired actions to the adversaries' scheming nature, hawkish elites are likely to perceive those favorable actions as the product of firmness or coercion on the part of the hawkish elites' state.

Dovish decision maker types, by contrast, are trusting, low in in-group bias, and believe opponents are at base friendly, leading dovish elites to perceive cooperative tendencies in adversaries and to see that adversaries' undesired actions may be at least partly the product of situational factors. ${ }^{7}$ The main point here is that, compared to hawkish decision makers, dovish elites are better able to empathize with adversaries and see situational reasons for adversaries' undesired behavior. Moreover, because dovish elites see a proclivity towards cooperation in their adversaries, they are likely to attribute adversaries' desirable actions to a cooperative disposition rather than - as hawkish types do - scheming on the part of the adversary or coercion from the dovish decision makers' side. Taken together, the foregoing arguments indicate hawkish decision makers' pronounced susceptibility to the fundamental attribution error and dovish decision makers' relative resistance to the error.

Differences in hawkish and dovish elites' proneness to the fundamental attribution are enhanced by hawkish decision makers' low conceptual complexity and dovish decision makers' high conceptual complexity. Dovish elites' high conceptual complexity allows them to see a number of reasons behind opponents' actions (see Hermann 2003: 195) including perhaps situational factors inducing opponents' unwished-for behavior or dispositional factors driving

\footnotetext{
${ }^{7}$ Regarding how low distrust and in-group bias aid in producing this perception of adversaries see Hermann (2003: 200).
} 
desirable actions on the part of opponents. Hawkish decision makers' low conceptual complexity, however, limits them to a more simplified, negative view of opponents in which opponents' undesired behaviors stem from hostile, scheming, expansionist dispositions and in which wished-for actions by the opponent are either duplicitous or forced by resolve or coercion on the part of the hawkish elites' side. Stated briefly, hawkish elites' low conceptual complexity reinforces their already heightened susceptibility to the fundamental attribution error while dovish elites' high conceptual complexity further inoculates them against it. All of these differences between hawkish and dovish decision makers suggest my seventh hypothesis: warhawks, hawks, and chickenhawks will commit the fundamental attribution error in their assessment of opponents' actions.

The closely-linked biases of concession aversion and risk seeking in losses, like the fundamental attribution error, are thought to be generally occurring. Recall from my previous discussion that according to prospect theory, individuals tend to assign more importance to losses (e.g., concessions) than gains. Individuals thus tend to be averse to suffering losses. Also, while individuals are apt to be risk avoidant in the pursuit of gains, their aversion to losses produces in them a tendency to be risk seeking in efforts to escape incurring losses, especially certain losses. As I explained in more depth earlier in this chapter, in the context of international interactions, especially negotiations, loss aversion presents itself as an aversion to making concessions. Risk seeking to avoid losses is in turn likely to manifest as gambits to avoid certain losses even at the risk of incurring greater possible losses if the gambit fails.

Although proponents of prospect theory (e.g., Kahneman and Tversky 1995; McDermott 1992) treat it as a general theory of risky choice applicable to foreign policy decision making, Kowert and Hermann (1997; see also Linde and Vis 2017) point out that at least large minorities 
of individuals fail to behave as prospect theory suggests they would. Kowert and Hermann argue that personality differences across individuals lead some to behave as prospect theory predicts while others' behaviors deviate from prospect theory's predictions. Like Kowert and Hermann, I argue that some decision-making elites behave in accordance with prospect theory but others do not. Specifically, my eighth hypothesis is that compared to dovish decision maker types, warhawks, hawks, and chickenhawks will exhibit greater concession aversion and will be more risk seeking in efforts to avoid making concessions or otherwise suffering certain losses. My ninth hypothesis is that owls, while exhibiting less concession aversion and risk seeking to avoid certain losses than hawkish decision makers, will be more concession averse and risk acceptant to escape certain losses than ravens or doves.

Before I explain the theoretical reasons behind these hypotheses, it is important to note that these hypotheses invite controversy because others (e.g., McDermott 1992) have used prospect theory to explain the foreign policy decision making of ostensibly dovish elites. For example, McDermott (1992: 237-238) asks why US president Jimmy Carter, despite "his predilection for the peaceful resolution of conflict," decided to use military force in an attempt to free American hostages held in Iran. She argues that prospect theory best explains Carter's decision. My hypotheses are thus subject to the criticism that prospect theory can explain not only the decision making of hawkish elites, but also dovish ones. In anticipation of this criticism I offer two retorts. The first is that, as this study argues, we currently have a poor understanding of hawkish and dovish decision makers. On closer examination using my classificatory scheme, one might find that ostensibly dovish decision makers like Carter are perhaps less dovish than they appear. This does not mean that such decision makers are chickenhawks, hawks, or warhawks. It does, however, mean that these decision makers should not be simply characterized 
as dovish. My preemptive rejoinder also does not mean that prospect theory fails to explain the behavior of a seemingly dovish decision maker. Again, my first argument here is that the decision maker may not indeed be so dovish. My second retort comes in the form of the theoretical reasoning underlying hypotheses eight and nine.

I hypothesize that hawkish decision makers are so concession averse in part because they view concessions differently than dovish decision makers. As Snyder and Diesing (1977: 299) argue, dovish decision makers - soft-liners in their terminology - see opponents' aims as limited and grievances as at least somewhat legitimate. Hawkish decision makers - hard-liners in Snyder and Diesing's language - see opponents' aims as boundless and grievances as illegitimate. Consequently, dovish decision makers are apt to see concessions demanded by opponents as reasonable while hawkish elites do not. By themselves these contrasting perceptions of opponents' demands do not provide a basis for claiming that hawkish but not dovish elites see concessions as losses or that dovish decision makers will be less concession averse and acceptant of risky behavior to avoid making concessions than hawkish ones. After all concessions to an opponent are by their very nature certain losses and, according to prospect theory, should elicit risky behavior to avoid granting them. But when these disparate perceptions of concessions are considered alongside differences between the personalities and beliefs of hawkish and dovish decision makers, the reasons for expecting hawkish elites, and to some extent owls, but not ravens or doves to be concession averse and risk seeking become much clearer.

The personalities of hawkish decision makers are characterized by a high task focus, and hawkish elites' operational code beliefs are characterized by a preference for conflictual strategies to achieve goals (i.e., successfully complete tasks). Given hawkish decision makers' 
perception that concessions demanded by opponents are unreasonable and illegitimate, it follows that hawkish elites see their task as avoiding granting those concessions. Of course refusing to make concessions to opponents could sour relations or exacerbate conflict between the hawkish elites' side and opponents, but hawkish decision makers are focused on completing the task as they see it, not on maintaining or improving relations with opponents. Moreover, because hawkish decision makers prefer conflictual strategies, refusing to grant concessions at the risk of starting or deepening a conflict is not a distasteful option for hawkish decision makers. In short, in their thinking - or, to use prospect theory terminology, framing - regarding losses, hawkish decision makers are predisposed to focus on concessions as certain losses while giving little thought to the potential losses soured relations or heightened conflict might otherwise represent. As a result, hawkish decision makers are very prone to concession aversion and risk seeking in order to avoid making concessions or accepting other certain losses.

In contrast to hawkish decision makers, ravens and doves' personalities are typified by a low task focus. This low task focus leads them to emphasize building or maintaining relationships with others (Hermann 2003: 199, 200) and to be more sensitive to others' "feelings and needs" (Shannon and Keller 2007: 84). Not surprisingly, then, decision makers with a low task focus are inclined to accommodate opponents (Shannon and Keller 2007: 84). Also in contrast to hawkish elites, ravens and doves' operational code beliefs stress using cooperative strategies in foreign policy. Considering that ravens and doves view opponents' demands as reasonable and that ravens and doves also focus on relationship building and maintenance, others' feelings and needs, cooperation, and accommodation, it follows that these types of decision-making elites engage in thinking about or framing losses very differently than do hawkish decision makers. Specifically, I posit that ravens and doves view making concessions - 
concessions they likely see as at least somewhat reasonable - to accommodate opponents as less of a loss than the loss that would result if a refusal to grant concessions damaged relations, hindered cooperation, or led to conflict with opponents. The upshot is that ravens and doves are far less likely than hawkish elites to be concession averse and thus also less apt to engage in risky actions to avoid concessions or similar certain losses. ${ }^{8}$

Owls are unique when it comes to the issue of concession aversion and risk seeking to avoid making concessions. Like ravens and doves, owls' operational code beliefs lead them to favor cooperative strategies in foreign policy. But unlike ravens and doves, owls' personalities are not characterized by a low task focus. At the same time, however, owls lack the high task focus possessed by hawkish decision maker types. Instead owls have a moderate task focus. Owls' moderate task focus is the source of their moderate tendencies to be concession averse and risk seeking in efforts to escape granting concessions to opponents.

As Hermann (2003: 198; see also Bass 1981; Byars 1972; 1973) argues, elites with a moderate task focus sometimes focus on tasks and sometimes focus on relationship building and maintenance. This mix of emphases makes my effort to predict owls' behavior more difficult. Acknowledging this difficulty, I argue that owls will generally value continued positive relations with opponents and avoiding new or escalated conflicts with adversaries. At the same time, however, I posit that owls' moderate task focus will make them averse to granting some of the concessions opponents demand. In presenting these propositions I assume first that owls will, like ravens and doves, treat harm to relations with opponents as real and consequential possible

\footnotetext{
${ }^{8}$ Note here that it is not necessarily the case that ravens and doves are immune to loss aversion; rather, ravens and doves think about the losses alternative courses of action (granting or refusing to grant concessions) might produce very differently than do hawkish decision makers. In this way my argument is somewhat in accord with prospect theory. However, my argument still departs from the tenets of prospect theory because the argument, contra prospect theory, implies that ravens and doves give greater weight to a possible loss (e.g., damaged relations) stemming from obstinacy over concessions than they assign to the certain loss entailed in the granting of concessions to opponents.
} 
losses. I also assume that owls will, similarly to hawkish elites, view concessions as important certain losses, too. In other words, in their thinking about losses, owls are distinct from the other five decision maker types because they seriously weigh the losses refusal to make concessions might cause and the certain losses entailed by granting concessions. Therefore owls are more likely to be concession averse and risk seeking to avoid concessions or similar losses than ravens or doves but less likely than hawkish elites to exhibit these biases.

The next bias to which hawkish decision makers have a pronounced susceptibility is the pseudo-certainty bias. Recall from earlier in this section that this bias tends to affect individuals confronted with a two (or more) stage problem where the initial stage is uncertain but the second stage, if reached, entails a result that is sure to happen. The upshot of this bias is that decision makers facing such a problem are inclined to overlook the initial, probabilistic stage and focus on the second, certain one. Kahneman and Renshon (2009: 91; Renshon and Kahneman 2017) argue this bias makes decision makers especially reticent to grant a concession that is strategically important. This is so because the decision makers focus on the strategic advantage such a concession would give an opponent in a future conflict rather than on the possibility that making the strategically valuable concession could prevent the worried-about future conflict.

Like the fundamental attribution error, concession aversion, and risk seeking in losses, the pseudo-certainty bias is often presented as a general tendency (see Tversky and Kahneman 1986; Kahneman and Tversky 1995). But at least sizable minorities appear to escape the bias, rendering it far from universal (Kahneman and Tversky 1986). Further, while Kahneman and Renshon (2009: 90-92; Renshon and Kahneman 2017) portray the pseudo-certainty bias as common, they note that hawkish elites are more prone to it than dovish ones. Following Kahneman and Renshon, my tenth hypothesis is that warhawks, hawks, and chickenhawks will be 
prone to the pseudo-certainty bias and thus highly averse to granting strategically valuable concessions to adversaries. Yet a question remains: why would hawkish decision makers be more susceptible to this bias than dovish decision makers? The answer, I argue, lies in the operational codes and personalities of hawkish and dovish decision makers.

The personalities of hawkish elites are marked by a high level of distrust and in-group bias, and their operational code beliefs lead them to view the world as conflictual and adversaries as basically hostile. Again, this mix of personality characteristics and beliefs leads hawkish decision makers to view adversaries as evil expansionists. I thus assume that hawkish elites fear granting a strategically significant concession to an adversary now will come back to haunt them down the road. After all, hawkish elites' distrusting personalities incline them to suspect that an adversary - an adversary they also see as fundamentally hostile and expansionist - will exploit the advantage gained from the strategically important concession in any future conflict. And, given hawkish elites' beliefs about the nature of the world and the adversary, a future conflict against the adversary is a seemingly real possibility.

Dovish elites, of course, are trusting, low in in-group bias, and believe the world is a basically harmonious place in which even opponents are at base friendly. Dovish decision makers are therefore less inclined to worry that making a strategically important concession to an opponent will be a long term blunder. Rather, they are predisposed to trust that granting such a concession could obviate a future conflict with that basically friendly opponent thus rendering the strategic value of the concession a moot point. As Snyder and Diesing (1977: 299) argue, dovish decision makers believe that after an adversary's "particular interests and grievances are satisfied, he will be transformed into a peaceful good neighbor." 
The final bias to which I expect hawkish decision makers are markedly more prone than dovish ones is the reactive devaluation bias. As I explain earlier in this section, in negotiations this bias inclines one to undervalue their opponent's proposals if for no other reason than that the opponent authored the proposal (Kahneman and Renshon 2009: 92; Maoz et al 2002; Renshon and Kahneman 2017; Ross 1995; Stillinger et al 1990; Stillinger and Ross 1991). The reactive devaluation bias, too, is often presented as a general tendency (Ross 1995), but the literature (Stillinger et al 1990) indicates that not all individuals appear equally prone to the bias. Still, although the literature notes exceptions to this bias, my expectation regarding hawkish and dovish decision makers' differential susceptibility to the reactive devaluation bias invites controversy. The chief reason for this is that Maoz et al (2002) find Israeli hawks and doves - in this case university students, not foreign policy decision-making elites - are prone to the reactive devaluation bias.

In arguing that hawkish decision makers are much more inclined to reactive devaluation than dovish ones, I am not disputing the findings of Maoz et al (2002); rather I am pointing out important differences between their study and mine. To begin, though the samples and subsamples Maoz et al study are relatively small, their discussion of the evidence focuses on aggregate levels. Their discussion also employs the language of general patterns and the statistical significance of treatment effects. As such, their focus is on these general patterns in the samples and subsamples, and rightly so. The nature of their study explicitly and appropriately does not emphasize exceptions to general patterns. My study has different goals, goals that explicitly emphasize exceptions to general patterns of bias susceptibility. In this way, my research is complementary, not antagonistic, to their study. Despite this complementarity, though, I would also point out that the Maoz et al study uses different means than I do to 
distinguish among hawkish and dovish individuals. Namely, the authors use partisan identification as a proxy for hawkishness and dovishness. As a result of these distinct conceptual frames for identifying hawks and doves, it is not surprising that my expectations clash somewhat with what Maoz et al find.

Moving on to my expectation regarding this bias, my eleventh hypothesis is that warhawks, hawks, and chickenhawks will be susceptible to the reactive devaluation bias. As with other biases, the reasons for hawkish elites' heightened proneness lie in the elites' personalities and operational codes. The personality traits that again come to the fore are the high levels of distrust and in-group bias typical of warhawks, hawks, and chickenhawks. The operational code elements at play here are hawkish decision makers' beliefs that opponents are at base hostile. A high level of distrust itself likely inclines hawkish elites to think an opponent's proposals for dispute or conflict resolution are not good faith, fair offers, but rather proposals that are good for the opponent and bad for the hawkish elites' side. When hawkish decision makers' distrust interacts with their high in-group bias and belief that opponents are fundamentally hostile to produce a view that adversaries are evil expansionists, this inclination becomes even more marked. Taken together, then, this admixture of personality and beliefs leads hawkish decision makers to exhibit the reactive devaluation bias and undervalue an adversary's proposals simply because the proposal is made by the adversary.

Dovish decision makers' personalities and operational codes, by contrast, leave them much more resistant to this bias. The more trusting personalities of dovish elites along with their belief that opponents are basically friendly make them apt to see an opponent's proposals for conflict or dispute settlement as sincere, evenhanded offers. Moreover, dovish decision makers' low in-group bias interacts with their trustfulness to produce a view of the world in which 
cooperation is possible but in which opponents may also face constraints (Hermann 2003: 200), constraints that may limit what opponents' proposals can offer to the dovish elites' side. Consequently, dovish decision makers are more likely than their hawkish counterparts to empathize with an opponent - an opponent the dovish elites belief is at base friendly - and recognize the possibility that even a relatively unfavorable proposal is still a good faith offer to be responded to with flexibility. ${ }^{9}$ In sum, dovish decision makers' personalities and beliefs make it unlikely that they will undervalue an opponent's proposal just because it is offered by the opponent.

As the foregoing discussion explains, warhawks, hawks, and chickenhawks are particularly susceptible to the fundamental attribution error, concession aversion, risk seeking to avoid certain losses, pseudo-certainty, and reactive devaluation. The errors and biases especially likely to afflict hawkish elites leave these decision maker types perceiving less potential for peaceful conflict resolution via mutual accommodation and more need for intransigence, assertiveness, or even aggression than would an objective observer (Kahneman and Renshon 2009; Renshon and Kahneman 2017). As I explain below, the largely distinct clusters of errors and biases affecting hawkish and dovish decision makers interact with other characteristics of each decision maker type to produce distinct foreign policy positions.

\section{Foreign Policy Positions}

Research has long and frequently linked operational code beliefs and personality traits to the foreign policy positions taken by a variety of foreign policy decision makers operating in diverse contexts. ${ }^{10}$ Similarly, past studies connect to behavior and foreign policy stands the

\footnotetext{
${ }^{9}$ On the issue of flexibility see Hermann 2003: 200.

${ }^{10}$ See Crichlow 1998, 2002, 2005, 2006; Drury 2006; Dyson 2006, 2007, 2009a, 2009b; Dyson and Parent 2017; Feng 2005; Foster and Keller 2014; Hermann 1980, 2003b; Hermann, Preston, Korany, and Shaw 2001; Keller
} 
cognitive errors and biases I describe above. ${ }^{11}$ Via the following six hypotheses, hypotheses twelve through seventeen, I propose to connect operational code beliefs, personality traits, susceptibility to cognitive errors and biases, preferences over outcomes, and beliefs about opponents' preferences over outcomes to the general foreign policy positions of warhawks, hawks, chickenhawks, owls, ravens and doves.

\section{Foreign Policy Positions Associated with Hawkish Decision Makers. Generally} speaking, I expect warhawks, hawks, and chickenhawks' foreign policy positions to advocate assertive or aggressive action and resistance to making concessions or otherwise 'giving ground' to opponents. In part, hawkish decision makers' assertive or aggressive foreign policy positions flow fairly directly from the personality traits and operational code beliefs they share. At the level of personality traits, it is important to first emphasize that hawkish elites are highly distrusting and have a strong in-group bias. In addition to producing in these decision makers an us-against-them mentality in which a group of "evil," aggressive adversaries is at the center of the threatening environment that is international politics, this combination of personality traits inclines warhawks, hawks, and chickenhawks to "highly aggressive and assertive behavior" (see Hermann 2003: 200; Shannon and Keller 2007: 84). Furthermore, even by itself, strong distrust is associated with aggressive foreign policy behavior, including decisions for war and unprovoked military build-ups (Driver 1977; see also Foster and Keller 2014).

Hawkish decision makers' personalities are also typified by low conceptual complexity. Low conceptual complexity, too, is associated with forceful and aggressive foreign policy

2005; Malici 2005, 2006; Shannon and Keller 2007; Stevenson 2006; Thies 2006; Walker 1977, 1995; Walker and Falkowski 1984; Walker and Schafer 2000; Walker, Schafer, and Young 1999.

${ }^{11}$ See Abrams 1990: 136; Bazerman 2001; Bazerman and Neale 1985; Betts 1999; Blainey 1973: 35; Farnham 1992; Heradsveit 1981; Jervis 1976: 323-329, 343-348, 1988, 1992; Johnson 2004; Johnson et al. 2006; Kahneman and Renshon 2009; Lebow 1981: 242-246; Levy and Vakili 1992; Maoz, Ward, Katz, and Ross 2002; McDermott 1992; McIerney 1992; Nincic 1997; Renshon and Kahneman 2017; Ross 1984: 247; Snyder 1991: 29; Snyder and Diesing 1977: 297-310; Stoessinger 1998: 211; Van Evera 1998, 1999: 14-34; Whyte and Levi 1994. 
behavior such as engaging in war or undertaking unprovoked arms build-ups (Driver 1977; see also Foster and Keller 2014; Hermann 1984; Preston 2001). This may be because, especially in threatening and stressful situations (e.g., crises and disputes), individuals with low conceptual complexity may see few options other than aggressive ones (Driver 1977: 339; see also Foster and Keller 2014).

Warhawks, hawks, and chickenhawks' operational code beliefs P-1 and I-1 further incline them towards conflictual foreign policy positions. In terms of these beliefs, hawkish elites' P-1 beliefs hold that international politics is a hostile arena in which opponents are fundamentally antagonistic (see Schafer and Walker 2006; Walker and Schafer 2006). Hawkish decision makers' I-1 beliefs lead them to favor conflictual means of dealing with these hostile opponents (see Schafer and Walker 2006; Walker and Schafer 2006). Evidence suggests that even decision makers whose I-1 beliefs generally reflect a preference for cooperation are prone to espouse conflictual foreign policy positions when they believe opponents are at least somewhat hostile and oriented towards conflictual foreign policies (Crichlow 2006: 83-89). Given hawkish decision makers' P-1 and I-1 beliefs, I expect them to be clearly in favor of assertive or aggressive foreign policies.

Taken together, warhawks, hawks, and chickenhawks' personalities and beliefs predispose them to support assertive or aggressive foreign policies. At the same time, the personality traits and operational code beliefs shared by hawkish elites directly lead them to resist making concessions to opponents or accepting other losses imposed by adversaries. Here, the most salient personality traits are hawkish decision makers' strong need for power and high task focus. A pronounced need for power fixates hawkish elites on controlling or dominating others, winning, and making gains (see Hermann 2003: 190-191; Shannon and Keller 2007: 84; 
Winter 1973; 2003). In negotiations a strong need for power makes hawkish decision makers hard, aggressive bargainers who view negotiations as a zero-sum game in which they seek to achieve gains at the expense of their opponents (see Hermann 2003: 190-191; Shannon and Keller 2007: 84; Winter 1973; 2003). The high task focus of hawkish decision makers further inclines them towards intransigence in negotiations by making them relatively insensitive to opponents' needs and feelings and thus less interested in accommodating opponents (see Shannon and Keller 2007: 84).

I expect that hawkish elites' advocacy of assertive or aggressive action and resistance to making concessions or otherwise giving way to opponents also stems from the cognitive errors and biases to which, as I hypothesize above, warhawks, hawks, and chickenhawks are all susceptible. The primary effect of these errors and biases is to amplify hawkish decision makers' tendency to be intransigent in negotiations and averse to otherwise ceding ground to adversaries. Intransigence, of course, may also play into hawkish elites' advocacy of assertive or aggressive foreign policies, as force may be needed to pay the cost of obstinacy at the negotiating table. Still, the impact of these errors and biases is likely to manifest most plainly as inflexibility in negotiations.

Of the biases impinging on hawkish elites, concession aversion most obviously influences their foreign policy positions. This bias leads hawkish decision makers to resist incurring the certain losses that concessions to an opponent represent (see Kahneman and Renshon 2009: 87; Kahneman and Tversky 1995: 56; Levy 2000: 209-210; Renshon and Kahneman 2017). The pseudo-certainty bias for its part makes warhawks, hawks, and chickenhawks very hesitant to grant concessions of strategic importance to an opponent for fear that the opponent will exploit the strategic gain in a future conflict (see Kahneman and Renshon 
2009: 91; Renshon and Kahneman 2017). Hawkish elites are further inclined against concessions or giving way to adversaries by the reactive devaluation bias. This bias predisposes hawkish elites to undervalue an opponent's proposals for the simple reason that the proposals are made by the opponent (see Kahneman and Renshon 2009: 92; Maoz et al 2002; Renshon and Kahneman 2017; Ross 1995; Stillinger and Ross 1991). Consequently, the reactive devaluation bias leaves hawkish decision makers apt to reject concessions and proposals for compromise offered by an adversary as trifling or made in bad faith (Ross 1995; see also Kahneman and Renshon 2009: 92; Renshon and Kahneman 2017).

The fundamental attribution error, too, contributes to hawkish decision makers' resistance to concessions to and accommodation of opponents, but this error also feeds into hawkish elites' support for assertive or aggressive foreign policies. Hawkish elites' susceptibility to the fundamental attribution error predisposes them to perceive an opponent's behavior, such as an opponent's statement of demands, as stemming from the adversary's hostile disposition rather than from such as things as genuine security concerns or domestic constraints impinging on the opponent (see Kahneman and Renshon 2009: 83-84; Levy 2003: 266; Renshon and Kahneman 2017; Tetlock 1998: 877). In other words, hawkish decision makers are unlikely to empathize with an opponent and the problems or constraints the opponent faces (see Levy 2003: 266). Moreover, in situations where an opponent itself makes concessions or behaves in an accommodative fashion, one likely hawkish interpretation is that the opponent is scheming rather than genuinely desirous of conciliation. ${ }^{12}$ Consequently, hawkish elites are unlikely to advocate reciprocating an opponent's accommodative moves by offering concessions or accommodation to the opponent. For these reasons I expect that the fundamental attribution error disinclines

\footnotetext{
${ }^{12}$ This interpretation derives largely from hawkish elites' high distrust (see Hermann 2003: 203).
} 
hawkish decision makers to accommodate an opponent's demands through concessions or other conciliatory acts.

The fundamental attribution error can also reinforce hawkish elites' propensity for advocating assertive or aggressive foreign policy. The reason for this is twofold. First, hawkish elites may well have to advocate assertive or aggressive action to back up their resistance to accommodating an opponent in negotiations. Second, if an opponent backs down or gives ground in negotiations, the fundamental attribution error likely leads hawkish decision makers to reason that the opponent is responding to resolve or coercion from the hawkish elites' side (see Snyder 1991: 29). ${ }^{13}$ As a result, hawkish decision makers are likely to believe that obstinacy or forceful action achieve desirable outcomes thus encouraging more intransigence, assertiveness, or aggression. Indeed, due to the fundamental attribution error, warhawks, hawks, and chickenhawks may come to view an opponent "as an innate aggressor who will bow to forceful resistance - a paper tiger" (Snyder 1991: 29). The perceptions that resolve in negotiations and assertive or aggressive acts can cow an opponent serve to buttress hawkish decision makers' predilection for intransigence and forcefulness in foreign policy.

While the other biases and errors I have discussed serve mainly to foster hawkish decision makers' inflexibility in negotiations, the risk seeking in losses bias encourages warhawks, hawks, and chickenhawks to take forceful foreign policy positions. Specifically, this bias makes hawkish elites likely to advocate risky conflictual foreign policy action to avoid granting concessions to an adversary or otherwise incurring certain losses at the hands of an opponent (see Berejikian and Early 2013; Farnham 1992; Jervis 1992; Kahneman and Tversky

\footnotetext{
${ }^{13}$ Of course, as I discuss in the preceding paragraph, the other interpretation is that the opponent's favorable actions are the result of scheming.
} 
1995; Levy 1992; 2000: 200-206; McDermott 1992). This bias, then, heightens hawkish elites' general inclination towards assertive and aggressive foreign policy stands.

The foregoing discussion delineates the central tendencies in hawkish decision makers' positions on foreign policy. There are, however, important differences between warhawks, hawks, chickenhawks. In particular, the hawkish elites vary in terms of their beliefs about their ability to exert control over events and historical development. They vary, too, in their susceptibility to positive illusions. I expect that these differences will ultimately lead the three hawkish decision maker types to take rather distinct foreign policy positions.

Warhawks are distinguished from hawks and chickenhawks by a strong belief that they are stronger than their opponents and can control events and shape historical development. This belief is reflected in warhawks' personalities and operational code beliefs (i.e., P-4 and P-4a). Largely because of this belief, warhawks also contrast sharply with hawks and chickenhawks in that warhawks are particularly susceptible to positive illusions.

When interacted with warhawks' belief that international relations is a conflictual realm in which opponents are at root hostile (operational code belief P-1) and that conflictual foreign policies are most efficacious (operational code belief I-1), warhawks' strong belief in their control over events and their belief that they are more powerful than opponents produces certain preferences. This interaction of beliefs also gives rise to perceptions of an adversary's preferences.

According to the logic of the Theory of Inferences about Preferences (TIP), warhawks' confidence in their abilities and belief that their strength is superior to that of their adversaries, compounded by their marked predilection for conflictual strategies, lead them to have the following ranking of preferences over outcomes of interactions with opponents: domination is 
preferred to deadlock, deadlock is preferred to settlement, and settlement is preferred to submitting. This preference ordering reveals warhawks as given to bullying (see Marfleet and Walker 2006: 57). Notably, in my typology, this preference ranking is unique to warhawks.

The logic of TIP also proposes that warhawks hold perceptions of adversaries that differ from those of other decision maker types, hawkish or dovish. The inverse of a warhawk's P-4a belief is the P-4b belief that warhawks' opponents see themselves as weaker than the warhawks' side. Because warhawks see their opponents as preferring hostile actions (i.e., due to warhawks' P-1 belief) but perceiving themselves as relatively weak, warhawks believe their adversaries prefer domination most, followed in descending order by settlement, submission, and deadlock. In other words, warhawks believe their opponents are bluffers (see Marfleet and Walker 2006: $60)$.

I expect that warhawks' own preferences as well as their beliefs about their adversaries' preferences will amplify the central tendencies shared by all three hawkish decision maker types and manifest in the warhawks' observable behavior. ${ }^{14}$ Specifically, I posit that warhawks will advocate making expansionist demands or aggressively initiating conflict (i.e., bullying). I also anticipate that, given warhawks' preferences and views of adversaries' preferences, warhawks will be especially likely to advocate a refusal to moderate demands even in the face of adversaries' resolve or resistance.

My expectations for warhawks' foreign policy stands also derive from such decision makers' proneness to positive illusions. As I explain above, warhawks are likely to be overly sanguine about their abilities (including their ability to determine outcomes) and the probability

\footnotetext{
${ }^{14}$ Recall that I treat warhawks' preferences and perceptions of adversaries' preferences as assumptions about warhawks' characteristics and do not attempt to submit these assumptions to direct empirical testing. I instead test these assumption indirectly via "observable implications" (King, Keohane, and Verba 1994: 28-29) of these preferences and perceptions. The observable implications are, specifically, warhawks' foreign policy positions.
} 
that events will transpire as they wish. This type of overconfidence has been empirically linked to the conflictual behavior I associate with warhawks. I thus expect positive illusions to reinforce the behavioral tendencies I hypothesize to characterize warhawks.

The foregoing discussion of hawkish decision makers in general and warhawks in particular gives rise to my twelfth hypothesis. Hypothesis twelve is as follows: warhawks' foreign policy positions will be characterized by advocacy for making expansionist demands, aggressively initiating conflict, and refusal to moderate demands. As will become evident as I discuss the foreign policy positions of hawks and chickenhawks, warhawks are the most hawkish of hawkish decision makers.

Despite sharing with warhawks the same baseline behavioral tendencies, hawks and chickenhawks will, I hypothesize, take foreign policy positions that vary substantially from those espoused by warhawks. At the same time, I expect hawks and chickenhawks to take up foreign policy positions that differ from each other. As I theorize, these differences stem firstly from hawks' and chickenhawks' beliefs about their ability to exert control over events and historical development. These beliefs affect hawks and chickenhawks' preferences over tactics and outcomes as well as their perceptions of opponents' preferences. Also of consequence, these decision maker types lack the susceptibility to positive illusions characteristic of warhawks.

The primary difference between hawks and warhawks is that the former have only a moderate belief that they are able to control events and historical development. Additionally, in contrast to warhawks, hawks perceive relative power parity between themselves and their adversaries. These beliefs are reflected in hawks' personality traits and operational codes (beliefs P-4 and P-4a). 
Due to hawks' P-4a belief that their strength is at approximate parity with their adversaries' power, and hawks' strong propensity for conflictual strategies, TIP indicates that the ordering of hawks' preferences over outcomes ranks domination first, settlement second, deadlock third, and submission last (see Marfleet and Walker 2006: 57). This preference ordering, which in my typology is exclusive to hawks, suggests hawks seek either to compel opponents to act as the hawks desire or to punish opponents' undesired actions. Hawks' views of their opponents' preferences are also unique in my categorization of decision maker types. The flipside of hawks' P-4a belief is a P-4b belief that their opponents see themselves as equal in strength to the hawks' side. Because hawks perceive their adversaries as favoring hostile actions and believing themselves equal to the hawks' side, hawks believe their adversaries also prefer domination to settlement, settlement to deadlock, and deadlock to submitting. Consequently, hawks believe their adversaries will either try to compel their side to act as the adversaries desire or to punish their side for actions the adversaries view as undesirable (see Marfleet and Walker 2006: 60).

I anticipate that hawks' preferences and their perceptions of their opponents' preferences will both interact with and temper somewhat the central tendencies common to all three hawkish decision maker types and present in the hawks' empirically observable behavior. ${ }^{15}$ Namely, I propose that hawks will advocate conflictual foreign policies either to compel other actors to behave as the hawks wish or to punish other actors for behaving contrary to the hawks' desires. Further, I propose that, due to hawks' preferences and views of adversaries' preferences, hawks will seek first to dominate their adversaries and make no concessions or otherwise accommodate

\footnotetext{
${ }^{15}$ Recall that I treat hawks' preferences and perceptions of adversaries' preferences as assumptions about hawks' characteristics and do not attempt to submit these assumptions to direct empirical testing. I instead test these assumption indirectly via "observable implications" (King, Keohane, and Verba 1994: 28-29) of these preferences and perceptions. The observable implications are, specifically, hawks' foreign policy positions.
} 
adversaries. Should domination be unachievable, however, I expect that hawks will seek some accommodation with opponents in order to reach a settlement that is favorable to the hawks' side. Failing that, hawks should seek to deadlock with their opponents rather than submit to adversaries. These expectations comprise hypothesis thirteen: hawks will compel or punish adversaries and will seek settlement only if domination fails. If settlement is also unobtainable, hawks will deadlock with adversaries rather than submit. ${ }^{16}$

Chickenhawks differ from both warhawks and hawks mainly in that chickenhawks have only a weak belief in their ability to exercise control over events or historical development. Also, in contrast to hawks and especially warhawks, chickenhawks see themselves as less powerful than their opponents. As with warhawks and hawks, these beliefs are evident in chickenhawks' personalities and operational codes (beliefs P-4 and P-4a).

Given TIP's logic, chickenhawks' predilection for conflictual strategies tempered by their belief that they are weaker than their adversaries leads them to possess the following distinct ordering of preferences over outcomes of interactions with opponents: domination is preferred over settlement, settlement is preferred over submission, and submission is preferred over deadlock. This preference ordering makes chickenhawks likely to try to bluff their adversaries (see Marfleet and Walker 2006: 57). The converse of chickenhawks' P-4a belief is their P-4b belief that their adversaries perceive themselves as the stronger actors. Due to chickenhawks' belief that their adversaries are inclined to hostile strategies and perceive themselves to be stronger than the chickenhawks' side, chickenhawks believe their opponents most prefer to

\footnotetext{
${ }^{16}$ This hypothesis may suggest that hawks depart problematically far from the central tendencies I claim typify all three hawkish decision makers. Most notably, it may appear that hawks are less concession averse or risk seeking in losses than warhawks. That impression would be false. I maintain that all three hawkish decision maker types share the same baseline tendencies. Hawks do not depart that far from central hawkish tendencies. Hawks' foreign policy positions do, however, differ from those of warhawks. Hawks' positions differ from warhawks' stands primarily because, compared to warhawks, hawks are resistant to positive illusions and less sanguine about their control over events and their power relative to the power of their opponents. Stated simply, hawks feel less able than warhawks to have their way vis-à-vis their adversaries and hawks' policy stances evince this sentiment.
} 
dominate, followed in decreasing order of preference by deadlocking, settling, and submitting. This belief about opponents is also unique to chickenhawks. Chickenhawks' perceptions of their opponents lead them to believe that their adversaries will try to bully them (see Marfleet and Walker 2006: 60).

As with warhawks and hawks, I expect chickenhawks' own preferences and their views of their adversaries' preferences to interact with the baseline tendencies shared by all three hawkish decision maker types and manifest in the chickenhawks' observable behavior. ${ }^{17} \mathrm{I}$ specifically anticipate that chickenhawks' preferences and perceptions of opponents' preferences will have a more significant tempering effect on the central tendencies of hawkish decision makers than is the case for hawks. I thus propose that chickenhawks will advocate threatening and making demands on adversaries. If dominating their opponents in this manner fails, however, I expect chickenhawks to advocate deescalating and reaching a settlement at the cost of concessions or other losses to opponents because chickenhawks do not believe themselves strong enough to maintain a deadlocked situation against their adversaries and wish to escape submission. In short, I posit that chickenhawks' ostensibly assertive or aggressive foreign policy stands are bluffs that opponents can successfully call. These propositions produce my fourteenth hypothesis: chickenhawks will take foreign policy positions advocating threats or demands against opponents, but failing domination will support backing down and seeking settlement at the price of concessions or other losses in order to avoid being forced to submit to adversaries. ${ }^{18}$

\footnotetext{
${ }^{17}$ Recall that I treat chickenhawks' preferences and perceptions of adversaries' preferences as assumptions about chickenhawks' characteristics and do not attempt to submit these assumptions to direct empirical testing. I instead test these assumptions indirectly via "observable implications" (King, Keohane, and Verba 1994: 28-29) of these preferences and perceptions. The observable implications are, specifically, chickenhawks' foreign policy positions. ${ }^{18}$ This hypothesis, like the preceding one, may seem to imply too large a deviation from the baseline tendencies I argue characterize all three hawkish decision maker types. Of greatest significance, it may appear that chickenhawks are far less concession averse or risk seeking in losses than warhawks or hawks. That interpretation would be incorrect. I hold that all three hawkish decision maker types possess the same baseline tendencies. Chickenhawks' foreign policy positions do, though, indeed differ markedly from those of warhawks and hawks.
} 
Foreign Policy Positions Associated with Dovish Decision Makers. As is evident in the hypotheses regarding hawkish elites, decision makers can share many characteristics and baseline behavioral tendencies yet, due to the impact of a few key variables, still take very different foreign policy stands. The differences in foreign policy positions across owls, ravens, and doves will be just as stark, if not more so, because decision makers of these types are a more motley collection. Still, there are many important commonalities among dovish decision makers.

I anticipate that owls, ravens, and doves' foreign policy positions will generally advocate cooperative action as well as at least some level of accommodation in negotiations with opponents. To some extent, cooperation and accommodation flow straightforwardly from dovish elites' shared personality traits and operational codes. In terms of personality traits, it is crucial to highlight dovish decision makers' weak in-group bias and low levels of distrust. This combination of personality traits leads dovish decision makers to perceive a non-threatening international arena in which cooperation is possible and achievable (see Hermann 2003: 200). Moreover, low distrust alone is associated with a lack of aggressive foreign policy behavior, especially a lack of serious aggression such as decisions to go war or undertake unprovoked military build-ups (Driver 1977; see also Foster and Keller 2014). In sum, low distrust and a weak in-group bias predispose dovish decision makers to seek cooperative foreign policies rather than assertive or aggressive ones.

The personalities of owls, ravens, and doves are also characterized by high conceptual complexity. High complexity is linked to a decreased likelihood of aggressive foreign policy

Chickenhawks' stances differ from warhawks and hawks' positions mainly because, in contrast to the other hawkish types, chickenhawks are far less confident in their control over events and their strength relative to their adversaries. Moreover, chickenhawks clearly lack the susceptibility to positive illusions typifying warhawks. Chickenhawks' lack of confidence simply leads them to ultimately take foreign policy stands that are strikingly different than their fellow hawkish decision maker types. This does not mean that chickenhawks want domination less than warhawks or hawks; chickenhawks just feel less able to pursue domination of opponents. 
behavior (Driver 1977; see also Foster and Keller 2014). Further, higher conceptual complexity is associated with an increased likelihood of seeking to maintain friendly relationships with foreign states (Hermann 1980: 36-38). High conceptual complexity thus inclines dovish elites towards nonaggressive, accommodative foreign policy positions. As a result, I expect dovish elites to be more willing than hawkish ones to advocate making concessions to adversaries or otherwise accommodating opponents.

A low need for power, too, typifies dovish decision makers' personalities. Given their low need for power, dovish elites should be less inclined than hawkish ones to treat negotiations as zero-sum games and comparatively much more inclined to accommodate opponents at the negotiating table (see Shannon and Keller 2007: 84). A weak need for power is also linked to foreign policy behavior based on maintaining friendly relationships with foreign states (Hermann 1980: 36-38). Owls, ravens, and doves' weak need for power should thus lead them to advocate being conciliatory and willing to offer concessions in negotiations.

Dovish elites' operational code beliefs P-1 and I-1 enhance their penchant for cooperative and accommodative foreign policy positions. Owls, ravens, and doves' P-1 beliefs maintain that international relations are essentially harmonious and opponents are basically friendly (see Schafer and Walker 2006; Walker and Schafer 2006). At the same time, dovish decision makers' I-1 beliefs lead them to prefer cooperative strategies in their dealings with others, including opponents (see Schafer and Walker 2006; Walker and Schafer 2006). In short, dovish elites believe opponents are at base friendly and believe that cooperative strategies are the preferred means of interacting with opponents.

Considered as a whole, these personality traits and beliefs predispose dovish decision makers to support cooperative and accommodative foreign policies. This predisposition is 
strengthened by the set of cognitive errors and biases to which, as I hypothesize, all dovish elites are susceptible. Before discussing the impact of these errors on dovish decision makers' foreign policy positions, it is important to point out that all dovish elites are, according to my hypotheses, also resistant to the fundamental attribution error, pseudo-certainty bias, and reactive devaluation bias. This means that owls, ravens, and doves lack several characteristics that foster assertive or aggressive foreign policy behavior and obstinacy in negotiations. Furthermore, as I hypothesize, ravens and doves (and to some extent owls) are resistant to concession aversion and risk seeking in losses, two biases that encourage advocacy for intransigence in negotiations and the use of assertive or aggressive foreign policies.

The errors and biases to which owls, ravens, and doves share susceptibility have effects opposite to the errors and biases impinging on hawkish decision makers. Dovish elites are likely affected by several errors. Specifically, they are apt to do all of the following: exaggerate adversaries' propensity for compromise, underestimate the level of conflict between their side and their opponents, exaggerate adversaries' internal hawkish-dovish factionalization (a form of unrealistic optimism known as the wishful thinking bias), overestimate the extent to which nonhawkish elements internal to their opponents share their own desire for accommodation, and overestimate the value of concessions they offer to adversaries. This cluster of cognitive errors and biases leads dovish decision makers to perceive more potential for peaceful, accommodative resolution of conflicts with opponents than would an objective observer. The consequences of these errors and biases, I argue, are to make dovish decision makers more inclined to pursue cooperative and accommodative foreign policies.

In sum, this set of personality traits, operational code beliefs, and cognitive errors and biases gives rise to the central tendencies in dovish elites' foreign policy positions. However, 
dovish decision makers vary crucially in terms of their beliefs about their own strength relative to that of their opponents, beliefs regarding their ability to exercise control over events and historical development, task focus, and proneness to positive illusions. I anticipate that these variations will produce markedly different foreign policy positions across the three dovish decision maker types.

Owls differ from ravens and doves in three consequential ways. First, owls have a moderate task focus. Second, owls firmly believe they are stronger than their adversaries and that they can exert control over events and historical development. Third, owls are especially prone to positive illusions.

Owls' moderate task focus, as I hypothesize above, makes them more concession averse and risk seeking in losses than ravens and doves. To briefly recapitulate my previous arguments, a moderate task focus is likely to have these effects because it leads owls to sometimes emphasize tasks and other times to focus on relationships with others (Hermann 2003: 198; see also Bass 1981; Byars 1972, 1973). During instances in which owls focus on tasks, I expect them to be more concession averse and risk seeking in losses. Owls are thus apt to be somewhat less accommodating of opponents' demands than ravens and doves. The reason is that owls are prone to sometimes resist accepting the certain losses entailed in granting concessions to opponents (see Kahneman and Renshon 2009: 87; Kahneman and Tversky 1995: 56; Levy 2000: 209-210; Renshon and Kahneman 2017). In such cases, owls are therefore also more likely to advocate risky conflictual foreign policies to back up their resistance to offering concessions or otherwise incurring the costs of accommodating adversaries (see Berejikian and Early 2013; Farnham 1992; Jervis 1992; Kahneman and Tversky 1995; Levy 1992; 2000: 200-206; 
McDermott 1992). In short, owls are likely to sometimes be more conflictual and less cooperative and accommodating than ravens and doves.

Perhaps more important to explaining what sets owls' foreign policy positions apart from those of ravens and doves is owls' marked belief that they are more powerful than their opponents and can control events and shape historical development. This belief is evident in owls' personalities and operational code beliefs (i.e., P-4 and P-4a). Primarily due to this belief, owls also contrast clearly with ravens and doves, in that owls are especially prone to positive illusions.

Due to owls' P-4a belief that they are stronger than their opponents and owls' basic inclination towards cooperative strategies (operational code belief I-1), TIP indicates that owls' strong belief in their superior strength and ability to control events combined with their predilection for cooperative strategies gives rise to a unique ranking of preferences over outcomes of interactions with opponents. Specifically, owls prefer settlement to domination, domination to deadlock, and deadlock to submitting. This preference ranking suggests owls seek to cooperate with their opponents, but in an exploitative manner (see Marfleet and Walker 2006: 57). The logic of TIP also specifies that owls perceive their opponents' preferences differently than other decision maker types in my categorization. The inverse of owls' P-4a belief is their P-4b belief that their adversaries see themselves as less powerful than the owls' side. Because owls see opponents as inclined towards cooperative actions and viewing themselves as weaker than the owls' side, owls believe opponents seek settlement first, followed in order of descending preference by deadlock, submission, and domination. Put simply, owls see opponents as appeasers (see Marfleet and Walker 2006: 60). 
I anticipate that owls' own preferences as well as their beliefs about their adversaries' preferences will substantially temper the baseline tendencies shared by all three dovish decision maker types and present in owls' empirically observable behavior. ${ }^{19}$ I propose that owls will advocate seeking a favorable (i.e., exploitative) outcome through mutual accommodation with opponents. In light of owls' personalities, operational code beliefs, and the errors and biases likely to influence their decisions, I anticipate that owls are optimistic that such favorable settlements will be obtained. If this cooperative but exploitative strategy fails, I expect owls to advocate conflictual foreign policies to dominate adversaries rather than deadlocking with or submitting to opponents.

My expectations for owls' foreign policy stances stem also from owls' susceptibility to positive illusions. As I discuss above, owls are apt to be overly confident about their abilities (including their ability to shape outcomes) and the likelihood that events will turn out as they desire. Evidence links this form of overconfidence to the conflictual behavior I anticipate owls are prone to undertake (see Johnson 2004; Johnson et al. 2006; Johnson and Tierney 2011). I therefore expect positive illusions to reinforce the conflictual tendencies inhering in owls.

The previous treatment of dovish decision makers generally and owls specifically produces my fifteenth hypothesis. Hypothesis fifteen is as follows: owls' foreign policy positions will be typified by an initial advocacy for seeking favorable outcomes through mutual accommodation. If mutual accommodation fails to achieve favorable outcomes, owls will advocate conflictual foreign policies to dominate their opponents in order to avoid deadlock with or submission to their opponents. This hypothesis marks owls as the most hawkish of the dovish

\footnotetext{
${ }^{19}$ Recall that I treat owls' preferences and perceptions of opponents' preferences as assumptions about owls' characteristics and do not attempt to submit these assumptions to direct empirical testing. I instead test these assumption indirectly via "observable implications" (King, Keohane, and Verba 1994: 28-29) of these preferences and perceptions. The observable implications are, specifically, owls' foreign policy positions.
} 
decision maker types..$^{20}$ Ravens and doves' foreign policy positions clearly contrast with those espoused by owls.

Ravens and doves differ from owls in part because ravens and doves have a low task focus and, as I hypothesize above, are relatively resistant to the positive illusions impinging on owls' decision making. ${ }^{21}$ Ravens and doves' low task focus makes them more likely than owls to pursue accommodation with opponents (see Shannon and Keller 2007: 84). At the same time, I expect ravens and doves' relative immunity to positive illusions - overconfidence in one's own abilities and likelihood of favorable outcomes - will incline them away from conflictual foreign policy positions (see Johnson 2004; Johnson et al. 2006; Johnson and Tierney 2011). Taken together, these characteristics should foster in ravens and doves a propensity to espouse foreign policy stands that are more conciliatory and cooperative and less conflictual than the foreign policy positions taken by owls.

Despite these similarities, ravens and doves vary substantially in their beliefs about their power relative to opponents' power and in their ability to exert control over events and historical development. These differences are evident at the levels of ravens and doves' personalities and operational codes (belief P-4 and P-4a). I expect the foreign policy positions of ravens and doves to reflect these differences.

\footnotetext{
${ }^{20}$ This hypothesis seems to show that owls deviate substantially, perhaps too substantially, from the central tendencies I posit as typical of all three dovish decision maker types. Most importantly, owls appear more conflictual and less cooperative/accommodating than the baseline behavioral tendencies of dovish decision makers suggest. Owls also seem to share with hawkish decision makers an aversion to concessions and a tendency to be risk seeking in losses. Furthermore, owls and warhawks are both especially prone to positive illusions. This impression is understandable, albeit misleading. I maintain that all three dovish decision maker types share the same central tendencies. Cooperation and accommodation are the touchstones of owls' foreign policy positions even if other characteristics pull owls in the direction of conflict and resistance to accommodation.

${ }^{21}$ The primary reason for this is that, compared to owls, ravens and doves perceive themselves as less powerful visà-vis their opponents and believe less strongly in their ability to exercise control over events and historical development. These perceptions and beliefs stem from ravens and doves' personality traits and operational codes (beliefs P-4 and P-4a).
} 
Ravens' personalities and operational codes (belief P-4) are characterized by a moderate belief that they can control events and historical development. Ravens' operational code belief P-4a also leads them to see themselves as relatively equal in power to their adversaries. Given ravens' P-4a belief and predilection for cooperative strategies, the logic of TIP indicates that ravens' ordering of preferences over outcomes ranks settlement over deadlock, deadlock over domination, and domination over submitting. This preference ranking is peculiar to ravens and suggests ravens will act to deter opponents from engaging in conflictual actions and reward opponents who are cooperative (see Marfleet and Walker 2006: 57). Ravens' beliefs about opponents' preferences are also unique in my typology. The inverse of ravens' P-4a belief is the P- $4 \mathrm{~b}$ belief that ravens' opponents perceive themselves as equal in power to the ravens' side. Because ravens believe their adversaries are inclined towards cooperative actions and see themselves as equal to the ravens' side, ravens perceive that opponents also rank settlement over deadlock, deadlock over domination, and domination over submission. Consequently, ravens believe adversaries will seek to deter the ravens' side from pursuing conflictual policies and reward the ravens' side for cooperative action (see Marfleet and Walker 2006: 60).

I expect that ravens' preferences and perceptions of their adversaries' preferences will interact with and to some extent mitigate the baseline tendencies common to all three dovish decision maker types and manifest in ravens' observable foreign policy positions. ${ }^{22}$ Specifically, I posit that ravens will advocate foreign policy action seeking first to achieve with opponents settlements based on mutual accommodation even if accommodation entails concessions from the ravens' side. Given ravens' personalities, operational code beliefs, and the errors and biases

\footnotetext{
${ }^{22}$ Recall that I treat ravens' preferences and perceptions of opponents' preferences as assumptions about ravens' characteristics and make no attempt to submit these assumptions to direct empirical testing. I instead test these assumption indirectly via "observable implications" (King, Keohane, and Verba 1994: 28-29) of these preferences and perceptions. The observable implications are, specifically, ravens' foreign policy positions.
} 
likely to affect their decision making, I expect ravens will think settlement likely to succeed. I anticipate that ravens expect this policy to succeed. I further expect, however, that if settlement via mutual accommodation is elusive, ravens will advocate deadlock with opponents. I also propose that ravens will remain open to foreign policy actions aimed at dominating opponents in order to avoid being forced to submit to adversaries. These propositions give rise to hypothesis sixteen: ravens will initially advocate seeking settlements via mutual accommodation. If settlements fail to materialize, ravens will advocate deadlock with opponents and keep open the option to seek domination of opponents so as not to risk being forced to submit. ${ }^{23}$

As stated earlier, doves' personalities and operational codes differ not only from those of owls, but also from ravens' personalities and operational codes. The most important differences are doves' weak belief in their ability to shape events and historical development coupled with their belief that they are weaker than their opponents. ${ }^{24}$ I anticipate that these beliefs will lead doves to espouse foreign policy positions that epitomize the baseline tendencies of dovish decision maker types.

Because doves' exhibit a predilection for cooperative strategies, possess a weak belief in their ability to exert control over events and historical development, and see themselves as weaker than their opponents, TIP's logic predicts that doves possess the following ranking of preferences over outcomes: settlement over deadlock, deadlock over submitting, and submitting

\footnotetext{
${ }^{23}$ This hypothesis may ostensibly imply that ravens depart significantly from the central tendencies I argue characterize all three dovish decision makers. Most significantly, it may appear that ravens are somewhat more conflict-oriented and less cooperative and accommodating than the baseline behavioral tendencies of dovish decision makers would predict. That interpretation would be incorrect. I hold that all three dovish decision maker types share the same baseline tendencies. To the extent that ravens' foreign policy positions favor conflictual action this reflects not only ravens' preferences over outcomes, but also ravens' perceptions of opponents' preferences. Ravens' characteristics lead them to expect peaceful settlements via mutual accommodation. In the event that such settlements are unobtainable, however, ravens believe that conflictual means may be necessary in order to avoid negative outcomes such as submitting to opponents. This does not mean that ravens are quick to conflict. The reverse is true - ravens seek cooperation and accommodation first. It does mean, though, that ravens will (reluctantly) advocate conflict if they deem it necessary.

${ }^{24}$ At the level of operational codes, these beliefs are, respectively, P-4 and P-4a.
} 
over domination. This preference ranking, which in my typology is unique to this decision maker type, denotes doves as appeasers (see Marfleet and Walker 2006: 57). Doves' beliefs about their opponents' preferences also distinguish them from other dovish decision makers. Parallel to doves' P-4a belief is their P-4b belief that opponents see themselves as more powerful than the doves' side. Given that doves believe opponents prefer cooperative strategies and perceive themselves as superior in strength, doves see adversaries as preferring settlement to domination, domination to deadlock, and deadlock to submission. Consequently, doves believe their adversaries are cooperative but exploitative opponents who aim to get the most favorable outcome in their dealings with the doves' side (see Marfleet and Walker 2006: 57). I anticipate doves' preferences and view of their opponents' preferences, when co-mingled with the central tendencies shared by all dovish decision maker types, will present in doves' behavior. ${ }^{25}$ Namely, I propose that doves will support foreign policy aimed at obtaining settlement with opponents, specifically settlement based on mutual accommodation including concessions from the doves' side. Given doves' personalities, operational code beliefs, and the errors and biases likely to affect their judgment, I expect doves believe such policy will achieve settlement. If this policy does not yield a settlement, though, I posit that doves, like ravens, will back deadlocking with adversaries. Should deadlocking also fail, however, I propose that doves will support appeasement via submitting to opponents' demands rather than attempting to dominate. Doves are unlikely to attempt to dominate adversaries because doves believe themselves to be weaker than their opponents. These propositions give rise to my seventeenth and final hypothesis: doves will initially advocate pursuing settlements through mutual

\footnotetext{
${ }^{25}$ Recall that I treat doves' preferences and perceptions of opponents' preferences as assumptions about doves' characteristics and do not attempt to directly test these assumptions against empirical evidence. I instead test these assumptions indirectly via "observable implications" (King, Keohane, and Verba 1994: 28-29) of these preferences and perceptions. The observable implications are, specifically, doves' foreign policy positions.
} 
Table 4: Hypotheses

1. Owls and warhawks alone clearly overestimate their capabilities and the importance of their own actions. Warhawks and owls also most apparently exhibit unrealistic optimism.

2. Owls, ravens, and doves underestimate the level of conflict between their side and their opponent or opponents.

3. Owls, ravens, and doves will overestimate hawkish-dovish divisions in their opponents.

4. Owls, ravens, and doves will exaggerate opponents' propensity for compromise.

5. Owls, ravens, and doves will overestimate the extent to which non-hawkish elements in their opponents share their own desire for compromise solutions.

6. Owls, ravens, and doves will overestimate the value of the concessions they offer to opponents.

7. Warhawks, hawks, and chickenhawks will commit the fundamental attribution error in their assessment of opponents' actions.

8. Compared to dovish decision maker types, warhawks, hawks, and chickenhawks will exhibit greater concession aversion and will be more risk seeking in efforts to avoid making concessions or otherwise suffering certain losses.

9. Owls, while exhibiting less concession aversion and risk seeking to avoid certain losses than hawkish decision makers, will be more concession averse and risk acceptant to escape certain losses than ravens or doves.

10. Warhawks, hawks, and chickenhawks will be prone to the pseudo-certainty bias and thus highly averse to granting strategically valuable concessions to adversaries.

11. Warhawks, hawks, and chickenhawks will be susceptible to the reactive devaluation bias.

12. Warhawks' foreign policy positions will be characterized by advocacy for making expansionist demands, aggressively initiating conflict, and refusal to moderate demands.

13. Hawks will compel or punish adversaries and will seek settlement only if domination fails. If settlement is also unobtainable, hawks will deadlock with adversaries rather than submit.

14. Chickenhawks will take foreign policy positions advocating threats or demands against opponents, but failing domination will support backing down and seeking settlement at the price of concessions or other losses in order to avoid being forced to submit to adversaries.

15. Owls' foreign policy positions will be typified by an initial advocacy for seeking favorable outcomes through mutual accommodation. If mutual accommodation fails to achieve favorable outcomes, owls will advocate conflictual foreign policies to dominate their opponents in order to avoid deadlock with or submission to their opponents.

16. Ravens will initially advocate seeking settlements via mutual accommodation. If settlements fail to materialize, ravens will advocate deadlock with opponents and keep open the option to seek domination of opponents so as not to risk being forced to submit.

17. Doves will initially advocate pursuing settlements through mutual accommodation. If settlements are elusive, doves will support deadlocking with adversaries but prepare to appease and submit in the event that a deadlock is untenable.

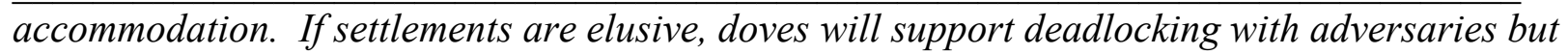

prepare to appease and submit in the event that a deadlock is untenable. ${ }^{26}$

\footnotetext{
${ }^{26}$ This hypothesis may seem to suggest that doves also deviate, albeit slightly, from the baseline tendencies I claim typify all three dovish decision makers. Of greatest importance, it may appear that doves, though the least conflictoriented of the six decision maker types, are still somewhat less cooperative and accommodating and more conflictual than would be expected given the central behavioral tendencies of dovish decision makers. Such a
} 


\section{Conclusion}

This chapter has presented a complex theoretical framework for categorizing foreign policy decision makers according to a six-fold typology of hawkish and dovish decision makers. Each decision maker type - warhawk, hawk, chickenhawk, owl, raven, and dove - is classified according to its characteristic personality traits, operational code beliefs, susceptibility to cognitive errors and biases, preferences over outcomes, and perceptions of adversaries' preferences over outcomes. The theoretical framework has also given rise to seventeen hypotheses. Eleven of the hypotheses have linked each decision maker type's personality traits and operational code beliefs to susceptibilities to cognitive errors and biases. The remaining six hypotheses draw on the characteristics (including susceptibilities to cognitive errors and biases) of hawkish and dovish decision makers to predict the foreign policy positions warhawks, hawks, chickenhawks, owls, ravens, and doves are likely to espouse. In the following chapter I operationalize the variables presented here and introduce the research methods I will use to test the validity of my typology and specific hypotheses.

perspective would be misleading. To the degree that doves' foreign policy positions support conflictual deadlocking acts, this should reflect doves' desire to avoid being too greatly exploited by their opponents. It is important to note that doves seek accommodation first and shift to deadlock only if accommodation fails to produce settlements. Further, if deadlocking is also unsuccessful, doves return to accommodation in a big way by preparing to submit to adversaries through appeasement. 


\section{Chapter 2: Research Design}

The previous chapter introduced the theoretical framework that guides this study. Within that typological framework are numerous independent variables (i.e., personality traits and operational code beliefs), the values of which determine whether the elites analyzed in my research have a place within the typology. Additionally, I argue the independent variables will affect several intervening variables (e.g., cognitive errors and assumed preferences). The effects of the independent and intervening variables will, as I hypothesize, ultimately explain and predict the dependent variable: the foreign policy position of an individual who matches one of the six decision maker types in my framework.

The research design presented in this chapter lays out in detail how I empirically test my theoretical framework in terms of its ability to classify decision makers as well as explain and predict their decision making and foreign policy behavior. In order to assess the classificatory ability of my framework, I analyze the content of selected elites' speech acts in order to measure their operational code beliefs and personality traits. To judge my theoretical framework's explanatory and predictive power, I test the hypotheses stemming from the framework via qualitative analysis of classified elites' decision making and foreign policy positions.

In what follows, I describe this study's application of content analysis and Alexander George and Andrew Bennett's (2004) qualitative congruence method. In the course of describing the methods this study applies, I also discuss the specific operationalization and measurement schemes for the independent, intervening, and dependent variables that are the focus of my research. I then briefly introduce the case and elites selected for analysis and explain why they were chosen. Finally, I explain the data I use to perform my analyses of the selected elites. 


\section{Classifying Decision Making Elites Using Content Analysis}

To profile decision making elites and assess whether they can be placed within my typology, this study relies on automated (quantitative) content analysis using two content analysis schemes, one developed for Leadership Trait Analysis (LTA) and the other developed for Operational Code Analysis (OCA). While the two systems of content analysis are distinct, both are indirect, "at a distance" (Dyson and Parent 2017; Foster and Keller 2014; Hermann 1980a; 1999; 2003; Post 2003; Renshon 2009; Schafer 2000; Schafer and Walker 2006; Shannon and Keller 2007; Winter 1980) methods of assessing individuals' psychological characteristics. Before delving into the specific LTA and OCA content analysis schemes and how they are used in this study, it is important that I explain this study's reliance on at a distance assessment and automated, quantitative content analysis.

The at a distance methods of psychological assessment employed by LTA and OCA generally, and this study in particular, are indirect in that they entail analyzing individuals' past verbal behavior - "what leaders say and how they say it" (Schafer 2000: 512) - in order to measure psychological characteristics without the researcher directly interacting with the individuals under study. This indirect assessment is made possible by "[psychological] constructs that let us theoretically connect the verbal behavior with psychological characteristics" (Schafer and Walker 2006: 26; see also e.g., Dille and Young 2000). For instance, elites who generally use high complexity words such as possibility and approximately are likely higher in conceptual complexity than elites who typically use low complexity words like certainly and absolutely (Hermann 1999: 22; 2003: 196). LTA, OCA, and the present study rely on at a distance methods because directly accessing decision making elites for the purpose of psychological evaluation is seldom, if ever, an option (Hermann 1999; 2003; Schafer 2000; Schafer and Walker 2006). 
The at a distance methods utilized in both the LTA and OCA research programs now commonly employ automated content analysis of decision making elites' speech acts (e.g., Foster and Keller 2014; Lazarevska, Sholl, and Young 2006; Renshon 2009; Shannon and Keller 2007). Likewise, this study depends upon automated content analysis of selected elites' verbal behavior. Notably, however, automated content analysis has certainly not always been used. And while LTA has since its early days (Hermann 1980a) typically relied upon quantitative content analysis, the content analysis characteristic of early OCA research was neither automated nor quantitative. Instead, OCA's early works used laborious and time consuming qualitative content analysis (Holsti 1970; Leites 1951; 1953; Walker 1977; Young and Schafer 1998). Even some more recent OCA work, though quantitative, continues to employ manual content analysis (e.g., Crichlow 2006; Walker, Schafer, and Young 1999).

Compared to automated and manual quantitative content analysis, qualitative content analysis has the advantage of better capturing the potentially important psychological idiosyncrasies of individual decision making elites (Schafer and Walker 2006: 26). However, the richness of qualitative content analysis comes at a steep price. Michael D. Young and Mark Schafer (1998: 71-72) describe the various costs of qualitative content analysis. First, such analysis is inherently labor intensive and time consuming, which limits the number of decision making elites who can be analyzed. Moreover, the subjectivity of qualitative content analysis renders its reliability difficult to assess and replication of such analyses practically impossible. Compounding on these problems, the ability of qualitative content analysis to capture individuals' idiosyncrasies, while in some ways a virtue, is a vice in that it makes cross-case comparison problematic. Young and Schafer note past efforts to mitigate some of these costs through the use of coding manuals (Holsti 1977) and inventories (Walker and Falkowski 1984), 
but argue that such efforts failed to alleviate the shortcomings of qualitative analysis, especially the problems stemming from its subjective nature.

Quantitative content analysis sacrifices much of the potentially important richness and idiosyncrasy-illuminating ability of qualitative content analysis, but achieves gains in objectivity, reliability, and replicability while simultaneously reducing the time and labor inputs required (Schafer and Walker 2006: 26-27; Young and Schafer 1998: 72). The upshot is that research using quantitative content analysis can examine more decision making elites and systematically compare them thereby producing the generalizable findings and cumulative knowledge that mark a successful research program (Schafer and Walker 2006: 27). Largely for these reasons, I opt for quantitative content analysis in this study. ${ }^{1}$

The decision to depend on quantitative content analysis requires a further choice between manual and automated methods of coding speech acts. Manual coding has the inherent benefit of keeping human discretion in the analysis process. Human discretion can prevent coding errors that automated methods may make. For example, with the ProfilerPlus automated content analysis software commonly used in OCA and LTA research, if in a speech Jimmy Carter said, “The U.S. strongly opposes,” instead of saying, "We strongly oppose," ProfilerPlus would incorrectly code Carter as having referred to a foreign entity's action instead of the United States' action (Schafer and Walker 2006: 42). Yet with some modifications made by the researcher, ProfilerPlus can be programmed to avoid this type of error (Schafer and Walker 2006: 42). Thus while manual quantitative content analysis would seem to have an important advantage over its automated cousin, small adjustments can do much to erode that advantage. Still, as Mark Schafer and Stephen G. Walker (2006: 39) point out, automated content analysis

\footnotetext{
${ }^{1}$ As I explain below, I use quantitative content analysis also due to practical considerations of data availability.
} 
tools like ProfilerPlus are "limited by the number of verbs and rules in the coding system and cannot subjectively interpret obscure phrases."

Despite the advantages of manual coding, I rely on ProfilerPlus's automated content analysis system largely because, as Schafer and Walker (2006: 38-39) argue, it possesses some crucial strengths that manual quantitative coding cannot claim. ${ }^{2}$ The first of these strengths is the removal of human mistakes (e.g., errors made due to coder fatigue) and biases (e.g., flawed coding stemming from political biases) from the content analysis process. This does not mean that automated content analysis is error free. As I have noted, automated coding tools can make mistakes. The important difference is that, to the extent automated coding produces mistakes, the automated content analysis tool is uniform in the mistakes it makes thus resulting in a low risk of biasing the data. The mistakes made by human coders, in contrast, are likely to be of the sort that produce biased data. The second strength, related to the first, is that automated content analysis produces coding that is 100 percent reliable; the automated content analysis software codes each and every speech act the same way. ${ }^{3}$ Beyond these advantages, automated content analysis has the added bonus of being quicker and less labor-intensive than manual content analysis. Also, unlike manual coding which requires a minimum of two coders to ensure reliability in the content analysis, automated content analysis is naturally 100 percent reliable and can be performed by a lone researcher. In sum, automated content analysis, while imperfect, is the most appropriate tool for conducting this study's at a distance assessment of selected decision making elites.

The LTA Content Analysis Scheme

\footnotetext{
${ }^{2}$ Again, as I discuss later I use quantitative content analysis also because of data availability considerations.

${ }^{3}$ By comparison, manual coding is prone to problems of imperfect inter-coder reliability, and inter-coder reliability of around 90 percent is considered acceptable for manual content analysis (see for example Crichlow 2006; Hermann 1999: 39; 2003: 210; Walker, Schafer, and Young 1999: 614).
} 
To assess the leadership traits of each decision making elite this study examines I use data processed by the content analysis system laid out by Margaret Hermann (1980a; 1984; $1999 ; 2003)$. In this scheme, the focus is on elites' words and how they use them (typically) in spontaneous, unscripted speech. Most commonly, units of analysis are individual interview responses taken from entire verbatim media interviews given by a decision maker (Hermann 2003: 179). As I discuss in the subsequent section on data collection, my analysis will include not only data from spontaneous interview responses, but also data drawn from scripted speeches. Operationalizing and Measuring Leadership Traits

In the LTA content analysis scheme delineated by Margaret Hermann (1980a; 1984; 1999 ; 2003) each personality trait has a very specific operational definition and system of measurement. This study's operationalization and measurement of the six relevant personality traits follows Hermann's system. My application of this system will, of course, follow the particular procedures of the ProfilerPlus content analysis software, but the substantive operationalization and measurement of personality traits derives from Hermann's scheme. In the remainder of this section I describe how each personality trait is operationalized and measured according to Hermann's scheme. A more detailed treatment of operationalization and measurement is provided by Hermann $(1999 ; 2003)$.

This study operationalizes distrust of others as the proportion of instances in a speech act (interview response or speech) that a decision making elite displays distrust of others (Hermann 1999: 31). Coding of this trait focuses on the presence or absence of evident distrust (including e.g., uneasiness, wariness, or perceptions of harmful actions) in noun phrases and nouns referring to entities besides the elite and entities with which the elite identifies. For each decision making elite, the overall measure of distrust of others is the mean of the percentages from all of the 
elite's speeches and interview responses analyzed. To determine whether an elite is high or low in distrust of others, I compare the elite's overall measure to a norming group of 284 political leaders. ${ }^{4}$ According to this norming group, a score greater than 0.19 represents high distrust of others, while a score under 0.07 signals low distrust of others. Scores ranging from 0.07 to 0.19 represent more moderate levels of distrust.

Operationally, this study defines in-group bias as the proportion of instances in a speech act (interview response or speech) that an elite discusses in-groups in a way that is favorable, implies strength, or identifies maintaining the group's "honor and identity" as a necessity (Hermann 1999: 29). Ultimately, each decision making elite's measure of in-group bias is the mean of the proportions from every one of the elite's interview responses and speeches analyzed. Based on the norming group, a score of more than 0.20 is a marker of a strong in-group bias, with a score less than 0.10 indicating a weak in-group bias. Moderate in-group bias is marked by scores of 0.10 or higher, but not exceeding 0.20 .

In terms of operationalization, this study defines conceptual complexity as the proportion of words associated with high complexity and words associated with low complexity words in an elite's speech or interview response (Hermann 1980a: 21;1999: 22). Examples of high and low complexity words are possibly and definitely, respectively. An individual decision maker's general measure on this variable is the mean percentage from all of the selected interview responses and speeches for that elite. Again using the norming group, a high value is one greater than 0.65 , and a low score is anything under 053 . Moderate scores are those ranging from 0.53 to 0.65 .

I operationalize a decision making elite's belief in their ability to control events as the proportion of instances in which the verbs in a speech act (interview response or speech) show

\footnotetext{
${ }^{4}$ The norming group data is available from Michael Young of Social Science Automation.
} 
the elite or an entity with which the elite identifies acknowledging initiating action or planning to act (Hermann 1999: 14). The overall measure of an elite's belief in their ability to control events is the mean percentage for all of the elite's speeches and interview responses examined. Scores from the norming group indicate that a high value for this variable is anything above 0.40 , while a low value is one under 0.30 . A moderate value for this variable is anything within one standard deviation of 0.35 (i.e., any value from 0.30 to 0.40 ).

This study operationalizes need for power as the proportion of instances in which the verbs in a speech act (interview response or speech) show the elite or an entity with which they identify acting (or having acted) to restore, establish, or maintain the power of the elite or the entity with which they identify (Hermann 1999: 15). The total measure of an elite's need for power is the mean percentage of all the selected verbal behavior for that decision maker. The norming group indicates that values over 0.31 signal a high need for power, with scores under 0.21 representing a low need for power. Moderate need for power is marked by values of 0.21 to 0.31 .

The final trait, task focus, is operationalized by this study as the proportion "of taskoriented words relative to the total number of task and group-maintenance words" present in a speech or interview response (Hermann 1999: 26). For each decision making elite, the overall measure of task focus is the mean of the percentages from all of the elite's analyzed speeches and interview responses. According to the norming group, decision makers with scores over 0.70 have a high task focus, while decision makers whose scores are under 0.56 have a low task focus. Decision makers with a moderate task focus are those within one standard deviation from 0.63 (i.e., decision makers with a score ranging from 0.56 to 0.70 ). 
Using Hermann's operational definitions in conjunction with data processed through ProfilerPlus content analysis software, I assess the decision making elites this study examines. The norming group further permits me to determine whether a given decision maker is high, low, or moderate on a given trait and facilitates making comparisons across decision makers. All of this allows me to determine the extent to which real world decision making elites may be classified by my six-fold typology.

The OCA Content Analysis Scheme

To assess the operational codes of the decision making elites this study examines, I rely on the content analysis system developed for the OCA research program by Walker, Schafer, and Young (1998). The scheme is referred to as the Verbs In Context System (VICS). As Schafer and Walker (2006: 30-31), two founders of VICS, explain, the scheme codes transitive verbs in individuals' references to self and others by focusing on the verbs' "direction" (cooperative or conflictual) and "intensity" (e.g., words or actions). ${ }^{5}$ The result of this content analysis, as Schafer and Walker (2006: 31) further explain, is "a broad picture of the way the actor sees the exercise of power in the political universe by self and others."

Operationalizing and Measuring Operational Codes

The VICS content analysis scheme laid out by Schafer, Walker, and Young (Schafer and Walker 2006: 30-42; Walker, Schafer, and Young 1998) provides a precise operational definition and system of measurement for each cognitive belief comprising a decision maker's operational code. My operationalization and measurement of the three beliefs pertinent to this study adheres to VICS. My employment of this scheme depends on the specific procedures of ProfilerPlus, of course, but the operationalization and measurement of elites' cognitive beliefs derives its

\footnotetext{
${ }^{5}$ In VICS the "recording unit" is an individual utterance (Schafer and Walker 2006: 32). Recording units are not equivalent to units of analysis, but should instead be thought of as data points to be aggregated into units of analysis (Schafer and Walker 2006: 43).
} 
substance from VICS. In what follows, I delineate the operationalization and measurement of each belief according to VICS. A more in-depth discussion of operationalization and measurement can be found in Schafer and Walker (2006: 30-42).

I operationalize philosophical belief P-1, a decision making elite's beliefs about the basic nature of politics and political opponents, as "the percentage of positive utterances about others [in the political universe] minus the percentage of negative utterances about others" (Schafer and Walker 2006: 33). The measure of this variable ranges from +1 to -1 , with high scores signaling an elite's general belief that others are friendly and low scores signaling a decision maker's general belief that others are hostile. This operationalization and system of measurement rests on the assumption that a decision making elite's perceptions about others' actions are broadly of representative of the elite's beliefs about the fundamental nature of politics and political opponents (Schafer and Walker 2006: 33).

To determine the extent to which a decision maker believes politics and political opponents are hostile or friendly, I compare the elite's overall measure to a norming group of 168 elites from various times and places. ${ }^{6}$ The mean P-1 score for elites in the norming group is 0.273 with a standard deviation of 0.280 . This study treats any decision making elite with an overall P-1 score at or exceeding 0.553 as having a high score and friendly view of the political world and the other actors who occupy it. In contrast, this study deems a decision maker with an overall P-1 score of -0.007 or lower to have a low score and hostile perception of politics and political opponents. I consider decision makers with overall P-1 scores within one standard deviation above or below 0.273 to have a moderate score and mixed perceptions of the political world and other political actors.

\footnotetext{
${ }^{6}$ The norming group data is available from Mark Schafer of the University of Central Florida's Political Science Department.
} 
This study operationalizes philosophical belief P-4a, a decision makers' belief in their ability to control historical development, as the ratio of actions they attribute to themselves to the actions they ascribe to other actors. This ratio is calculated by dividing all of the actions decision makers attribute to themselves by the total of actions they attribute to themselves and other actors. This variable's measure ranges from 0 to 1 , with higher scores representing a greater belief in one's ability to control historical development. I in turn operationalize philosophical belief P-4b, a decision making elites' beliefs regarding other actors' ability to control historical development, as the ratio of actions they ascribe to other actors to the actions they ascribe to themselves. I calculate this ratio by dividing all of the actions elites ascribe to other actors by the total of actions they attribute to themselves and other actors. The measure of this variable also ranges from 0 to 1 , with higher scores representing a greater belief in others' ability to control historical development. Underlying the operationalization and measurement of these variables is the assumption that when elites' verbal behavior signals that they perceive themselves as taking more (less) action relative to other actors, they believe their ability to control historical development is greater (less) than that of other actors (Schafer and Walker 2006: 34, 51).

In order to ascertain the strength of a decision maker's belief in their ability to control historical development, I compare the elite's overall P-4a score against the norming group. ${ }^{7}$ In the norming group, the mean P-4a score for elites is 0.207 with a standard deviation of 0.114 . This study classifies any decision making elite having an overall P-4a score equal to or greater than 0.321 as having a high score and thus a strong belief in their ability to control historical

\footnotetext{
${ }^{7}$ I do not compare overall P-4b scores to the norming group because P-4b is the opposite of P-4a, meaning that "when P-4a is more than one standard deviation from norming group's mean, $\mathrm{P}-4 \mathrm{~b}$ is more than one standard deviation from the mean in the opposite direction and falls within one standard deviation when P-4a is also within one standard deviation" (Malici and Buckner 2008: 790). In short, because P-4b is the mirror image of P-4a, it is not necessary to compare both scores to the norming group in order to determine a decision maker's belief in their ability to control events.
} 
development. Conversely, I treat any decision maker possessing an overall P-4a score of 0.093 or less to have a low score and to believe they have relatively little control over historical development. This study treats decision makers with overall P-4a scores within one standard deviation of 0.207 as having moderate scores and perceiving their ability to control historical development as relatively equivalent to other political actors (see Malici and Buckner 2008: 791).

Operationally, this study defines instrumental belief I-1, decision making elites' belief about optimal strategies for political action, as the balance of their conflictual and cooperative references to themselves or their in-groups. This is calculated by taking "the percentage of cooperative $(+)$ utterances [elites make] when talking about [themselves or their in-groups] minus the percentage of conflictual (-) utterances regarding [themselves or their in-groups]" (Schafer and Walker 2006: 35). The measure of this variable ranges between -1 and +1 , with higher scores denoting a greater sense that cooperative strategies are more efficacious and lower scores signaling a belief that conflictual strategies are more effective (Schafer and Walker 2006: $35)$.

To establish whether a decision maker favors cooperative or conflictual strategies, I once more compare the elite's overall measure to the norming group of 168 elites. The mean I-1 score for elites is 0.346 with a standard deviation of 0.336 . This study treats any decision making elite with an overall I-1 score at or exceeding 0.682 as having a high score and favoring cooperative strategies. In contrast, this study deems a decision maker with an overall I-1 score of 0.010 or lower to have a low score and view conflictual strategies as more efficacious. I consider decision makers with overall I-1 scores within one standard deviation above or below 0.346 to have a moderate score and mixed views regarding what strategies best serve. 
Employing these operational definitions and data processed with ProfilerPlus, I profile the decision makers under study here. For each operational code belief, I compare selected decision makers' mean scores to the norming group, permitting me to determine whether a given decision maker is high, low, or moderate for each belief and allowing comparison of decision makers. In doing so, I will be able to further determine whether the selected elites fit within my typology.

\section{Connecting Content Analysis to Classification}

Quantitative values on the belief and personality trait variables operationalized above are essential to comparing the studied elites to the types in my six-fold classificatory framework. The decision makers selected for this analysis may not fit any of the types. For any that do, however, their personality traits and beliefs, plus associated assumptions about their preferences and beliefs about their opponent's preferences, will allow me to test hypotheses about those elites. ${ }^{8}$ Those hypotheses, which center on cognitive error and bias susceptibilities and foreign policy positions, are tested qualitatively. The next section details the qualitative analysis I employ.

\section{Qualitative Analysis of Decision Making and Behavior}

\section{The Congruence Method}

My classification of elites based on their belief and personality trait variables benefits from long-established and specific guidelines for measurement and analysis of those variables. The qualitative analysis needed to test my framework's hypothesized relationships among independent, intervening, and dependent variables, and thereby the explanatory and predictive ability of the framework, can draw on nothing like so specific a set of guidelines. Indeed

\footnotetext{
${ }^{8}$ Assumptions about each decision maker type's preferences and their beliefs about opponent's preferences are discussed in Chapter 1 and briefly revisited in the next section of this chapter.
} 
analysis of the relationships between independent and intervening variables as well as their effects on the dependent variable (an elite's foreign policy position) is fraught with methodological challenges.

One challenge is that theories of errors and biases associated with hawkishness have been established and tested in experiments where the variables are controlled and the measurement of their effects (e.g., the percentage of participants who select a particular response option from a defined list) is relatively straightforward (see Kahneman and Renshon 2009; Renshon and Kahneman 2017). ${ }^{9}$ In the 'real world' environment of foreign policy making analyzing cognitive errors and biases and their effects on elites' behavior is far from straightforward. Recall Jervis's (1976: 7) argument that in the study of international politics "there is no easy way to determine the accuracy of perceptions." In other words, identifying an elite's biases or errors is difficult because we do not truly know whether or to what extent their cognitive processes lead them to view information imperfectly. How is a researcher to know the elites they study are viewing the world through distorted lenses? Moreover, Kahneman and Renshon (2009: 92; Renshon and Kahneman 2017) argue that it is "impossible" and "unreasonable" to explain and predict foreign policy decision making and behavior via cognitive errors and biases. They are particularly skeptical of post hoc analyses that identify the work of errors and biases with the aid of hindsight. Given that cognitive errors and biases are central to eleven of the seventeen hypotheses in my theoretical framework, the challenge of analyzing these variables and assessing their effects is quite serious.

Similarly an elite's preference ranking of foreign policy outcomes and their belief about their opponent's own preference ranking are variables that bring analytical challenges. As the

\footnotetext{
${ }^{9}$ Except to the extent that dovish decision makers' hypothesized tendency to overestimate an opponent's internal disagreement can be seen as unrealistic optimism, dovish errors have only been posited by Snyder and Diesing (1977: 302-304). No theories of those errors have been established or tested.
} 
“Theory of Inferences about Preferences (TIP)" (Marfleet and Walker 2006; Walker 2004) makes clear, these preference rankings derived from operational code beliefs are inferred, not measured as are the beliefs underlying them. In this study, as noted in the previous chapter, I assume a decision maker matched to one of the types in my classification will possess their type's preference ranking and belief about their opponent's preferences, but neither is something that can or will be directly observed or assessed.

Likewise, my hypotheses linking beliefs and personality traits to cognitive error and bias susceptibility and foreign policy positions rest on inferred causal relationships. Such relationships cannot be directly observed. In sum, the causal relationships proposed by my theoretical framework can be studied only indirectly.

The analytical difficulties presented by my framework's variables and their hypothesized causal relationships are serious, but they are not insurmountable. For starters, the theoretical underpinnings of my variables and hypotheses suggest what Gary King, Robert Keohane, and Sidney Verba (1994: 28-29) label "observable implications". That is, when the effects of variables manifest in the information processing or foreign policy behavior of a decision maker observable data is generated. One might not be able to get inside the head of the individual, but what that individual says or does, when observed through the lens of theory, will provide evidence of a variable's effect and permit hypothesis testing.

The observable implications of the variables and their proposed relationships permit me to conduct my qualitative analysis using the "congruence method" as laid out by Alexander George and Andrew Bennett (2004: 181-192). This elegantly simple method tests hypotheses by assessing whether the outcome - the observable implication - on an intervening or dependent variable is predicted or explained by the value of one or more independent variables. In this 
study, of course, I must also assess whether the outcome on the dependent variable is consistent with the outcome on intervening variables. My decision to employ the congruence method rests not only on the method's simplicity, but also on another of the method's key qualities.

Specifically, as George and Bennett (2004: 182) argue, hypothesis testing via congruence does not require empirical analysis of the actual causal relationship between variables. This quality is particularly valuable due to my inability to trace the processes of the causal relationship between variables in my framework.

The Problem of Post Hoc Analysis

While the congruence method addresses one set of problems besetting my analysis, it does not in itself address Kahneman and Renshon's (2009: 92-93; Renshon and Kahneman 2017) criticism of post hoc analyses, the results of which the authors see as "at best tentative and incomplete." What separates my analysis from the post hoc analyses that inspire skepticism in Kahneman and Renshon, though, is that my theoretical framework predicts outcomes on intervening and dependent variables via values on independent variables. This allows evidence of the causal relationships hypothesized by my framework to be regarded with much greater confidence.

$\underline{\text { Operationalization of Intervening and Dependent Variables }}$

The challenges facing the qualitative component of my analysis include the very operationalization of the intervening and dependent variables. Whereas the independent variables are operationalized quantitatively and measured via an automated system that rules out subjectivity on the part of the researcher, the intervening and dependent variables are not as stark in either operational definition or measurement. Still, as the following shows, the intervening 
and dependent variables to be analyzed are operationalized and measured according to explicit standards.

Intervening Variables: Preferences and Beliefs about Opponent's Preferences

As noted previously, this pair of mirror image variables are assumed to be operative in decision makers who match to one of the types in my classificatory scheme. Neither variable is operationalized or directly analyzed in this study. Their hypothesized impact on elites' behavior will be observable, and indirectly so, only in terms of decision makers' foreign policy positions. Aspects of individuals' foreign policy positions are the observable implication of these variables' proposed effect.

Intervening Variables: Cognitive Errors and Biases

To assess decision makers' cognitive errors and biases I focus on what the elites say during the decision making process. Specifically, I examine verbal behavior outside of public speeches and interviews. As much as is possible I want to study what they say in private, what they say in discussions of incoming information and policy. The reason for examining what is said out of the public eye is that the public speech data, whether scripted or spontaneous, used to measure beliefs and personality traits should not also be used to measure the errors and biases those beliefs and personality traits are hypothesized to explain and predict. To do so would make the relationships among the variables impossible to disentangle.

My assessment of studied elites' verbal behavior will weigh what is said against the information that was apparently available to the decision makers. While, as Jervis (1976: 7) argues, measuring the inaccuracy of perceptions is difficult, analyzing the perceptions decision makers express in light of the information to which they are exposed will provide insight into the biases and errors that impinge on the elites' cognition. The insight achieved will be necessarily 
limited, but will still offer value in terms of understanding decision makers' information processing.

In the remainder of this section I operationalize the cognitive error and bias variables analyzed in this work. For clarity of organization I begin with the errors and biases Kahneman and Renshon (2009; Renshon and Kahneman 2017) associate with hawkishness. ${ }^{10}$ Then, I operationally define the errors and biases Snyder and Diesing (1977) attribute to doves. It bears noting that the set of hawkish errors and biases has been better defined and far more thoroughly studied than the set tied to dovish decision makers.

As discussed in the previous chapter, positive illusions take three forms. Each requires its own operational definition. The first is an individual's exaggeratedly favorable view of their own character and capabilities (Kahneman and Renshon 2009: 81; Renshon and Kahneman 2017: 59-61). Here the focus is on capabilities. I operationalize this particular manifestation of positive illusions as a decision maker's expressions of positive views of their abilities that downplay or dismiss received information challenging their verbalized sanguine perceptions. The second positive illusion is "illusion of control" (Kahneman and Renshon 2009: 81; Renshon and Kahneman 2017: 59-61), an overestimation of one actions' importance in determining outcomes. This positive illusion is operationalized as an elite's verbal behavior highlighting the importance of their (or their side's) actions in determining a foreign policy outcome, while minimizing or rejecting received evidence suggesting one or more foreign actors' actions will be significantly influential. Third is "unrealistic optimism" (Kahneman and Renshon 2009: 81-82; Renshon and Kahneman 2017: 59-61). I define this illusion operationally as an individual's

\footnotetext{
${ }^{10}$ Note that in my theoretical framework some purportedly hawkish errors and biases are hypothesized to influence dovish elites. Specifically, owls are thought to share warhawks' susceptibility to positive illusions. Maintaining distinctions between hawkish and dovish errors and biases here is simply an organizational choice.
} 
optimistic statements about likely foreign policy outcomes that disregard or downplay received information of a cautionary or pessimistic nature.

As described in the preceding chapter, the fundamental attribution error may manifest in two ways and the variable's operationalization reflects that. On the one hand, an elite exhibiting this error will state views of an adversary's undesirable actions that attribute the actions to the adversary's disposition and reject or talk down evidence that the adversary's actions were influenced by situational factors. On the other hand, a decision maker subject to this error will express perceptions of an adversary's desirable actions that attribute the actions to situational factors while minimizing or being dismissive of information suggesting those actions are attributable to the adversary's disposition.

The next bias, reactive devaluation, is a particularly tricky variable. Recall that this bias leads a decision maker to undervalue their opponent's proposals merely because the adversary makes the proposal (Kahneman and Renshon 2009: 92; Maoz, Ward, Katz, and Ross 2002; Renshon and Kahneman 2017; Ross 1995; Stillinger and Ross 1990). One can only glimpse this bias in the 'real world' when a proposal made by an opponent is greeted with skepticism or suspicion by a decision maker who reacts more favorably to the same proposal when it is suggested by a positively regarded third party. Consequently, I define reactive devaluation operationally as an elite's negative reception of an adversary's proposal when the same or equivalent proposal made by a non-opponent third party is favorably received.

The operational definition of the pseudo-certainty bias is a decision maker's expression of opposition to granting an opponent a present concession based on the view that what is ceded to the opponent will be used against the decision maker's side in the event of a future conflict. To be considered evidence that this bias is operative, the statement of such opposition needs to 
coincide with the elite's rejection or minimization of available arguments or evidence to the effect that the concession would reduce the likelihood of future conflict. Both elements are essential to the operationalization of this variable.

Another bias pertaining to concessions is concession aversion. I operationalize this variable as an elite's verbalized emphasis on losses coincident with dismissal or discounting of gains when rationalizing opposition to granting a concession. Of course, the gains really may be outweighed by the losses entailed in concession. Such a judgment is not the concern of this study. The not inconsiderable task of my analysis is to tease out decision makers' weighting of gains and losses in order to assess whether concession aversion is likely playing a role in the calculations.

The final bias tied to hawkishness is risk seeking in losses. Due to the various forms situations of actual or potential loss can take, the operational definition of this variable is situation-dependent. To begin, the arguments of Jervis (1992: 192-193) and Jack Levy (2000: 200-210; 2003: 270-271) suggest that this bias can manifest as an individual expressing greater concern with preserving their side's reputation or position than improving the status of either. In the speech of an elite susceptible to this bias I expect to see preservation highlighted in foreign policy areas where the status quo is challenged, while foreign policy areas where opportunities for improvement are evident will be given less attention. Admittedly, this particular definition is fuzzy and requires careful assessment of nuance in order to avoid falsely claiming the bias is active.

In situations of actual violent conflict the operational definition of risk seeking in losses is clearer. Under such circumstances the bias can be operationalized as a decision maker arguing for continued conflict on the grounds that the costs and losses already incurred must not be in 
vain (see Levy 2000: 204). When an elite is on the losing side of an ongoing conflict the variable is defined as the individual advocating fighting on in the (perhaps slim) hope of resurrecting their side's fortunes rather than accepting a certain loss by conceding defeat (see Kahneman and Renshon 2009: 89-90; Renshon and Kahneman 2017). If a decision maker's side has been defeated, the operationalization of this bias is statements by the elite rejecting the postdefeat status quo and advocating renewed conflict to restore their side's pre-defeat status (see Jervis 1992: 196; Levy 2000: 206-213).

I now turn to the operationalization of errors Snyder and Diesing (1977: 302-304) associate with dovish elites. The first of the five, underestimating the level of conflict, is defined as an elite's positive assessment of the level of conflict between their side and their opponent while downplaying or disregarding available information suggesting a greater level of conflict than the decision maker acknowledges. I operationalize the next error, overestimating the opponent's propensity for compromise, as a decision maker's sanguine view of their opponent's desire for compromise coincident with minimization or dismissal of received evidence to the contrary. The operational definition of overestimating the opponent's internal disagreement, the third error, is an individual expressing a perception of significant conflict between an opponent's dovish and hawkish decision makers while rejecting or talking down data suggesting a greater level of internal agreement within the opponent's decision making apparatus. The fourth error, overestimating agreement with the opponent's dovish elements, is operationalized as an elite claiming agreement with an opponent's dovish decision makers but downplaying or dismissing information indicative of disagreement. Overestimating the value of their side's concessions, the final error, is defined as a decision maker emphasizing the worth of their side's concessions to an 
opponent while disregarding or making light of evidence that the opponent places less value on the concessions.

\section{The Dependent Variable: Foreign Policy Positions}

As is the case for the analysis of cognitive errors and biases, my examination of selected decision makers focuses on what the elites say in private during the decision making process. Again, the justification for studying only what is said privately is that the public speech data analyzed to measure personality traits and beliefs ought not be used to measure the foreign policy positions I argue are explained and anticipated by those personality traits and beliefs.

The operational definition of foreign policy positions has two components. The first is the degree to which an elite does or does not advocate conflictual policy in the form of issuing demands, making threats, or actually using force. The second is the extent of a decision maker's support for, or opposition to, conciliatory policy. Such policy centers on offering concessions or granting concessions to meet an opponent's demands.

Of note, my hypotheses predict an elite's policy positions can change over the course of continued interactions with an opponent. Consequently, analysis of this variable must include evaluation at all points in a foreign policy event. To consider only the foreign policy position a decision maker espouses at one particular moment in time would permit only an incomplete assessment of this variable.

\section{Case Selection: The George W. Bush Administration and the Iraq Decision}

I have selected for analysis several top officials from the George W. Bush administration. Specifically, this study will analyze President George W. Bush, Vice President Richard "Dick" Cheney, National Security Advisor Condoleezza Rice, Secretary of State Colin Powell, Secretary of Defense Donald Rumsfeld, Deputy Secretary of State Richard Armitage, and Deputy 
Secretary of Defense Paul Wolfowitz. These elites were chosen for analysis not just because they occupied key positions within a foreign policy decision making apparatus. Indeed the primary reason for their selection is that observers ranging from academicians (e.g., Badie 2010; Robison 2006) to journalists (e.g., Bamford 2002; Gompert, Binnendijk, and Lin 2014; Harnden 2003; Left 2002) applied the hawk and dove labels to members of this decision making group. Cheney, Rumsfeld, and Wolfowitz typically receive the hawk label (see for examples, Binnendijk, and Lin 2014; Robison 2006), though Rice and Bush have also been termed hawks (Left 2002; see also Badie 2010: 286), while Powell and Armitage are generally painted with the dove brush (Harnden 2003; Robison 2006). The application of the terms hawk and dove to so many of the top officials in one decision making apparatus makes these elites an obvious choice as the testing ground for my theoretical framework and its more detailed and nuanced conceptualization of hawkish and dovish decision makers.

My choice of these elites is reinforced by the fact that their tenures in the positions they occupied during the period I study all began at nearly the same time. As a result, they existed within roughly the same informational environment as they developed their foreign policy positions. This is important for assessing and comparing how the decision makers processed and responded behaviorally to information.

The specific case within which I analyze these individuals is the US decision to invade Iraq. I choose this case not primarily because it ended in the initiation of a very conflictual foreign policy, namely war, but because it represents a discrete policy selection in which all the officials chosen for study played some part. As such, this case provides a clear end point for my assessment of the all the elites and their decision making. A less clearly defined foreign policy episode would impede my ability to ensure that I am analyzing all elites within the same 
information and policy environments, and in turn undermine my ability to assess the individuals on equal terms.

The importance of the invasion is, of course, also part of the reason I choose this case. The human, political, and economic ramifications of the invasion and subsequent conflict have been tremendous. A better understanding of how the invasion came about would be valuable, and I hope I can make my own small contribution to that better understanding.

\section{Data Collection for Quantitative and Qualitative Analyses}

In this section I explain my data collection procedures for my quantitative and qualitative analyses. Before delving into the details, though, recall that I explicitly avoid overlap in the verbal data used for the quantitative and qualitative components of my study. The reason for this is, as I explain above, that the data quantitatively analyzed to measure the Bush administration officials' beliefs and personality traits should not also be analyzed qualitatively to measure the errors, biases, and foreign policy positions those beliefs and personality traits are hypothesized to explain and predict. Allowing that overlap in the data would create an analytical muddle.

\section{Collecting Data for Quantitative Content Analysis}

The data used in my quantitative analysis are obtained from the studies of Shannon and Keller (2007) and Sam Robison (2006). Shannon and Keller's findings provide the data for LTA personality trait variables. The data for OCA belief variables come from Robison's findings. Robison and Shannon and Keller present the findings from their own quantitative analyses as standardized values. Consequently, I have had to reverse engineer the standardized values they report in order to generate the non-standardized data necessary for my own analysis of the selected decision makers' personalities and beliefs. My reverse engineering of Shannon and 
Keller's personality trait findings is detailed in Appendix A. Reverse engineering of Robison's operational code findings is explained in Appendix B.

Reliance on these scholars' works is necessitated by problems in collecting data from primary sources. Specifically, the United States Department of Defense Archives' (United States Department of Defense) holdings of speaking events for Secretary of Defense Donald Rumsfeld and Deputy Secretary of Defense Paul Wolfowitz are unavailable. This lack of similarly complete primary data sources for all selected Bush administration officials makes Robison (2006) and Shannon and Keller's (2007) data, which were collected when archival holdings for all seven officials were available, the best resources for meaningful analysis and comparison of the elites under study here. As I discuss below, while the data from Robison and Shannon and Keller are not ideal, the data do meet, respectively, OCA and LTA standards. The data also match quite well with the needs of the present study.

\section{LTA Data}

Data derived from Shannon and Keller's (2007) quantitative analysis are an overall excellent fit with my analytical goals. First, Shannon and Keller examine all of the Bush administration officials under examination in the present study, and their focus, too, is on the US decision to invade Iraq. Second, the authors analyze all of the personality traits included as independent variables in my theoretical framework. Third, as I briefly explain below, their data collection procedures meet the standards of the LTA research program. Finally, and also detailed below, Shannon and Keller collect and analyze data from spontaneous and scripted speech acts. Their analysis of data from both types of speech departs from LTA research standards, but is an analytical approach I also adopt. 
Shannon and Keller's (2007: 92) data collection largely follows the standards set by Hermann (2003: 178-181). They have collected spontaneous verbal material from the selected decision makers' responses to questions asked in press conferences and interviews. All collected responses are 100 words long or longer. For each of the Bush administration officials Shannon and Keller collected a minimum of 180 such responses, far exceeding the 50 response minimum stipulated by Hermann. The verbal material for each official covers the beginning of 2001 to 2004, thus following the standard of gathering data from the beginning of a decision maker's time in their official position through the entire period under study. ${ }^{11}$

Shannon and Keller (2007: 92) do in one respect deviate from standard LTA practice in that they also collect and analyze verbal material from scripted speeches the Bush administration decision makers' made between January 2001 and the end of 2004. According to the standards Hermann $(1980 \mathrm{a} ; 1984 ; 1999 ; 2003)$ provides, media interviews are the data source of choice for LTA research because they are likely more spontaneous than speeches, which may obscure an individual's personality traits for two reasons. One reason is that speeches are often carefully tailored in terms of what the decision maker says and how they say it, therefore perhaps limiting the extent to which the decision maker's speech acts faithfully reflect their personality. ${ }^{12}$ The other, more serious issue is that a decision maker's speeches are typically written by someone other than the decision maker, with an attendant danger that their utterances are not conveying their own personality traits. ${ }^{13}$ Relatively spontaneous utterances made by an elite in the course

\footnotetext{
${ }^{11}$ The start date for collection is determined by Hermann's (2003: 180) admonition to analyze data from an individual's entire tenure in office in order to avoid variable values that are context-specific.

${ }^{12}$ Hermann (1980a: 14; see also Hermann 1980b) refers to this as the "planned communication" effect. Elsewhere this effect has been labeled "impression management" (Schafer 2000: 514; Tetlock and Manstead 1985).

${ }^{13}$ This has been referred to as the "ghost writing" effect (Hermann 1980a: 14; see also Hermann 1980b) or "ghostwriter effect" (Dille 2000: 579).
} 
of a public interview are thus considered by Hermann more likely to actually reveal the elite's personality traits.

Despite these reasons to focus only on spontaneous verbal behavior in media interviews, there are grounds for including speeches in this study's analysis. For one, David Winter (2003: 174) notes that even though elites' speeches are likely drafted by a speechwriter, elites select their speechwriters and not infrequently provide input to the speechwriters. Winter (2003: 174) also points out that speechwriters "know how to craft words, phrases, and images to fit the style and personalities of their clients." Moreover, as Winter argues, even the relatively spontaneous verbal behavior presumed to be exhibited in media interviews may in fact be carefully planned or perhaps even scripted. In the end, it is useful to acknowledge, as Winter (2003: 174-175) does, that, whether planned or spontaneous, an elite's words are their words and thus "are a reasonable guide to the [elite's] personality."14

As Winter's views suggest, there is a debate over the sources of verbal material that should be used when assessing elites' personality traits. Empirical evidence pertinent to this debate is mixed and reflects the unsettled nature of this matter. For example, in a study of US presidents Ronald Reagan and George H.W. Bush, Brian Dille (2000) reports no significant difference in conceptual complexity measures derived from separate content analyses of spontaneous and planned utterances. On the other hand, in a study of US presidents Carter and Clinton, Dille and Young (2000) find significant differences in conceptual complexity measures produced by separately content analyzing planned and spontaneous remarks. Dille and Young's findings should be taken quite seriously because Dille (2000: 579) notes that conceptual

\footnotetext{
${ }^{14}$ Similar arguments have been made by Scott Crichlow (1998: 689-69) and others (Schafer 2000; Schafer and Walker 2006: 46-47).
} 
complexity is a personality trait thought unlikely to significantly differ between planned and spontaneous verbal behavior.

In light of the disagreement over what constitutes valid source material and the mixed empirical record pertinent to this debate, some (Shannon and Keller 2007: 91; Walker 2000) suggest performing content analysis of both planned and spontaneous verbal behavior. This suggestion is not simply based on disagreement and the conflicting empirical findings regarding measurements produced by spontaneous and prepared speech acts. As Walker (2000: 600) notes, whether decision making elites' behavior “correlates more strongly and consistently with observations from spontaneous or prepared statements" remains an open question. Because my own study is concerned with effectively assessing decision making elites' personality traits and explaining their behavior, it is important that I take this unanswered question seriously.

Given the foregoing discussion, my assessment of decision making elites' personality traits will follow Hermann's scheme with one deviation. Namely, my analysis, like that of Shannon and Keller (2007), includes content analysis of data from both media interviews and speeches. In analyzing both types of verbal behavior, my study follows the precedent not only of Shannon and Keller, but also others, including Hermann (Winter, Hermann, Weintraub, and Walker 1991). However, considering Hermann's concerns about using speeches, the evidence that different source materials can produce different measures of personality traits, and recommendations that analysts take care when aggregating data from the two source materials (on this third point see Walker 2000: 599), I will first separately examine data from content analyses of utterances from interviews and speeches. Doing so will allow me to compare measures derived from both types of source material and determine the best approach to assessing the Bush administration officials' personality traits (see Shannon and Keller 2007: 91). 
Before proceeding to a discussion of the OCA data I use, it is necessary to note that while data derived from Shannon and Keller's (2007) findings serve this study well, the data do have one drawback. Specifically, the authors' dataset covers 2001 through 2004. Starting with the beginning of Bush administration officials' tenures aligns perfectly with the LTA standards I follow, but ideally the data I analyze would cover a period ending on 19 March 2003, the day President Bush ordered the invasion of Iraq. Seeking to avoid using data from after 19 March 2003 is based on my desire to ensure that the personality traits I argue ultimately affect an elite's policy position are only the traits that characterize that individual before and at the time of policy implementation. Values on personality trait variables might change following major events (Hermann 2003: 207), and the invasion of Iraq and its aftermath certainly qualify as major events. Consequently, potential post-implementation changes in trait variable values may affect my analysis. The risk posed by this drawback must be acknowledged, but, given the state of data availability and the otherwise excellent match between their data and the objectives of my study, the risk is both necessary and, I believe, acceptable.

\section{OCA Data}

Data drawn from Robison's (2006) quantitative findings on the beliefs of Bush administration officials also mesh well with the needs of the present analysis. First, the data cover the same officials and particular beliefs I have selected for examination here.

Additionally, Robison started his data collection with speech acts from January 2001, the beginning of the officials' tenures and the same starting point as the LTA data I use. Third, as I briefly describe below, Robison's data collection procedures meet the OCA research program's standards. 
Robison (2006), adhering to OCA conventions, collects verbal material from scripted speaking engagements (see e.g., Crichlow 1998; Drury 2006; Feng 2005; 2006; Keck 2003; Malici and Malici 2005; Renshon 2008; Schafer, Robison, and Aldrich 2006; Thies 2006; Walker, Schafer, and Young 1998; 2003). Robison further follows OCA practices by collecting data only from foreign policy-focused speeches (Renshon 2008: 833; Walker, Schafer, and Young). Limiting collection to foreign policy-centric speeches is important because, as Renshon (2008: 833; see also Walker, Schafer, and Young 2003) notes, "operational codes may be domain specific". As OCA research emphasizes how elites perceive and respond to the international environment, analyzing speeches primarily pertaining to foreign policy is appropriate.

Although the data derived from Robison's (2006) study are a good match for my analysis, they do have two downsides. First, Robison's collection of speech acts for the selected decision makers does not extend past September 2002. Having data through 19 March 2003, the point at which Bush ordered war with Iraq, would be preferable. Data through that date would help ensure that the beliefs I propose affect an elite's decision making and policy position are the beliefs that typify that individual up to and including the time policy is enacted. Still, I do not have reason to expect any particular bias to be imparted by the fact that the quantitative belief data I analyze covers the shorter period from January 2001 through September 2002.

The second, more problematic drawback is that whereas Shannon and Keller (2007) collect spontaneous and scripted speech data Robison collects only scripted speech. This means that I cannot compare belief variable values based on scripted speech to those based on spontaneous speech as I am able to do with personality trait variable values. Given that OCA studies using VICS (as Robison's does) often analyze only planned, scripted speech (see e.g., 
Crichlow 1998; Drury 2006; Renshon 2008; Walker, Schafer, and Young 1998), Robison's lack of OCA data from spontaneous speech may seem a non-issue. Like Hermann (1980a; 1999; 2003), however, OCA researchers are cognizant of the potential problems associated with using planned verbal behavior. ${ }^{15}$ But, employing the same arguments I discuss earlier in this chapter, they (see Crichlow 1998: 689-690; Schafer 2000; Schafer and Walker 2006: 46-47; Winter 2003: 174-175) justify analyzing speeches and other forms of planned communication. Moreover, Schafer and Walker (2006: 47) argue that speeches are especially useful source material because they are often formulated by a state's top-level decision makers and thus represent "the 'state's' operational code," the state's "official views."

There are three reasons, though, why also having data collected from spontaneous verbal behavior would be preferable for the operational code portion of my quantitative analysis. First, I am interested less in the state's operational code than in the operational codes of the state's individual decision makers. If prepared speeches indeed "are generally the product of the state's decision-making apparatus," (Schafer and Walker 2006: 47) then they may mask internal disagreements and struggles between hawkish and dovish decision making elites. In contrast, as Scott Crichlow's (2006) study of decision making in Margaret Thatcher's cabinet shows, analyzing spontaneous remarks provides an avenue for getting at intra-elite disagreement. ${ }^{16}$ The second reason for wishing to include spontaneous verbal behavior comes in the form of evidence demonstrating that individuals' operational codes may vary between prepared and spontaneous speech acts (Dille 2000; Schafer and Crichlow 2000). The third reason for also analyzing data from spontaneous utterances is that such source materials may simply be superior to planned

\footnotetext{
${ }^{15}$ I note these problems in the section pertaining to the LTA content analysis scheme and do not reiterate them here. ${ }^{16}$ Crichlow (2006) examined "comments from question-and-answer engagements...in the House of Commons." While some of these comments may well have been prepared, it seems likely, given the context, that at least some of the comments were fairly spontaneous.
} 
communication. Indeed, based on a study of Bill Clinton, Schafer and Crichlow (2000: 559) state "that [operational code] measurements based on spontaneous comments are preferable, particularly in providing sensitive measures of personal predispositions."

Despite the limitations of data derived from Robison's (2006) study, the data still meet the needs of my analysis quite well. The data cover all of the belief variables and Bush administration officials included in my analysis. Further, Robison's data collection satisfies the standards of OCA research. And, as is the case with data drawn from Shannon and Keller's (2007) research, the risks to my own analysis presented by the limitations of data from Robison are necessary and acceptable.

Collecting Data for Qualitative Analysis

The private speech data I gather for my qualitative analysis will come primarily from indepth journalistic accounts of decision making in the formulation of the policy to invade Iraq. Ideally, primary sources or comprehensive academic secondary sources would be used, but neither source type is a viable option given the short time that has elapsed since the invasion. In order to mitigate my data limitations, I will collect data from multiple sources. This will afford me the greatest opportunity to corroborate evidence and obtain the most accurate possible assessment of the intervening variables, dependent variable, and my hypotheses.

\section{Conclusion}

The following two chapters put my research design into practice. The next chapter presents my quantitative analysis of Bush administration officials' operational code beliefs and personality traits. The fourth chapter examines those same officials' susceptibilities to errors and biases as well as the decision makers' foreign policy positions. It is in chapter four that the hypotheses arising from my theoretical framework are tested. 


\section{Chapter 3: Quantitative Analysis}

In this chapter I present my quantitative analysis of the selected Bush administration officials' personality traits and operational code beliefs. To the extent possible I use the findings to classify the officials according to my six-fold typology. I also utilize the officials' traits and beliefs to hypothesize about and anticipate their decision-making errors and biases as well as foreign policy positions.

\section{Bush Administration Decision Makers: Analysis and Hypotheses}

In this section I analyze the beliefs and personality traits of the seven Bush administration decision makers selected for study. As the findings permit I classify the decision makers and hypothesize about the foreign policy positions the officials will decide to take, as well as the errors and biases that will affect those decisions. My presentation of the analysis and hypotheses is organized by individual decision maker in alphabetical order based on the decision makers' surnames.

For each decision maker I first compare the personality trait scores derived from spontaneous and scripted speech acts. As noted in the previous chapter, I will make no such comparison for operational code belief scores. Comparing personality trait scores by source material allows me to gain insight into the differences in the officials' prepared and spontaneous verbal behavior. Such insight may prove important both to the classifying of decision makers within my typology and to my hypothesizing. My analysis of each decision maker will then consider their personality trait and operational code belief scores. As I explain for each decision maker, in this portion of my analysis overall personality trait scores take the place of separate scores for spontaneous and scripted speech. 
In my analysis of the decision makers' personality trait and belief scores the general norming group scores presented in the previous chapter are my baseline for operationalization. To provide a more nuanced understanding of the officials' scores I also compare the scores to scores drawn from subsets of the Leadership Trait Analysis (LTA) and Operational Code Analysis (OCA) norming groups, as well as norming groups derived solely from the scores of the selected Bush administration officials. The subset of the LTA norming group I use is a group of 15 Anglo-United States decision makers. The OCA subset consists of post-World War II US decision makers. The intra-Bush administration norming groups are, of course, comprised of all seven officials selected for analysis in this study. Again, for the analysis of personality traits this intra-administration norming group uses overall scores, not scores based solely on spontaneous or scripted speech acts. The more fine-grained view of the individuals provided through the use of multiple norming groups aids in the tasks of classifying the officials and hypothesizing about their decision-making.

$\underline{\text { Richard Armitage, Deputy Secretary of State }}$

As is apparent in tables $5 \mathrm{a}, 5 \mathrm{~b}$, and $5 \mathrm{c}$, there is some notable variation between Armitage's scripted and spontaneous speech. ${ }^{1}$ The importance of these variations, however, should not be overstated. No variation moves Armitage from the hawk to dove column for any trait, nor vice versa. In fact, the variations by speech type are more often than not within one standard deviation. Given these findings, classification of Armitage will rely on analysis of his

\footnotetext{
${ }^{1}$ Across all three norming groups Armitage's scripted speech indicates more belief in his ability to control events than is evident in his spontaneous utterances. Armitage's level of distrust is consistently moderate regardless of speech type, except when compared to the intra-administration group, in which case his level of distrust is comparatively low. His in-group bias scores are almost uniformly low, but his scripted speech shows moderate ingroup bias when compared to the selected Bush administration officials as a whole. Armitage's scripted speech garners moderate need for power scores across norming groups, but the scores for his spontaneous speech are low against the full and intra-administration norming groups, with a moderate score when compared to the Anglo-US norming group. The final trait showing notable variation is task focus. For this trait Armitage is moderate in all instances except spontaneous speech compared to the intra-administration group; his score is high in that comparison. Armitage's conceptual complexity scores are uniformly moderate regardless of speech type.
} 
overall trait scores. There is simply too little variation by speech type to make parsing his verbal behavior analytically profitable.

Table 5a: Armitage's Scripted vs. Spontaneous Personality Trait Scores Compared to Full LTA Norming Group

\begin{tabular}{lllc} 
& Scripted & Spontaneous & Norming Group Mean/Standard Deviation \\
Control & 0.33 (Moderate) & 0.28 (Low) & $0.35 / 0.05$ \\
Complex & 0.57 (Moderate) & 0.62 (Moderate) & $0.59 / 0.06$ \\
Distrust & 0.14 (Moderate) & 0.09 (Moderate) & $0.13 / 0.06$ \\
In-group & 0.08 (Low) & 0.05 (Low) & $0.15 / 0.05$ \\
Power & 0.23 (Moderate) & 0.20 (Low) & $0.26 / 0.05$ \\
Task & 0.62 (Moderate) & 0.68 (Moderate) & $0.63 / 0.07$ \\
\hline
\end{tabular}

Table 5b: Armitage's Scripted vs. Spontaneous Personality Trait Scores Compared to Anglo-US Norming Group

\begin{tabular}{lllc} 
& Scripted & Spontaneous & Norming Group Mean/Standard Deviation \\
Control & 0.33 (Moderate) & 0.28 (Low) & $0.36 / 0.04$ \\
Complex & 0.57 (Moderate) & 0.62 (Moderate) & $0.60 / 0.05$ \\
Distrust & 0.14 (Moderate) & 0.09 (Moderate) & $0.12 / 0.03$ \\
In-group & 0.08 (Low) & 0.05 (Low) & $0.13 / 0.03$ \\
Power & 0.23 (Moderate) & 0.20 (Moderate) & $0.24 / 0.04$ \\
Task & 0.62 (Moderate) & 0.68 (Moderate) & $0.62 / 0.06$ \\
\hline
\end{tabular}

Table 5c: Armitage's Scripted vs. Spontaneous Personality Trait Scores Compared to Administration Norming Group

\begin{tabular}{lllc} 
& Scripted & Spontaneous & Norming Group Mean/Standard Deviation \\
Control & 0.33 (Moderate) & 0.28 (Low) & $0.33 / 0.02$ \\
Complex & 0.57 (Moderate) & 0.62 (Moderate) & $0.60 / 0.03$ \\
Distrust & 0.14 (Moderate) & 0.09 (Low) & $0.15 / 0.04$ \\
In-group & 0.08 (Moderate) & 0.05 (Low) & $0.07 / 0.01$ \\
Power & 0.23 (Moderate) & 0.20 (Low) & $0.25 / 0.03$ \\
Task & 0.62 (Moderate) & 0.68 (High) & $0.61 / 0.05$ \\
\hline
\end{tabular}

Table 5d displays in bold typeface Armitage's OCA belief scores and overall LTA scores. These scores are compared to scores from the various norming groups. The norming 
group scores for each trait and belief are displayed in parentheses, with the mean score presented first, followed by the standard deviation for scores on that variable.

No matter the norming group to which he is compared Armitage fits in neither the hawkish or dovish camp, much less matches one of the six decision maker types. There is some variation in his low-moderate-high ratings across norming groups. None of that variation, however, moves him between the hawkish and dovish sets of types.

$\underline{\text { Table 5d: Armitage's Personality Trait (Overall) and Belief Scores }}$

$\begin{array}{lllll}\text { LTA Scores } & & & & \\ \text { Compared to: } & & \text { Full } & \text { Anglo-US } & \text { Administration } \\ & & & & \\ \text { Control } & \mathbf{0 . 3 1} & (0.35 / 0.05) \text { Moderate } & (0.36 / 0.04) L o w & (0.33 / 0.02) \text { Moderate } \\ \text { Complex } & \mathbf{0 . 6 0} & (0.59 / 0.06) \text { Moderate } & (0.60 / 0.05) \text { Moderate } & (0.60 / 0.03) \text { Moderate } \\ \text { Distrust } & \mathbf{0 . 1 1} & (0.13 / 0.06) \text { Moderate } & (0.12 / 0.03) \text { Moderate } & (0.15 / 0.04) \text { Moderate } \\ \text { In-group } & \mathbf{0 . 0 7} & (0.15 / 0.05) L o w & (0.13 / 0.03) L o w & (0.07 / 0.01) \text { Moderate } \\ \text { Power } & \mathbf{0 . 2 1} & (0.26 / 0.05) \text { Moderate } & (0.24 / 0.04) \text { Moderate } & (0.25 / 0.03) L o w \\ \text { Task } & \mathbf{0 . 6 5} & (0.63 / 0.07) \text { Moderate } & (0.62 / 0.06) \text { Moderate } & (0.61 / 0.05) \text { Moderate }\end{array}$

OCA Scores

\begin{tabular}{lllll} 
Compared to: & & Full & Post-WWII US & Administration \\
& & & & \\
P-1 & $\mathbf{0 . 3 2 2}$ & $(0.273 / 0.280)$ Moderate & $(0.27 / 0.19)$ Moderate & $(0.175 / 0.123)$ High \\
P-4 & $\mathbf{0 . 1 7 4}$ & $(0.207 / 0.114)$ Moderate & $(0.21 / 0.06)$ Moderate & $(0.188 / 0.034)$ Moderate \\
I-1 & $\mathbf{0 . 4 8 5}$ & $(0.346 / 0.336)$ Moderate & $(0.38 / 0.22)$ Moderate & $(0.146 / 0.279)$ High \\
\hline
\end{tabular}

The norming group against which Armitage most clearly stands out is the Bush administration. Armitage's beliefs and traits are unremarkable compared to decision makers in general, Anglo-US policy makers, and post-WWII US decision makers, but he looks somewhat dovish against the backdrop of the Bush administration. In the intra-administration comparison his low need for power, high P-1, moderate P-4, and high I-1 scores match him most closely to the Raven type within the dovish set.

Given that Armitage fits no decision maker type, predictions about his decision making and policy positions will be necessarily quite limited. Only two of hypotheses from the 
theoretical framework can be used to directly generate such predictions. Beyond that only qualified expectations can be presented.

Armitage's low-to-moderate belief that he can control events - reflected in his personality and operational code beliefs - viewed from the perspective of hypothesis one predicts that Armitage will not exhibit the positive illusions to which owls and warhawks are prone. His predominantly moderate scores across other beliefs and traits lead to an expectation that he will be generally resistant to hawkish and dovish errors and biases. That said, his P-1 score is high relative to the intra-administration group. Consequently, his more optimistic view of the world and opponents may make him somewhat more susceptible to dovish errors and biases than other selected Bush administration officials. At the same time, according to hypothesis nine, his moderate task focus should tend to incline him to have at least an owl's moderate level of susceptibility to concession aversion and, relatedly, risk-seeking in losses. His low in-group bias ratings when assessed against the full norming group and Anglo-US subset could be construed to indicate susceptibility to dovish biases and errors, but those ratings on that trait are not by themselves sufficient to draw from the theoretical framework any expectations of such susceptibility.

Armitage's consistently moderate task focus further suggests he may be somewhat disinclined to support compromise in foreign policy, focusing more on the tasks like security than on maintaining relationships via conciliation. This tendency would be reinforced by any concession aversion or risk-seeking in losses evident in his decision making processes. His high P-1 and I-1 scores, relative to the intra-administration group, however, indicate that he will be more likely to espouse policies of compromise and cooperation than other selected elites. Still, his moderate P-4 score, which makes him look something like a Raven among his fellow 
administration members, gives rise to an expectation that hypothesis sixteen might shed some light on Armitage's foreign policy positions. Specifically, if mutual accommodation fails to produce settlement with Iraq, Armitage may well advocate policy producing deadlock. His moderate belief that he has control over events should stop him short of proposing a more assertive policy of domination.

\section{George W. Bush, President}

Tables $6 \mathrm{a}, 6 \mathrm{~b}$, and $6 \mathrm{c}$ reveal numerous discrepancies between Bush's spontaneous and scripted verbal behavior. ${ }^{2}$ Similar to the case of Armitage, though, one should not make too much of these variations. Variations between spontaneous and scripted speech do not move Bush between the dovish and hawkish categories of decision makers. Although Bush's trait score variations by speech type typically exceed trait score standard deviations, the variations do not clearly show one type of speech act tending towards more dovishness (or hawkishness) than the other. Notably, however, compared to the administration group Bush's scripted speech tends, with the exception of his task focus score, towards hawkishness. All things considered, focusing on his overall trait scores remains the best course for analysis. The variations by speech act type are not so consistently great or clear in direction that they constitute a compelling case for distinguishing between them in efforts to classify Bush or hypothesize about his decision

\footnotetext{
${ }^{2}$ Bush's scores for belief in his ability to control events are nearly uniformly moderate, though his scripted speech score is high relative to the administration group. Compared against all three norming groups Bush's spontaneous speech indicates moderate conceptual complexity while his scripted speech acts are characterized by low complexity. Bush's distrust scores for scripted speech are consistently high. His spontaneous speech, by contrast, is moderate in distrust in relation to the full and administration norming groups (it is high in comparison to the AngloUS group). In-group bias scores for Bush are always at a lower rating for spontaneous speech than scripted utterances. When viewed in relation to the Anglo-US and administration groups, Bush's scripted speech is rated as high in need for power, whereas his spontaneous verbal behavior rates moderate for that trait. Against the full norming group Bush's need for power is moderate regardless of speech type. Bush's scripted speech uniformly demonstrates low task focus, with his spontaneous speech consistently receiving moderate ratings.
} 
making and policy positions. Indeed, choosing to favor one speech type or the other would be an arbitrary choice and analyzing both separately would produce far more heat than light.

Table 6a: Bush's Scripted vs. Spontaneous Personality Trait Scores Compared to Full LTA Norming Group

\begin{tabular}{llll} 
& Scripted & Spontaneous & Norming Group Mean/Standard Deviation \\
Control & 0.39 (Moderate) & 0.35 (Moderate) & $0.35 / 0.05$ \\
Complex & 0.51 (Low) & 0.60 (Moderate) & $0.59 / 0.06$ \\
Distrust & 0.21 (High) & 0.18 (Moderate) & $0.13 / 0.06$ \\
In-group & 0.10 (Moderate) & 0.08 (Low) & $0.15 / 0.05$ \\
Power & 0.31 (Moderate) & 0.24 (Moderate) & $0.26 / 0.05$ \\
Task & 0.49 (Low) & 0.60 (Moderate) & $0.63 / 0.07$ \\
\hline
\end{tabular}

Table 6b: Bush's Scripted vs. Spontaneous Personality Trait Scores Compared to Anglo-US Norming Group

\begin{tabular}{lllc} 
& Scripted & Spontaneous & Norming Group Mean/Standard Deviation \\
Control & 0.39 (Moderate) & 0.35 (Moderate) & $0.36 / 0.04$ \\
Complex & 0.51 (Low) & 0.60 (Moderate) & $0.60 / 0.05$ \\
Distrust & 0.21 (High) & 0.18 (High) & $0.12 / 0.03$ \\
In-group & 0.10 (Moderate) & 0.08 (Low) & $0.13 / 0.03$ \\
Power & 0.31 (High) & 0.24 (Moderate) & $0.24 / 0.04$ \\
Task & 0.49 (Low) & 0.60 (Moderate) & $0.62 / 0.06$ \\
\hline
\end{tabular}

Table 6c: Bush's Scripted vs. Spontaneous Personality Trait Scores Compared to Administration Norming Group

\begin{tabular}{lllc} 
& Scripted & Spontaneous & Norming Group Mean/Standard Deviation \\
Control & 0.39 (High) & 0.35 (Moderate) & $0.33 / 0.02$ \\
Complex & 0.51 (Low) & 0.60 (Moderate) & $0.60 / 0.03$ \\
Distrust & 0.21 (High) & 0.18 (Moderate) & $0.15 / 0.04$ \\
In-group & 0.10 (High) & 0.08 (Moderate) & $0.07 / 0.01$ \\
Power & $0.31($ High) & 0.24 (Moderate) & $0.25 / 0.03$ \\
Task & 0.49 (Low) & 0.60 (Moderate) & $0.61 / 0.05$ \\
\hline
\end{tabular}


Bush's overall LTA scores and OCA belief scores are shown in bold typeface in Table 6d. The norming group scores for each trait and belief are presented in parentheses, with the mean score shown first and the standard deviation shown second. Bush's scores for each variable are compared to the norming group scores.

Bush does not match with any of the six decision maker types. He does not even fall within the hawkish or dovish categories. Variation in his low-moderate-high ratings across norming groups is present only for LTA variables. In the case of in-group bias, this variation

\section{Table 6d: Bush's Personality Trait (Overall) and Belief Scores}

\section{LTA Scores}

$\begin{array}{lllll}\text { Compared to: } & & \text { Full } & \text { Anglo-US } & \text { Administration } \\ & & & & \\ \text { Control } & \mathbf{0 . 3 7} & (0.35 / 0.05) \text { Moderate } & (0.36 / 0.04) \text { Moderate } & (0.33 / 0.02) \text { High } \\ \text { Complex } & \mathbf{0 . 5 5} & (0.59 / 0.06) \text { Moderate } & (0.60 / 0.05) \text { Moderate } & (0.60 / 0.03) \text { Low } \\ \text { Distrust } & \mathbf{0 . 1 9} & (0.13 / 0.06) \text { Moderate } & (0.12 / 0.03) \text { High } & (0.15 / 0.04) \text { Moderate } \\ \text { In-group } & \mathbf{0 . 0 9} & (0.15 / 0.05) \text { Low } & (0.13 / 0.03) \text { Low } & (0.07 / 0.01) \text { High } \\ \text { Power } & \mathbf{0 . 2 8} & (0.26 / 0.05) \text { Moderate } & (0.24 / 0.04) \text { Moderate } & (0.25 / 0.03) \text { Moderate } \\ \text { Task } & \mathbf{0 . 5 5} & (0.63 / 0.07) \text { Low } & (0.62 / 0.06) \text { Low } & (0.61 / 0.05) \text { Low }\end{array}$

\section{OCA Scores}

\begin{tabular}{lllll} 
Compared to: & \multicolumn{2}{l}{ Full } & Post-WWII US & Administration \\
& & & & \\
P-1 & $\mathbf{0 . 1 7 4}$ & $(0.273 / 0.280)$ Moderate & $(0.27 / 0.19)$ Moderate & $(0.175 / 0.123)$ Moderate \\
P-4 & $\mathbf{0 . 2 2 2}$ & $(0.207 / 0.114)$ Moderate & $(0.21 / 0.06)$ Moderate & $(0.188 / 0.034)$ Moderate \\
I-1 & $\mathbf{0 . 3 1 1}$ & $(0.346 / 0.336)$ Moderate & $(0.38 / 0.22)$ Moderate & $(0.146 / 0.279)$ Moderate \\
\hline
\end{tabular}

moves Bush's rating from the dovish to hawkish grouping for that trait when Bush is compared to other members of his administration. Notably, when compared to other administration officials the ratings for Bush's belief that he can control events shows a discrepancy between LTA and OCA variables.

Identifying any pattern in the relationship between Bush and the typology is difficult. When compared to the full LTA and OCA norming groups Bush is very middle-of-the-road, though one could interpret his low in-group bias and task focus ratings as pulling him toward the 
dovish column. Against the Anglo-US leader subset of the LTA norming group, Bush's traits show conflicting hawkish and dovish tendencies; he is distrustful, but low in task focus and ingroup bias. In some respects Bush looks more hawkish when his personality traits are juxtaposed only to those of other administration officials. He is low in complexity and high in in-group bias. One might even argue that those traits combined with his high rating for control edge him towards being a warhawk. That said, Bush's task focus is low compared to others in his administration, making him look dovish on that trait. Moreover, his rating on distrust, which was high compared to Anglo-US leaders in general, is only moderate relative to the other administration members. The discrepancy between his LTA and OCA ratings on control clouds assessment of his belief that he can control events and further complicates placing Bush within the typology. Finally, his uniformly unremarkable ratings on P-1 and I-1 leave Bush in between the hawkish and dovish camps.

This unclear relationship between Bush and the typology greatly complicates hypothesizing about his decision making and policy positions. None of the theoretical framework's hypotheses can be directly or unproblematically brought to bear on the task of predicting or explaining Bush's behavior. Moreover, even formulating qualified expectations is fraught with critical difficulties.

Viewed in isolation, Bush's universally moderate P-1 ratings, exhibiting a belief that the world and other actors are neither wholly hostile nor totally benign, lead to an expectation that he will exhibit resistance hawkish or dovish errors and biases. One cannot, however, consider only Bush's P-1 ratings. His mix of low, moderate, and high trait scores for conceptual complexity, distrust, and in-group bias fundamentally undermine any expectations that might be derived from his consistent P-1 ratings. Moreover, Bush's mixed trait ratings generally deny a foundation for 
using the theoretical framework to form expectations about his susceptibilities to errors and biases. Bush's mixed trait ratings and exclusively moderate operational code belief ratings similarly produce an inability to state clear expectations about his decision making and policy positions.

The only aspect of Bush's personality traits and beliefs that permits relatively clear insight from the theoretical framework is his belief in his ability to control events. In terms of his personality traits and operational code Bush generally appears to have only a moderate belief that he can control events. To the extent that he is moderate in this respect, hypothesis one suggests Bush will lack warhawks' and owls' susceptibility to positive illusions regarding his abilities, actions, and likelihood of success. When his personality traits are compared to the intra-administration norming group, however, Bush rates high in his belief that he can exert control over events. Hypothesis one does, then, suggest that Bush may be more susceptible to positive illusions than other members of his administration. This expectation must be qualified by recognition that Bush's P-4 rating is moderate relative to the intra-administration norming group. Consequently, one cannot say with anything like certainty that Bush's belief that he can control events is stronger than that of other administration member studied here.

\section{$\underline{\text { Richard Cheney, Vice President }}$}

Cheney's personality trait scores (Tables 7a-7c) show some differences between his spontaneous and scripted speech. ${ }^{3}$ Although some of the discrepancies in Cheney's trait scores

\footnotetext{
${ }^{3}$ Only in the case of his belief that he can exert control over events is there complete consistency between speech types, with all ratings standing at moderate. His scripted speech acts uniformly rate as low in conceptual complexity, whereas his spontaneous speech rates as moderate to high in conceptual complexity. Cheney's scores for distrust are moderate for both speech types, except in the case of his scripted speech compared to the Anglo-US norming group. In that comparison his scripted speech rates high in distrust. Cheney's in-group bias ratings are nearly uniformly low, but when he is compared to the intra-administration norming group his scripted speech rates high for the trait. Compared to the Anglo-US and intra-administration norming groups Cheney's scripted verbal behavior rates high in need for power. Assessed against the full LTA norming group his scripted speech indicates a moderate need for power. His spontaneous speech garners moderate need for power ratings regardless of the
} 
Table 7a: Cheney's Scripted vs. Spontaneous Personality Trait Scores Compared to Full LTA Norming Group

\begin{tabular}{lllc} 
& Scripted & Spontaneous & Norming Group Mean/Standard Deviation \\
Control & 0.35 (Moderate) & 0.34 (Moderate) & $0.35 / 0.05$ \\
Complex & 0.51 (Low) & 0.64 (Moderate) & $0.59 / 0.06$ \\
Distrust & 0.16 (Moderate) & 0.13 (Moderate) & $0.13 / 0.06$ \\
In-group & 0.09 (Low) & 0.04 (Low) & $0.15 / 0.05$ \\
Power & 0.29 (Moderate) & 0.26 (Moderate) & $0.26 / 0.05$ \\
Task & 0.57 (Moderate) & 0.76 (High) & $0.63 / 0.07$ \\
\hline
\end{tabular}

Table 7b: Cheney's Scripted vs. Spontaneous Personality Trait Scores Compared to Anglo-US Norming Group

\begin{tabular}{llll} 
& Scripted & Spontaneous & Norming Group Mean/Standard Deviation \\
Control & 0.35 (Moderate) & 0.34 (Moderate) & $0.36 / 0.04$ \\
Complex & 0.51 (Low) & 0.64 (Moderate) & $0.60 / 0.05$ \\
Distrust & 0.16 (High) & 0.13 (Moderate) & $0.12 / 0.03$ \\
In-group & 0.09 (Low) & 0.04 (Low) & $0.13 / 0.03$ \\
Power & 0.29 (High) & 0.26 (Moderate) & $0.24 / 0.04$ \\
Task & 0.57 (Moderate) & 0.76 (High) & $0.62 / 0.06$ \\
\hline
\end{tabular}

Table 7c: Cheney's Scripted vs. Spontaneous Personality Trait Scores Compared to Administration Group

\begin{tabular}{lllc} 
& Scripted & Spontaneous & Norming Group Mean/Standard Deviation \\
Control & 0.35 (Moderate) & 0.34 (Moderate) & $0.33 / 0.02$ \\
Complex & 0.51 (Low) & 0.64 (High) & $0.60 / 0.03$ \\
Distrust & 0.16 (Moderate) & 0.13 (Moderate) & $0.15 / 0.04$ \\
In-group & 0.09 (High) & 0.04 (Low) & $0.07 / 0.01$ \\
Power & 0.29 (High) & 0.26 (Moderate) & $0.25 / 0.03$ \\
Task & 0.57 (Moderate) & 0.76 (High) & $0.61 / 0.05$ \\
\hline
\end{tabular}

norming group comparison. Task focus scores derived from Cheney's scripted speech rate as moderate against all norming groups. Task focus scores based on spontaneous speech, by contrast, are uniformly high. 
are eye-catching, care must be taken not to exaggerate the discrepancies' significance. That said, some of the differences are indeed noteworthy. For several traits the score differences between spontaneous and scripted verbal behavior greatly exceed the norming group standard deviations. For task focus, one trait characterized by just such a large discrepancy, Cheney's spontaneous speaking is uniformly more in the hawkish column. Moreover, when Cheney is examined in relation to the administration group the differences on two traits move him between the hawkish and dovish camps for those traits. The conceptual complexity shown in his scripted speech is low, but his spontaneous speech is marked by a high degree of conceptual complexity. His scripted speech thus makes him appear hawkish while his spontaneous utterances give him a dovish cast. Conversely, his scripted speech indicates a hawkish high in-group bias that stands in contrast to the dovish low in-group bias found in his spontaneous speech.

The differences found in the last two traits noted directly above hit on a key reason not to overemphasize the differences between Cheney's spontaneous and scripted verbal behavior. Specifically, the variations by source material sometimes make Cheney appear hawkish, but in other instances give him a dovish appearance. In other words, the differences do not systematically move Cheney closer to one decision maker type cluster or the other. Additionally, for most traits, any differences between Cheney's spontaneous and scripted speech do not move his ratings for those traits from the hawkish to dovish category or from the dovish to hawkish column. Taken all together, analyzing Cheney's overall trait scores is a better course than picking between his scripted and spontaneous verbal behavior, or analyzing both separately. Much as is the case for Bush, picking one over the other would be an arbitrary choice and examining both individually would produce a tangled analysis. 
Overall LTA scores and OCA belief scores for Cheney can be found in Table 7d (boldface type). Cheney's scores for each trait and belief are compared to the norming group scores displayed in parentheses. The mean norming group score is followed by the standard deviation for that score.

Cheney does not clearly fit within either the dovish or hawkish category. Of course, then, he matches none of the individual hawkish or dovish decision maker types. Variation in his lowmoderate-high ratings across norming groups is present only for two LTA variables. Neither variation is, though, large enough to move his rating from the hawkish to dovish category, or the other way around.

Table 7d: Cheney's Personality Trait (Overall) and Belief Scores

\section{LTA Scores}

$\begin{array}{lllll}\text { Compared to: } & & \text { Full } & \text { Anglo-US } & \text { Administration } \\ \text { Control } & \mathbf{0 . 3 5} & (0.35 / 0.05) \text { Moderate } & (0.36 / 0.04) \text { Moderate } & (0.33 / 0.02) \text { Moderate } \\ \text { Complex } & \mathbf{0 . 5 7} & (0.59 / 0.06) \text { Moderate } & (0.60 / 0.05) \text { Moderate } & (0.60 / 0.03) \text { Moderate } \\ \text { Distrust } & \mathbf{0 . 1 5} & (0.13 / 0.06) \text { Moderate } & (0.12 / 0.03) \text { Moderate } & (0.15 / 0.04) \text { Moderate } \\ \text { In-group } & \mathbf{0 . 0 7} & (0.15 / 0.05) \text { Low } & (0.13 / 0.03) \text { Low } & (0.07 / 0.01) \text { Moderate } \\ \text { Power } & \mathbf{0 . 2 8} & (0.26 / 0.05) \text { Moderate } & (0.24 / 0.04) \text { Moderate } & (0.25 / 0.03) \text { Moderate } \\ \text { Task } & \mathbf{0 . 6 7} & (0.63 / 0.07) \text { Moderate } & (0.62 / 0.06) \text { Moderate } & (0.61 / 0.05) \text { High }\end{array}$

\section{OCA Scores}

\begin{tabular}{lllll} 
Compared to: & & Full & Post-WWII US & \multicolumn{1}{l}{ Administration } \\
P-1 & $\mathbf{0 . 2 3 5}$ & $(0.273 / 0.280)$ Moderate & $(0.27 / 0.19)$ Moderate & $(0.175 / 0.123)$ Moderate \\
P-4 & $\mathbf{0 . 1 7 6}$ & $(0.207 / 0.114)$ Moderate & $(0.21 / 0.06)$ Moderate & $(0.188 / 0.034)$ Moderate \\
I-1 & $\mathbf{- 0 . 2 8 6}$ & $(0.346 / 0.336)$ Low & $(0.38 / 0.22)$ Low & $(0.146 / 0.279)$ Low \\
\hline
\end{tabular}

The view of Cheney provided by his ratings across norming groups is relatively clear. His LTA ratings are generally moderate. Judged against the whole norming group and AngloUS subset Cheney is unremarkable, with his low in-group bias giving him, if anything, a slightly dovish cast. Compared to the administration group Cheney still looks moderate, but his high task focus makes him appear a bit more hawkish. 
Cheney stands out more when his OCA ratings are examined. His P-1 and P-4 ratings are consistently moderate no matter the norming group to which he is compared, but his equally consistent low I-1 ratings mark him as inclined to see conflictual strategies as best. His moderate P-4 and control (LTA) ratings combined with his low I-1 ratings put him closer to the hawk type than any other. This fit is reinforced by his high task focus, but only when Cheney is compared to other Bush administration officials. Keep in mind, however, that Cheney is largely moderate in his belief and personality trait ratings, with his in-group bias ratings more often than not going in a dovish direction.

Inability to match Cheney to a decision maker type denies a good basis for using the framework's hypotheses to predict Cheney's decision making and policy positions. Only one hypothesis, hypothesis one, does clearly permit prediction of Cheney's behavior. Another hypothesis, hypothesis nine, has some utility for formulating a prediction about Cheney's decision making and policy positions. The best possible otherwise is to posit some expectations. Even these expectations will be subject to important qualifications.

Cheney's uniformly moderate belief he can control events (evident in his LTA and OCA scores) allows the use of hypothesis one to predict that Cheney will not have owls' and warhawks' propensity for positive illusions. His generally moderate scores on other beliefs and traits give rise to an expectation that he will also have limited susceptibility to most dovish and hawkish errors and biases. The fact that his in-group bias is low relative to the full and AngloUS norming groups does not by itself catalyze the theoretical framework to generate expectations about his decision making or policy positions. His consistently low I-1 ratings, however, predict that he will prefer conflictual strategies and does lead to some expectations. According to the theoretical framework, that preference inclines him somewhat towards the 
hawkish biases of concession aversion and risk seeking to avoid losses. Also, recall that Cheney has a high task focus when compared to the Bush administration as a whole. A high task focus should compound the effect of his low I-1 score and, all other things being equal, make him more prone to these hawkish biases than his fellow administration members. Even the moderate task focus found in Cheney's comparison against the other norming groups will, according to hypothesis nine, at minimum leave him with an owl's moderate susceptibility to concession aversion and risk-seeking in losses.

Given Cheney's consistently low I-1 ratings, his moderate-to-high task focus, and his potential susceptibilities to the hawkish biases of concession aversion and risk-seeking in losses, Cheney should support conflictual foreign policy and oppose compromise. His conflictual leanings will likely be moderated somewhat by his other traits and beliefs, perhaps especially his middling belief that he can control events. He may, like a hawk, prefer to dominate but opt for a settlement or deadlock if domination is not readily achievable.

\section{Colin Powell, Secretary of State}

Tables $8 \mathrm{a}, 8 \mathrm{~b}$, and $8 \mathrm{c}$ show that there are only three instances of trait score variation between Powell's spontaneous and scripted speech. ${ }^{4}$ The small number of discrepancies between spontaneous and scripted speech provide no compelling justification for further separate analysis of Powell's spontaneous and scripted verbal behavior. The fact that in no case does the difference in trait rating move one of Powell's traits from the dovish to hawkish category, or vice versa, also militates against any other course than analyzing Powell's overall scores. In fact,

\footnotetext{
${ }^{4}$ None of these instances is found in the comparison of Powell to the full LTA norming group. When Powell is compared to the Anglo-US norming group his scripted speech indicates a moderate task focus while his spontaneous speech is marked by a high task focus. The same task focus disparity is seen when Powell is examined in relation to the intra-administration norming group. Compared to the administration group he also shows a discrepancy on conceptual complexity. Namely, his scripted speech points to low conceptual complexity in contrast to the moderate conceptual complexity characterizing his spontaneous utterances.
} 
score differences by speech type are more often than not smaller than one standard deviation.

Consequently, subsequent analysis examines only Powell's overall LTA trait scores.

Table 8a: Powell's Scripted vs. Spontaneous Personality Trait Scores Compared to Full LTA Norming Group

\begin{tabular}{lllc} 
& Scripted & Spontaneous & Norming Group Mean/Standard Deviation \\
Control & 0.35 (Moderate) & 0.35 (Moderate) & $0.35 / 0.05$ \\
Complex & 0.55 (Moderate) & 0.63 (Moderate) & $0.59 / 0.06$ \\
Distrust & 0.09 (Moderate) & 0.10 (Moderate) & $0.13 / 0.06$ \\
In-group & 0.08 (Low) & 0.06 (Low) & $0.15 / 0.05$ \\
Power & 0.28 (Moderate) & 0.26 (Moderate) & $0.26 / 0.05$ \\
Task & 0.61 (Moderate) & 0.70 (Moderate) & $0.63 / 0.07$ \\
\hline
\end{tabular}

Table 8b: Powell's Scripted vs. Spontaneous Personality Trait Scores Compared to Anglo-US Norming Group

\begin{tabular}{lllc} 
& Scripted & Spontaneous & Norming Group Mean/Standard Deviation \\
Control & 0.35 (Moderate) & 0.35 (Moderate) & $0.36 / 0.04$ \\
Complex & 0.55 (Moderate) & 0.63 (Moderate) & $0.60 / 0.05$ \\
Distrust & 0.09 (Moderate) & 0.10 (Moderate) & $0.12 / 0.03$ \\
In-group & 0.08 (Low) & 0.06 (Low) & $0.13 / 0.03$ \\
Power & 0.28 (Moderate) & 0.26 (Moderate) & $0.24 / 0.04$ \\
Task & 0.61 (Moderate) & 0.70 (High) & $0.62 / 0.06$ \\
\hline
\end{tabular}

Table 8c: Powell's Scripted vs. Spontaneous Personality Trait Scores Compared to Administration Norming Group

\begin{tabular}{lllc} 
& Scripted & Spontaneous & Norming Group Mean/Standard Deviation \\
Control & 0.35 (Moderate) & 0.35 (Moderate) & $0.33 / 0.02$ \\
Complex & 0.55 (Low) & 0.63 (Moderate) & $0.60 / 0.03$ \\
Distrust & 0.09 (Low) & 0.10 (Low) & $0.15 / 0.04$ \\
In-group & 0.08 (Moderate) & 0.06 (Moderate) & $0.07 / 0.01$ \\
Power & 0.28 (Moderate) & 0.26 (Moderate) & $0.25 / 0.03$ \\
Task & 0.61 (Moderate) & 0.70 (High) & $0.61 / 0.05$ \\
\hline
\end{tabular}

Powell's overall LTA scores and OCA belief scores appear in boldface type in Table 8d.

In parentheses are shown the norming group scores for each trait followed by the standard 
deviation for that trait. Powell's overall trait and belief scores are compared to the relevant norming group values.

Regardless of the norming group against which he is compared, Powell fits none of the decision maker types. He does not even fall under the broader labels of hawkish or dovish. Variation in his low-moderate-high ratings across norming groups is present for one operational code belief and two personality traits. In no instance does such variation move Powell's rating from the hawkish to dovish category, or from dovish to hawkish.

Table 8d: Powell's Personality Trait (Overall) and Belief Scores

\section{LTA Scores}

$\begin{array}{lllll}\text { Compared to: } & & \text { Full } & \text { Anglo-US } & \text { Administration } \\ \text { Control } & \mathbf{0 . 3 5} & (0.35 / 0.05) \text { Moderate } & (0.36 / 0.04) \text { Moderate } & (0.33 / 0.02) \text { Moderate } \\ \text { Complex } & \mathbf{0 . 5 9} & (0.59 / 0.06) \text { Moderate } & (0.60 / 0.05) \text { Moderate } & (0.60 / 0.03) \text { Moderate } \\ \text { Distrust } & \mathbf{0 . 0 9} & (0.13 / 0.06) \text { Moderate } & (0.12 / 0.03) \text { Moderate } & (0.15 / 0.04) \text { Low } \\ \text { In-group } & \mathbf{0 . 0 7} & (0.15 / 0.05) \text { Low } & (0.13 / 0.03) \text { Low } & (0.07 / 0.01) \text { Moderate } \\ \text { Power } & \mathbf{0 . 2 7} & (0.26 / 0.05) \text { Moderate } & (0.24 / 0.04) \text { Moderate } & (0.25 / 0.03) \text { Moderate } \\ \text { Task } & \mathbf{0 . 6 5} & (0.63 / 0.07) \text { Moderate } & (0.62 / 0.06) \text { Moderate } & (0.61 / 0.05) \text { Moderate }\end{array}$

\section{OCA Scroes}

\begin{tabular}{lllll} 
Compared to: & \multicolumn{2}{c}{ Full } & Post-WWII US & Administration \\
& & & & \\
P-1 & $\mathbf{0 . 2 5 1}$ & $(0.273 / 0.280)$ Moderate & $(0.27 / 0.19)$ Moderate & $(0.175 / 0.123)$ Moderate \\
P-4 & $\mathbf{0 . 2 4 0}$ & $(0.207 / 0.114)$ Moderate & $(0.21 / 0.06)$ Moderate & $(0.188 / 0.034)$ High \\
I-1 & $\mathbf{0 . 4 2 4}$ & $(0.346 / 0.336)$ Moderate & $(0.38 / 0.22)$ Moderate & $(0.146 / 0.279)$ Moderate \\
\hline
\end{tabular}

Powell's generally moderate ratings on personality traits and operational code beliefs P-1 and I-1 convey a very much middle-of-the-road impression. When compared to the intraadministration norming group, Powell's low distrust rating shades towards the dovish side. Likewise, when assessed against the full LTA norming group and the Anglo-US norming group subset Powell's low in-group bias confers on him a slightly dovish appearance. Powell's P-4 rating is high when he is compared to the intra-administration norming group. That P-4 rating and concomitant low distrust and moderate task focus scores on the LTA side make Powell look 
more like an owl than any other decision maker type. Keep in mind, though, that Powell remains far from fitting closely the owl type. Moreover, when his relevant LTA and OCA scores are compared to the administration group there is a ratings discrepancy on his belief that he can control events.

Powell's lack of a clear place in the decision maker typology leaves little ability to state predictions about his decision making process or foreign policy positions. Only two of the theoretical framework's hypotheses can be brought to bear on the task. The most one do beyond that is offer circumscribed expectations.

Powell's belief in his ability to control events is a facet of his LTA and OCA scores that does allow one of the hypotheses to predict his behavior. Powell's personality and operational code are generally characterized by a moderate belief that he can control events. Insofar as he is truly moderate in this belief, hypothesis one predicts he will lack warhawks' and owls' susceptibility to positive illusions. When Powell's P-4 belief is assessed against the intraadministration norming group, however, he rates high in his belief that he can control events. Hypothesis one would then suggest that he might be more prone to positive illusions than some other administration members under study here. The preceding expectation is subject to an important caveat. Specifically, at the level of his personality traits Powell's belief he can control events is only moderate relative to the intra-administration norming group. As such, it is impossible to state unreservedly that his belief he can exert control over events is greater than that of the other administration members included in the norming group.

Based on Powell's largely moderate ratings for the remaining belief and trait scores, he should exhibit resistance to other dovish and hawkish errors and biases. Powell's low in-group bias ratings when compared to the full and Anglo-US norming groups might be seen to suggest 
susceptibility to dovish errors and biases, but those ratings for that trait are not alone sufficient to coax from the theoretical framework any expectations of such susceptibility. The same must be said about Powell's low distrust relative to the administration group. By itself, that low rating does not trigger any specific expectations arising from the framework. According to hypothesis nine, his consistently moderate task focus does, though, predispose him to have at least an owl's moderate susceptibility to concession aversion and risk-seeking in losses.

Powell's uniformly moderate task focus additionally leads to an expectation he will have some disinclination to take conciliatory foreign policy positions, focusing more on tasks such as security than on compromising to maintain relationships. This disinclination would be made stronger by any concession aversion or risk-seeking in losses apparent in his decision making. Powell's moderate P-4 ratings compared to the full and post-WWII US leader norming groups, however, suggest any resistance to concessions will be tempered by his moderate belief that he can exert control events. Compared to the intra-administration group, though, Powell's P-4 score is high. To the extent that he opposes compromise and concessions in policy he may exhibit more commitment to that opposition than a similarly inclined administration member who is less confident in their ability to control events.

One final point must be made about the expectation that Powell will be inclined to oppose policies of conciliation. Specifically, he should only be moderately opposed. His moderate task focus confers no expectation of intransigence. Powell does not have Cheney's strong belief that conflictual strategies are best, nor do his other traits and beliefs lead the framework to predict a hawkish decision maker's fundamental resistance to compromise. $\underline{\text { Condoleezza Rice, National Security Advisor }}$ 
As tables 9a, 9b, and 9c make apparent, there are frequent discrepancies between Rice's spontaneous and scripted verbal behavior. ${ }^{5}$ The number of discrepancies in ratings between speech types, and especially the sometimes stark differences, at first blush appear to call for further separate analysis of Rice's spontaneous and scripted speech. This first impression is reinforced when one considers that the differences are in some cases quite consistent. Rice's scripted speech in all comparisons is lower in task focus than her spontaneous speech, for example. The overall picture is, however, more complicated.

Disparities are there and sometimes large, but there is also general consistency for some traits. After all, Rice's spontaneous and scripted utterances uniformly indicate a moderate need for power and belief that she exerts control over events. Further, the discrepancies do not always tend toward one type of speech reflecting dovishness and the other reflecting hawkishness. True, her more hawkish distrust and in-group bias ratings are found in scripted speech. That said, her scripted speech is in all comparisons rated low in task focus, but her spontaneous speech rates

\footnotetext{
${ }^{5}$ The discrepancies shown in Table 9c are quite stark. There are, though, examples of consistency, too. Measures of Rice's need for power and belief that she can control events consistently rate as moderate regardless of source material or the norming group to which she is compared. Her scores for distrust are all but universally rated moderate. The sole exception is her high distrust rating for scripted speech compared against the Anglo-US norming group.

The case of her in-group bias scores is also one of near uniformity. Her scores on that trait are low for both scripted and spontaneous speech, except when her scripted verbal behavior is compared to the intra-administration norming group. In that comparison her in-group bias score rates as high, a substantial departure from her spontaneous speech.

Rice's task focus ratings for scripted speech are uniformly low. Her spontaneous verbal behavior points to a moderate task focus when compared to the full norming group and Anglo-US subset. Compared against the intraadministration norming group her spontaneous speech indicates a high task focus.

Rice's conceptual complexity ratings show the most complicated variation. When viewed in relation to the full norming group Rice's conceptual complexity ratings are moderate regardless of speech act type. Compared to the Anglo-US norming group Rice's scripted speech is low in conceptual complexity, but her spontaneous speech reflects moderate conceptual complexity. The discrepancy in her ratings is much greater when she is examined against the intra-administration norming group. In that comparison her scripted verbal behavior is low in conceptual complexity. Her spontaneous speech, in contrast, reflects a high level of conceptual complexity.
} 
moderate to high in task focus. What is more, the instances of hawkish high in-group bias and distrust ratings are not the norm for her on those traits. Her in-group bias ratings are low in all Table 9a: Rice's Scripted vs. Spontaneous Personality Trait Scores Compared to Full LTA Norming Group

\begin{tabular}{lllc} 
& Scripted & Spontaneous & Norming Group Mean/Standard Deviati \\
Control & 0.33 (Moderate) & 0.32 (Moderate) & $0.35 / 0.05$ \\
Complex & 0.54 (Moderate) & 0.65 (Moderate) & $0.59 / 0.06$ \\
Distrust & 0.17 (Moderate) & 0.12 (Moderate) & $0.13 / 0.06$ \\
In-group & 0.09 (Low) & 0.05 (Low) & $0.15 / 0.05$ \\
Power & 0.26 (Moderate) & 0.22 (Moderate) & $0.26 / 0.05$ \\
Task & 0.53 (Low) & 0.67 (Moderate) & $0.63 / 0.07$ \\
\hline
\end{tabular}

Table 9b: Rice's Scripted vs. Spontaneous Personality Trait Scores Compared to Anglo-US Norming Group

\begin{tabular}{lllc} 
& Scripted & Spontaneous & Norming Group Mean/Standard Deviation \\
Control & 0.33 (Moderate) & 0.32 (Moderate) & $0.36 / 0.04$ \\
Complex & 0.54 (Low) & 0.65 (Moderate) & $0.60 / 0.05$ \\
Distrust & 0.17 (High) & 0.12 (Moderate) & $0.12 / 0.03$ \\
In-group & 0.09 (Low) & 0.05 (Low) & $0.13 / 0.03$ \\
Power & 0.26 (Moderate) & 0.22 (Moderate) & $0.24 / 0.04$ \\
Task & 0.53 (Low) & 0.67 (Moderate) & $0.62 / 0.06$ \\
\hline
\end{tabular}

Table 9c: Rice's Scripted vs. Spontaneous Personality Trait Scores Compared to Administration Norming Group

\begin{tabular}{lllc} 
& Scripted & Spontaneous & Norming Group Mean/Standard Deviation \\
Control & 0.33 (Moderate) & 0.32 (Moderate) & $0.33 / 0.02$ \\
Complex & 0.54 (Low) & 0.65 (High) & $0.60 / 0.03$ \\
Distrust & 0.17 (Moderate) & 0.12 (Moderate) & $0.15 / 0.04$ \\
In-group & 0.09 (High) & 0.05 (Low) & $0.07 / 0.01$ \\
Power & 0.26 (Moderate) & 0.22 (Moderate) & $0.25 / 0.03$ \\
Task & 0.53 (Low) & 0.67 (High) & $0.61 / 0.05$ \\
\hline
\end{tabular}

cases but the one: her scripted speech compared to the intra-administration group. Similarly, her distrust ratings are all low, with the sole exception of her scripted speech relative to the AngloUS group. In sum, analyzing her overall scores is the proper course. To give either speech type 
pride of place would be the product of an arbitrary decision and trying to draw conclusions from separate analyses of both would be a muddle.

Table 9d presents in bold typeface Rice's overall LTA scores and OCA belief scores.

These scores are compared against scores from the several norming groups. The norming group scores for each trait and belief are displayed in parentheses, with the mean score presented first, followed by the standard deviation for scores on that trait or belief.

Table 9d: Rice's Personality Trait (Overall) and Belief Scores

\section{LTA Scores}

$\begin{array}{lllll}\text { Compared to: } & & \text { Full } & \text { Anglo-US } & \text { Administration } \\ & & & & \\ \text { Control } & \mathbf{0 . 3 2} & (0.35 / 0.05) \text { Moderate } & (0.36 / 0.04) \text { Moderate } & (0.33 / 0.02) \text { Moderate } \\ \text { Complex } & \mathbf{0 . 5 9} & (0.59 / 0.06) \text { Moderate } & (0.60 / 0.05) \text { Moderate } & (0.60 / 0.03) \text { Moderate } \\ \text { Distrust } & \mathbf{0 . 1 4} & (0.13 / 0.06) \text { Moderate } & (0.12 / 0.03) \text { Moderate } & (0.15 / 0.04) \text { Moderate } \\ \text { In-group } & \mathbf{0 . 0 7} & (0.15 / 0.05) \text { Low } & (0.13 / 0.03) \text { Low } & (0.07 / 0.01) \text { Moderate } \\ \text { Power } & \mathbf{0 . 2 4} & (0.26 / 0.05) \text { Moderate } & (0.24 / 0.04) \text { Moderate } & (0.25 / 0.03) \text { Moderate } \\ \text { Task } & \mathbf{0 . 6 0} & (0.63 / 0.07) \text { Moderate } & (0.62 / 0.06) \text { Moderate } & (0.61 / 0.05) \text { Moderate }\end{array}$

\section{OC Scores}

\begin{tabular}{lllll} 
Compared to: & & Full & Post-WWII US & \multicolumn{1}{l}{ Administration } \\
& & & & \\
P-1 & $\mathbf{0 . 2 2 4}$ & $(0.273 / 0.280)$ Moderate & $(0.27 / 0.19)$ Moderate & $(0.175 / 0.123)$ Moderate \\
P-4 & $\mathbf{0 . 1 3 6}$ & $(0.207 / 0.114)$ Moderate & $(0.21 / 0.06)$ Low & $(0.188 / 0.034)$ Low \\
I-1 & $\mathbf{0 . 1 4 1}$ & $(0.346 / 0.336)$ Moderate & $(0.38 / 0.22)$ Low & $(0.146 / 0.279)$ Moderate \\
\hline
\end{tabular}

Rice matches none of the six decision maker types. Nor does she fit either of the broader dovish or hawkish categories. There is some variation in ratings across norming group comparisons. In none of the instances of variation, however, does Rice's rating move from the dovish to hawkish category, or, conversely, from the hawkish to dovish range.

Mostly moderate ratings on personality traits make classification of Rice difficult. Rice only deviates from moderate ratings for in-group bias, and only when she is compared to the whole norming group and Anglo-US norming group subset. Those low in-group bias ratings move her somewhat towards the dovish column, but their importance should not be overstated. 
The impression conveyed by her operational code belief ratings is somewhat clearer, at least when she is compared to Post-WWII US leaders. In that comparison, Rice shows a belief that she is relatively unable to control events while simultaneously believing conflictual policies are most effective. That combination would, if anything, mark her as closer to the chickenhawk decision maker type. Recall, though, that her LTA rating for in-group bias is in some cases low, a rating associated with dovishness. Note also that Rice's LTA ratings for her belief that she can control events are consistently moderate and thus sometimes are at odds with Rice's P-4 ratings. ${ }^{6}$

Rice's lack of fit within the typology and her generally moderate trait and belief scores greatly limit the theoretical framework's ability to offer predictions about her decision making and policy positions. The framework's hypotheses do not provide a basis for such predictions, with two exceptions discussed below. Limited expectations are forthcoming in other cases, but that is all.

Rice's low-to-moderate belief that she can control events is an area of her personality and operational code that allows the use of one hypothesis to predict her behavior. To wit, hypothesis one predicts she will not have owls' and warhawks' proclivity for positive illusions. Rice's other nearly uniformly moderate belief and trait ratings give rise to an expectation that she will also have limited susceptibility to dovish and hawkish biases and errors. That said, Rice does exhibit low in-group bias in relation to the whole and Anglo-US LTA norming groups. Those ratings could be interpreted as indicating susceptibility to dovish errors. A low rating for that trait is, however, by itself insufficient to draw such expectations from the theoretical framework. Rice's consistently moderate task focus ratings, by contrast, do catalyze the framework to produce an expectation. Specifically, Rice's moderate task focus should,

\footnotetext{
${ }^{6}$ Please note that only in the intra-administration comparison is such a contradiction relatively clear. The other LTA and OCA norming groups consist of collections of decision makers not identical between the research programs.
} 
according to hypothesis nine, predispose her to exhibit, at minimum, an owl's moderate proneness to concession aversion and, likewise, risk-seeking in losses. To the extent that Rice believes conflictual actions are most effective (as her I-1 rating relative to the post-WWII US norming group suggests) her susceptibility to those biases should be heightened.

In terms of foreign policy positions, Rice's uniformly moderate task focus leads to an expectation she may demonstrate some disinclination to support compromise and conciliation, focusing instead on maintaining security. This disinclination would be strengthened by any concession aversion or risk-seeking in losses in Rice's decision making processes. To the extent that her I-1 belief favors conflictual strategies - again, as her comparison to post-WWII US leaders suggests it does - Rice's resistance to concessions should be further strengthened. Indeed, her low I-1 rating in that comparison may translate into her support for assertive or aggressive policies. Recall, however, that Rice's low-to-moderate belief (in terms both of LTA traits and operational code beliefs) that she can control events puts her closest, if still not close, to the chickenhawk decision maker type. As such, she may back down from support for policies of domination if they fail to meet with success over the opposing side. Inasmuch as she is like a chickenhawk her stages of backing down will run from seeking settlement to supporting submission to the opponent. She should favor submission over deadlock because she would likely doubt her ability to sustain deadlock. By contrast, to the degree to which her belief that she can control events is more moderate Rice should support a policy of deadlock rather than submission if neither domination nor settlement is achieved. One must not, though, lose sight of the fact that she is still rather far from fitting the profile of a chickenhawk. Consequently, the expectation that she will behave at all like one is weak.

\section{Donald Rumsfeld, Secretary of Defense}


Rumsfeld's personality trait scores (Table 10a-10c) as often as not show discrepancies between his spontaneous and scripted verbal behavior. ${ }^{7}$ The frequency of discrepancies between Rumsfeld's spontaneous and scripted verbal behavior as well as the fact that the discrepancies are similar across norming group comparisons give the differences the appearance of being systematic. Taken together these observations suggest separate analysis of Rumsfeld's scripted and spontaneous speech is warranted. There are, however, three key reasons to doubt the merits of separate analysis.

First, for only one trait - belief in ability to control events - is the discrepancy great enough to span from a low rating to high, or vice versa. That large discrepancy exists only when Rumsfeld is compared to the intra-administration norming group. It is also worth noting that that difference has no bearing on whether Rumsfeld is closer to the hawkish or dovish category of decision makers. Second, the disparities between ratings of Rumsfeld's scripted and spontaneous utterances do not consistently pull him towards either the hawkish or dovish camps. His spontaneous speech consistently generates high, dovish ratings on conceptual complexity, whereas his scripted speech demonstrates only moderate conceptual complexity. At the same time Rumsfeld's spontaneous verbal behavior uniformly produces moderate, less dovish task focus ratings, while his scripted speech consistently exhibits dovish low task focus. Third, Rumsfeld's ratings for distrust, in-group bias, and need for power show no divergence between scripted and spontaneous speech. For these reasons subsequent analysis relies on Rumsfeld's

\footnotetext{
${ }^{7}$ Rumsfeld's spontaneous speech produces moderate (compared to the full and Anglo-US norming groups) and high (compared the intra-administration norming group) ratings for belief in ability to control events, while his scripted speech generates only low ratings on that trait. Regarding conceptual complexity, Rumsfeld's scripted speech rates uniformly as moderate. His spontaneous utterances, in contrast, consistently garner high ratings. Finally, Rumsfeld's spontaneous speech exhibits moderate task focus across all norming group comparisons, while his scripted utterances exhibit low task focus with equal consistency. His ratings for distrust, in-group bias, and need for power do, though, show consistency for both speech types.
} 
overall personality trait scores. Favoring one type of speech would force arbitrary decision making. Examining both separately would result in a needlessly confused analysis.

Table 10a: Rumsfeld's Scripted vs. Spontaneous Personality Trait Scores Compared to Full LTA Norming Group

\begin{tabular}{llll} 
& Scripted & Spontaneous & Norming Group Mean/Standard Deviation \\
Control & 0.29 (Low) & 0.36 (Moderate) & $0.35 / 0.05$ \\
Complex & 0.63 (Moderate) & 0.68 (High) & $0.59 / 0.06$ \\
Distrust & 0.17 (Moderate) & 0.16 (Moderate) & $0.13 / 0.06$ \\
In-group & 0.07 (Low) & 0.06 (Low) & $0.15 / 0.05$ \\
Power & $0.22($ Moderate) & 0.26 (Moderate) & $0.26 / 0.05$ \\
Task & $0.55($ Low $)$ & 0.66 (Moderate) & $0.63 / 0.07$ \\
\hline
\end{tabular}

Table 10b: Rumsfeld's Scripted vs. Spontaneous Personality Trait Scores Compared to Anglo-US Norming Group

\begin{tabular}{lllc} 
& Scripted & Spontaneous & Norming Group Mean/Standard Deviation \\
Control & 0.29 (Low) & 0.36 (Moderate) & $0.36 / 0.04$ \\
Complex & 0.63 (Moderate) & 0.68 (High) & $0.60 / 0.05$ \\
Distrust & 0.17 (High) & 0.16 (High) & $0.12 / 0.03$ \\
In-group & 0.07 (Low) & 0.06 (Low) & $0.13 / 0.03$ \\
Power & 0.22 (Moderate) & 0.26 (Moderate) & $0.24 / 0.04$ \\
Task & 0.55 (Low) & 0.66 (Moderate) & $0.62 / 0.06$ \\
\hline
\end{tabular}

Table 10c: Rumsfeld's Scripted vs. Spontaneous Personality Trait Scores Compared to Administration Norming Group

\begin{tabular}{lllc} 
& Scripted & Spontaneous & Norming Group Mean/Standard Deviation \\
Control & 0.29 (Low) & 0.36 (High) & $0.33 / 0.02$ \\
Complex & 0.63 (Moderate) & 0.68 (High) & $0.60 / 0.03$ \\
Distrust & 0.17 (Moderate) & 0.16 (Moderate) & $0.15 / 0.04$ \\
In-group & 0.07 (Moderate) & 0.06 (Moderate) & $0.07 / 0.01$ \\
Power & 0.22 (Moderate) & 0.26 (Moderate) & $0.25 / 0.03$ \\
Task & $0.55($ Low $)$ & 0.66 (Moderate) & $0.61 / 0.05$ \\
\hline
\end{tabular}

Rumsfeld's overall LTA scores and OCA belief scores are displayed in boldface type in Table 10d. His scores for each trait and belief are assessed against the norming group scores 
displayed in parentheses. The mean norming group score precedes the standard deviation for that score.

None of the six decision maker types is a match for Rumsfeld, nor does he even fit within either of the broader hawkish or dovish categories. There is variation in his ratings across norming groups. No variation, though, moves him from the dovish to hawkish camp, or vice versa.

Table 10d: Rumsfeld's Personality Trait (Overall) and Belief Scores

\section{LTA Scores}

\begin{tabular}{lllll} 
Compared to: & \multicolumn{2}{l}{ Full } & Anglo-US & Administration \\
Control & $\mathbf{0 . 3 3}$ & $(0.35 / 0.05)$ Moderate & $(0.36 / 0.04)$ Moderate & $(0.33 / 0.02)$ Moderate \\
Complex & $\mathbf{0 . 6 5}$ & $(0.59 / 0.06)$ Moderate & $(0.60 / 0.05)$ Moderate & $(0.60 / 0.03)$ High \\
Distrust & $\mathbf{0 . 1 7}$ & $(0.13 / 0.06)$ Moderate & $(0.12 / 0.03)$ High & $(0.15 / 0.04)$ Moderate \\
In-group & $\mathbf{0 . 0 7}$ & $(0.15 / 0.05)$ Low & $(0.13 / 0.03)$ Low & $(0.07 / 0.01)$ Moderate \\
Power & $\mathbf{0 . 2 4}$ & $(0.26 / 0.05)$ Moderate & $(0.24 / 0.04)$ Moderate & $(0.25 / 0.03)$ Moderate \\
Task & $\mathbf{0 . 6 1}$ & $(0.63 / 0.07)$ Moderate & $(0.62 / 0.06)$ Moderate & $(0.61 / 0.05)$ Moderate
\end{tabular}

\section{OCA Scores}

\begin{tabular}{lllll} 
Compared to: & \multicolumn{2}{c}{ Full } & Post-WWII US & Administration \\
& & & & \\
P-1 & $\mathbf{- 0 . 0 3 3}$ & $(0.273 / 0.280)$ Low & $(0.27 / 0.19)$ Low & $(0.175 / 0.123)$ Low \\
P-4 & $\mathbf{0 . 1 7 9}$ & $(0.207 / 0.114)$ Moderate & $(0.21 / 0.06)$ Moderate & $(0.188 / 0.034)$ Moderate \\
I-1 & $\mathbf{0 . 0 1 4}$ & $(0.346 / 0.336)$ Moderate & $(0.38 / 0.22)$ Low & $(0.146 / 0.279)$ Moderate \\
\hline
\end{tabular}

Rumsfeld stands out most when his LTA scores are compared to the Anglo-US norming group subset and his operational code belief scores are compared to those of Post-WWII US leaders. Here Rumsfeld looks somewhat like a hawk. He is high in distrust, sees politics as conflictual, believes conflictual strategies are best, and is moderate in his belief that he can control events. That said, his in-group bias here is low and his other LTA ratings are moderate. When compared to the entire LTA and OCA norming groups Rumsfeld is centrist, with his low in-group bias providing the only pull to one category, and that is the dovish one. In relation to the Bush administration group Rumsfeld is still overall moderate, and his high conceptual complexity (dovish) and low P-1 ratings (hawkish) are at odds with one another. 
The lack of a match between Rumsfeld and any decision maker type leaves the theoretical framework's hypotheses largely unable to predict his decision making behavior and policy positions. Only hypotheses one and nine allow for predictions about Rumsfeld's behavior. Aside from those predictions, only some rather limited expectations may be offered. Rumsfeld's consistently moderate belief that he can control events - evidenced both in his personality traits and operational code beliefs - allows the use of hypothesis one to predict that he will not have owls' and warhawks' susceptibility to positive illusions. Rumsfeld's equally consistent moderate task focus permits hypothesis nine to predict that he will exhibit, at minimum, owls' proneness to the biases of concession aversion and risk-seeking in losses. As discussed below, there are reasons to expect that Rumsfeld's propensity for concession aversion and risk-seeking to avoid losses will exceed that of owls.

Rumsfeld's uniformly low P-1 ratings, which indicate a view of the world and opponents characterized by hostility, should heighten his concession aversion and risk-seeking in losses. To the extent that his I-1 score is also low, as is the case when Rumsfeld is compared to the postWWII US norming group, one should expect a favorable view of conflictual strategies to provide additional reinforcement of Rumsfeld's susceptibility to these biases. Recall, though, that Rumsfeld's I-1 scores rate only as moderate when compared to the full and intra-administration norming groups.

There is little in the way of other expectations regarding Rumsfeld's decision making processes. At first blush one might expect Rumsfeld's consistently low P-1 ratings and high distrust (compared to the Anglo-US norming group subset) to make him prone to the reactive devaluation bias, the fundamental attribution error, and the pseudo-certainty bias. Low P-1 values and high distrust would militate for greater susceptibility to these biases and error, but in 
Rumsfeld they are countered by conceptual complexity ratings that range no lower than moderate and in-group bias ratings that are more often than not low (and exceeding moderate in no norming group comparison). In light of these countervailing tendencies in Rumsfeld's beliefs and personality one cannot present anything resembling a clear expectation about Rumsfeld's susceptibility to these hawkish biases and error.

Similarly, one cannot present straightforward expectations about Rumsfeld's proneness to dovish errors and biases. Rumsfeld's low P-1 and, to a lesser extent, moderate-to-high distrust might be seen as characteristics inoculating him against these errors and biases. His low P-1 and moderate-to-high distrust are, however, at least somewhat countered by his low-to-moderate ingroup bias and moderate-to-high conceptual complexity.

Regarding Rumsfeld's foreign policy positions, at least some expectations may be put forward. Rumsfeld's consistently low P-1 and uniformly moderate task focus give rise to an expectation that he will be at least somewhat predisposed to oppose conciliatory foreign policy. The tendency would be strengthened by any concession aversion or risk-seeking in losses Rumsfeld's decision making exhibits. Additionally, to the extent that Rumsfeld's I-1 belief favors conflictual strategies - as it does when he is compared to the post-WWII US leader norming group - Rumsfeld's opposition to compromise will be further strengthened. Moreover, there are reasons not only to expect that Rumsfeld will be disinclined to support compromise, but also to expect that he will support more conflictual foreign policies. The primary reason is Rumsfeld's low P-1 ratings. Rumsfeld's belief that the world and opponents are hostile should incline him towards conflictual policies (see Crichlow 2006: 83-89). This inclination would only be enhanced if Rumsfeld's I-1 belief favors conflictual strategies (as it does relative to the postWWII US norming group). 
While one should generally expect Rumsfeld to support conflictual foreign policies and oppose compromise, his foreign policy positions should also be affected by his moderate belief that he can control events. Specifically, one should anticipate Rumsfeld's foreign policy preferences, and thus policy positions, will bear some resemblance to those of a hawk. He should first favor domination but opt for settlement if domination is elusive. If settlement also proves elusive, Rumsfeld should back deadlock over submission. Paul Wolfowitz, Deputy Secretary of Defense

As is made clear in tables $11 \mathrm{a}, 11 \mathrm{~b}$, and $11 \mathrm{c}$ differences between Wolfowitz's scripted and spontaneous speech are solidly the rule, not the exception. ${ }^{8}$ The sheer number of rating discrepancies between Wolfowitz's scripted and spontaneous verbal behavior may reasonably be seen to call for a separate analysis of the two speech types. This view is reinforced by the frequent consistency in the differences. For instance, Wolfowitz's scripted speech is moderate in conceptual complexity in all comparisons, while his spontaneous utterances are just as consistently high in conceptual complexity.

There are, though, two main considerations that counsel against separate analysis. First, in no case is the disparity between speech types large enough to nudge Wolfowitz from the

\footnotetext{
${ }^{8}$ There are only two examples of consistency between speech types. First, when Wolfowitz is compared to the full LTA norming group his ratings on his belief that he can control events are moderate regardless of speech type. In the other two comparisons Wolfowitz's scripted speech produces moderate ratings for this trait, while his spontaneous speech generates low ratings. Second, in relation to the Anglo-US norming group subset Wolfowitz's spontaneous and scripted verbal behavior both rate high in distrust. Against the full and administration norming groups Wolfowitz's spontaneous speech is characterized by a high degree of distrust, whereas his scripted speech is only moderate in distrust.

For all other traits there are no examples of consistency between types of verbal behavior. Wolfowitz's ratings on conceptual complexity are consistently high for his spontaneous speech and uniformly moderate for his scripted utterances. Compared to the full and Anglo-US norming groups Wolfowitz's spontaneous verbal behavior rates as low in in-group bias, but his scripted speech is moderate for this trait. Assessed against the administration norming group Wolfowitz's scripted utterances rate as high in in-group bias, while his spontaneous utterances exhibit moderate in-group bias. For all three norming group comparisons his scripted speech indicates moderate need for power; his spontaneous speech evinces low need for power. Wolfowitz's spontaneous verbal behavior rates as moderate for task focus regardless of the norming group to which he is compared. His scripted speech indicates a low task focus, also irrespective of the norming group against which he is compared.
} 
hawkish to dovish category, or from the dovish to hawkish camp. Second, the disparities do not clearly show one speech type tending towards more hawkishness (or dovishness) than the other. Consider the following examples. Wolfowitz's spontaneous speech compared to the full and

Table 11a: Wolfowitz's Scripted vs. Spontaneous Personality Trait Scores Compared to Full LTA Norming Group

\begin{tabular}{lllc} 
& Scripted & Spontaneous & Norming Group Mean/Standard Deviation \\
Control & 0.33 (Moderate) & 0.30 (Moderate) & $0.35 / 0.05$ \\
Complex & 0.61 (Moderate) & 0.67 (High) & $0.59 / 0.06$ \\
Distrust & 0.18 (Moderate) & 0.21 (High) & $0.13 / 0.06$ \\
In-group & 0.11 (Moderate) & $0.06(\mathrm{Low})$ & $0.15 / 0.05$ \\
Power & 0.25 (Moderate) & 0.19 (Low) & $0.26 / 0.05$ \\
Task & 0.55 (Low) & 0.61 (Moderate) & $0.63 / 0.07$ \\
\hline
\end{tabular}

Table 11b: Wolfowitz's Scripted vs. Spontaneous Personality Trait Scores Compared to Anglo-US Norming Group

\begin{tabular}{lllc} 
& Scripted & Spontaneous & Norming Group Mean/Standard Deviation \\
Control & 0.33 (Moderate) & 0.30 (Low) & $0.36 / 0.04$ \\
Complex & 0.61 (Moderate) & 0.67 (High) & $0.60 / 0.05$ \\
Distrust & 0.18 (High) & 0.21 (High) & $0.12 / 0.03$ \\
In-group & 0.11 (Moderate) & 0.06 (Low) & $0.13 / 0.03$ \\
Power & 0.25 (Moderate) & 0.19 (Low) & $0.24 / 0.04$ \\
Task & 0.55 (Low) & 0.61 (Moderate) & $0.62 / 0.06$ \\
\hline
\end{tabular}

Table 11c: Wolfowitz's Scripted vs. Spontaneous Personality Trait Scores Compared to Administration Norming Group

\begin{tabular}{lllc} 
& Scripted & Spontaneous & Norming Group Mean/Standard Deviation \\
Control & 0.33 (Moderate) & 0.30 (Low) & $0.33 / 0.02$ \\
Complex & 0.61 (Moderate) & 0.67 (High) & $0.60 / 0.03$ \\
Distrust & 0.18 (Moderate) & 0.21 (High) & $0.15 / 0.04$ \\
In-group & 0.11 (High) & 0.06 (Moderate) & $0.07 / 0.01$ \\
Power & 0.25 (Moderate) & 0.19 (Low) & $0.25 / 0.03$ \\
Task & 0.55 (Low) & 0.61 (Moderate) & $0.61 / 0.05$ \\
\hline
\end{tabular}


administration norming groups indicates a high, hawkish level of distrust, but his scripted speech points to only a moderate level of distrust. Conversely, Wolfowitz's spontaneous speech in all comparisons demonstrates a dovish low need for power, but his scripted speech is equally uniform in indicating a moderate need for power. Given that the disparities between speech type are neither large enough to shift him between the hawkish and dovish categories for any trait, nor even consistently hawkish or dovish in direction, there is not a convincing case for distinguishing between types of verbal behavior in classification of, or hypothesizing about, Wolfowitz. Any choice between speech types would be arbitrary and separate analyses of both speech types would produce an analytical morass. The following analysis will instead focus on only his overall LTA scores.

Overall LTA scores and OCA belief scores for Wolfowitz can be found in Table 11d (boldface type). His scores for each trait and belief are compared to the parenthetical norming group scores. The mean norming group score is followed by the standard deviation for that score.

Table 11d: Wolfowitz's Personality Trait (Overall) and Belief Scores

\section{LTA Scores}

\begin{tabular}{lllll} 
Compared to: & \multicolumn{2}{c}{ Full } & Anglo-US & Administration \\
Control & $\mathbf{0 . 3 1}$ & $(0.35 / 0.05)$ Moderate & $(0.36 / 0.04)$ Low & $(0.33 / 0.02)$ Moderate \\
Complex & $\mathbf{0 . 6 4}$ & $(0.59 / 0.06)$ Moderate & $(0.60 / 0.05)$ Moderate & $(0.60 / 0.03)$ High \\
Distrust & $\mathbf{0 . 2 0}$ & $(0.13 / 0.06)$ High & $(0.12 / 0.03)$ High & $(0.15 / 0.04) H i g h$ \\
In-group & $\mathbf{0 . 0 9}$ & $(0.15 / 0.05)$ Low & $(0.13 / 03)$ Low & $(0.07 / 0.01) H i g h$ \\
Power & $\mathbf{0 . 2 2}$ & $(0.26 / 0.05)$ Moderate & $(0.24 / 0.04)$ Moderate & $(0.25 / 0.03)$ Moderate \\
Task & $\mathbf{0 . 5 8}$ & $(0.63 / 0.07)$ Moderate & $(0.62 / 0.06)$ Moderate & $(0.61 / 0.05)$ Moderate
\end{tabular}

\section{OCA Scores}

\begin{tabular}{lllll} 
Compared to: & & Full & Post-WWII US & Administration \\
P-1 & & & & \\
P-4 & $\mathbf{0 . 0 5 4}$ & $(0.273 / 0.280)$ Moderate & $(0.27 / 0.19)$ Low & $(0.175 / 0.123)$ Moderate \\
I-1 & $\mathbf{0 . 1 8 6}$ & $(0.207 / 0.114)$ Moderate & $(0.21 / 0.06)$ Moderate & $(0.188 / 0.034)$ Moderate \\
\hline
\end{tabular}


Wolfowitz fits none of the decision maker types. He does not even clearly belong in either the broader dovish or hawkish camps. There are several variations in his trait and belief ratings across norming groups. In the case of in-group bias, the variation ranges from a dovish low to a hawkish high.

Although Wolfowitz does not straightforwardly match a single type or even fit within either broader category, he is best characterized as leaning hawkish. His distrust ratings are high across the board. When compared to the entire OCA norming group and the Post-WWII US leaders subset of that group Wolfowitz has hawkish low I-1 ratings. When compared to the PostWWII US subset Wolfowitz has a low P-1 rating, also hawkish. Finally, in relation to other Bush administration officials assessed here Wolfowitz has a strong in-group bias. His mostly moderate ratings for belief in ability to control events combined with his hawkish leanings make him look most like a hawk.

Characterizing Wolfowitz as a hawk does, however, run into some difficulties.

Wolfowitz is high in conceptual complexity compared to the intra-administration norming group, a dovish-looking position on the spectrum. Additionally, his in-group bias ratings are low except when Wolfowitz is compared to the administration group. That, too, makes him look more dovish. One must also note that his P-1 and I-1 ratings are not universally low and hawkish. Finally, his ratings on need for power and task focus are consistently moderate, not high and hawkish.

Given that Wolfowitz does not plainly fit any one decision maker type, the ability of the theoretical framework to produce predictions about his decision making processes and policy positions is rather constrained. Only two hypotheses can be used to produce such predictions. Past that only qualified expectations are possible. 
Hypotheses one and nine are the two hypotheses which can apply to Wolfowitz. Their predictions are presented in turn. In terms of his personality and operational code Wolfowitz's belief that he can control events ranges from low to moderate depending on the norming group to which he is compared. His low-to-moderate ratings for these variables allow hypothesis one to predict that Wolfowitz will not exhibit owls' and warhawks' propensity for positive illusions. Wolfowitz's uniformly moderate task focus will, according to hypothesis nine, leave him susceptible to other biases. In particular, hypothesis nine predicts that Wolfowitz will at the very least exhibit an owl's moderate proneness to concession aversion and risk-seeking in losses.

There is, though, reason to expect Wolfowitz's susceptibility to concession aversion and risk-seeking to avoid losses will be greater than an owl's. Compared to the full OCA norming group and post-WWII US leader subset of that norming group Wolfowitz has low I-1 ratings, indicating a belief that conflictual strategies are most effective. To the extent that these ratings capture the true beliefs of Wolfowitz, his proneness to this pair of biases should be exacerbated.

Beyond these predictions and expectations the view of Wolfowitz is much murkier. Wolfowitz's consistently high distrust ratings could be seen as leaving him susceptible to a trio of hawkish errors and biases: fundamental attribution error, pseudo-certainty bias, and reactive devaluation bias. High distrust is not alone sufficient to predict susceptibility to these errors and biases, but an expectation of such susceptibility is reinforced by Wolfowitz's low P-1 belief relative to the post-WWII US leader subset of the OCA norming group. Also acting to reinforce this impression is his high in-group bias rating when compared against the intra-administration norming group. However convincing this view of Wolfowitz might appear, though, there are several reasons it is actually quite problematic. First, Wolfowitz's P-1 ratings are moderate when he his examined against the intra-administration and full OCA norming groups. Second, 
his in-group bias ratings are low when he is compared to the full LTA norming group and its Anglo-US subset. Third, Wolfowitz's conceptual complexity ratings, which bear on his susceptibility to the fundamental attribution error, range from moderate to a high, dovish rating. In sum, it is impossible to state with confidence that Wolfowitz will be particularly susceptible to the fundamental attribution error, pseudo-certainty bias, or reactive devaluation bias.

There are, however, several reasons to expect that Wolfowitz will be relatively resistant to dovish errors. For one, only his low in-group bias ratings compared to two of the three LTA norming groups provide any basis for expecting proneness to dovish errors. Conversely, his consistently high distrust ratings, low-to-moderate P-1 ratings, and low-to-moderate I-1 ratings, all suggest at least some resistance to the errors. Further, it must be noted that Wolfowitz's ingroup bias rating is high when he is assessed against the Bush administration norming group.

Given Wolfowitz's resistance to dovish errors, his consistently moderate task focus, and his likely moderate susceptibility to both concession aversion and risk-seeking in losses, one should expect him to be somewhat inclined to oppose policies of compromise. His low-tomoderate I-1 and P-1 ratings buttress this expectation to a point, but do not provide a solid foundation for anticipating more clearly conflictual policy positions. His constellations of other trait and belief ratings are characterized at least by indeterminacy, and sometimes contradiction. As such they give no direction in anticipating his foreign policy positions.

\section{Conclusion}

This chapter's quantitative analysis of seven Bush administration officials' personalities and beliefs has produced important questions. In particular, the lack of a clear fit between the administration members and the theoretical framework's decision maker types begs two questions. First, is the framework's classificatory ability, and thus its predictive power, now in 
doubt? After all, as noted in the previous chapter, these officials have been so often discussed using the labels of hawk and dove, but none can be plainly called hawkish or dovish according to the typology. This contemplation leads into the second question: is the popular discussion of these elites oversimplified or mistaken in its application of the labels? The remainder of this section addresses these questions in turn.

Definitive judgment on the theoretical framework's value as a classificatory and predictive tool will require more research than this single study (recommendations for future research are discussed in the final chapter), but some points regarding the value of the framework are worth making here. To begin, while none of the Bush administration officials analyzed here fits a decision maker type from the framework, there are differences across the officials that line up with the hawk and dove labels variously applied to the decision makers by others. Cheney, Rumsfeld, and Wolfowitz, the officials typically labeled as hawkish (see e.g., Binnendjik and Lin 2014; Robison 2006), all have moderate-to-low ratings on either operational code belief P-1 or I1. Recall that lower P-1 ratings are associated with a more hostile view of opponents and the world, as well as more support for conflictual policy (see Crichlow 2006: 83-89; George 1969: 199-203; Schafer and Walker 2006: 33). Remember, too, that lower I-1 ratings reflect a stronger belief the conflictual foreign policies are best (see e.g., George 1969: 205-211; Schafer and Walker 2006: 35). Rice, who has also been deemed a hawk (Left 2002; see also Badie 2010: 286) but less often so, has uniformly moderate P-1 ratings, but garners a low I-1 rating compared to the post-WWII US leaders norming group. Powell and Armitage, the two decision makers commonly termed doves (Harnden 2003; Robison 2006), have P-1 and I-1 ratings no lower than moderate, with Armitage having moderate-to-high ratings for both traits. ${ }^{9}$ In short the different

\footnotetext{
${ }^{9}$ Bush, like Powell, has consistently moderate P-1 and I-1 ratings, but contrary to Powell has been labeled by some a hawk (Left 2002; see also Badie 2010: 286).
} 
labels applied by others to the decision makers do correspond with differences in the individuals' beliefs.

The match between others' applications of hawkish and dovish labels to the officials and patterns in my findings is reinforced when some of Vaughn P. Shannon and Jonathan W.

Keller's (2007: 88-91) findings are considered. Notably, Shannon and Keller do not focus on the decision makers as hawks or doves per se. Their discussion of the officials' different levels of support for conflict and varying willingness to pursue conflictual foreign policies in the face of international legal and public opposition does, though, clearly parallel those aforementioned works that $d o$ emphasize hawk and dove labels. In particular, Shannon and Keller's findings show Cheney, Rumsfeld, and Wolfowitz to be the most hawkish in that they are strongly proconflict and willing to defy the international community. They find Powell (whom they do label a dove) and Armitage to be the most dovish insomuch as they wished to accommodate the international community and avoid war. Bush and Rice are, in Shannon and Keller's findings, between the other decision maker groupings; the two decision makers supported war over international objections, but did so less consistently or vociferously than Cheney, Rumsfeld, and Wolfowitz. These findings not only line up well with others' depictions of the decision makers (see e.g., Badie 2010: 286; Binnendjik and Lin 2014; Harnden 2003; Left 2002; Robison 2006), but also have considerable harmony with the operational code P-1 and I-1 belief patterns I describe in the previous paragraph. ${ }^{10}$

The importance of correspondence between how the labels hawk and dove are used by others and patterns in the findings of the present analysis should not be overstated. The foregoing discussion does not alter the conclusion that there is no clear match between the

\footnotetext{
${ }^{10}$ The sole stark exception is that Bush and Powell, who both have consistently moderate P-1 and I-1 ratings, appear rather distinct from one another in Shannon and Keller's (2007: 88-91) findings, with Powell markedly less supportive of conflict and more inclined to adhere to international standards and opinion than Bush.
} 
selected officials and the framework's decision maker typology. Still, what the discussion does suggest is that there are psychological differences between decision makers labeled hawkish or dovish. There is something to the labels, something worth further research and perhaps refinement of the theoretical framework and its typology.

Before proceeding to address the second question raised by my findings, it bears noting that Shannon and Keller's (2007) study of the same Bush administration officials helps to make another point regarding my theoretical framework's value. Specifically, they find that while their hypotheses about the effect of personality traits on elites' foreign policy decisions are only partly supported by the findings of their analysis, those hypotheses still help to explain the actions of the Bush administration officials and thus still have value. Likewise, my theoretical framework can still have value as an explanatory or predictive analytical tool even if it cannot plainly classify a given decision maker.

Much of the foregoing discussion contributes to answering the second question, that of whether popular discourse about these elites is simplistic or wrong in its use of the hawk and dove labels. The labels do generally line up with a pattern of differences in the operational codes of the decision makers to which they are applied. At the same time, the labels obscure the many commonalities across the Bush administration officials. Indeed when one pulls back and compares the decision makers not to one another in the intra-administration norming groups but instead to the larger OCA and LTA norming groups and subgroups, the officials as a group are characterized more by sameness than difference. Relative to the whole LTA norming group and its Anglo-US subset all of the decision makers have dovish low in-group bias ratings. Again compared to those LTA groups, the Bush administration officials share consistently moderate ratings on conceptual complexity and need for power. Further, except for Bush - who rates as 
low on this trait - all of the officials are characterized by steadily moderate task focus in relation to the whole and Anglo-US LTA norming groups. Finally, in terms of both LTA traits and OCA beliefs the officials are, when examined against the larger LTA and OCA norming groups and subgroups, moderate or moderate-to-low in their belief that they can exert control over events.

In sum, beneath the apparent differences and contrasting labels the Bush administration officials are largely similar. Popular discussion of these officials as hawks and doves does, then, seem to be oversimplified. The discussion gives rise to a monochromatic view of the officials where a more realistic perspective would capture the shades of grey distinguishing the individuals. Simplistic the public discourse may be, but use of the hawk and dove labels is not therefore necessarily wrong. The monikers do correspond to differences apparent in the officials' psychology.

The present analysis also raises another question, one that will be addressed in the next chapter. Specifically, will the selected Bush administration officials exhibit any of the errors and biases, or take any of the foreign policy positions, associated with the framework's hawkish or dovish decision maker types? Hypotheses one and nine have routinely offered predictions about the selected elites' decision making. The other hypotheses have not been usable as a means to straightforwardly formulate predictions about the individuals' foreign policy positions. Generally, I have been able to posit only qualified expectations about their decision making processes and policy positions. Consequently, the next chapter's objectives will not only focus on hypothesis testing but also on an inductive exploration of the data that might inform the theoretical framework.

As a final point, although this chapter has generated several questions, questions are not its only product. My analysis of scripted and spontaneous verbal material from the selected Bush 
administration decision makers can speak to the debate (discussed in the previous chapter) over which types of speech LTA researchers should analyze (see e.g., Dille 2000; Hermann 2003; Winter 2003). Namely, in the case of these individuals there were differences in variable values by speech act type, but the differences were not of sufficient magnitude or clarity of direction to lead me to favor one type over the other. The findings, then, tend towards supporting David Winter's (2003: 174-175) assessment that both speech types, in spite of their differences, are the words of the decision maker and thus "are a reasonable guide to the [decision maker's] personality." 


\section{Chapter 4: Qualitative Analysis}

This chapter presents the findings from my qualitative analysis. I identify the selected elites' foreign policy positions. I also discuss evidence regarding errors and biases and their role in the decision making underlying those positions. The results of my analysis are ultimately employed to assess my theoretical framework.

The chapter is organized as follows. I first briefly introduce the foreign policy situation, vis-à-vis Iraq, facing the Bush administration officials. This introduction necessitates a little post-Gulf War background on US-Iraq relations. In the second section I discuss the course of the officials' foreign policy deliberations over Iraq, covering the period from the beginning of the administration up to the implementation of the final policy of war. Through this discussion I present my analysis of the foreign policy positions of the selected officials. The third section addresses the selected officials' susceptibilities or resistance to errors and biases as well as the effects any identified susceptibilities or resistance had on the elites' policy positions. In the fourth section I individually summarize my findings for each decision maker and assess my theoretical framework against the results of the qualitative analysis. The concluding section presents an overall assessment of the theory and considers whether patterns in the findings might inform the framework.

\section{US-Iraq Relations: A Very Brief Backgrounder}

When the Bush administration came into office in 2001 United States foreign policy towards Iraq had for nearly 10 years been defined by the post-Gulf War containment of Saddam Hussein's regime (Ricks 2006: 4). George H.W. Bush's administration had immediately after the Gulf War incited the Iraqi military, Shiites, and Kurds to overthrow Saddam, but then withheld military support as Saddam quashed the rebellions (Gordon and Trainor 2006: 11-12; 
Ricks 2006: 5-6). The US only interceded on the ground to the extent that American forces were eventually used to make safe a space for Kurds in Iraq's north (Ricks 2006: 8-9). Aside from those early actions US policy after the Gulf War largely centered on containment via no-fly zone enforcement actions in the south and north of Iraq, United Nations weapons inspections monitoring Iraq for weapons of mass destruction (WMD), and economic sanctions (Gordon and Trainor 2006: 12; Ricks 12-15). The sole major escalation of US activity against Iraq during this period came with the Desert Fox strikes of 1998, in which United Kingdom and US forces bombed suspected weapons sites as a reaction to Saddam's resistance to weapons inspections (Gordon and Trainor 2006: 13; Ricks 2006: 18-19). Also in 1998, Congress passed, and President William Clinton signed, legislation making regime change the policy of the US (see Woodward 2004: 169). These more assertive moves in 1998 aside, when the Bush administration took the reins of executive power in 2001 containment of Saddam's Iraq was the established and de facto policy.

\section{Foreign Policy Deliberation and Positions}

\section{Pre-9/11 Period}

Michael R. Gordon and Bernard E. Trainor (2006: 14) argue that President George W. Bush, Vice President Richard "Dick" Cheney, and "most of [Bush's] national security team" entered office with the assumption "that something had to be done" about Iraq. Thomas Ricks (2006: 27) notes, though, that according to Patrick Clawson, an expert on the Middle East familiar with Washington, D.C. neoconservatives, “[t]here wasn't really a 'war party' inside the Bush administration before $9 / 11 \ldots$ there really was just [Deputy Secretary of Defense Paul] Wolfowitz, pleading for more attention to Iraq." Ricks (2006: 28) further notes that continuation of containment was Bush's initial policy; National Security Advisor (NSA) Condoleezza Rice 
made certain to other officials that intervening in Iraq was not on the table at the time. Indeed in the early days of the Bush administration critics on the outside saw the administration as softening on Iraq compared to the Clinton administration (Ricks 2006: 28).

The period prior to11 September 2001 contains few documented policy deliberations about Iraq involving all or most of the selected elites. A principals meeting (i.e., a meeting of the National Security Council [NSC] but without the president) on 1 June 2001 addressed Iraq, but no policy path was agreed (Gordon and Trainor 2006: 14). The Bush administration officials studied here were, though, pursuing Iraq policy programs before the $9 / 11$ attacks.

Secretary of State Colin Powell sought new "smart sanctions" (Mann 2004: 301; Ricks 2006: 28; see also Woodward 2002: 83) which would allow into Iraq more civilian goods while making more restricted access to anything with military applications. Powell's approach emphasized diplomacy and working to enlist the help of allies, with force an option only after all else had failed (Gordon and Trainor 2006: 14). Powell's smart sanctions policy position initially prevailed with Bush (Ricks 2006: 28), but Wolfowitz, since assuming his position in the administration, had wanted to back Iraqi opponents of Saddam (Woodward 2002: 83). Between 31 May and 26 July 2001 Wolfowitz worked on an "enclave strategy" in which US forces would take the oil fields in the south of Iraq and use that territory and wealth to serve as a base for Saddam's opponents to use in their efforts to topple Saddam (Woodward 2004: 21-22). Powell, who was aware of Wolfowitz's policy position, stated his opposition to Wolfowitz's plan personally to Bush, with the president stating that he was "in no hurry to go look for trouble" (Woodward 2004: 22).

During this period Secretary of Defense Donald Rumsfeld developed a strategy that represented something of a midpoint between the policy positions of Powell and Wolfowitz. 
Specifically, Rumsfeld advocated a policy of more vigorously prosecuting the no-fly zone enforcement by UK and US air forces in order to undermine Saddam (Gordon and Trainor 2006:

15). He called for disproportionately retaliating against any Iraqi use of force against British and American warplanes (Gordon and Trainor 2006: 15). For example, rather than simply target Iraqi air defenses in response to an attack, UK and US planes could strike the transports Saddam's Republican Guard used to move tanks around Iraq (Gordon and Trainor 2006: 15). Post-9/11 Period

Iraq in Early War on Terror Deliberations

Following the terrorist attacks of 11 September 2001 all of the selected decision makers saw Saddam as a threat and eventual target in what came to be known as the "war on terror" (Woodward 2002: 49). This does not mean, however, that they were in agreement regarding how or when to act. There was much deliberation and debate about Iraq and Saddam within the Bush administration.

Although Rumsfeld was not previously focused on Iraq (Gordon and Trainor 2006: 10), the very day of the terrorist attacks he was quick to discuss with aides moving against Saddam in retaliation (Woodward 2004: 24-25). At the next day's NSC meeting Rumsfeld suggested to the other officials under study striking Iraq, not just the Al Qaeda organization responsible for the 9/11 attacks (Woodward 2002: 48). According to Bob Woodward (2002: 48), Rumsfeld was treating the attacks as an opportunity to immediately attack Iraq.

During that same NSC meeting Powell opposed an early strike against Iraq, citing as his reasons concern that doing so would threaten the solidity of the coalition of US allies as well as the American public's focus on Al Qaeda (Woodward 2002: 49). Cheney, who used the meeting to propose pursuing state sponsors of terror (but not specifically Iraq), countered Powell's 
viewpoint stating that he was more interested in eliminating threats than building and maintaining a coalition (Woodward 2002: 48). Rumsfeld similarly emphasized the need for serious coalition members over a larger coalition with less commitment. Ending the deliberation, Bush called for delaying any decision on Iraq (Woodward 2002: 49)

In additional meetings on 15 September 2001 Rumsfeld again raised the question of striking Iraq, noting that US forces would be closer to Iraq on account of buildup for the coming action against Afghanistan and that Iraq had more targets to hit compared to Afghanistan (Woodward 2002: 84; see also Ricks 2006: 30). Of note, though Rumsfeld seemed to suggest making an attack on Iraq US policy (see Gordon and Trainor 2006: 16; Ricks 2006: 30), Bob Woodward $(2002: 84,88)$ explicitly points out that the Secretary of Defense made no specific policy recommendation. The Secretary of Defense did, however, ask Wolfowitz to bring up Iraq (Gordon and Trainor 2006: 16), and I presume he knew Wolfowitz would advocate acting against Iraq.

At the meetings Wolfowitz, acting on Rumsfeld's encouragement, proposed the US take on Iraq "during the first round" (Gordon and Trainor 2006: 16) of the campaign against terrorism. ${ }^{1}$ He opined that attacking Saddam's regime, which he believed was fragile, would be relatively easy and was in any case something the US needed to do to ensure others knew the US was serious about its war against terrorism (Gordon and Trainor 2006: 16; Ricks 2006: 30; Woodward 2002: 83). Wolfowitz further claimed that Iraq under Saddam represented a strategic threat, noting as an example of threatening behavior that Saddam had publicly stated the 9/11

\footnotetext{
${ }^{1}$ Writing at an earlier date Woodward (2004: 25) states that on 15 September 2001 "none of the president's top advisers recommended attacking Iraq as a first step in the terrorism war". In Bush at War, though, Woodward (2002: 49) claims "Paul D. Wolfowitz... was committed to a policy that would make Iraq a principal target of the first round in the war on terrorism."
} 
attacks were a dose of what the US had inflicted on Arabs (Gordon and Trainor 2006: 16). ${ }^{2}$ Wolfowitz perceived Iraqi support for terror, even estimating "a 10 to 50 percent chance Saddam was involved in the September 11 terrorist attacks" (Woodward 2002: 83)

Powell served as a counterbalance to Rumsfeld and Wolfowitz, repeatedly speaking against any attack on Iraq (Woodward 2002: 91; 2004: 25). He warned that coalition partners might withdraw if action broadened beyond the targets of Al Qaeda and Afghanistan, and expressed his feeling that Afghanistan was unwinnable without help, much less a broader conflict (Gordon and Trainor 2006: 16; Woodward 2002: 81, 84; 2004: 25). Although Powell wanted an Afghanistan-first policy for the war on terror, he did concede that evidence of Iraqi involvement in 9/11 could bring support for striking Saddam at a later time (Gordon and Trainor 2006: 16; Woodward 2002: 84). The Secretary of State added that he did not see Iraq as behind the attacks (Woodward 2002: 87).

Rumsfeld rebutted Powell, saying the "the argument that the coalition wouldn't tolerate Iraq argues for a different coalition" (Woodward 2002: 88; see also Gordon and Trainor 2006: 16). Bush voiced agreement with Rumsfeld's sentiment, stating he did not want others to determine the conduct of the war against terrorism and asserting the US could and would act alone if necessary (Woodward 2002: 81). Cheney, however, somewhat reversed his stance from the 12 September NSC meeting, and argued against war with Iraq in the short term because doing so threatened the coalition (Woodward 2002: 91; 2004: 25).

During a recess in the day's meetings Wolfowitz engaged Bush and Cheney in a side conversation to reiterate and build on his argument for an early targeting of Iraq (Gordon and Trainor 2006: 16; Woodward 2002: 84). He used the opportunity of his audience with the

\footnotetext{
${ }^{2}$ Michael Gordon and Bernard Trainor (2006: 16) point out that "some State Department officials saw it [i.e., Saddam's statement] as bluster."
} 
president and vice president to propose his enclave strategy as preparation for ousting Saddam (Gordon and Trainor 2006: 16). Bush seemed receptive to Wolfowitz's proposal to act against Iraq (Gordon and Trainor 2006: 16).

Bush may have been open to Wolfowitz's position, but he retained serious reservations regarding a move against Saddam and informed his officials that he was tabling the topic of Iraq (Woodward 2002: 84-85). As the meetings came to a close, Bush expressed to the then Joint Chiefs chair, General Hugh Shelton that he would first focus on Afghanistan (Gordon and Trainor 2006: 17). Shelton told him that was the right decision, saying striking Iraq would cause problems in the coalition and Middle East, as well as averring that he saw no connection between Iraq and the 9/11 terrorist attacks (Gordon and Trainor 2006: 17). The next day, 16 September, during a conversation with Rice Bush said Afghanistan was the first order of business, but the subject of Iraq would be revisited (Woodward 2004: 26). At a NSC meeting on the $17^{\text {th }}$ Bush informed the other officials "to keep working on plans for military action against Iraq" but not to hurry (Woodward 2002: 99; see also Gordon and Trainor 2006: 17; Woodward 2004: 26). The president stated he believed the 9/11 attacks had Iraqi involvement, noting that the evidence was yet to be obtained (Woodward 2002: 99).

On 20 September 2001 Bush told UK Prime Minister Tony Blair "Iraq was not the immediate problem" (Ricks 2006: 31). During a meeting of the NSC the same day the president delayed a pending routine strike enforcing the Iraqi no-fly zone, calling for patience and "clarity of the mission" (Woodward 2002: 107). Twice more late in that month Bush stated his position of waiting to address Iraq, saying, however, that if Saddam were to be caught involved in terrorism, the US would take action (Woodward 2002: 137, 167). At this time the president again expressed his belief that Saddam was likely behind the 9/11 attacks (Woodward 2002: 
167). In sum, the deliberations of the month show Bush convinced of Saddam's hostility towards, and action against, the US, but they also show the president reticent to strike Iraq so early in the war on terror.

Bush's reluctance to attack Iraq clearly was not shared by Wolfowitz, and Rumsfeld, too, seems to have remained interested in moving against Iraq early in terrorism fight. In the days following the 15 September meetings Wolfowitz issued memos to Rumsfeld pressing the issue of targeting Iraq (Ricks 2006: 31). During a NSC meeting on 25 September Rumsfeld again raised the question of expanding the war beyond Afghanistan (Woodward 2002: 137). His question prompted one of Bush's late-September calls for patience regarding Iraq (Woodward 2002: 137). Barton Gellman (2008: 226), citing Douglas Feith (Undersecretary of Defense for Policy during Bush's first term), noted Rumsfeld was at this time already focused on the potential connections between Iraq, weapons of mass destruction (WMD), and terrorist groups. This may help explain why at a 30 September principals meeting Rumsfeld became one of the first administration officials to suggest a policy of preemptive strikes (Woodward 2002: 176).

Rice and Powell, in contrast to the Secretary of Defense and his deputy, expressed interest in avoiding war with Iraq as September wound down. Powell privately expressed his disdain for the idea of going after Iraq to General Shelton (Woodward 2002: 61). For her part, in a principals meeting on 24 September, Rice asked the following questions:

What is our strategy with respect to countries that support terrorism like Iran, Iraq, Libya, Syria, and Sudan? How do we define the hurdles they have to jump over to get on the right side of the war on terrorism (Woodward 2002: 131-132)?

Where Wolfowitz was proposing how the US could move to topple Saddam Rice was exploring how Saddam could rehabilitate Iraq in the eyes of US policy. 
Policy deliberation on Iraq dropped off after September's flurry of discussion. ${ }^{3}$ Still, there are during the final quarter of 2001 some glimpses into the developing policy positions of the decision makers. Woodward (2004: 39) reports that by around the end of November Powell and Deputy Secretary of State Richard Armitage wanted Saddam overthrown but at a later date and such that the post-Gulf War coalition against Saddam would remain cohesive. There is in this period also evidence about Bush's position, and it shows change in the president's thinking. On 21 November after an NSC meeting Bush requested Rumsfeld work in secret with General Thomas Franks (then head of US Central Command [CENTCOM]) on updating plans for war with Iraq (Woodward 2004: 1-4). ${ }^{4}$ The purpose of the planning, the president said, was ousting Saddam, but added toppling the Iraqi leader would be done only if necessary (Woodward 2004: 2).

On 26 November the Secretary of Defense met with Franks, instructing him to begin plans for toppling Saddam (Gordon and Trainor 2006: 21). Just over a month later Franks presented his initial planning to Bush, Cheney, Powell, Rice, and Rumsfeld (Gordon and Trainor 2006: 31-32; Woodward: 2004: 52-66). In a sign that Bush's policy position was indeed moving towards war with Iraq, the president agreed that the US military should begin shifting resources in preparation for attacking Saddam (Woodward 2004: 58-63). The year ended, then, with Bush leading a change in the direction of US policy on Iraq. Developments during a Lull in Deliberations: The First Half of 2002

\footnotetext{
${ }^{3}$ On 2 October 2001 Rumsfeld issued a top secret "Strategic Guidance" purporting to lay out what Bush ordered, which was a "global war on terrorism" waged with "[a]1l tools of national power" (Woodward 2002: 189) against terrorists and the terrorists' state and non-state sponsors, with a special focus on stopping terrorists from obtaining the capacity to use WMD. Then, at a 9 October NSC meeting Rumsfeld again brought up taking action beyond Afghanistan, but Woodward (2002: 216) notes that "[n]o one seemed interested." Notably, no mention of Iraq by Rumsfeld is reported for either the Strategic Guidance or NSC meeting. Also of note, Woodward (2002: 189) states that while Rumsfeld's Strategic Guidance conveyed to his department certainty regarding Bush's policy, other departments were less sure in presuming to know the president's mind.

${ }^{4}$ Only Rice had been informed of the president's instruction to Rumsfeld, and even then Bush did not explain the reason for setting Rumsfeld to work on planning (Woodward 2004: 4).
} 
Until August 2002 deliberation among the selected officials on what to do about Iraq was in a state of dormancy. The absence of policy discussions did not, though, mean that there were no policy developments. On 16 February 2002 Bush signed orders authorizing the Central Intelligence Agency to covertly aid the US military to oust Saddam (Woodward 2002: 329-330; 2004: 108-109). This order demonstrates Bush's increasingly clear shift towards a conflictual foreign policy on Iraq.

The absence of deliberation among the administration officials also did not mean there was no more official discussion of Iraq prior to August. On 6 February Director of Central Intelligence George Tenet testified publicly before the Senate Intelligence Committee that Iraq was "capable of producing WMD" and that "Saddam never abandoned his nuclear weapons programs" (Woodward 2004: 194). He did not say Saddam had, or was close to having, nuclear weapons, only that he feared Saddam would obtain fissile material needed for such weapons (Woodward 2004: 194). This information on WMD meshed with Rumsfeld and Cheney's suspicions about Saddam (Gordon and Trainor 2006: 126). Cheney saw Iraqi WMD capabilities and the links he perceived between Saddam and terrorism as requiring the US to strike (Woodward 2004: 194).

The CIA's June report on Iraq's ties to Al Qaeda was, however, less in line with the views of Cheney or Rumsfeld (Gordon and Trainor 2006: 126-127). In the report the CIA did not rule out the potential for cooperation between Iraq and Al Qaeda, but stated that they were wary of one another (Gordon and Trainor 2006: 127). While someone in the CIA complained confidentially, saying the report overstated the possible link, Rumsfeld, Cheney, and Wolfowitz were of the opinion that the CIA tended to underestimate threats (Gordon and Trainor 2006: 127). 
The Policy Debate Resumes: UN or Unilateralism

Deliberation among the selected decision makers was rekindled when on 5 August Powell, worried about the direction of war planning under Franks, proposed privately to Bush (Rice was also present) that the US should build a coalition or obtain United Nations action to address the Iraqi threat (Gordon and Trainor 2006: 71; Woodward 2004: 151). Powell especially recommended Bush seek UN action in the form of new weapons inspections, saying that UN action might leave Saddam in place but still solve the problem posed by Iraq (Gordon and Trainor 2006: 71; Woodward 2004:151). Powell's recommendation indicates a policy position less conflictual than that of administration officials like Wolfowitz who were more focused on forcibly removing Saddam from power. Indeed Powell informed Bush that working through the UN would give Saddam the opportunity to comply, abandon his WMD, and put the US in the position of dropping a regime change policy (Gordon and Trainor 2006: 71; Woodward 2004: 151). Bush accepted Powell's argument, even the possibility that Iraqi compliance could see Saddam maintain his position, and agreed to pursue United Nations Security Council (UNSC) action (Gordon and Trainor 2006: 71).

During a 14 August principals meeting Powell repeated the proposal for a coalition or UN action he had previously pitched to the president, saying there would be no international support for war without the UN or other coalition, perhaps not even from the UK (Woodward 2002: $335 ;$ 2004: 156). Powell argued that diplomacy must be the first path forward and that Bush should speak to the UN General Assembly (Woodward 2002: 335; 2004: 156). Cheney, Rice, and Rumsfeld supported Powell's call for seeking UN action, though Cheney warned that working through the UN would leave the US bogged down in international deliberations and compromises (Woodward 2002: 335-336; 2004: 156-157). The vice president proceeded to 
argue that Bush's speech should focus on the UN's failures and irrelevancy, especially its inability to solve the problem of Saddam and his WMD (Woodward 2002: 336; 2004: 157). Rice concurred with Cheney's suggestion for the president's speech (Woodward 2002: 336; 2004: 157).

Two days later at a meeting of the NSC Powell's proposal that Bush speak before the UN was revisited, with Cheney, Powell, Rice, and Rumsfeld maintaining their agreement with a policy of obtaining UN action on Iraq (Woodward 2002: 336; 2004: 161). Bush agreed to giving the speech, saying, in Woodward's (2004: 161) words, that the speech should not "require so much of Iraq that it would look as if [the US] were not serious." This reinforces the impression of the 5 August meeting with Powell that Bush supported leaving room for Iraq to return to compliance. Bush's agreement to seek UN action should not, however, be taken as indication that he was without doubts about the UN, nor that he was committing to a UN-only policy of acting on Saddam. After the NSC meeting Bush, echoing Cheney's suggestion of the 14 August principals meeting, told speechwriter Michael Gerson the speech should inform the UN it must confront Iraq or choose to be irrelevant (Woodward 2004: 161).

The resumption of the officials' discussion about Iraq coincided with a renewed public debate about US policy towards that country. Former Secretary of State Henry Kissinger wrote an opinion piece for the 12 August edition of The Washington Post in which he applauded Bush for seeking action on Iraq, but also cautioned that the administration should obtain international support (Ricks 2006: 48; Woodward 2004: 163). James Baker, Secretary of State under President George H.W. Bush, also publicly argued that the US should seek multilateral action (Ricks 2006: 48; Woodward 2004: 163). Where Kissinger and Baker warned against the US acting unilaterally, Brent Scowcroft, National Security Advisor to George H.W. Bush argued 
explicitly against striking Saddam. Scowcroft wrote a 15 August Wall Street Journal opinion piece, "Don't Attack Saddam" in which he argued that Saddam was unlikely to work with terrorists and that there was very little to suggest an Iraqi role in the 9/11 terror attacks (Ricks 2006: 47; Woodward 2004: 159-160). Scowcroft further asserted that international consensus was against war in Iraq, meaning the US would be left to "difficult and expensive" unilateral action, including "a large-scale, long-term military occupation" (Ricks 2006: 47; Woodward 2004: 159-160). During this same period, and in contrast to the arguments of Baker, Kissinger, and Scowcroft, one-time Rumsfeld aide Ken Adelman wrote in the Wall Street Journal that Saddam was more dangerous that Al Qaeda because of his tremendous resources (Woodward 2004: 164-165). Adelman added that weapons inspections under the UN would not end the threat of Saddam and that Bush's delay in deposing Saddam was dangerous (Woodward 2004: $165)$.

The public debate did not go unnoticed within the administration. Powell thanked Scowcroft for the other's opinion piece against war, saying it would be helpful in his own efforts to persuade Bush (Woodward 2004: 160). Powell's gratitude provides additional evidence of his opposition to war with Iraq. Rice privately expressed to Scowcroft anger over the editorial, but gave no indication of hers or the president's foreign policy position (Woodward 2004: 160). Cheney responded to the very public cautionary, antiwar arguments by telling Bush privately and during an NSC meeting that he planned to counter those arguments in a public speech (Woodward 2004: 163-164). According to Woodward (2004: 163) Cheney feared the move towards war with Iraq was threatened by calls for patience and diplomatic solutions via the UN; that fear prompted him to seek Bush's approval for his speech. In reaction to Adelman's pro-war editorial Cheney confided to a friend that "Ken has been extremely helpful in all this....and I 
really appreciate what he has done and it's been great" (Woodward 2004: 165). In sum, the private reactions of Powell and Cheney offer insight into their policy positions.

In his public speech the vice president portrayed renewed weapons inspections as an ineffectual option and argued unequivocally that Saddam had WMD and intended to use them against the US and its allies (Woodward 2004: 164). Cheney argued that the US must act to address the threat (Woodward 2004: 164). ${ }^{5}$ Reacting to Cheney's speech, on 2 September Powell met privately with Bush and Rice to ask if the president still supported a policy of renewed weapons inspections (Woodward 2004: 167). Bush stated his continued support for seeking new UN inspections, but added he had doubts about the efficacy of inspections (Woodward 2004: 167). This exchange between Powell and Bush indicates both still wanted a policy that included a diplomatic solution via the UN.

Even as Bush was reiterating his support for UN inspections, however, the president showed that he wanted other policy avenues paved as well. He told Cheney, Powell, Rice, and Rumsfeld that he desired Congress to authorize an attack on Iraq (Woodward 2004: 167). Then, on 4 September Bush met with key members of Congress and reaffirmed a policy of regime change, approved by legislation in 1998, citing the threat posed by Saddam (Woodward 2004: 167). Bush's openness to war was demonstrated again during a 7 September meeting with Blair and Cheney, in which the president stated he was committed to a UN-first approach (including requesting a resolution for new inspections) but also told Blair he wanted British military support for what likely would be war (Gordon and Trainor 2006: 71; Mann 2004: 342; Woodward 2002: 346-347; 2004: 177-178).

\footnotetext{
${ }^{5}$ Recall from my research design that I do not use public verbal behavior as evidence for determining a decision maker's foreign policy position. I have only included this brief description of Cheney's speech in order to provide a better understanding of Powell's private reaction to it.
} 
At a principals meeting on 6 September Powell reiterated his position that the administration needed to seek UN action, calling specifically for a new UN resolution to resume weapons inspections (Woodward 2002: 346; 2004: 175). Cheney opposed requesting a UN resolution on Iraq, saying the US would get bogged down in UN processes (Woodward 2002: 345; 2004: 174). The Secretary of State, seeing Cheney's interest in war behind his opposition to the UN route, countered that UN support would be necessary to sell war with Iraq and warned of negative ramifications (e.g., foreign opposition to war requiring worldwide closure of US embassies) in the event the US launched a unilateral attack (Woodward 2002: 346; 2004: 175). Cheney dismissed Powell's warning, claiming that the threat posed by Saddam was all that mattered (Woodward 2004: 175). He proposed submitting this policy to the UN: Saddam has violated past resolutions and, as Woodward (2002: 346) retells it, "the United States reserves its right to act unilaterally."

The following day's NSC meeting saw Powell repeat his arguments, with Cheney, joined by Rumsfeld, making the case against seeking a new UN resolution (Woodward 2002: 346-347; 2004: 176). The two men added to the claim that working through the UN would hobble the US, arguing that a UN resolution would allow Saddam to drag out the process through negotiation and delay action without really complying (Woodward 2002: 346; 2004: 176). Cheney continued his argument against a resolution and new inspections by asserting that inspectors, who would be drawn from other countries, would have fewer worries and doubts about Saddam and thus be more likely deceived (Woodward 2004: 176). The upshot, then, would be inconclusive findings that would impede a decision to topple the Iraqi leader (Woodward 2004: 176). At the end of that 7 September NSC meeting Bush appeared to stick to the policy of seeking a new UN resolution (Woodward 2002: 346). 
As the drafting of Bush's 12 September speech to the UN proceeded, though, the president's position was revealed in greater detail. When Gerson inquired about the content of the speech, Bush explained that he was neither as pessimistic as Cheney, nor as optimistic as Powell regarding the UN and inspections, adding that his commitment was to the ouster of Saddam and the removal of WMD, not to the UN (Woodward 2004: 180). Indeed Bush then pulled the request for a resolution from drafts of his speech in response to the repeated counterarguments of Cheney and the Secretary of Defense (Woodward 2002: 346).

Powell protested the change in Bush's speech, and in the ensuing debate was able to get Cheney, Rice, and Rumsfeld to agree to a vaguer request for UN action (Woodward 2002: 347). The vice president, however, continued to urge Saddam's removal and voice opposition to a resolution, while Rumsfeld hinted at similar opposition (Woodward 2002: 348). Despite the principals' agreement to water down the US request of the UN, Bush ultimately decided to ask for a resolution (Woodward 2002: 348-349; 2004: 183). He held to that position even after Rice raised the possibility that Bush's speech could contain a demand for Saddam to disarm in a month or face a US-led assault on Iraq (Woodward 2004: 181). ${ }^{6}$

After Bush's 12 September speech did in fact call for a UN resolution, debate among the selected officials turned to the content of the resolution, specifically how strict to make the requirements of the weapons inspections (Woodward 2004: 220). Cheney and the Secretary of Defense pushed for a strict resolution stipulating the following: no flight or driving in areas subject to inspection, UNSC permanent members' right to deploy their inspection agents to accompany UN inspectors, the removal of previously excluded sites (e.g., Saddam's residences) from the list of areas exempt from inspection, and, perhaps most important, a finding of "material breach" (violation of the UN resolution) would automatically authorize military action

\footnotetext{
${ }^{6}$ I see no indication that Rice raised this option because it reflected her policy position.
} 
against Iraq to force compliance (Woodward 2004: 220-221). Believing this strict resolution was intended to fail in the UN, Powell presented the draft to all UNSC members' representatives and then reported in a NSC meeting that the draft received no support (Woodward 2004: 221).

On 26 September Bush held a meeting with 18 members of the House (Woodward 2004: 188). During this meeting Bush once again showed the limits of his commitment to a UN solution for Iraq. The president expressed reluctance to go war, but added that Saddam was a threat and that regime change by force was feasible (Woodward 2004: 188-189). When asked about the UN, Bush replied that he was not abandoning the UN process, but was not going to become bogged down in diplomatic wrangling about the resolution (Woodward 2004: 189). Five days later in a meeting with Cheney and House International Relations Committee members Bush said the US must act, and claimed the US could simultaneously fight two foes (Woodward 2004: 190).

The debate among the selected officials received an exogenous shock when on 1 October the intelligence agencies of the US issued a National Intelligence Estimate on the WMD capabilities of Iraq (Gordon and Trainor 2006: 128-129; Ricks 2006: 52; Woodward 2004: 197). "Baghdad has chemical and biological weapons" declared the summary "Key Judgments" (Woodward 2004: 197). The rest of the report was more equivocal, sometimes contradictory to its own Key Judgments (Woodward 2004: 197-198). The estimate stated "[w]e have low confidence in our ability to assess when Saddam would use WMD," also stating with low confidence that "Saddam, if sufficiently desperate might" help terrorists stage a WMD attack (Woodward 2004: 198-199; see also Gordon and Trainor 2006: 129). Regarding nuclear weapons, the estimate offered "moderate confidence" in stating that Saddam did not possess nuclear weaponry or means to produce a nuclear weapon but probably would possess such a 
weapon sometime between 2007 and 2009 (Woodward 2004: 199). The prediction of a future Iraqi nuclear weapon rested on the claim that Iraq was in the process of "reconstituting its nuclear program" (Ricks 2006: 52), a claim disputed in a footnote presenting the State Department's disagreement along with some doubts from the Department of Energy (Gordon and Trainor 2006: 128-129).

According to a general who spoke often with Rumsfeld, Bush and the Secretary of Defense were still undecided on the question of war with Iraq prior to the NIE (Ricks 2006: 52). The NIE, though, persuaded both that war was necessary (Ricks 2006: 52). The same general reported that the NIE did not persuade Powell to support war; rather, the Secretary of State thought the report should be used to "leverage the international community [to act]" (Ricks 2006: $52)$.

The NIE was also important to the 10 and 11 October votes in the House and Senate, respectively, granting Bush authority to use force against Iraq (Woodward 2004: 200-203). Cheney and Rice had no later than early September wanted such authorization (Woodward 2004: 168). Powell, too, wanted authorization, and in the run-up to the 11 October Senate vote he lobbied Maine Republican Susan Collins to vote to give Bush authority to use force (Woodward 2004: 203). According to Woodward (2004: 168, 203), Powell and Rice primarily wanted Congressional approval for force in order to enhance US leverage in the UN process. Battles Within and Without: UN Negotiations and Continued Internal Debate

Though Congress gave Bush authorization to use force and the president appeared more inclined to war and less patient with diplomacy, the UN resolution process was still active as 2002 wore on. Powell confronted the task of developing a UN resolution that could win approval from the administration and the UNSC (Woodward 2004: 221-223). Gaining approval 
in the UNSC largely hinged on obtaining French support, and French Foreign Minister Dominique de Villepin demanded a two-resolution path in the UN (Mann 2004: 347; Woodward 2004: 222-225). The first resolution, de Villepin proposed, would renew weapons inspections, and if inspections identified violations constituting "material breach" of the resolution, a second resolution to authorize force against Iraq would be required (Mann 2004: 347; Woodward 2004: 222-225).

The French demand was unacceptable to Bush as well as Cheney, both of whom saw a two-resolution procedure as too great an obstacle to striking Saddam if he were found in material breach (Woodward 2004: 222). Cheney, for his part, demanded any resolution give Saddam 30 days after passage to fully disclose his WMD programs (Woodward 2004: 222). Cheney meant this stipulation to ensnare Saddam; Saddam could lie by vowing no WMD, or he could confess thus proving his earlier lies, but in either case he would be found in material breach and subject to military action without the need for any additional resolution (Woodward 2004: 222). Bush, Rice, Rumsfeld, and even Powell supported Cheney's proposal (Woodward 2004: 222).

De Villepin accepted resolution language requiring Saddam to disclose, but maintained the French position that war could only be authorized by a second resolution after the discovery of any Iraqi violations (Woodward 2004: 222). Bush was willing to adopt a resolution that was more vaguely suggestive of a two-stage process but also would more easily find Saddam in material breach - violations in the form of false statements or lacking cooperation, if found, would be submitted for UNSC consideration (Woodward 2004: 221-223). Powell was left to persuade the French to approve the lower threshold for material breach and abandon their requirement of a separate resolution for force (Woodward 2004: 221-223). The Secretary of State took back to de Villepin the resolution language approved by Bush, but the French Foreign 
Minister now objected to the lesser material breach requirement, arguing that a determination of material breach should require a false statement and failure to cooperate with the UN (Woodward 2004: 223-225). Bush, Cheney, and Rumsfeld expressed resistance to raising the bar for a material breach finding, with Powell and Rice seeking compromise on the resolution language (Woodward 2004: 225). By 7 November, however, at least Bush had decided to compromise with the higher standard for material breach (Woodward 2004: 225). Following the deal with de Villepin the UNSC unanimously passed Resolution 1441, which basically stated Saddam would face "serious consequences" for material breach under the resolution's disclosure and inspection requirements (Mann 2004: 347; Woodward 2004: 226).

The intra-administration debate over the UN resolution may appear to say more about how the selected elites viewed the UN than their policy positions vis-à-vis Iraq. The debate does, though, actually provide further insight into the decision makers' desired policy towards Iraq. Cheney's proposals, as previously noted, were meant to ensure Saddam would be found in material breach and pave a straightforward path to authorizing war. His opposition to a second resolution for force and a higher standard for material breach add to the impression that he wanted a resolution that would produce endorsement of war. The vice president's views, then, strongly suggest his continued position that war was the proper policy. Rumsfeld's preference for a weaker material breach standard is similarly suggestive, if less strongly so, of support for war. Bush's opposition to a two-resolution procedure for authorizing war, as well his resistance to a higher material breach threshold, would tend to indicate a conflictual policy position. His eventual compromise on both issues, by contrast, points to a continued willingness to give Saddam a chance to comply and avoid war. Powell's pursuit of compromise and agreement with France further indicates his position that the US should seek first a solution via the UN and 
weapons inspections. He did support Cheney’s proposed resolution language, but clearly remained committed to a UN process that could avoid war. The debate reveals relatively less about Rice's policy position, but her support of Powell's efforts for compromise at minimum hint at openness to a diplomatic, UN-based solution. ${ }^{7}$

Iraq's WMD Disclosure, UN Weapons Inspections, and US Moves towards War

Iraq announced inspectors could return, and weapons inspectors began their work in Iraq late in November 2002 (Mann 2004: 347; Woodward 2004: 234). Shortly thereafter Iraq issued its disclosure declaration, claiming no WMD (Mann 2004: 349; Woodward 2004: 234). US war preparations called for deployment notifications to begin during this same time period, but Bush directed the notifications slowed and staggered to allow inspections and diplomacy more time (Woodward 2004: 231-234).

Iraq's disclosure was generally seen by US and foreign officials as incomplete and drawn from outdated information (Mann 2004: 349). Chinese, French, German, and Russian officials saw Iraq's disclosure as requiring further inspection (Mann 2004: 349). Cheney, however, saw the Iraqi disclosure as patently false and in a NSC meeting called for Bush to declare Saddam in material breach and consider the Iraqi lies, as he saw them, justification for war (Woodward 2004: 234-235). Bush, Powell, Rice, and Rumsfeld did not support Cheney’s position, instead viewing Saddam as at least looking cooperative (Woodward 2004: 235).

With Cheney's position unsupported, war was delayed and inspections continued (Woodward 2004: 235). The inspections did not initially find violations (Woodward 2004: 234). Beginning near the end of December, though, Rice informed Bush of evidence purported to show

7 In fact, in September Rice told Bush that South Africa's nuclear disarmament was a model showing the UN process could work and avoid war (Woodward 2004: 180). 
that inspections were not aggressive and were falling behind Iraqi efforts to destroy evidence (Woodward 2004: 250, 253).

There are signs during this same late-2002 period that Bush began losing patience with the process (Woodward 2004: 240, 250). On 18 December Bush met with José María Aznar, President of Spain, and said the US would oust Saddam without UNSC permission (Woodward 2004: 240). Bush then added that war was still a last resort and the question of whether the US would go to war was not yet decided (Woodward 2004: 240). The next day during a briefing on war planning, General Franks, the officer in charge of preparations for war against Iraq saw Bush's questions regarding timing as evidence that Bush was increasingly inclined to strike Saddam (Woodward 2004: 224). Still, the president did not yet appear ready to make the final decision for war. On 21 December Director of Central Intelligence George Tenet and his deputy, John McLaughlin presented to Bush, Cheney, and Rice "The Case" regarding Iraqi WMD (Woodward 2004: 247-250). Bush was disappointed with the evidence, finding little of the case convincing (Woodward 2004: 249). Even after Tenet called the case "a slam dunk," Bush said it required "a lot more work" (Woodward 2004: 249-250).

By the first days of 2003, however, Bush had lost more confidence in the UN process of inspections (Woodward 2004: 253-245). He had asked Rice at the end of 2002 if they should now go to war, and she had answered yes (Woodward 2004: 251). On 3 or 4 January 2003, the president seemed to have arrived at the same position Rice had taken days earlier, telling his NSA, "Probably going to have to, we're going to have to go to war" (Woodward 2004: 254). Rice saw this as Bush's final position on what policy to take on Iraq (Woodward 2004: 254).

Over the next ten days Bush made statements further indicating his shift to a policy of going to war to oust Saddam. He told Rumsfeld, "Look, we're going to have to do this [i.e., go 
to war with Iraq] I'm afraid" (Woodward 2004: 261). On 8 January the president told a private gathering of Republican Congressional leaders that war was likely because Saddam had not disarmed (Woodward 2004: 257). Bush was clearer in his position during a private meeting with Iraqi opposition leaders on 10 January, saying “He [Saddam] should disarm but he won't, therefore we will remove him from power" (Woodward 2004: 258). Then, on the $13^{\text {th }}$, Bush strongly insinuated to Saudi Ambassador Prince Bandar that the US was going to launch a war to topple Saddam (Woodward 2004: 266-267). ${ }^{8}$ Later that day Bush told Powell inspections were not working, Saddam was not truly complying, and the US was therefore going to war (Woodward 2004: 269-270). Bush even began adding democratization of Iraq to his policy of removing Saddam, a position Cheney agreed with and embraced (Woodward 2004: 275, 284). Bush had moved to the policy of war Cheney had been advocating for some time and then went beyond it to include transforming Iraq into a democracy.

When Bush told Powell the US would be attacking Iraq the Secretary of State pledged to support Bush's decision (Woodward 2004: 271-272). This does not mean that Powell had himself adopted a pro-war position. According to Woodward (2004: 272-273), Powell privately decided to continue pursuing a diplomatic course to avoid war.

As the president was on his way to adopting a policy of war "The Case" was reworked, and on 25 January 2003 Cheney's chief of staff, Lewis "Scooter" Libby presented it to a group including Armitage, Rice, and Wolfowitz (Woodward 2004: 289). The new iteration of the document was meant to detail Saddam's WMD threat, Iraqi efforts to foil inspections, and Saddam's terrorist connections (Woodward 2004: 289). Wolfowitz believed the case was strong, with thin spots regarding Saddam's terrorist connections being attributable to the strong security

\footnotetext{
${ }^{8}$ Cheney, in a meeting with Bandar and Rumsfeld, had already told the Saudi Ambassador that the US would remove Saddam; Bush was simply confirming the message his vice president had delivered without explicitly making a policy statement (see Woodward 2004: 263-267).
} 
Al Qaeda maintained (Woodward 2004: 290). Armitage saw the case presented as "overreaching and hyperbole" (Woodward 2004: 290, 295). The Deputy Secretary of State had just days before resisted giving a speech in favor of war based on "Apparatus of Lies," a document produced by the White House, which he saw as old material lacking a clear case for war (Woodward 2004: 286). He was clearly similarly unimpressed by the evidence Libby presented.

Two days after Libby’s presentation UN inspection leaders Hans Blix and Mohamed ElBaradei presented their preliminary findings before the UNSC (Woodward 2004: 293-294). Blix reported that Iraq was not accepting of disarmament, but added that "cooperation was on the whole good" (Woodward 2004: 293). Regarding biological weapons, he stated that Iraq likely had manufactured anthrax in quantities greater than declared and might still have possessed some (Woodward 2004: 293). Blix indicated that chemical weapon information was unclear and contradictory (Woodward 2004: 293). ElBaradei's reported there were no signs of Iraq having resumed work on developing nuclear weapons (Woodward 2004: 293). Both men said more time and inspections were needed (Woodward 2004: 293-294).

Blix's testimony was challenged by intelligence suggesting he did not want to provide a casus belli and might soft peddle future reports to avoid doing so (Woodward 2004: 293-294). According to Woodward (2004: 294), “Rice told the president she didn't believe Blix was necessarily lying [about what was found]. He was just deeply conflicted." Bush, though, was made more set on war and saw Cheney's pessimism about the UN process as prescient (Woodward 2004: 294).

Bush may have been ready to abandon the UN track and begin war, but an ally important to US war plans was not. On 31 January UK Prime Minister Blair called on Bush to obtain another UN resolution authorizing war, saying he had promised a second resolution to his 
Labour party (Woodward 2004: 296). Bush and Cheney were opposed to seeking another resolution (Woodward 2004: 296). Powell, too, concurred with opposition to an additional resolution; a second resolution would take too long to achieve and in Powell's eyes the first resolution, 1441, was sufficient to justify US-led military action (Woodward 2004: 296-297). The president understood that Blair was in need, though, and pledged to seek another resolution rather than risk losing his British ally (Woodward 2004: 297).

The president's agreement on trying for a second resolution should not be seen as a softening of his position that war with Iraq was the proper course; rather Bush was seeking to accommodate an ally's domestic political requirements. Interpreting Powell's opposition to another resolution is more difficult. As noted previously, Powell had promised to support Bush's decision for war. How much of Powell's opposition at the time reflected his own policy position, as to opposed to that of his president, is unclear.

Whatever were his own views as of 31 January, Powell began work on the next task assigned to him. Powell was charged with presenting the US case against Saddam Hussein on 5 February before the UN, but as he prepared he found the packet of summarized intelligence supplied by Libby to be unclear, with human intelligence particularly thin (Gordon and Trainor 2006: 131; Woodward 2004: 297-298). Nonetheless, he believed Saddam was hiding weapons why else would the Iraqi leader endure an ostracized existence under sanctions (Woodward 2004: 298)? The Secretary of State went to the CIA to undertake his own search of the available intelligence, and asked Armitage to assist (Woodward 2004: 299). Armitage, too, believed Iraq had WMD, but did not see strong evidence in the intelligence he and Powell were poring over (Woodward 2004: 299). What they saw as the best evidence for WMD violations was, they recognized, often only suggestive, but Powell incorporated into his speech what he deemed 
convincing, sometimes against the advice of his own department's intelligence arm (Gordon and Trainor 2006: 133; Woodward 2004: 299-300).

Powell had seen the evidence for Saddam's ties to terrorism as even less convincing, and he had not held Cheney's belief that Saddam had worked with Al Qaeda (Woodward 2004: 300301). After examining the intelligence himself the Secretary of State did, however, agree to include in his speech that at least one Al Qaeda associate, Abu Musab al-Zarqawi, may have made Iraq a base for his activities (Woodward 2004: 300-301). Despite deciding to include Zarqawi in his speech, Powell noted that the strongest statement he could make was that Saddam was harboring Zarqawi (Woodward 2004: 301). Powell went further towards accusing Saddam of working with Al Qaeda when he decided to incorporate into his speech defector testimony that "Iraq had taught Al Qaeda operatives how to make poison gas or germ weapons" (Gordon and Trainor 2006: 133-134).

Woodward's (2004: 297-301) account of Powell and Armitage's review of intelligence suggests that both decision makers believed Saddam had WMD but saw the evidence as weak and often suggestive. Woodward's description also indicates Powell remained relatively unconvinced of Iraqi links to terrorism. Michael Gordon and Bernard Trainor's (2006: 131-134) account, by contrast, depicts Powell as very much changed by his examination of the available intelligence. Gordon and Trainor (2006: 133), writing later than Woodward, report the following about Powell from his chief of staff, Larry Wilkerson: "It is safe to say that he changed his mind. He was convinced by what the agency and members of the IC [intelligence community] were able to present him." That Powell decided to put in his speech stronger claims rejected by his own department does indeed hint at a change in the Secretary of State's thinking. 
On 5 February, the day Powell delivered his speech to the UN, Bush and Rice met with some Congress members, though Bush left after brief remarks (Woodward 2004: 307). Rice explained that other potential solutions to the Iraqi threat had been tried, and war was now the right course (Woodward 2004: 308). She did not guarantee that WMD would be found, but said if inspections continued, Saddam would beat the inspections and divide the UNSC (Woodward 2004: 308). Rice was saying to members of Congress what she had earlier said to Bush: war was the proper policy.

Though the Bush administration may have been on the path towards war, others outside the US were still opposed, or at least trying to avoid, war. Two days after Powell's speech Bush received word of efforts by Jordan, Saudi Arabia, Turkey, and other countries to arrange for Saddam to choose exile in order to avoid war (Woodward 2004: 314). The president was receptive but offered no guarantee that the US would respect Saddam's safety in exile (Woodward: 2004: 314). French President Jacques Chirac called the same day to tell Bush that he opposed war and that he was optimistic about the possibility of Saddam choosing exile (Woodward 2004: 313). Then, on 10 February France, Germany, and Russia jointly declared war was not yet justified, and called for more inspections and peaceful disarmament (Woodward 2004: 315).

Opponents of war with Iraq received support for their position when, in UNSC testimony during February and March 2003, inspectors Blix and ElBaradei delivered evidence that challenged the US case for war, in some instances even directly contradicting Powell's speech (Chilcot et al. 2016: 29; Ricks 2006: 94; Woodward 2004: 316-317). ElBaradei testified that there was no evidence of prohibited nuclear programs and Iraq's weapon production abilities were much degraded (Chilcot et al. 2016: 29; Ricks 2006: 94). Blix reported that, while he could 
not guarantee no WMD or WMD programs, there was no evidence of existing weapons or programs (Chilcot et al. 2016: 29; Woodward 2004: 316-317). He acknowledged minor declarations violations on Iraq's part, but stated "the period of disarmament through inspection could still be short." (Woodward 2004: 317).

Although Powell went before the UNSC to rebut Blix's core claim that more inspections could bring Iraqi disarmament and to assert that force had to be treated as a solution, Bush ordered a slowing of war preparations to allow more time for the diplomacy - especially coaxing of allies facing domestic opposition to war - needed after Blix's report (Woodward 2004: 319). Following a 22 February meeting with the leaders of Italy, Spain, and the UK Bush decided to try for another UN resolution deeming Saddam noncompliant with Resolution 1441 (Woodward 2004: 319-320). Cheney, as before, was opposed to seeking another resolution, but Bush again saw that Blair's political situation required trying to obtain one (Woodward 2004: 319).

The US and its allies tried for a second resolution, but by 12 March Bush found there were insufficient votes to pass a second resolution through the UNSC (Chilcot et al. 2016: 34; Woodward 2004: 344-345). Even before realizing the second resolution would fail, Bush had begun work on what he would say publicly to Saddam to warn of impending military action against Iraq (Woodward 2004: 340-341). Bush was inclined to making an ultimatum, an idea Rumsfeld proposed during a 5 March NSC meeting (Woodward 2004: 330, 341). As work on ultimatum drafts continued Rumsfeld pushed for giving Saddam only 48 hours to leave power, and Bush agreed with Rumsfeld's position (Woodward 2004: 347, 357-358). Rice initially opposed an ultimatum, but only because she wanted the US statement to simply announce the coming military action (Woodward 2004: 342). 
The discussion of what Bush would say publicly was not a discussion about whether the US would act militarily. On 17 March Bush told Congressional leaders even if Saddam ceded power the US would intervene to prevent ethnic conflict, remove Saddam's Baathist supporters, and eliminate WMD (Woodward 2004: 368-369). What the discussion does show is the commitment of Bush, Rice, and Rumsfeld to the policy of removing Saddam.

Also on 17 March the US and allies withdrew the second resolution from UNSC consideration (Chilcot et al. 2016: 38; Woodward 2004: 364-365). That night Bush issued his ultimatum to Iraq in a televised speech (Chilcot et al. 2016: 38; Woodward 371-372). On 19 March Bush ordered execution of Operation of Iraqi Freedom, and war against Iraq was fully underway the next day.

The beginning of the war marked the end of policy deliberations over what to do about Saddam Hussein's Iraqi regime. Those deliberations had begun even before the $9 / 11$ terrorist attacks and at times deeply divided the Bush administration. The foregoing section has recounted the administration's debates and discussions in order to show the development of the selected decision makers' foreign policy positions. Ultimately, and despite their different paths to it, all of the officials arrived at a position of supporting war against Iraq. ${ }^{9}$ The next section explores how cognitive errors and biases may have influenced the decision making processes behind the elites' policy positions.

\section{Error and Biases in the Decision Making of Bush Administration Officials}

My theoretical framework proposes dovish and hawkish decision maker types are prone to different cognitive errors and biases, with owls and warhawks sharing pronounced susceptibility to positive illusions. Of course, the previous chapter's findings show that the

\footnotetext{
9 There is some question about Armitage's policy positions, but he appears to have supported war, at least by the time the war began (see Ricks 2006: 52). I will address this question later in this chapter.
} 
decision makers under study here do not neatly align with the decision maker types laid out in my framework. Still, my examination of the selected Bush administration officials suggests that proneness or resistance to positive illusions affected their decision making. Other errors and biases, hawkish or dovish, may also have impinged on the selected elites' decision making, but I do not find evidence to that effect. ${ }^{10}$

In what follows I discuss positive illusions and their role in the decision making and policy positions of the studied officials. This section first presents relevant information one can realistically expect was available to all of the decision makers. I next address the decision makers individually, including as required additional pertinent information available to a specific official. I then discuss my conclusions about the decision maker's susceptibility or resistance to positive illusions as well as what effect that susceptibility or resistance seems to have had on the individual's policy position.

\section{$\underline{\text { Positive Illusions }}$}

Evidence of proneness or resistance to positive illusions among the selected decision makers centers on two questions raised in foreign policy deliberations and war planning: What would be required to successfully remove Saddam by force and ensure a stable post-Saddam Iraq? What would be the broader repercussions of an invasion to oust Saddam?

\section{War Planning and Policy Deliberations as Sources of Information Relevant to Positive Illusions}

Answers to the question of what would be necessary to oust Saddam and manage Iraq afterwards came largely, but not exclusively, from war plans existing prior to, and developed

\footnotetext{
${ }^{10}$ Certainly the Bush administration officials' decision making - individually and as a group - was characterized by other deficiencies and psychological faults, including cognitive errors and biases. Dina Badie (2010) finds that the officials were subject to "groupthink" which produced defective decision making and a shift to more conflictual foreign policy on Iraq. Michael Mazaar (2007) also argues that groupthink harmed Bush administration decision making on Iraq. Mazaar adds that agenda-setting dynamics help explain flaws in Bush's decision making, especially the president's poor search for information relevant to the choice of invading Iraq. Aaron Rapport (2012) uses "construal level theory" from the field of psychology to explain errors in Bush and Rumsfeld's decision making processes regarding postwar operations in Iraq.
} 
during, the Bush administration. When the administration entered office the existing plan for invading and occupying Iraq, OPLAN 1003-98, called for 380,000-500,000 troops and an occupation that might take a decade (Gordon and Trainor 2006: 4, 26-28). OPLAN 1003-98 had been developed under General Anthony Zinni during his time as head of CENTCOM, and the plan's troop number was based in no small part on his concerns that post-Saddam Iraq would suffer ethnic fragmentation requiring a stabilizing force (Gordon and Trainor 2006: 26-28).

War planning during the Bush administration was directed by CENTCOM commander General Tommy Franks, Zinni’s successor (Gordon and Trainor 2006: 28; Ricks 2006: 32-34; Woodward 2004: 36-38). Franks was well aware of OPLAN 1003-98's troop and time estimates, as he, according to Zinni, was the key figure in the development of the plan (Gordon and Trainor 2006: 28). Moreover, Franks reviewed the plan with Rumsfeld before officially beginning to develop new plans on 1 December 2001 (Woodward 2004: 36-37).

On 28 December Franks briefed Bush, Cheney, Powell, Rice, and Rumsfeld on the initial planning work - referred to as the commander's estimate - notably stating that 275,000 troops would be needed (Gordon and Trainor 2006: 31-32). Then, during a 7 February 2002 briefing of at least Bush, Cheney, Powell, and Rumsfeld, Franks presented version five of his estimate, which proposed a successful invasion would need 225 days (including staging, but not including occupation) and roughly 300,000 troops (Gordon and Trainor 2006: 36; Woodward 2004: 99103). This planning was put to an official "paper drill" test on 23 March 2002, and The New York Times published the results in May, reporting invasion would seriously strain military personnel and supplies of some crucial arms (Woodward 2004: 114-115).

Also in May 2002, Franks separately reported his latest planning to the principals and Bush (Gordon and Trainor 2006: 50-52; Woodward 2004: 124). The troop and time 
requirements were unchanged in the main plan, but Franks offered alternative deployment timelines to speed up invasion should one be ordered (Gordon and Trainor 2006: 50-52;

Woodward 2004: 124). Powell voiced his concerns that compared to the Gulf War the proposed force size was smaller and the planned logistical system was much more limited (Woodward 125-126). Rice, who was concerned that Saddam could draw his forces to the capital for a "Fortress Baghdad" last stand, voiced particular interest in a plan that left Saddam less time for such a move (Woodward 2004: 64, 125). Bush explicitly asked Franks about the possibility of a Fortress Baghdad outcome, and Franks explained that such a scenario could not be prevented if Saddam wanted to make a stand (Woodward 2004: 126).

As summer 2002 approached and Franks was working on a faster invasion plan, a Joint Chiefs of Staff-initiated study found speedy action could accomplish military objectives with a smaller force (Gordon and Trainor 2006: 52-53). The study did not, however, deal with occupation and stability operations (Gordon and Trainor 2006: 52-53). Franks's planning, by contrast, did begin addressing occupation in addition to ways of accelerating invasion operations. At a 5 August meeting of the NSC Franks presented faster invasion options (Woodward 2004: $145-147)$. He also explained that occupation could start with as many as 265,000 troops, a number that could be reduced to 50,000 within 18 months, events allowing (Woodward 2004: 148). During the meeting Bush expressed to Franks and the other officials his interest in the speedier operational timelines, but also his persistent concerns about Fortress Baghdad (Woodward 2004: 146-147).

In the remainder of 2002 and on into 2003 warnings about invading Iraq issued from various quarters, introducing new viewpoints. Some warnings came from contemporary political and military leaders. On 4 September in a meeting with Congressional leaders Senator Carl 
Levin, insinuating reticence on the part of many long-serving military officers, told Bush "[t]he military has deep concerns" (Woodward 2004: 170). Woodward (2004: 207) notes that input such as that offered by Levin led Bush and Rumsfeld to set an October meeting with the Joint Chiefs, a meeting in which the officers shared their views with Bush, Cheney, Rice, and Rumsfeld. ${ }^{11}$ Admiral Vern Clark and General John P. Jumper voiced some concerns about capabilities and weapons production being stretched, but both also stated their belief that the war plans were workable, even praiseworthy (Gordon and Trainor 2006: 101; Woodward 2004: 207). General Eric Shinseki said the troop number might be too small and expressed concern about the ability of logistics to keep up with the advance, but he also backed the war plan (Gordon and Trainor 2006: 101; Ricks 2006: 74; Woodward 2004: 207). General James L. Jones worried aloud about urban combat and biological or chemical battlefield conditions; he did not apparently support or oppose the war plan (Woodward 2004: 208). Also in October, Rumsfeld took the opportunity of an NSC meeting to reiterate that although there was hazard in not striking Saddam, war with Iraq might lead Saddam to attempt a Fortress Baghdad scenario or use WMD (Woodward 2004: 205-206).

During this period's policy deliberations cautionary perspectives about war with Iraq were not limited only to the invasion stage of operations. Post-invasion stability and occupation garnered greater attention. At the October NSC meeting in which Rumsfeld warned about Fortress Baghdad and WMD attacks the Secretary of Defense also warned that Iraq might be prone to ethnic conflict after the fall of Saddam's regime (Woodward 2004: 205-206). Then, during a briefing delivered to Bush and his cabinet on 15 January 2003, other experts, too, warned that ethnic conflict may arise (Woodward 2004: 277). Nearly six weeks later General

\footnotetext{
${ }^{11}$ Gordon and Trainor (2006: 101) date this meeting to 30 January, not October. Ricks (2006: 74) describes the meeting as having taken place as winter 2002 neared. Disagreements about timing aside, the three accounts of the meeting's content mesh well.
} 
Shinseki of the Joint Chiefs testified to the Senate Armed Services Committee and, noting Iraq's size and ethnic tensions, said "several hundred thousand soldiers" would likely be needed for the occupation (Ricks 2006: 96-97; see also Gordon and Trainor 2006: 102). Shinseki repeated his projection in the House during testimony in March (Ricks 2006: 99-100). A briefing to Bush and other top officials on 10 March reiterated the importance of occupation, noting the need to establish order (Gordon and Trainor 2006: 161-162).

In late 2002 and early 2003 concerns about invading and, especially, occupying Iraq were not only to be heard from US political and military leaders. Concerns were raised by multiple outside actors. In August 2002 Cheney and Rumsfeld were told by leaders of the Iraqi opposition to expect looting and disorder after Saddam's ouster, and the prediction was relayed to others in the administration (Gordon and Trainor 2006: 157). During October James Fallows of The Atlantic, Michael O'Hanlon of the Brookings Institution, and seminar participants at the Washington Institute for Near East Policy all publicly warned that occupying Iraq would be difficult (Ricks 2006: 64-65). O'Hanlon specifically articulated the possibility of a years-long occupation with over 100,000 soldiers (Ricks 2006: 64-65). Joschka Fischer, Foreign Minister for Germany in a public exchange with Rumsfeld similarly predicted the US would "have to occupy Iraq for years and years" (Ricks 2006: 94-95).

In sum, the whole period of planning the war and occupation was pervaded by information suggesting invasion and post-Saddam stabilization would meet with challenges, perhaps even serious adversity. There was also information more conducive to an optimistic outlook. I have presented some, but not all, of that information above. Additional information supporting a sanguine outlook must be noted. 
Some elements of the Iraqi opposition reliably predicted invasion and occupation would achieve ready success. In fall 2001 Iraqi National Congress head Ahmed Chalabi argued Saddam would be easily toppled, Iraq's own military would provide a stable post-Saddam Iraq, and Iraq would become pro-Western (Gordon and Trainor 2006: 18-19). As war neared in January 2003 Iraqi opposition leaders again offered a hopeful outlook, saying invading forces would be greeted warmly, Iraqi democracy was feasible, ethnic divisions were not as bad as commonly believed, and occupying forces would be needed no more than three years (Woodward 2004: 258-260). US war plans shared some of the Iraqi opposition's optimism. Franks's war plans assumed the Iraqi public would withdraw support from Saddam if they believed the US was going to topple the Baathist regime (Woodward 2004: 81). Likewise, planning for the occupation assumed help with occupation would come from surrendering Iraqi regular army units and other Iraqi institutions (Gordon and Trainor 2006: 105, 161-162).

The generally available information pertaining to the requirements of a successful invasion and post-war stabilization could, then, have led the selected officials to starkly different conclusions and policy decisions. The administration's decision makers were, though, also faced with considerations beyond Iraq itself. As they deliberated and decided they were presented with information about possible broader repercussions of a war with Iraq.

\section{Information about War's Broader Repercussions}

The possible wider consequences of war with Iraq were a part of policy deliberations even from the early stages and later featured prominently in public discussion about Iraq. Immediately after the 9/11 attacks Powell and General Shelton warned that attacking Iraq would be harmful to the US-led anti-terror coalition, with Shelton adding that war with Iraq would disrupt the surrounding region (Gordon and Trainor 2006: 17; Mann 2004: 302). A little more 
than a year later, even as war planning was far along, Rumsfeld produced a list of potential follow-on challenges arising from war with Iraq (Woodward 2004: 205-206). Included in the list were oil disruptions and the possibility that other countries would exploit the opportunity created by the US commitment of resources to Iraq (Woodward 2004: 206).

In the public debate over invading Iraq prominent figures also voiced fears about the repercussions of war. In August 2002 Scowcroft argued on television that war with Iraq might destabilize the region and "destroy the war on terrorism" (Woodward 2004: 149). Soon thereafter Senator Ted Kennedy and former US Vice President and presidential candidate Al Gore warned that attacking Iraq could cause regional instability, a spike in terror attacks, and increased danger to Israel (Woodward: 2004: 351).

In short, there were a variety of broader considerations militating against positive illusions in decision making about Iraq policy. Indeed the sources upon which I have drawn do not present much in the way of arguments that invading Iraq would have broader positive knockon effects. Woodward (2004: 259) does, though, point out that Iraqi dissident Kanan Makiya suggested the ouster of Saddam would improve Middle Eastern perceptions of the US.

The information presented to this point has been that which one can reasonably presume was generally available to the administration officials selected for this study. I next individually discuss the elites to identify their susceptibility or resistance to positive illusions as well as any role positive illusions or a relative lack thereof played in their decision making. As needed, I discuss additional relevant information available to a specific decision maker.

\section{Armitage and Positive Illusions}

The accounts used here provide very little evidence pertaining to Armitage's resistance or proneness to positive illusions. Armitage's initial view that an attack on Saddam should be 
delayed in order to help maintain the cohesiveness of the post-Gulf War anti-Saddam coalition, however, suggests some resistance to positive illusions. A decision maker with unrealistically sanguine perceptions of their side's abilities would likely have less concern about the aid allies could provide to a military campaign. His early position also exhibits resistance to the illusion of control; Armitage's concern about allies seems to show he saw the actions of coalition partners as significant.

Additionally, the Deputy Secretary of State later worried the concentrated military staging points stipulated by war planning were vulnerable to attack, especially attack by WMD (Gordon and Trainor 2006: 71). He feared such an attack would leave the invasion force very small and without reinforcements (Gordon and Trainor 2006: 71). This evidence from Armitage's thinking on the war plans at least points to some resistance to the positive illusion of unrealistic optimism. His perception of a vulnerability contained in the war planning indicates openness to cautionary or pessimistic information.

These are but two pieces of evidence relevant to positive illusions. Still, they do provide insight. Taken together, the two episodes show in Armitage's decision making a resistance to all three forms of positive illusions. Resistance to positive illusions helps account for evidence of his reticence to attack Iraq.

\section{Bush and Positive Illusions}

As president, Bush was presented with information beyond that generally available to the other decision makers. Some of the additional information available to Bush came from private briefings by General Franks. Typically these private briefings only gave Bush a preview of what would be presented to the whole NSC, but on 20 April 2002 Franks presented Bush with an alternative war plan that specified smaller numbers of troops and a shorter period of preparation 
for invasion than was found in the plans contemporaneously presented to the NSC (Woodward 2004: 121, 135).

Powell also provided to Bush information and viewpoints that were not shared with all of the other decision makers. On 5 August 2002 Powell met with Bush (and Rice) to present a list of reasons for caution regarding war with Iraq (Gordon and Trainor 2006: 71, 149; Woodward 2002: 331-333; 2004: 150-151). Powell argued war could do the following: cause regional instability, undermine the regimes of America's regional allies, harm the war on terror, upset oil markets, lead Saddam to strike Israel, and generally damage US foreign policy and international relationships (Gordon and Trainor 2006: 71, 149; Woodward 2002: 331-333; 2004: 150-151). The Secretary of State added that, considerations of the wider repercussions aside, war with Iraq and the subsequent occupation would present serious challenges (Gordon and Trainor 2006: 71, 149; Woodward 2002: 331-333; 2004: 150-151). Iraq was a large country to invade and locating Saddam, whose ouster was a key objective, would be difficult (Woodward 2002: 333). Powell stated his belief the invasion would prevail, but cautioned that US occupation might not be well received by the population (Woodward 2002: 332-333). The Secretary of State, knowing Bush wanted to make democratization a goal of the occupation, further asserted that transplanting democracy in Iraq would be hard (Woodward 2004: 150). The US would be responsible for stabilizing and governing Iraq for years (Gordon and Trainor 2006: 71; see also Woodward 2004: 150). The war and occupation would be costly, Powell argued, and the economic impacts needed to be taken into account (Woodward 2002: 332). He followed up his litany of warnings by concluding that the US could win the fight but needed a coalition for a successful overall outcome; UN or allies' support was a must (Woodward 2002: 333-334; 2004: 151). Powell 
explicitly ruled out the path of unilateralism. He said to Bush, "[i]t's nice to say we can do it unilaterally, except you can't'" (Woodward 2002: 333; 2004: 150).

Powell's message to Bush contained much to counter any positive illusions. He reminded Bush of the possible consequences of war during a conversation on 13 January 2003 (Woodward 2004: 270). The president said he understood the potential ramifications (Woodward 2004: 270).

The cautionary arguments Powell made were largely echoed in letters Ike Skelton, a Representative from Missouri, wrote Bush on 4 September 2002 and 18 March 2003 (Ricks 2006: 59-60, 103). Skelton said he believed the US would best Iraq's military and depose Saddam, but warned of the dangers inherent in occupying a country with an authoritarian history, ethnic divisions, and a closed-off economy (Ricks 2006: 59). He voiced concerns that "[a new] regime might be rejected by the Iraqi people, leading to civil unrest and even anarchy" (Ricks 2006: 59). Skelton further called on Bush to tell the US public what the war and years of occupation would cost in terms of soldiers deployed and money expended (Ricks 2006: 60). The views shared by the Missouri congressman should have served as reinforcement to Powell's case for caution.

Evidence from various stages of Bush's decision making indicates a mix of susceptibility and resistance to positive illusions. At a 15 September 2001 NSC meeting Bush expressed reticence to strike Iraq early in the war against terrorism on the grounds that the US should avoid taking on too many simultaneous objectives (Woodward 2002: 84). This suggests resistance to both unrealistic optimism and unduly positive views of his state's abilities.

During the same meeting, though, Bush asserted his willingness and ability for unilateral action (Woodward 2002: 81), which might point to unrealistically positive perceptions of 
American capabilities and the illusion of control. Six days later, however, Bush acknowledged the necessity of coalition partners (Woodward 2002: 113). After Powell's 5 August 2002 appeal for caution in the decision on war Bush reiterated his desire for a coalition (Woodward 2002: 334; 2004: 151). The president's subsequent actions to maintain the support of coalition allies such as the UK (detailed in the second section of the present chapter), actions that sometimes went against his personal preferences, clearly mark a turn away from a view that unilateralism was feasible and further point to resistance to positive illusions.

Evidence from war planning discussions and briefings also demonstrates a mix of positive illusions and resistance to them. Bush's concerns about Fortress Baghdad exhibit resistance to all three varieties of positive illusions. The president was recognizing Saddam's ability to greatly influence the course and costs of war thus showing Bush resistant to the illusion of control and unrealistic optimism. He was also recognizing potential limits to the US military's ability to readily prevail in armed conflict against Iraq. Bush's lukewarm response to General Franks's 20 April 2002 proposals for a smaller force and shorter preparation period (see Woodward 2004: 121) is also suggestive of resistance to positive illusions. Unrealistic optimism or unduly sanguine views of the American military's abilities, if present in the president's thinking on this aspect of war planning, should have led Bush to react more enthusiastically to a proposal for a smaller, faster invasion.

Bush's decision making regarding the occupation, by contrast, does appear to display positive illusions. Despite the chorus of voices warning the US would face a years-long occupation requiring large numbers of troops and intensive involvement in running Iraq, Bush assumed the US would only need to facilitate Iraqis' own work to rebuild and administer Iraq (Gordon and Trainor 2006: 142). This assumption suggests Bush may have been prone to 
unrealistic optimism regarding this stage of policy implementation.

In sum, evidence from Bush's decision making about the invasion plans and unilateralism versus coalition building suggests relative resistance to positive illusions, but his thinking on the occupation seems to exhibit unrealistic optimism. Resistance to positive illusions appears likely to have contributed both to Bush's position against striking Iraq earlier in the war on terror as well as his policy of coalition building and trying to act via the UN. On the other hand, his susceptibility to positive illusions regarding occupation planning may have contributed to his eventual decision to opt for invasion by reducing his estimates of war's longer term costs.

\section{Cheney and Positive Illusions}

Cheney also received some notable information that was not equally available to the other decision makers. Some of this information projected a rather optimistic view of war with Iraq, but most cast war in a pessimistic light. The optimistic perspective came from Doug MacGregor, a colonel working on Pentagon efforts to reshape the US Army (Gordon and Trainor 2006: 33-35). MacGregor believed the war and occupation could be successfully conducted by a mobile force totaling 31,500 soldiers, and his views were provided to Cheney via former Speaker of the House Newt Gingrich (Gordon and Trainor 2006: 34-35).

MacGregor's sanguine views were countered by other perspectives presented to Cheney. In March 2002 Yemen's president, Ali Abdullah Saleh warned Cheney “that Saddam did not want to go to war but would use chemical weapons if attacked" (Gordon and Trainor 2006: 43). Five months later leaders in the Iraqi opposition told Cheney that looting and disorder would follow the defeat of Saddam's regime (Gordon and Trainor 2006: 157). This pair of warnings challenged MacGregor's argument that a small force could carry off the invasion and occupation of Iraq. 
Cheney's preference for secrecy and tendency to share his views only with Bush (Gordon and Trainor 2006: 44) mean there is relatively little evidence of his positions or how he processed information as he made decisions. What evidence is available indicates that Cheney's decision making about war with, and occupation of, Iraq was increasingly subject to positive illusions as time went on. During a 15 September 2001 NSC meeting Cheney opposed war with Iraq as an early step in the war on terror due to the risk of harming coalition-building (Woodward 2002: 91). This suggests resistance both to the illusion of control and unduly positive views of American capabilities. Cheney appears to be acknowledging the importance of international partners' actions and America's need for assistance from allies. Later, however, Cheney seems to have become confident the US could successfully act unilaterally. During a principals meeting on 6 September 2002 Cheney was explicitly dismissive of Powell's warnings about the negative consequences of unilateral US action (Woodward 2002: 346).

This reversal points to susceptibility to the illusion of control and unrealistically positive perceptions of the United States' ability to achieve success alone. Further supporting a conclusion that Cheney was susceptible to positive illusions, on 17 March 2003 the vice president expressed to US legislative leaders his belief that invading forces would "be greeted as liberators" by the Iraqi population (Woodward 2004: 370). Cheney did add that an occupation would be needed, but sounded confident in its success and voiced no concerns that occupation would be lengthy or costly (Woodward 2004: 370). Cheney had been presented with information that could be used to justify such optimism about the invasion and occupation of Iraq, but he also had been faced with information predicting great adversity in the war and postwar occupation. He appears to have accepted the information supporting optimism and 
dismissed that which was pessimistic or cautionary. It seems, then, that the vice president was susceptible to unrealistic optimism in his thinking about the prospect of going to war.

Cheney's susceptibility to positive illusions, which increased over the course of policy deliberations and war planning, seems to have affected his policy position in two ways. First, his

confidence in America's ability to act unilaterally partly explains his opposition to working with the UN, an opposition he maintained even as prominent figures like Powell and close allies like the UK argued vigorously for continuing to seek a UN-based solution. Second, Cheney's optimism about the invasion and occupation of Iraq likely influenced his pro-war position by lowering his estimates of the costs involved in both stages of the operation.

\section{Powell and Positive Illusions}

Powell's decision making regarding Iraq clearly and consistently demonstrated resistance to positive illusions. In mid-2001 Powell took notice of Wolfowitz's enclave strategy for removing Saddam, regarding as "lunacy" Wolfowitz's expectation that Iraqis would flock to the US side (Woodward 2004: 22). A few months later, in the immediate aftermath of the 9/11 attacks, Powell opposed suggestions that the US should quickly move against Iraq, arguing that such action would threaten US coalition-building efforts (Woodward 2002: 49; Mann 2004:

302). Over the course of successive policy deliberations, Powell continued to voice his concerns about war with Iraq. Most notable was Powell's 5 August 2002 meeting with Bush (discussed in detail above) in which the Secretary of State listed various reasons for caution in deciding to attack Iraq, some of which Powell reiterated in a 10 January 2003 conversation with the president (Gordon and Trainor 2006: 71, 149; Woodward 2002: 331-333; 2004: 150-151, 269). As noted previously, Powell also warned the other principals against unilateralism, predicting negative repercussions if the US acted alone (Woodward 2002: 346). This evidence from policy 
deliberations suggests resistance to all three types of positive illusions. The Secretary of State's views of US abilities demonstrated an acknowledgment of those abilities' limits. His acknowledgment of such limitations combined with recognition that foreign actors' (allies and opponents) behavior mattered to the outcome of US policy also indicates resistance to the illusion of control. Powell further demonstrated a pronounced lack of susceptibility to unrealistic optimism. His skepticism towards Wolfowitz's enclave strategy combined with Powell's own cautionary advice to Bush and the other selected officials plainly reveal the Secretary of State's openness to information of a pessimistic nature.

Powell's resistance to positive illusions is also evident in his thinking on the war plans for invading and occupying Iraq. Over the course of planning he repeatedly opined that the proposed force was too small (Gordon and Trainor 2006: 31-32, 71; Woodward 2004: 80). Powell worried aloud, too, that the small number of points designated for staging, reinforcements, and supplies made the invasion vulnerable to counterattack (Woodward 2004: 324). Additionally, Powell expressed his concern that war planning gave too little thought to postwar Iraq and the occupation (Gordon and Trainor 2006: 70). The Secretary of State's worries about war planning reflect recognition of limits to US abilities, the importance of Iraqi actions in determining the outcome of war, as well as the possibility of serious challenges, even failures. In other words, Powell's views on the war planning also demonstrate resistance to all three forms of positive illusions.

In terms of policy deliberations and war planning, then, Powell exhibited resistance to positive illusions. Powell's lack of positive illusions also appears clearly to have influenced the policy positions he took. Indeed his concerns about the challenges and broader negative repercussions of war with Iraq, especially unilateral war, do much to explain why he was so slow 
to accept turning away from UN process and instead adopting a policy position in support of war.

Rice and Positive Illusions

As National Security Advisor, Rice received some of the same additional information available to the president. Significantly, she was present on 5 August 2002 when Powell presented Bush with his list of reasons to approach war cautiously (Gordon and Trainor 2006: 71, 149; Woodward 2002: 331-333; 2004: 150-151). Rice even seems to have received some information that may not have risen to the level of the president. Marine Major Jeff Kojac, an NSC staffer, briefed Rice that occupation might need 364,000-480,000 troops (Gordon and Trainor 2006: 103). In early January 2003 a top aide to Jacques Chirac, France's President, visited Rice and warned against war, arguing invasion could destabilize the region, whip up protest, and enhance Al Qaeda recruitment (Mann 2004: 349).

Rice's response to Chirac's aide is illustrative of her resistance to positive illusions. She rejected the aide's anti-war conclusions but did not dispute the risks he asserted (Mann 2004: 349). Indeed Rice appears to have been quite open to recognizing the risks of war. She seems to have been more worried about a Fortress Baghdad situation than any of the other selected decision makers; it was a concern she returned to across months of war planning (Woodward 2004: 126, 133, 174). What these few instances suggest is Rice's resistance to all three varieties of positive illusions. Her fears about Fortress Baghdad indicate perceptions of limits to US abilities, recognition that the outcome of a war would be significantly influenced by the actions of Saddam (this recognition represents avoiding the illusion of control), and a resistance to unrealistic optimism. Rice's acknowledgment of the risks listed by Chirac's aide also points to a lack of susceptibility to unrealistic optimism. 
In determining the role Rice's resistance to positive illusions played in her foreign policy position, the exchange with Chirac's aide is again instructive. Rice did not dispute his assertion that war entailed potential negative consequences, but she did dispute his conclusion that the risks made war unacceptable (Mann 2004: 349). To Rice the threat Saddam posed made the risks of not invading greater than the risks of war (Mann 2004: 349). This single episode appears generally representative of the decision making behind her policy position. Rice did not come to support a policy of invasion because she thought it would be easy and low-cost; she supported war in spite of its dangers.

\section{Rumsfeld and Positive Illusions}

Rumsfeld, being Secretary of Defense, was more involved in the war planning than the other six officials under analysis, and this involvement provided him information not readily available to most, if not all, of them. One aspect of that additional information is relevant to the present analysis. Before Franks presented the other officials with his early estimates that 275,000-300,000 troops would be needed for war with Iraq, he had proposed to Rumsfeld that a force of 385,000 would be needed (Gordon and Trainor 2006: 29). Additionally, it was through the war planning process that Rumsfeld was, like Cheney, exposed to MacGregor's argument that the war and occupation could be handled successfully by a mobile force of 31,500 troops (Gordon and Trainor 2006: 33-35). Not all of the additional information available to Rumseld, though, came from war planning. Rumsfeld was with Cheney in August 2002 when Iraqi dissidents warned of looting and disorder in the aftermath of invasion (Gordon and Trainor 2006: 157).

Whatever the cautionary information available to Rumsfeld, the Secretary of Defense seems to have largely downplayed it in favor of information of an optimistic nature. Throughout 
the war planning process Rumsfeld pushed for a smaller force and a shorter preparation period. When in late 2001 he was briefed on OPLAN 1003-98 and its stipulation that 380,000-500,000 troops would be needed for war with Iraq, Rumsfeld responded by saying a force of 125,000 troops was likely overkill (Gordon and Trainor 2006: 3-4). The Secretary of Defense was offhandedly dismissive of the existing plan and its "long-standing military principles about the force levels that were needed to defeat Iraq... and control a population of more than 24 million" (Gordon and Trainor 2006: 4). Soon thereafter it was Rumsfeld's disapproval that led Franks to cut his estimated troop requirement by 85,000-110,000 soldiers (Gordon and Trainor 2006: 29). Even when Franks's planning compromised on the lower number of 275,000 troops Rumsfeld still wanted fewer (Gordon and Trainor 2006: 29, 31-32, 36; Woodward 2004: 101, 133). In part, Rumsfeld's desire to cut the troop number was linked to his view that occupation by the invading force would be a short affair requiring only that the US facilitate the Iraqis' own work to rebuild and administer the country (Gordon and Trainor 2006: 141-142). His approach was to quickly withdraw most of the American force (Gordon and Trainor 2006: 142). So strong was Rumsfeld's belief in a smaller force that he later interfered with actual deployments such that the larger planned force and logistics to support it were delayed and not in place at the time the US land force commander for the war thought they were needed (Gordon and Trainor 2006: 95101). Further, the Secretary of Defense planned to ultimately limit the size of the invasion and occupation force by curtailing additional force deployments once fighting was underway (Gordon and Trainor 2006: 103).

Rumsfeld's decision making regarding war plans exhibited susceptibility to two forms of positive illusion. In expressing his confidently optimistic views about what could be done with a small force, he was plainly dismissive of evidence and arguments calling for a larger force. His 
sanguine perspective on invasion and occupation, in turn, suggests unrealistic optimism.

Rumsfeld had been warned of disorder in the wake of invasion and, as discussed previously, had himself noted the possibility of Fortress Baghdad during combat and ethnic conflict in the invasion's aftermath. Still, he held firm both to his optimism about what could be achieved with a small force as well as his belief that the occupation would be brief and allow the speedy withdrawal of American troops.

The Secretary of Defense's susceptibility to positive illusions provides insight into his policy position on war with Iraq. His optimism about the outcome of invasion and occupation helps explain why he began suggesting striking Iraq immediately after $9 / 11$. He seems not to have seen war with Iraq as an endeavor that would require so much that it would detract from other objectives in the war on terror. His confidence that war would be successful and relatively easy also aids in accounting for his support of a strict UN resolution that would make justifying war easier. Where more pessimistic officials like Powell sought to avoid war until late in policy deliberations, Rumsfeld appears to have been desirous of a quicker course to conflict.

\section{Wolfowitz and Positive Illusions}

Wolfowitz exhibited even more optimism about the prospects of war with Iraq than Rumsfeld. His previously discussed pre-9/11 enclave strategy rested on assumptions of Iraqi support for the US Powell referred to as "lunacy" (Woodward 2004: 22). The Deputy Secretary of Defense argued on 15 September 2001 that Saddam's regime was weak and could be toppled with relative ease, perhaps more easily than ousting the Taliban in Afghanistan (Woodward 2002: 83; 2004: 21). In the weeks just prior to the invasion's beginning, Wolfowitz's optimism remained unshaken by the many warnings about the potential challenges of invading and occupying Iraq. When Rumsfeld asked a group of his chief officials for their estimates regarding 
the time from the start of the war to the ouster of Saddam military officers' estimates ranged from weeks to three months, with Franks predicting "weeks, not months" (Woodward 2004: 325326). The estimates offered by two CIA officials ran from 13 days to three weeks (Woodward 2004: 326). Wolfowitz predicted the shortest period: seven days to Saddam's overthrow (Woodward 2004: 326). The Deputy Secretary of Defense was offering a prediction rather more sanguine than that of Franks, the officer who had overseen the military's planning. Then, even after Shinseki's cautionary testimony to Congress on the subject of occupying Iraq, Wolfowitz shared with high-ranking US officers "that he thought within a few months of the invasion the US troop level in Iraq would be thirty-four thousand" (Ricks 2006: 97).

Wolfowitz's belief that invading and occupying Iraq would be easy combined with his clear disregard for, or dismissal of, information contrary to his belief strongly suggests he was susceptible to the positive illusion of unrealistic optimism. Likewise, he maintained his sanguine view of America's ability to quickly and easily achieve its objectives in the face of credible information to the contrary (e.g., Shinseki's testimony). His susceptibility to these positive illusions goes a long way to explaining his early, consistent, and vigorous advocacy for war against Iraq. Wolfowitz wanted Saddam overthrown and appears to have believed the task would be quick and low-cost.

\section{Discussion: Findings and Theory}

In this section I assess the study's theoretical framework against the findings. This portion of the chapter proceeds as follows. For each decision maker I first summarize my findings for that individual. I then determine how closely the findings match the expectations derived from my framework and the previous chapter's quantitative analysis.

\section{Findings and Theory Assessment}




\section{Armitage}

The Deputy Secretary of State's decision making exhibited resistance to positive illusions. In terms of his foreign policy position, Armitage wanted to oust Saddam. When he thought the US should move against the Iraqi regime is unclear. Woodward (2004: 39) states that in November 2001 Armitage wanted to wait until the cohesion of the post-Gulf War coalition against Saddam could be ensured. Ricks (2006: 52) cites evidence that before October 2002 Armitage was among the administration's "hawks" seeing the necessity of ousting Saddam and believing that the attack needed to come soon.

Armitage's resistance to positive illusions is anticipated by his low-to-moderate belief in his ability to control events and thus offers some support for my theoretical framework. His interest in preserving the post-Gulf War coalition suggests a greater, more dovish focus on relationships than his moderate task focus predicts. Armitage's policy position also runs contrary to expectations derived my theory. Issues of timing aside, his position that the US should act to overthrow Saddam was consistent and indicates domination of the Iraqi regime was firmly his preferred policy. Hypothesis sixteen anticipates settlement would be Armitage's preferred policy with a move to supporting domination coming only if settlement or deadlock were not achieved. The findings thus offer some support for my theoretical framework but on balance run counter to it.

Bush

Bush's decision making indicated a mix of susceptibility and resistance to positive illusions. His foreign policy positions were similarly complicated. Before the 9/11 attacks Bush favored continued containment of Iraq. Right after 9/11 Bush saw Saddam as a future but not immediate target. His policy position also generally emphasized the importance of building a 
coalition to support US action. But beginning in November 2001 Bush progressively shifted his position towards support of war to remove Saddam from power. At the same time, however, Bush also supported a policy of giving the UN and weapons inspections under its auspices a chance to address the Iraqi threat without removing Saddam. Essentially, the president supported a two-track policy, but with war the increasingly favored option. By mid-January 2003 Bush had clearly decided on a policy of war.

As noted in the previous chapter, my theoretical framework offers few expectations about Bush's decision making or policy positions. In actuality, my framework predicts only that Bush, given his potentially greater belief that he can control events, might exhibit more susceptibility to positive illusions than the other officials selected for study. Bush's mix of resistance and proneness to positive illusions does conform to my qualified expectation. He did exhibit more susceptibility to positive illusions compared to Armitage, Powell, and Rice but less susceptibility than Rumsfeld and Wolfowitz. In that sense, Bush's behavior offers support for the theoretical framework.

Cheney

Cheney exhibited some resistance to positive illusions in early deliberations about Iraq policy, but displayed increased susceptibility later. His foreign policy position was rather consistent, but showed some changes over time. At least by the early post-9/11 period Cheney wanted to strike Iraq. His somewhat mixed early views on the importance of coalition support, though, contributed to his call to delay war. From February 2002 Cheney became more supportive of invading Iraq. Indeed Cheney supported going to war quickly, even if that meant acting unilaterally. His general opposition to seeking UN action on Iraq was based in no small part on his view that the UN process would delay war. 
The vice president's early resistance to positive illusions is in line with expectations derived from the theoretical framework and its first hypothesis, but this confirmation for the theory is negated by the increased role of positive illusions in Cheney's later decision making. Cheney's uniformly moderate ratings on his belief he can control events predict resistance to positive illusions. His support for war combined with his later willingness for unilateralism and his opposition to acting through the UN do, though, fit expectations derived the theoretical framework. His low I-1 belief ratings anticipate his support for conflictual policy. Cheney’s moderate-to-high task focus ratings also suggest that he would exhibit more concern with tasks like security than relationships (e.g., relations with the UN). In sum, Cheney's decision making and policy positions both support and challenge the theory.

Powell

The Secretary of State's decision making was marked by clear and consistent resistance to positive illusions. His foreign policy positions showed more variance, but a consistent logic. Before the 11 September 2001 terror attacks Powell's policy position was one of using diplomatic means and allies to improve containment of Saddam via sanctions; force was to be used only after all else had failed. Post-9/11 he viewed Saddam as a threat to be targeted later, and he favored acting with a coalition. He even demonstrated that he was not set on a policy of striking Iraq. From August 2002 through early 2003 Powell supported and actively pursued a policy of addressing Iraq via the UN and weapons inspections, a policy he recognized might preclude war and the ouster of Saddam. Powell did not shift to a policy position favoring war until late January or early February 2003.

Powell's resistance to positive illusions runs somewhat counter to expectations derived from my theoretical framework's first hypothesis. While resistance is expected of Powell, my 
framework anticipates Powell would, if anything, exhibit greater susceptibility to positive illusions than at least some of the other officials. The reason for that expectation is Powell's high P-4 rating compared to the intra-administration norming group. The findings indicate, though, that Powell was perhaps the decision maker most resistant to positive illusions. Powell's policy positions also run contrary to expectations. According to my theoretical framework Powell should have been inclined to moderately oppose conciliatory policies, but of the decision makers under study he was the last to support war and the most vociferous and committed advocate of the UN process that might have left Saddam's regime intact. The Secretary of State's decision making and policy positions, then, mostly disconfirm the theoretical framework. Rice

Bush's National Security Advisor demonstrated steady resistance to positive illusions. Her foreign policy positions also demonstrated consistency up to late 2002. After 11 September 2001 she saw Saddam as an eventual target, but initially supported avoiding war, suggesting instead providing a way for Saddam to rehabilitate Iraq in the eyes of the US. Later, she supported the course of working through the UN. By the end of 2002, however, Rice had adopted a pro-war position.

The resistance to positive illusions indicated by Rice's decision making conforms to expectations based on the theory and her moderate-to-low belief she can control events. Her openness to conciliation with Iraq and support for working with the UN throughout most of the analyzed period, however, do not mesh with expectations drawn from my theoretical framework. Rice's behavior demonstrated more concern for relationships and inclination for conciliation than anticipated in light of her moderate task focus. The NSA's willingness to pursue conciliation and slowness to adopt a pro-war position also run counter to what my theory 
predicts given her moderate-to-low I-1 ratings. Further, the framework leads to an expectation that Rice would act - if she behaved like any decision maker type - similar to a chickenhawk. A chickenhawk would favor conflict first, but opt for conciliation should conflict not succeed. Rice, contrary to that expectation, sought conciliation first, shifting to support of war second. Taken together, the findings pertaining to Rice provide some support for the theory, but also disconfirmation.

\section{Rumsfeld}

Rumsfeld exhibited consistent susceptibility to positive illusions. His foreign policy positions were also rather consistent. Before the 9/11 attacks the Secretary of Defense supported a policy of containment, but advocated more aggressive military action in response to any Iraqi provocations. After 9/11 Rumsfeld proposed striking Iraq early and downplayed concerns about the reaction of America's coalition partners. Rumsfeld generally expressed opposition to seeking a UN resolution on Iraq, seeming to instead support war. Recall that when the US did seek UN action, Rumsfeld argued for resolution language that was harsh and likely to precipitate UN endorsement of war with Iraq. There is some question as to whether Rumsfeld was set on war as the US began working with the UN, but he seems to have been decisively in the pro-war column after the National Intelligence Estimate (NIE) was released in October 2002.

Rumsfeld's susceptibility to positive illusions is contrary to what is predicted by my framework. His consistently moderate belief in his ability to control events suggests resistance to positive illusions. His focus on Iraq as a target, lack of concern about coalition partners, and opposition to working with UN do, however, fit with my expectations. His moderate task focus explains his low prioritization of relationships. Rumsfeld's support for conflictual policies also matches expectations based on my theory. His consistently low P-1 ratings and, to a lesser 
extent, moderate-to-low I-1 ratings indicate he should be inclined towards conflictual policy positions. Considered as a whole, the findings for Rumsfeld offer more confirmation than disconfirmation for my theory.

\section{Wolfowitz}

The Deputy Secretary of Defense reliably displayed susceptibility to positive illusions. Wolfowitz was equally reliable in his adherence to conflictual policy positions. From the beginning of the Bush administration he energetically advocated forcibly removing Saddam from power.

Wolfowitz's susceptibility to positive illusions clashed with expectations based on my framework. His moderate-to-low belief in his ability to control events predicts resistance to this bias. His steadfast support for militarily ousting Saddam is also contrary to expectations drawn from my theory. His moderate task focus and moderate-to-low I-1 and P-1 ratings provide some expectation that Wolfowitz would be disinclined to compromise and conciliation, but they do not predict plainly conflictual policy positions. Wolfowitz's early and dogged support for conflict is especially surprising considering that his P-1 and I-1 scores rate as moderate relative to the Bush administration norming group. The findings regarding Wolfowitz's decision making and policy positions uniformly, then, challenge my theoretical framework.

\section{Conclusion}

The qualitative analysis's findings offer a mix of confirmation and disconfirmation for my theoretical framework. Expectations about susceptibility or resistance to positive illusions sometimes match the Bush administration officials' decision making well, but in other cases officials' behavior plainly departs from predictions. My theoretical framework correctly anticipates the susceptibility or resistance of Armitage, Bush, and Rice. Expectations that 
Rumsfeld and Wolfowitz would be resistant to positive illusions are, however, not borne out by the evidence. Cheney and Powell's susceptibility or resistance to positive illusions partly, but by no means completely, conforms to my expectations.

The decision makers' expected foreign policy positions, based on my theory, mostly do not match their actual positions. The policy positions of Cheney and Rumsfeld are anticipated by the theoretical framework, but those of Armitage, Powell, Rice, and Wolfowitz are not. My theory does not provide expectations about Bush's foreign policy position.

The divided judgment on the theoretical framework begs the question of whether there are corresponding patterns in the qualitative and quantitative findings that are not anticipated by the theory and which might inform its future development in order to improve it explanatory and predictive utility. I briefly discuss my examination of two potential patterns I have identified and how they may or may not inform my theoretical framework. One pattern relates to positive illusions. The other pertains to foreign policy positions.

Rumsfeld's consistent susceptibility to positive illusions and equally consistent moderate, not high, belief (in terms of LTA and OCA variables) in his ability to control events, seem to suggest a lower threshold for proneness to positive illusions. Wolfowitz also exhibited reliable susceptibility to positive illusions and is generally moderate in his belief he can control events. The ratings for Wolfowitz do, though, show him as low in this belief when his personality trait measures are compared to the Anglo-US LTA norming group. Further, Powell is higher than Rumsfeld in his belief (for both OCA and LTA variables) that he can exert control over events, yet Powell exhibited perhaps the greatest resistance to positive illusions. Therefore, rather than indicate that even a moderate belief in one's ability to control events leads to pronounced susceptibility to positive illusions, the findings tentatively suggest this belief and proneness to 
positive illusions may have little or no causal relationship. At the very least the findings of this study do not add up to a clear case for revising this aspect of the theory.

Wolfowitz was the earliest and most outspoken advocate of conflictual US policy towards Iraq. He also receives uniformly high distrust ratings. Rumsfeld, whose distrust ratings range from moderate to high, was also an early and consistent supporter of conflict against Iraq. This appears to suggest moderate or higher distrust might alone account for and predict support for conflictual foreign policy. Such a suggestion aligns well with previous research indicating distrustful decision makers have a marked proclivity for advocating forceful action (Driver 1977; Foster and Keller 2014; Shannon and Keller 2007: 84). Bush is, however, higher in distrust than Rumsfeld, but was more open than Rumsfeld to diplomatic resolution and slower to adopt a policy position in favor of war. Additionally, Cheney is lower in distrust than Bush, yet he was quicker than Bush to adopt a pro-war position. Cheney was also less open to a diplomatic resolution than Bush. In short, this study shows a less-than-clear relationship between distrust and conflictual foreign policy positions. Distrust may indeed need to be given a more prominent place in my theoretical framework, but the present findings are insufficient to justify such a change.

In sum, the findings both support and challenge my theoretical framework, thus producing a mixed assessment. While some aspects of the findings hint at changes that might be made to the theoretical framework, there are no clear patterns showing the necessity or direction of such changes. What does appear clear is that further empirical analysis is needed to better determine the explanatory and predictive utility of the theory. In the next chapter I propose directions for future research. 


\section{Chapter 5: Conclusion}

This study's theoretical and analytical work on hawkish and dovish decision makers has been motivated by two factors. The first is the centrality of "hawks" and "doves" in popular (e.g., Bamford 2002; Harnden 2003; Left 2002) and scholarly accounts (e.g., Iklé 2005; Heffington 2016; Schultz 2005; Snyder and Diesing 1977; Stanley 2009a, 2009b; Vasquez 1993) of international conflict stages ranging from rivalry, to war, to peace. The second is our poor understanding of the hawk and dove labels. Very few efforts (e.g., Hagan 1994; Snyder and Diesing 1977) have been made to improve our insight into why some decision makers are hawks while others are doves. Our comprehension of the hawk and dove labels is further limited by their typical crude treatment as dichotomous, one-size-fits-all categorizations. Such treatment fails to address potentially significant differences across decision makers within the hawkish and dovish categories. Stated simply, hawkish and dovish elites are key to explaining conflict and peace, but we do not know much about them and what "makes them tick," nor has much been done to find out.

Through the present work I have attempted to rectify this situation by constructing a theoretical framework offering systematic means to identify hawkish and dovish decision makers as well as the potential variations across individuals within the two categories. In the process of building the framework I synthesized theory and findings from existing studies of hawkish and dovish elites in the international security subfield of International Relations (IR), the Operational Code (OCA) and Leadership Trait Analysis (LTA) research programs within the IR subfield of foreign policy analysis (FPA), and the study of cognitive errors and biases within political psychology. The resulting framework has provided a six-fold psychology-based typology comprising three dovish and three hawkish decision maker types. The types are distinguished 
via differing beliefs, personality traits, preferences (stemming from beliefs), and perceptions of opponents' preferences. Types are also differentiated by hypothesized (hypotheses one through eleven) variable susceptibilities to certain cognitive errors and biases. Proneness to biases and errors is, as I have argued, affected by the other variables that characterize the types, but differential susceptibility to errors and biases also further distinguishes the decision maker types and aids in explaining and predicting their behavior. From my theoretical framework and its typology I have ultimately drawn six hypotheses predicting each decision maker type's positions on foreign policy.

I have empirically tested my framework's six-fold typology and seventeen hypotheses through a mixed-methods approach consisting of, on the one hand, quantitative content analysis and norming group comparisons and, on the other hand, qualitative congruence testing. The subjects I analyzed are President George W. Bush and six top officials within his administration: Richard Armitage (Deputy Secretary of State), Richard "Dick" Cheney (Vice President), Colin Powell (Secretary of State), Condoleezza Rice (National Security Advisor), Donald Rumsfeld (Secretary of Defense), and Paul Wolfowitz (Deputy Secretary of Defense). This group's selection for study is due primarily to the fact that either the hawk or dove label has been applied to all seven of them by academics (e.g., Badie 2010; Robison 2006) or journalists (e.g., Bamford 2002; Gompert, Binnendijk, and Lin 2014; Harnden 2003; Left 2002). That fact makes these decision makers an excellent group against which to assess my theoretical framework. In my qualitative congruence testing I have specifically focused on these officials' decision making and policy positions leading up to the March 2003 United States-led invasion of Iraq.

The findings of my quantitative analysis in chapter three produce two central conclusions. First, while differences in the decision makers' operational code beliefs do mesh 
with others' use of the hawk and dove labels (see e.g., Badie 2010; Binnendjik and Lin 2014; Robison 2006) or similar language (Shannon and Keller 2007) to discuss Bush administration officials, there is no clear match between the officials and my framework's decision maker types. Consequently, my framework's classificatory ability and thus its ability to explain and predict decision making behavior and policy positions are not found to be strong. Second, the lining up of others' application of hawk and dove labels with apparent differences in the officials' operational code beliefs does point to the existence of real and discernible psychological differences between the individuals to which the labels are applied. This observation in turn suggests that despite the findings' limited support for my framework additional research and potential refinement of the framework are worthwhile pursuits.

My quantitative analysis has also generated another finding warranting mention here. Specifically, I find that differences between the selected decision makers' scripted and spontaneous verbal behavior, though present and sometimes noteworthy, are not so large or clear in direction that they lead me to choose one speech type for analysis over the other. This finding can help inform the debate (see chapter two) over the speech types LTA researchers should select for analysis (see e.g., Dille 2000; Hermann 2003; Winter 2003). Namely, these findings fall on the side of David Winter's (2003: 174-175) view that both speech types are valid data sources for the analysis of decision makers' personality traits.

Findings from the qualitative analysis also give rise to two central conclusions. First, the results of the congruence testing provide both confirmation and disconfirmation for my theoretical framework and its hypotheses. Expectations drawn from my theory and hypothesis one regarding proneness or resistance to positive illusions in some instances mesh well with the officials' decision making. In other instances, however, decision makers' behavior patently 
clashes with expectations. As for expectations based on my framework regarding the decision makers' foreign policy positions, the evidence is largely disconfirmatory. The officials' anticipated foreign policy stances generally do not correspond to their actual positions.

The second conclusion stemming from my qualitative analysis is that there are aspects of the findings suggestive of changes that might improve my theoretical framework. These components of the findings do not, though, rise to the level of clear patterns demonstrating the need for, or direction of, such alterations. Additionally, adjusting the theoretical framework after a single study - especially considering that the study's findings provide both disconfirmation and confirmation of the framework - is premature.

In sum, the present study's theoretical framework represents an important effort to fill the need for a better, more sophisticated, and more systematic approach to identifying, and predicting the behavior of, hawkish and dovish decision makers. The mixed assessment of the framework arising from the combination of empirical support for, and challenges to, the theory do, however, raise concerns about the framework's classificatory, explanatory, and predictive abilities. Still, the very fact that the framework is systematically testable marks an improvement upon previous efforts to theorize about hawkish and dovish decision makers. If anything, the mix of confirmation and disconfirmation for the framework calls for additional research to further test and perhaps refine the theory. In what follows I suggest three directions for future research.

The most obvious direction for future research is to study more decision makers to which the hawk and dove labels have been applied. Analyzing these decision makers may well present the fastest and surest path to fruitful testing of, and possible refinement to, the theoretical framework. If other so-called hawks and doves also fail to match to the framework's six-fold 
decision maker typology, or do not generally behave in accordance with the theory's hypotheses, then either the direction of necessary changes to the framework, or maybe even the need to set aside the framework, will become more evident. Examples of other such decision makers which might be profitably analyzed can be found among the membership of US President John F. Kennedy's Executive Committee, also known as ExComm (see Alsop and Bartlett 1962). Of this group those marked as hawks include Dean Acheson (Secretary of State in the Harry S. Truman administration), McGeorge Bundy (National Security Advisor), Douglas Dillon (Secretary of the Treasury), and John McCone (Central Intelligence Agency Director) (Alsop and Bartlett 1962). Members branded doves are Robert Kennedy (Attorney General), Robert Lovett (Secretary of Defense under President Truman), and Robert McNamara (Secretary of Defense) (Alsop and Bartlett 1962).

Studying more decision makers who have been described as hawks or doves may be an obvious and productive course for future research, but it is by no means the only course. Analyzing elites who have been described as neither hawks nor doves may also prove beneficial. The findings from such analyses could be helpfully contrasted with findings about elites who have been labeled hawkish or dovish. Knowing how middle-of-the-road decision makers are psychologically similar to, and different from, hawkish and dovish ones could aid in determining which psychological variables are most important in distinguishing among decision makers. An example of an in-between decision maker can also be found in ExComm. Stewart Alsop and Charles Bartlett (1962: 20) describe President Kennedy's Secretary of State, Dean Rusk as “a dawk or a hove" indicating that he was "something in between."

The final suggestion for future research is about the foreign policy situations selected for study rather than the decision makers facing them. Specifically, some future research should 
analyze decision makers in foreign policy episodes characterized by multiple iterations of negotiations between opponents, negotiations involving demands and concessions, or at least offers of concessions. The foreign policy case examined by this work does not possess any instances of negotiation between the US and Iraq. As a result evidence pertaining to errors and biases like concession aversion was absent from the data. Studies examining cases with negotiations could bring a fuller testing of, and new perspective to, my theoretical framework. Whichever direction it takes, further study is needed. This project has contributed to research on hawks and doves as well as cross-fertilization among political psychology and the International Relations subfields of international security and foreign policy analysis. Additional research can build on what this study has begun and may refine the project's theoretical framework into a more powerful classificatory, explanatory, and predictive tool. 


\section{References}

Abrams, Herbert L. 1990. "Disabled Leaders, Cognition, and Crisis Decision-Making." In Accidental Nuclear War, eds. Derek Paul, Michael D. Intrilligator and Paul Smoker. Toronto: Science for Peace/Samuel Stevens \& Company, 136-149.

Allison, Graham T., Albert Carnesale, and Joseph S. Nye. 1985. Hawks, Doves, and Owls : An Agenda for Avoiding Nuclear War. 1st ed. New York: Norton.

Alsop, Stewart, and Charles Bartlett. 1962. "In Time of Crisis." Saturday Evening Post, December 8, 15-20.

Altman, Daniel. 2015. "The Strategist's Curse: A Theory of False Optimism as a Cause of War." Security Studies 24 (June): 284-315.

Badie, Dina. 2010. "Groupthink, Iraq, and the War on Terror: Explaining US Policy Shift toward Iraq." Foreign Policy Analysis 6 (October): 277-296.

Bamford, James. 2002. "Untested Administration Hawks Clamor for War.” USA Today. September 16. http://usatoday30.usatoday.com/news/opinion/2002-09-16-oplede_x.htm (January 6, 2017).

Bar-Joseph, Uri, and Rose McDermott. 2008. "Change the Analyst and Not the System: A Different Approach to Intelligence Reform.” Foreign Policy Analysis 4 (April): 127-145.

Bass, Bernard M. 1981. Stogdill's Handbook of Leadership: A Survey of Theory and Research. Rev. ed. New York: The Free Press.

Bazerman, Max H. 2001. "Why Negotiations Go Wrong." In The Negotiation Sourcebook, eds. Ira Asherman and Sandy Asherman. Amherst, MA: Human Resource Development Press, 219-24.

Berejikian, Jeffrey D., and Bryan R. Early. 2013. "Loss Aversion and Foreign Policy Resolve." Political Psychology 34 (October): 649-671.

Betts, Richard K. 1999. "Review: Must War Find a Way?: A Review Essay.” International Security 24 (Fall): 166-98.

Blainey, Geoffrey. 1973. The Causes of War. New York: Free Press.

Byars, Robert S. 1973. "Small-Group Theory and Shifting Styles of Political Leadership." Comparative Political Studies 5 (January): 443-69.

Byars, Robert S. 1972. “The Task/Affect Quotient.” Comparative Political Studies 5 (April): 109-20. 
Chilcot, John, Lawrence Freedman, Roderic Lyne, Usha Prashar. 2016. The Report of the Iraq Inquiry: Executive Summary. July 6. http://www.iraqinquiry.org.uk/media/247921/thereport-of-the-iraq-inquiry_executive-summary.pdf (June 5, 2017).

Crichlow, Scott. 2006. "The Eyes of Kesteven: How the Worldviews of Margaret Thatcher and Her Cabinet Influenced British Foreign Policy." In Beliefs and Leadership in World Politics: Methods and Applications of Operational Code Analysis, eds. Mark Schafer and Stephen G. Walker. New York: Palgrave MacMillan, 77-100.

Crichlow, Scott. 1998. "Idealism or Pragmatism? An Operational Code Analysis of Yitzhak Rabin and Shimon Peres." Political Psychology 19 (December): 683-706.

Crichlow, Scott. 2002. "Legislators' Personality Traits and Congressional Support for Free Trade." The Journal of Conflict Resolution 46 (October): 693-711.

Crichlow, Scott. 2005. "Lincoln, Seward and the United Kingdom." White House Studies 5 (Summer): 411-422.

Dille, Brian. 2000. "The Prepared and Spontaneous Remarks of Presidents Reagan and Bush: A Validity Comparison for at-a-Distance Measurements." Political Psychology 21 (September): 573-85.

Dille, Brian, and Michael D. Young. 2000. "The Conceptual Complexity of Presidents Carter and Clinton: An Automated Content Analysis of Temporal Stability and Source Bias." Political Psychology 21 (September): 587-96.

Driver, Michael J. 1977. "Individual Differences as Determinants of Aggression in the InterNation Simulation." In A Psychological Examination of Political Leaders, ed. Margaret G. Hermann. New York: The Free Press, 337-353.

Drury, A. Cooper. 2006. "Economic Sanctions and Operational Code Analysis: Beliefs and the Use of Economic Coercion." In Beliefs and Leadership in World Politics: Methods and Applications of Operational Code Analysis, eds. Mark Schafer and Stephen G. Walker. New York: Palgrave MacMillan, 187-200.

Dyson, Stephen Benedict. 2007. "Alliances, Domestic Politics, and Leader Psychology: Why Did Britain Stay out of Vietnam and Go into Iraq?" Political Psychology 28 (December): 647-666.

Dyson, Stephen Benedict. 2009. "Cognitive Style and Foreign Policy: Margaret Thatcher's Black-and-White Thinking.” International Political Science Review 30 (January): 33-48.

Dyson, Stephen Benedict. 2006. "Personality and Foreign Policy: Tony Blair's Iraq Decisions." Foreign Policy Analysis 2 (July): 289-306. 
Dyson, Stephen Benedict. 2009. "Stuff Happens": Donald Rumsfeld and the Iraq War. Foreign Policy Analysis 5 (October): 327-347.

Dyson, Stephen Benedict. 2013. "What Really Happened in Planning for Postwar Iraq?" Political Science Quarterly 127 (September): 455-488.

Dyson, Stephen Benedict, and Matthew J. Parent. 2017. "The Operational Code Approach to Profiling Political Leaders: Understanding Vladimir Putin." Intelligence and National Security. April 11. http://www.tandfonline.com/doi/abs/10.1080/02684527.2017.1313523 (June 2, 2017).

Farnham, Barbara. 1992. "Roosevelt and the Munich Crisis: Insights from Prospect Theory." Political Psychology 13 (June): 205-235.

Feng, Huiyun. 2006. "Crisis Deferred: An Operational Code Analysis of Chinese Leaders across the Strait." In Beliefs and Leadership in World Politics: Methods and Applications of Operational Code Analysis, eds. Mark Schafer and Stephen G. Walker. New York: Palgrave MacMillan, 151-170.

Feng, Huiyun. 2005. "The Operational Code of Mao Zedong: Defensive or Offensive Realist?" Security Studies 14 (October): 637-662.

Foster, Dennis M., and Jonathan W. Keller. 2014. "Leaders' Cognitive Complexity, Distrust, and the Diversionary Use of Force." 10 (July): 205-223.

Gelb, Leslie H. 1992. "Foreign Affairs; No More Hawks and Doves." The New York Times. October 8. http://www.nytimes.com/1992/10/08/opinion/foreign-affairs-no-more-hawksand-doves.html (June 4, 2017).

Gellman, Barton. 2008. Angler: The Cheney Vice Presidency. New York: Penguin Books.

George, Alexander L. 1969. “The 'Operational Code': A Neglected Approach to the Study of Political Leaders and Decision-Making." International Studies Quarterly 13 (June): 190222.

George, Alexander, and Andrew Bennett. 2004. Case Studies and Theory Development in the Social Sciences. Cambridge: MIT Press.

George W. Bush White House. 2009. "White House Press Briefings.” The White House President George W. Bush Archives. https://georgewbushwhitehouse.archives.gov/news/briefings/ (May 2, 2016).

Gompert, David C., Hans Binnendijk, and Bonny Lin. 2014. "The Iraq War: Bush's Biggest Blunder.” Newsweek. December 25. http://www.newsweek.com/iraq-war-bushs-biggestblunder-294411 (January 6, 2017). 
Gordon, Michael R., and Bernard E. Trainor. 2006. COBRA II: The Inside Story of the Invasion and Occupation of Iraq. New York: Pantheon Books.

Hagan, Joe D. 1994. “Domestic Political Systems and War Proneness.” Mershon International Studies Review 38 (October): 183-207.

Hagan, Joe D. 1993. Political Opposition and Foreign Policy in Comparative Perspective. Boulder: L. Rienner.

Handel, Michael I. 1989. War, Strategy, and Intelligence. London: F. Cass.

Harnden, Toby. 2003. "Hawks and Doves Unite over Iraq." The Telegraph. January 23. http://www.telegraph.co.uk/news/worldnews/northamerica/usa/1420042/Hawks-anddoves-unite-over-Iraq.html (January 6, 2017).

Heffington, Colton. 2016. "Do Hawks and Doves Deliver? The Words and Deeds of Foreign Policy in Democracies.” Foreign Policy Analysis 0 (June): 1-22.

Heradstveit, Daniel. 1979. The Arab-Israeli Conflict : Psychological Obstacles to Peace. Oslo: Universitetsforlaget.

Hermann, Margaret G. 1999. “Assessing Leadership Style” Social Science Automation https://socialscience.net/docs/LTA.pdf (January 7, 2017).

Hermann, Margaret G. 2003. “Assessing Leadership Style: Trait Analysis.” In The Psychological Assessment of Political Leaders with Profiles of Saddam Hussein and Bill Clinton, ed. Jerrold M. Post. Ann Arbor: University of Michigan Press, 178-214.

Hermann, Margaret G. 1980a. "Explaining Foreign Policy Behavior Using the Personal Characteristics of Political Leaders.” International Studies Quarterly 24 (March): 7-46.

Hermann, Margaret G. 1980b. “On 'Foreign Policy Makers, Personality Attributes, and Interviews: A Note on Reliability Problems"'. International Studies Quarterly 24 (March): 67-73.

Hermann, Margaret G. 1984. "Personality and Foreign Policy Decisionmaking: A Study of 53 Heads of Government." In Foreign Policy Decision Making: Perception, Cognition, and Artificial Intelligence, eds. Donald A. Sylvan and Steve Chan. New York: Praeger, 53-80.

Hermann, Margaret G., Thomas Preston, Baghat Korany, and Timothy M. Shaw. 2001. "Who Leads Matters: The Effects of Powerful Individuals." International Studies Review 3 (Summer): 83-131.

Holsti, Ole R. 1967. “Cognitive Dynamics and Images of the Enemy.” Journal of International Affairs 21 (Fall/Winter): 16-39. 
Holsti, Ole R. 1970. "The 'Operational Code' Approach to the Study of Political Leaders: John Foster Dulles' Philosophical and Instrumental Beliefs." Canadian Journal of Political Science 3 (March): 123-157.

Holsti, Ole R. 1977. The "Operational Code" as an Approach to the Analysis of Belief Systems : Final Report to the National Science Foundation Grant No. Soc75-15368. Durham: Duke University.

Iklé, Fred Charles. 2005. Every War Must End. 2nd rev. ed. New York: Columbia University Press.

Jervis, Robert. 1982. “Deterrence and Perception.” International Security 7 (Winter): 3-30.

Jervis, Robert. 1976. Perception and Misperception in International Politics. Princeton: Princeton University Press.

Jervis, Robert. 1992. "Political Implications of Loss Aversion." Political Psychology 13 (June): 187-204.

Jervis, Robert. 1988. "War and Misperception.” The Journal of Interdisciplinary History 18 (Spring): 675-700.

Johnson, Dominic D. P. 2004. Overconfidence and War: The Havoc and Glory of Positive Illusions. Cambridge: Harvard University Press.

Johnson, Dominic D.P., Rose McDermott, Emily S. Barrett, Jonathan Cowden, Richard Wrangham, Matthew H. McIntyre, and Stephen Peter Rosen. 2006. "Overconfidence in Wargames: Experimental Evidence on Expectations, Aggression, Gender and Testosterone." Proceedings of the Royal Society B 273 (October): 2513-2520.

Johnson, Dominic D.P., and Dominic Tierney. 2011. "The Rubicon Theory of War: How the Path to Conflict Reaches the Point of No Return.” International Security. (Summer): 740.

Kahneman, Daniel, and Jonathan Renshon. 2009. "Hawkish Biases." In American Foreign Policy and the Politics of Fear: Threat Inflation since 9/11, eds. A. Trevor Thrall and Jane K. Cramer. New York: Routledge, 79-96.

Kahneman, Daniel, and Amos Tversky. 1995. "Conflict Resolution: A Cognitive Perspective.” In Barriers to Conflict Resolution, eds. Kenneth J. Arrow, Robert H. Mnookin, Lee Ross, Amos Tversky and Robert B. Wilson. New York: W.W. Norton \& Company, 44-61.

Kahneman, Daniel, and Amos Tversky. 1979. "Prospect Theory: An Analysis of Decision under Risk." Econometrica 47 (March): 263-291. 
Keck, Shelli. 2003. "The Operational Code of Nikita Khruschev Before and After the Cuban Missile Crisis.” Ph.D. diss. Midwestern State University.

Keller, Jonathan W. 2005. "Constraint Respecters, Constraint Challengers, and Crisis Decision Making in Democracies: A Case Study Analysis of Kennedy Versus Reagan.” Political Psychology 26 (December): 835-867.

Kelley, Harold H., and John L. Michela. 1980. "Attribution Theory and Research.” Annual Review of Psychology 31 (February): 457-501.

King, Gary, Robert O. Keohane, and Sidney Verba. 1994. Designing Social Inquiry : Scientific Inference in Qualitative Research. Princeton: Princeton University Press.

Kowert, Paul A., and Margaret G. Hermann. 1997. "Who Takes Risks? Daring and Caution in Foreign Policy Making." The Journal of Conflict Resolution 41 (October): 611-637.

Lazarevska, Elena, Jayne M. Sholl, Michael D. Young. 2006. "Links Among Beliefs and Personality Traits: The Distinctive Language of Terrorists." In Beliefs and Leadership in World Politics: Methods and Applications of Operational Code Analysis, eds. Mark Schafer and Stephen G. Walker. New York: Palgrave MacMillan, 171-184.

Lebow, Richard Ned. 1981. Between Peace and War: The Nature of International Crisis. Baltimore: Johns Hopkins University Press.

Left, Sarah. 2002. "Iraq: Hawks and Doves." The Guardian. September 10. https://www.theguardian.com/world/2002/sep/10/iraq.sarahleft (January 6, 2017).

Leites, Nathan. 1953. A Study of Bolshevism. New York: Free Press.

Leites, Nathan. 1951. The Operational Code of the Politburo. New York: McGraw-Hill Book Company, Inc.

Levy, Jack S. 2000. "Loss Aversion, Framing Effects, and International Conflict: Perspectives from Prospect Theory." In Handbook of War Studies II, ed. Manus I. Midlarsky. Ann Arbor: Michigan University Press, 193-221.

Levy, Jack S. 1983. "Misperception and the Causes of War: Theoretical Linkages and Analytical Problems." World Politics 36 (October): 76-99.

Levy, Jack S. 2003. "Political Psychology and Foreign Policy." In Oxford Handbook of Political Psychology, eds. David O. Sears, Leonie Huddy and Robert Jervis. New York: Oxford University Press, 253-284.

Levy, Jack S. 1992. "Prospect Theory and International Relations: Theoretical Applications and Analytical Problems." Political Psychology 13 (June): 283-310. 
Levy, Jack S. 1997. "Prospect Theory, Rational Choice, and International Relations." International Studies Quarterly 41 (March): 87-112.

Levy, Jack S., and Lily I. Vakili. 1992. "Diversionary Action by Authoritarian Regimes: Argentina in the Falklands/Malvinas Case." In The Internationalization of Communal Strife, ed. Manus I. Midlarsky. London: Routledge, 118-146.

Linde, Jona, and Barbara Vis. 2017. "Do Politicians Take Risks Like the Rest of Us? An Experimental Test of Prospect Theory Under MPs." Political Psychology 38 (February): 102-117.

Malici, Akan. 2005. "Discord and Collaboration between Allies: Managing External Threats and Internal Cohesion in Franco-British Relations During the 9/11 Era." The Journal of Conflict Resolution 49 (February): 90-119.

Malici, Akan. 2006. "Reagan and Gorbachev: Altercasting at the End of the Cold War." In Beliefs and Leadership in World Politics: Methods and Applications of Operational Code Analysis, eds. Mark Schafer and Stephen G. Walker. New York: Palgrave MacMillan, 127-150.

Malici, Akan, and Allison L. Buckner. 2008. "Empathizing with Rogue Leaders: Mahmoud Ahmadinejad and Bashar Al-Asad." Journal of Peace Research 45 (November): 783-800.

Malici, Akan, and Johnna Malici. 2005. "The Operational Codes of Fidel Castro and Kim Il Sung: The Last Cold Warriors?" Political Psychology 26 (June): 387-412.

Mann, James. 2004. Rise of the Vulcans: The History of Bush's War Cabinet. New York: Viking.

Maoz, Ifat, Andrew Ward, Michael Katz, and Lee Ross. 2002. "Reactive Devaluation of an 'Israeli' Vs. 'Palestinian' Peace Proposal.” The Journal of Conflict Resolution 46 (August): 515-546.

Marfleet, B. Gregory. (2000) The Operational Code of John F. Kennedy During the Cuban Missile Crisis: A Comparison of Public and Private Rhetoric. Political Psychology 21:545-58.

Marfleet, B. Gregory, and Stephen G. Walker. 2006. "A World of Beliefs: Modeling Interactions among Agents with Different Operational Codes." In Beliefs and Leadership in World Politics: Methods and Applications of Operational Code Analysis, eds. Mark Schafer and Stephen G. Walker. New York: Palgrave MacMillan, 53-76.

Mazaar, Michael J. 2007. “The Iraq War and Agenda Setting.” Foreign Policy Analysis 3 (January): 1-23.

McDermott, Rose. 1992. "Prospect Theory in International Relations: The Iranian Hostage Rescue Mission." Political Psychology 13 (June): 237-263. 
McInerney, Audrey. 1992. "Prospect Theory and Soviet Policy Towards Syria, 1966-1967." Political Psychology 13 (June): 265-82.

Menon, Tanya, Oliver J. Sheldon, and Adam D. Galinsky. 2014. "Barriers to Transforming Hostile Relations: Why Friendly Gestures Can Backfire." Negotiation and Conflict Management Research 7 (February): 17-37.

Neale, Margaret A., and Max H. Bazerman. 1985. "The Effects of Framing and Negotiator Overconfidence on Bargaining Behaviors and Outcomes." The Academy of Management Journal 28 (March): 34-49.

Nincic, Miroslav. 1997. "Loss Aversion and the Domestic Context of Military Intervention." Political Research Quarterly 50 (March): 97-120.

Nisbett, Richard E., and Lee Ross. 1980. Human Inference: Strategies and Shortcomings of Social Judgment. Englewood Cliffs: Prentice-Hall, Inc.

Nordlinger, Eric A. 1995. Isolationism Reconfigured : American Foreign Policy for a New Century. Princeton: Princeton University Press.

Nye, Joseph S., Graham T. Allison, and Albert Carnesale. 1985. "Analytic Conclusions: Hawks, Doves, and Owls." In Hawks, Doves, and Owls: An Agenda for Avoiding Nuclear War, eds. Graham T. Allison, Albert Carnesale and Joseph S. Nye. New York: W.W. Norton \& Company, 206-222.

Post, Jerrold. 2003. "Assessing Leaders at a Distance: The Political Personality Profile." In The Psychological Assessment of Political Leaders with Profiles of Saddam Hussein and Bill Clinton, ed. Jerrold M. Post. Ann Arbor: University of Michigan Press, 69-104.

Preston, Thomas. 2001. The President and His Inner Circle : Leadership Style and the Advisory Process in Foreign Affairs. New York: Columbia University Press.

Quattrone, George A., and Amos Tversky. 1988. "Contrasting Rational and Psychological Analyses of Political Choice." The American Political Science Review 82 (September): 719-736.

Rapport, Aaron. 2012/2013. "The Long and Short of It: Cognitive Constraints on Leaders' Assessments of 'Postwar' Iraq.” International Security 37 (Winter): 133-171.

Rasler, Karen A., William R. Thompson, and Kathleen M. Chester. 1980. "Foreign Policy Makers, Personality Attributes, and Interviews: A Note on Reliability Problems." International Studies Quarterly 24 (March): 47-66.

Renshon, Jonathan. 2008. "Stability and Change in Belief Systems." Journal of Conflict Resolution 52 (December): 820-849. 
Renshon, Jonathan. 2009. "When Public Statements Reveal Private Beliefs: Assessing Operational Codes at a Distance.” Political Psychology 30 (August): 649-661.

Renshon, Jonathan. 2015. "Losing Face and Sinking Costs: Experimental Evidence on the Judgment of Political and Military Leaders.” International Organization 69 (July): 659695.

Renshon, Jonathan, and Daniel Kahneman. 2017. "Hawkish Biases and the Interdisciplinary Study of Conflict Decision-Making." In Advancing Interdisciplinary Approaches to International Relations, eds. Steve A. Yetiv and Patrick James. Cham, Switzerland: Palgrave Macmillan, 51-82.

Ricks, Thomas. 2006. Fiasco: The American Military Adventure in Iraq. New York: The Penguin Press.

Robb, Alice. 2013. "Let's Kill All the Hawks and Doves! As Lazy Metaphors, That Is.” New Republic. November 25. https://newrepublic.com/article/115734/hawks-doves-originsmetaphors-war-peace-supporters (June 4, 2017).

Roberts, Joel. 2004. “Dem Calls Cheney a 'Chickenhawk'.” CBS News. April 29. http://www.cbsnews.com/news/dem-calls-cheney-a-chickenhawk/ (January 6, 2017).

Robison, Sam. 2006. "George W. Bush and the Vulcans: Leader-Advisor Relations and America's Response to the 9/11 Attacks." In Beliefs and Leadership in World Politics: Methods and Applications of Operational Code Analysis, eds. Mark Schafer and Stephen G. Walker. New York: Palgrave MacMillan, 101-126.

Ross, Dennis. 1984. "Risk Aversion in Soviet Decisionmaking." In Soviet Decisionmaking for National Security, eds. Jiri Valenta and William Potter. London: Allen \& Unwin, 237251.

Ross, Lee. 1977. "The Intuitive Psychologist and His Shortcomings: Distortions in the Attribution Process." In Advances in Experimental Social Psychology, ed. L. Berkowitz. New York: Academic Press, 173-220.

Ross, Lee. 1995. "Reactive Devaluation in Negotiation and Conflict Resolution." In Barriers to Conflict Resolution, eds. Kenneth J. Arrow, Robert H. Mnookin, Lee Ross, Amos Tversky and Robert B. Wilson. New York: W.W. Norton \& Company, 26-43.

Ross, Lee, and Constance Stillinger. 1991. "Barriers to Conflict Resolution.” Negotiation Journal 7 (October): 389-404.

Schafer, Mark. 1999. "Cooperative and Conflictual Policy Preferences: The Effect of Identity, Security, and Image of the Other." Political Psychology 20 (December): 829-844. 
Schafer, Mark. 1997. "Images and Policy Preferences." Political Psychology 18 (December): 813-829.

Schafer, Mark. 2000. "Issues in Assessing Psychological Characteristics at a Distance: An Introduction to the Symposium." Political Psychology 21 (September): 511-527.

Schafer, Mark, and Scott Crichlow. 2000. "Bill Clinton's Operational Code: Assessing Source Material Bias.” Political Psychology 21 (September): 559-571.

Schafer, Mark, and Scott Crichlow. 2010. Groupthink Versus High-Quality Decision Making in International Relations. New York: Columbia University Press.

Schafer, Mark, Sam Robison, and Bradley Aldrich. 2006. "Operational Codes and the 1916 Easter Rising in Ireland: A Test of the Frustration-Aggression Hypothesis." Foreign Policy Analysis 2 (January): 63-82.

Schafer, Mark, and Stephen G. Walker. 2006. "Operational Code Analysis at a Distance: The Verbs in Context System of Content Analysis.” In Beliefs and Leadership in World Politics: Methods and Applications of Operational Code Analysis, eds. Mark Schafer and Stephen G. Walker. New York: Palgrave MacMillan, 25-52.

Schafer, Mark, and Stephen G. Walker. 2006. Beliefs and Leadership in World Politics: Methods and Applications of Operational Code Analysis. New York: Palgrave MacMillan.

Schultz, Kenneth A. 2005. "The Politics of Risking Peace: Do Hawks or Doves Deliver the Olive Branch?” International Organization 59 (January): 1-38.

Shafir, Eldar. 1992. "Prospect Theory and Political Analysis: A Psychological Perspective." Political Psychology 13 (June): 311-322.

Shannon, Vaughn P., and Jonathan W. Keller. 2007. "Leadership Style and International Norm Violation: The Case of the Iraq War." Foreign Policy Analysis 3 (January): 79-104.

Snyder, Glenn Herald, and Paul Diesing. 1977. Conflict among Nations : Bargaining, Decision Making, and System Structure in International Crises. Princeton: Princeton University Press.

Snyder, Jack L. 1991. Myths of Empire: Domestic Politics and International Ambition. Ithaca: Cornell University Press.

Stanley, Elizabeth A. 2009a. "Ending the Korean War: The Role of Domestic Coalition Shifts in Overcoming Obstacles to Peace.” International Security 34 (Summer): 42-82.

Stanley, Elizabeth A. 2009b. Paths to Peace : Domestic Coalition Shifts, War Termination and the Korean War. Stanford: Stanford University Press. 
Stevenson, Matthew. 2006. "Economic Liberalism and the Operational Code Beliefs of Us Presidents: The Initiation of Nafta Disputes, 1989-2002." In Beliefs and Leadership in World Politics: Methods and Applications of Operational Code Analysis, eds. Mark Schafer and Stephen G. Walker. New York: Palgrave MacMillan, 201-218.

Stillinger, C., M. Epelbaum, D. Keltner, and L. Ross. 1990. The 'Reactive Devaluation' Barrier to Conflict Resolution. Stanford: Stanford University Press.

Stoessinger, John George. 1998. Why Nations Go to War. 7th ed. New York: St. Martin's.

Svenson, Ola. 1981. "Are We All Less Risky and More Skillful Than Our Fellow Drivers" Acta Psychologica 47 (February): 143-148.

Tetlock, Philip E. 1998. "Social Psychology and World Politics.” In The Handbook of Social Psychology, eds. Daniel Gilbert, Susan T. Fiske and Gardner Lindzey. New York: McGraw-Hill, 869-912.

Tetlock, Philip E., and Anthony S. Manstead. 1985. "Impression Management Versus Intrapsychic Explanations in Social Psychology: A Useful Dichotomy? Psychological Review 92 (January): 59-77.

Thies, Cameron G. 2006. "Bankers and Beliefs: The Political Psychology of the Asian Financial Crisis." In Beliefs and Leadership in World Politics: Methods and Applications of Operational Code Analysis, eds. Mark Schafer and Stephen G. Walker. New York: Palgrave MacMillan, 219-236.

Tversky, Amos, and Daniel Kahneman. 1981. "The Framing of Decisions and the Psychology of Choice.” Science 211 (January): 453-458.

Tversky, Amos, and Daniel Kahneman. 1986. "Rational Choice and the Framing of Decisions." The Journal of Business 59 (October): S251-S278.

United States Department of Defense. 2009. "DoD News" U.S. Department of Defense Archive. http://archive.defense.gov/news/articles.aspx (May 2, 2016).

United States Department of State. 2009. "Remarks, Testimony, Speeches, and Briefing by Department of State Officials." U.S. Department of State Archive. https://20012009.state.gov/r/pa/ei/speeches/index.htm (May 2, 2016).

Van Evera, Stephen. 1999. Causes of War: Power and the Roots of Conflict. Ithaca: Cornell University Press.

Van Evera, Stephen. 1994. "Hypotheses on Nationalism and War." International Security 18 (Spring): 5-39.

Vasquez, John A. 1993. The War Puzzle. New York: Cambridge University Press. 
Walker, Stephen G. 2000. “Assessing Psychological Characteristics at a Distance: Symposium Lessons and Future Research Directions." Political Psychology 21(September): 597-602.

Walker, Stephen G. 1977. "The Interface between Beliefs and Behavior: Henry Kissinger's Operational Code and the Vietnam War." The Journal of Conflict Resolution 21 (March): 129-168.

Walker, Stephen G. 1983. "The Motivational Foundations of Political Belief Systems: A ReAnalysis of the Operational Code Construct." International Studies Quarterly 27 (June): 179-202.

Walker, Stephen G. 1995. "Psychodynamic Processes and Framing Effects in Foreign Policy Decision-Making: Woodrow Wilson's Operational Code.” Political Psychology 16 (December): 697-717.

Walker, Stephen G. 2004. "Role Identities and the Operational Codes of Political Leaders." In Political Psychology as a Perspective on Politics, ed. Margaret G. Hermann. London: Elsevier, 71-106.

Walker, Stephen G., and Lawrence S. Falkowski. 1984. "The Operational Codes of U.S. Presidents and Secretaries of State: Motivational Foundations and Behavioral Consequences." Political Psychology 5 (June): 237-66.

Walker, Stephen G., and Mark Schafer. 2006. "Belief Systems as Causal Mechanisms in World Politics: An Overview of Operational Code Analysis." In Beliefs and Leadership in World Politics: Methods and Applications of Operational Code Analysis, eds. Mark Schafer and Stephen G. Walker. New York: Palgrave MacMillan, 3-24.

Walker, Stephen G., and Mark Schafer. 2000. "The Political Universe of Lyndon B. Johnson and His Advisors: Diagnostic and Strategic Propensities in Their Operational Codes." Political Psychology 21 (September): 529-543.

Walker, Stephen G., and Mark Schafer. 2007. "Theodore Roosevelt and Woodrow Wilson as Cultural Icons of U.S. Foreign Policy.” Political Psychology 28 (September): 747-776.

Walker, Stephen G., Mark Schafer, and Michael D. Young. 1999. "Presidential Operational Codes and Foreign Policy Conflicts in the Post-Cold War World." The Journal of Conflict Resolution 43 (October): 610-625.

Walker, Stephen G., Mark Schafer, and Michael D. Young. 2003. "Profiling the Operational Codes of Political Leaders." In The Psychological Assessment of Political Leaders with Profiles of Saddam Hussein and Bill Clinton, ed. Jerrold M. Post. Ann Arbor: University of Michigan Press, 215-245. 
Walker, Stephen G., Mark Schafer, and Michael D. Young. 1998. "Systematic Procedures for Operational Code Analysis: Measuring and Modeling Jimmy Carter's Operational Code." International Studies Quarterly 42 (March): 175-189.

Whyte, Glen, and Ariel S. Levi. 1994. "The Origins and Function of the Reference Point in Risky Group Decision Making the Case of the Cuban Missile Crisis." Journal of Behavioral Decision Making 7 (December): 243-260.

Winter, David G. 1980. "An Exploratory Study of the Motives of Southern African Political Leaders Measured at a Distance." Political Psychology (Summer): 75-85.

Winter, David G. 2003. "Measuring the Motives of Political Actors at a Distance." In The Psychological Assessment of Political Leaders with Profiles of Saddam Hussein and Bill Clinton, ed. Jerrold M. Post. Ann Arbor: University of Michigan Press, 153-177.

Winter, David G. 1973. The Power Motive. New York: Free Press.

Winter, David G., Margaret G. Hermann, Walter Weintraub, and Stephen G. Walker. 1991. "The Personalities of Bush and Gorbachev Measured at a Distance: Procedures, Portraits, and Policy.” Political Psychology 12 (June): 215-245.

Winter, David G., and Abigail J. Stewart. 1977. "Content Analysis as a Technique for Assessing Political Leaders." In A Psychological Examination of Political Leaders, ed. Margaret G. Hermann. New York: The Free Press, 28-61.

Woodward, Bob. 2002. Bush at War. New York: Simon \& Schuster.

Woodward, Bob. 2004. Plan of Attack. New York: Simon \& Schuster.

Young, Michael D., and Mark Schafer. 1998. "Is There Method in Our Madness? Ways of Assessing Cognition in International Relations." Mershon International Studies Review 42 (May): 63-96. 


\section{Appendix A}

\section{Reverse Engineering Leadership Trait Analysis Findings}

Vaughan P. Shannon and Jonathan W. Keller, in their 2007 analysis of Bush administration officials' personality traits, do not present raw scores for the individual decision makers' traits. Intsead, the authors provide trait values standardized to the Anglo-United States LTA norming group. The trait values presented by Shannon and Keller (2007: 93) are standardized such that "for each [trait], the mean is 50 and the standard deviation is $10 . "$

In order to undertake the analysis required for my purposes the standardized values must be transformed to non-standardized scores. What follows is the procedure I use to derive the non-standardized, raw scores from the standardized trait values. The procedure is used for each of the six LTA variables included in my thereotical framework and for each of the seven Bush administration officials selected for this study.

I begin by subtracting 50 from the standardized value for the trait variable. I then divide the product of the first step by 10 in order to arrive at the z-score for the variable's measurement. I next multiply the z-score by the Anglo-US LTA norming group standard deviation for the trait. To the product of that multiplication I add the Anglo-US LTA norming group mean for the trait. The result of that addition is the raw measure of the trait variable. 


\section{Appendix B}

\section{Reverse Engineering Operational Code Analysis Findings}

In his 2006 analysis of Bush administration officials' Operational Codes Sam Robison provides only standardized values for measurements of beliefs P-1, P-4, and I-1. Specifically, he provides z-scores based on comparison of the Bush administration officials to the post-World War II United States OCA norming group. Further, he provids two different z-scores for each belief measure for each official. One z-score is for measurement of the individual's belief using the decision maker's speech prior to the 11 September 2001 terrorist attacks. The other is for measurement of the belief using speech from after that date.

The objectives of my analysis require transforming the z-scores to non-standardized scores. What follows is the procedure I use to derive the non-standardized, raw scores from the z-scores. The procedure is used for each of the three OCA belief variables included in my thereotical framework and for each of the seven Bush administration officials under study here.

The first step is to multiply the pre-9/11 z-score for a belief measurement by the postWWII US OCA norming group standard deviation for the belief. The second step is to add the product of the first step to the post-WWII US OCA norming group mean for the belief. The result of this addition is the raw measure of the belief for the pre-9/11 period. The third step is multiplying the post-9/11 z-score for the belief measurement by the post-WWII US OCA norming group standard deviation for the belief. Step four is adding the product of the third step to the post-WWII US OCA norming group mean for the belief. The product of the fourth step is the raw measure of the belief for the post-9/11 period. The final step consists of adding the preand post-9/11 raw measures together, then dividing the sum by two in order to produce the 
average of the two measures. This averaged measure is the overall score for the belief. It is this overall score which I use in my own analysis. 